
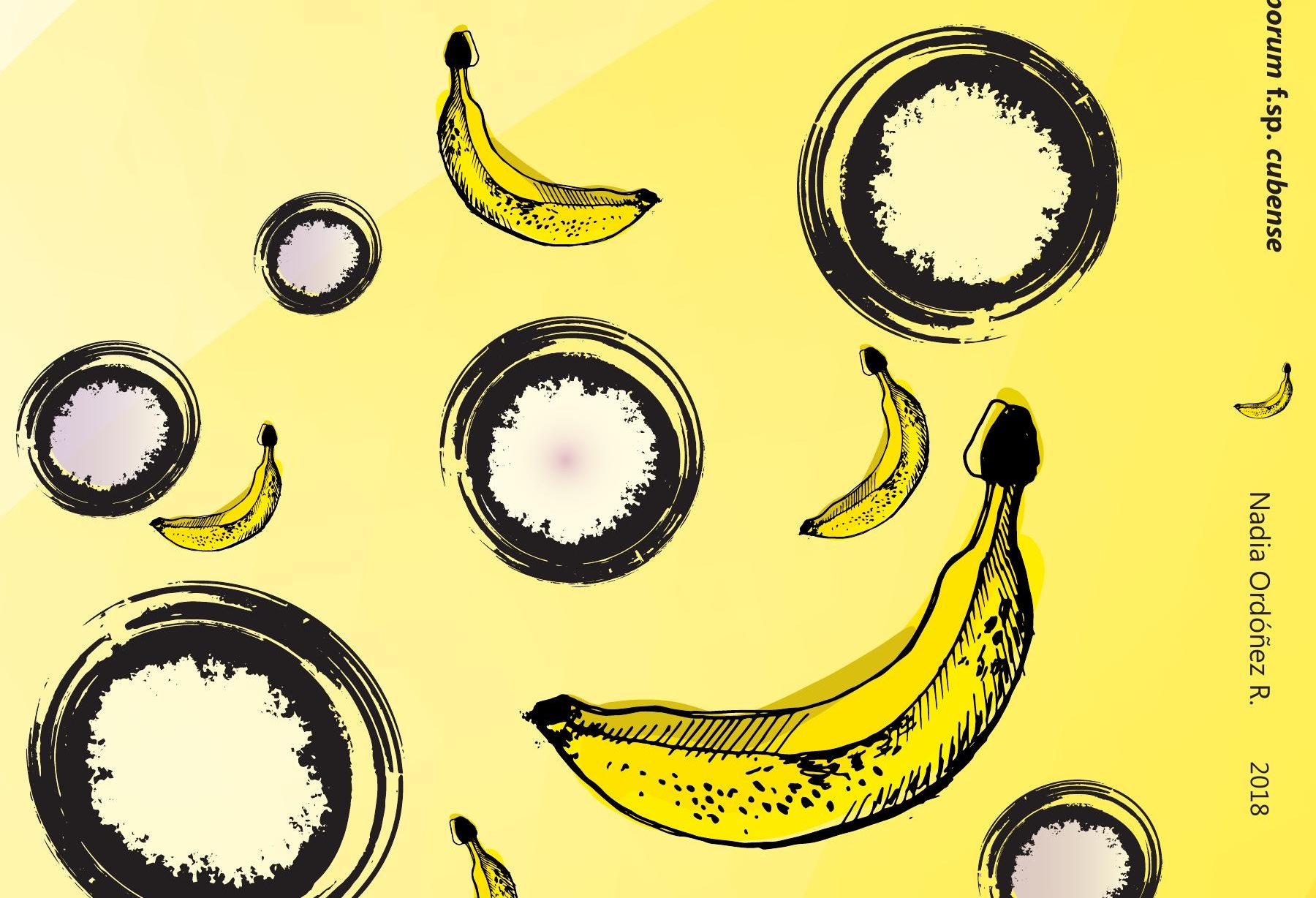

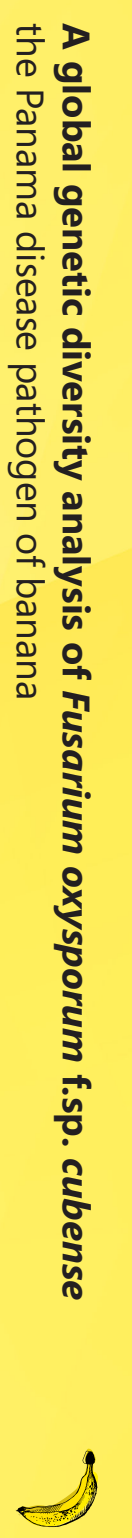

A global genetic diversity analysis of Fusarium oxysporum f.sp. cubense the Panama disease pathogen of banana

Nadia Ordóñez R.
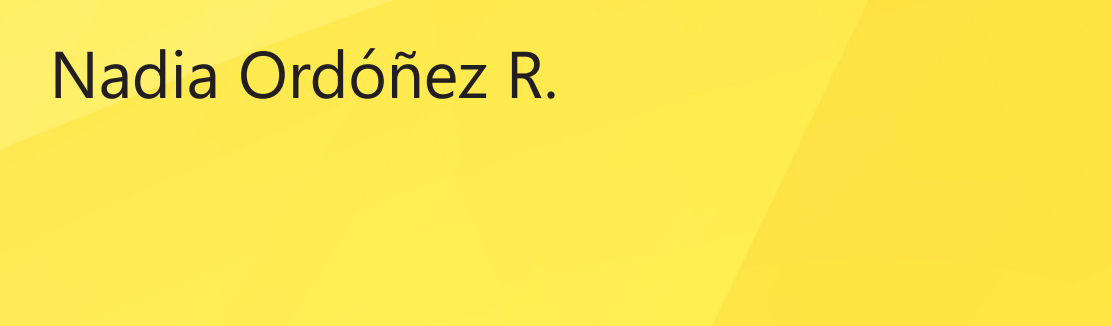
Propositions

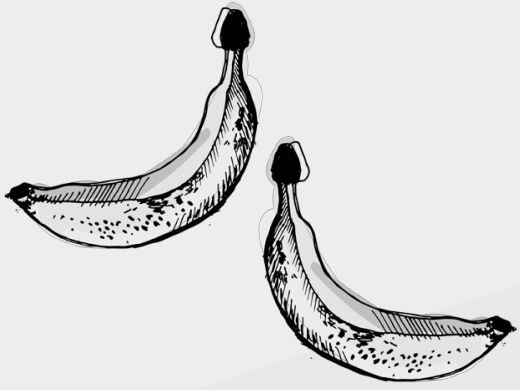

1. A multiple marker analysis of the pathogen Fusarium oxysporum f.sp. cubense combined with vegetative compatibility characterization is the most efficient strategy for revealing its population structure.

(this thesis)

2. The current nomenclature of races in Fusarium oxysporum f.sp. cubense is inadequate and hence obsolete.

(this thesis)

3. The possibility of off-target alterations (Baltimore et al., 2015 Science 348, 36-38) should not limit the application of CRISPR genomic engineering technology in plants or even humans.

4. Computer vision recognition built on last century images risks to recreate previous gender biases into robots (Zhao et al., 2017, In Proceedings of the Conference on Empirical Methods in Natural Language Processing, Denmark, 2979-2989).

5. The only justification for an army to exist nowadays is a response to senseless hostility where dialog is not feasible.

6. Science only contributes to human progress if combined with business ideas and humanity.

Propositions belonging to the $\mathrm{PhD}$ thesis, entitled:

A global genetic diversity analysis of Fusarium oxysporum f.sp. cubense, the Panama disease pathogen of banana

Nadia Ordóñez R.

Wageningen, 16 October 2018

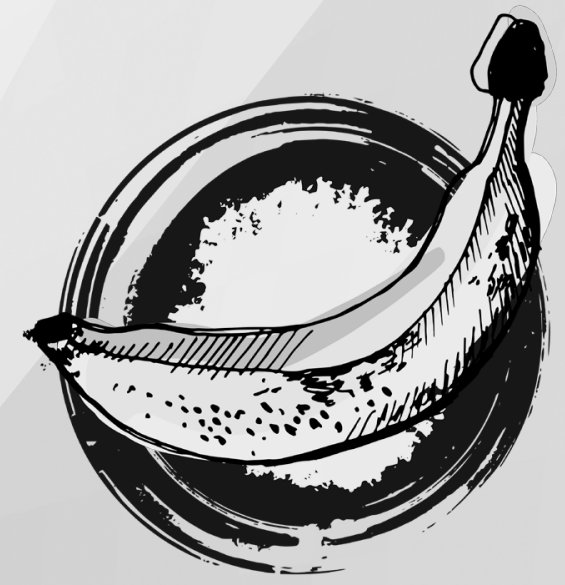




\section{A global genetic diversity analysis of Fusarium oxysporum f.sp. cubense \\ the Panama disease pathogen of banana}

Nadia Ordóñez R. 


\section{Thesis committee}

\section{Promotor}

Prof. Dr G.H.J. Kema

Special Professor Tropical Phytopathology

Wageningen University \& Research

\section{Co-promotors}

Dr M.F. Seidl

Assistant Professor at the Laboratory of Phytopathology

Wageningen University \& Research

Dr H.J.G. Meijer

Post Doc at Wageningen Plant Research

Wageningen University \& Research

\section{Other members}

Prof. Dr A. di Pietro, University of Córdoba, Spain

Prof. Dr A.F.J.M. van den Ackerveken, Utrecht University

Prof. Dr M.E. Schranz, Wageningen University \& Research

Dr J.J. Stoorvogel, Wageningen University \& Research

This research was conducted under auspices of the Graduate School Experimental Plant Sciences (EPS). 


\title{
A global genetic diversity analysis of Fusarium oxysporum f.sp. cubense the Panama disease pathogen of banana
}

\author{
Nadia Ordóñez R.
}

\section{Thesis}

submitted in fulfillment of the requirements for the degree of doctor at Wageningen University by the authority of the Rector Magnificus,

Prof. Dr A.P.J. Mol, in the presence of the

Thesis Committee appointed by the Academic Board to be defended in public on Tuesday 16 October 2018 at 4 p.m. in the Aula. 
Nadia Ordóñez R.

A global genetic diversity analysis of Fusarium oxysporum f.sp. cubense, the Panama disease pathogen of banana,

156 pages.

$\mathrm{PhD}$ thesis, Wageningen University, Wageningen, the Netherlands (2018)

With references, with summaries in English, Spanish and Dutch

ISBN 978-94-6343-298-6

DOI https://doi.org/10.18174/453455 


\section{Contents}

Chapter $1 \quad$ General introduction 7

Chapter 2 Worse comes to worst: Bananas and Panama disease - when

plant and pathogen clones meet

Chapter 3 A Loop-Mediated Isothermal Amplification assay based on

unique markers derived from genotyping by sequencing data

for rapid in-plant diagnosis of Fusarium oxysporum f.sp.

cubense tropical race 4 in banana

Chapter 4 The phylogeography of the banana Fusarium wilt pathogen

Fusarium oxysporum f.sp. cubense

Chapter 5 Unveiling the pathogenicity of the widest array of genetically

diverse Fusarium oxysporum f.sp. cubense isolates on

'Gros Michel' and 'Grand Naine' banana cultivars

Chapter 6

General discussion

Summaries

Acknowledgements

About the author

List of publications

Education statement of the Graduate School 
"Whatever you do will be insignificant, but it is very important that you do it."

- Mahatma Gandhi

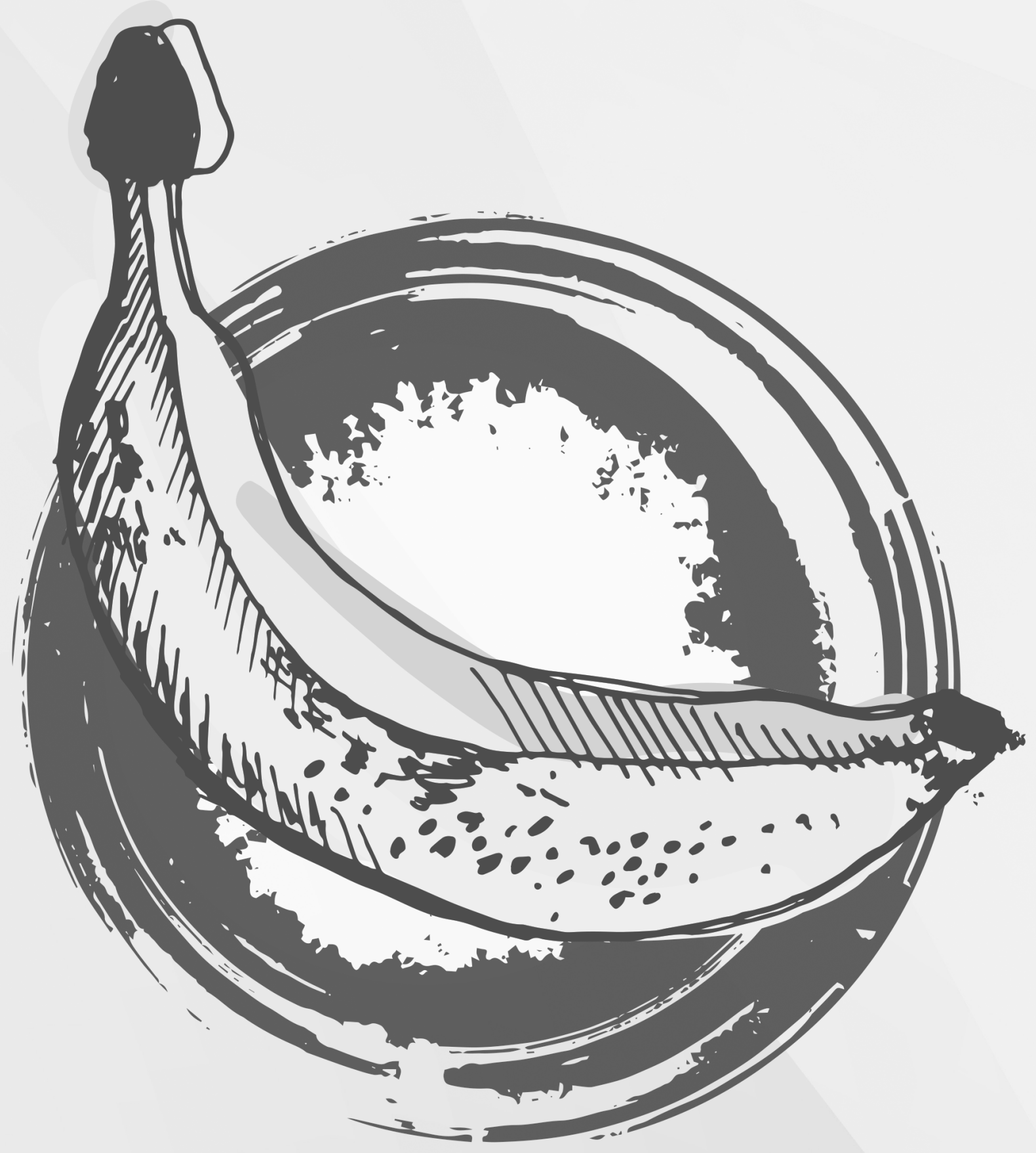




\section{CHAPTER 1}

\section{General introduction}

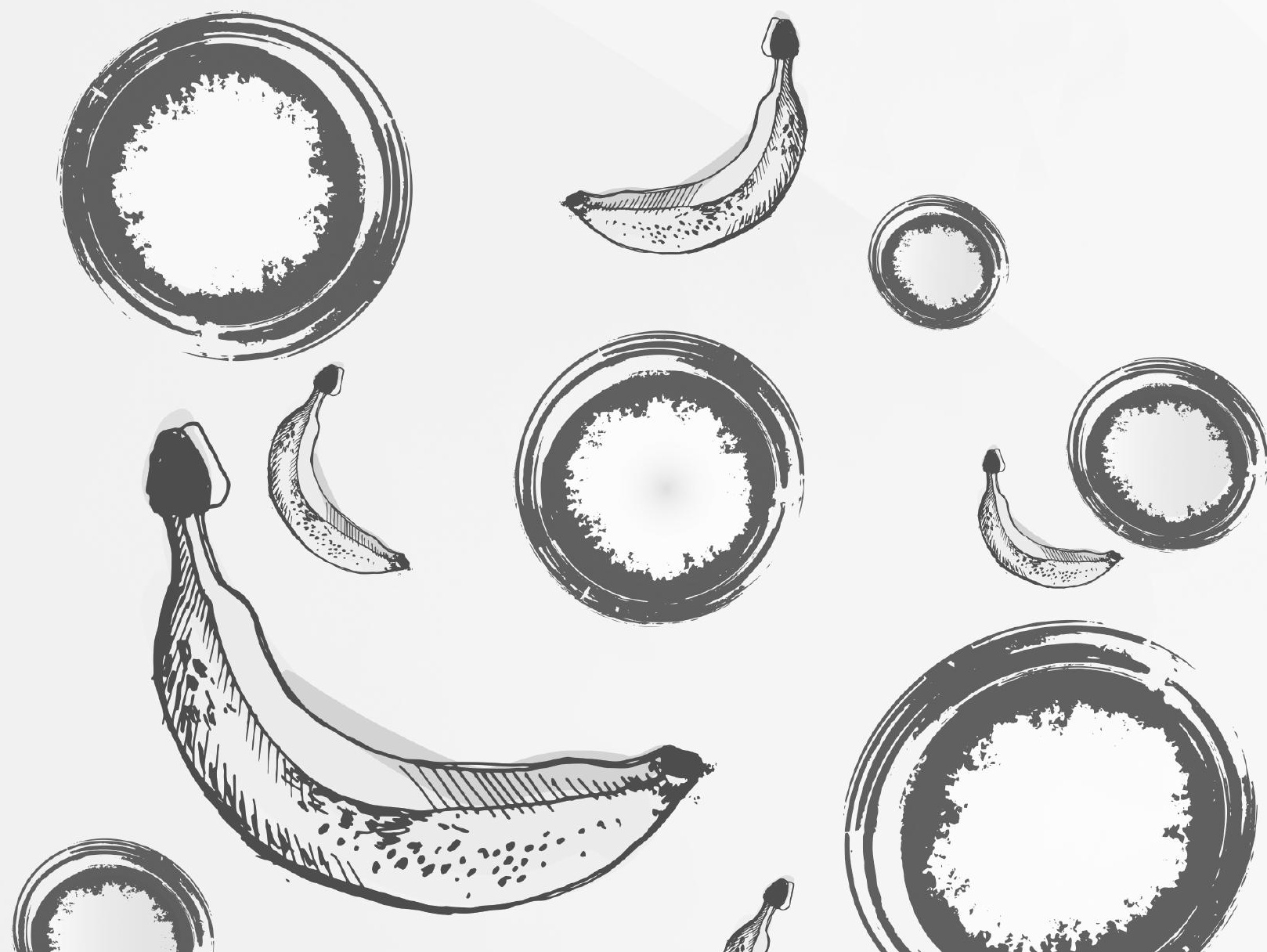




\section{BANANAS: IMPORTANCE, ORIGIN AND FUNGAL DISEASES}

Bananas are an essential staple food for developing countries, particularly in Africa where the consumption of banana is higher than in Asia and Latin America, and generates substantial economic income for small and large producers (Frison \& Sharrock, 1998). As staple food with a high carbohydrate content (Pareek, 2016), bananas are an important calorie source in the diet of over 500 million inhabitants in banana producing countries (Aurore et al., 2009). Bananas are not only eaten raw as dessert or sweet bananas, but also cooked such as plantains and cooking bananas. Additionally, they are used as raw materials in diverse regional products, for instance in beer, juice or flour production (Aurore et al., 2009; Ekesa et al., 2012). Equally important, bananas are a cash crop for small farmers that serve domestic markets and for banana producing countries exporting to international markets. Nearly $85 \%$ of the total production of bananas is designated to local markets and only $15 \%$ enters international markets (FAOSTAT, 2013). In 2014, world banana production reached 78.8 million tonnes, with India contributing with $38 \%$ of produced bananas (FruitTrop, 2017). In descending order, India, Uganda, China, The Philippines, Ecuador and Brazil are globally the largest banana producing countries (Fig. 1). Importantly, East Africa is the largest bananaproducing and consuming region in Africa, with Uganda having the highest consumption of bananas that may exceed 1.6 kilograms per capita per day (Thornton \& Cramer, 2012). Notably, the export trade of bananas is particularly important for The Philippines and several exporting countries in Latin America such as Ecuador, Costa Rica, Guatemala and Colombia (Aurore et al., 2009; Dita et al., 2013; FruitTrop, 2017), where the banana industry influences social and political structures (Jansen, 2006; Koeppel, 2008). In 2016, the volume of global gross banana exports reached a record high of 18.6 million tonnes, with Ecuador contributing with $32 \%$ of exported bananas (FruitTrop, 2017).

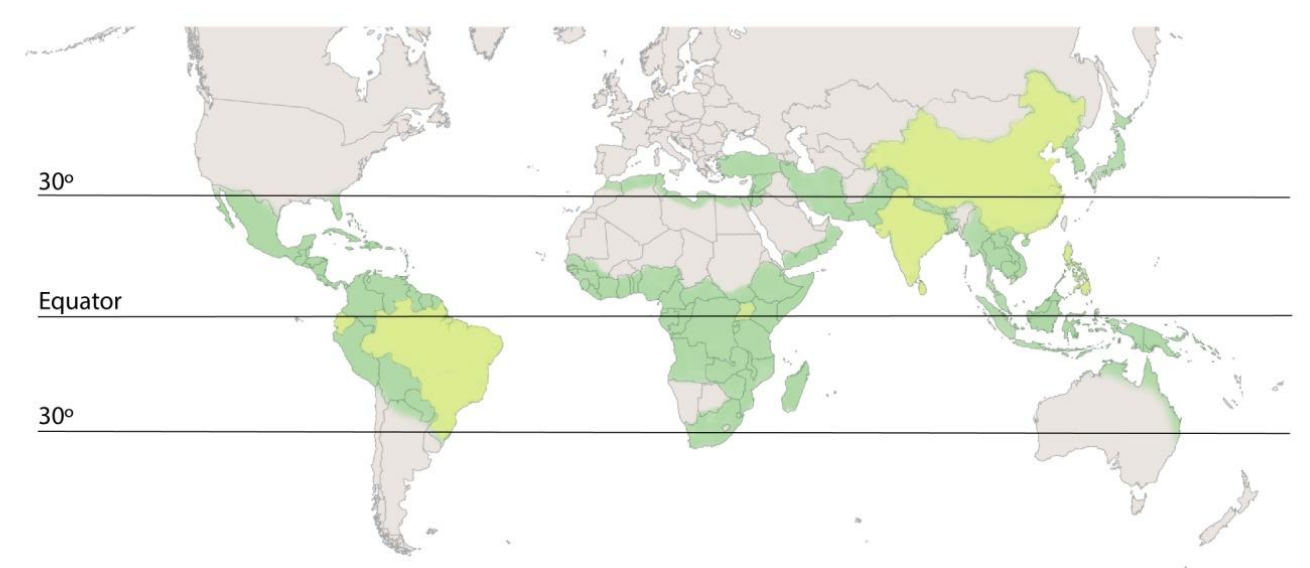

Figure 1. Banana (dessert and plantain types) producing countries worldwide (indicated in green), with India, Uganda, China, The Philippines, Ecuador and Brazil as the top six largest producers (indicated in yellow). Countries listed in FAOSTAT (http://www.fao.org/faostat/en/\#data). 
The modern range of commercially cultivated banana varieties (cultivars) originated in the Indo-Malayan archipelago in Southeast Asia (Heslop-Harrison \& Schwarzacher, 2007; Perrier et al., 2011), where domestication started around 7,000 years ago (D'Hont et al., 2012). The domestication from wild to edible, hence seedless, bananas involved natural hybridizations between diverse species and subspecies, facilitated by human transportation of plants, as well as parthenocarpy, a phenomenon where fertile diploid bananas develop seedless fruits (D'Hont et al., 2012; Heslop-Harrison \& Schwarzacher, 2007; Perrier et al., 2011). From Southeast Asia, bananas were eventually transported to Africa by early human migration, and later to America during the colonization (D'Hont et al., 2012; Marin et al., 1998; Perrier et al., 2011; Robinson \& Sauco, 2010), where multinational companies contributed to building "banana republic" empires across Central and South America (Jansen, 2006; Koeppel, 2008). Currently, bananas are globally cultivated in areas located around $30^{\circ}$ North and South of the Equator, under tropical and subtropical conditions that have sufficient rainfall or irrigation (Fig. 1).

Edible bananas are predominantly related to the Musa section in the genus Musa (family Musaceae, order Zingiberales) (Häkkinen, 2013). These edible bananas are diploid, triploid or tetraploid sterile hybrids derived from two wild seedy species, Musa acuminata alone or from hybridization with Musa balbisiana (D'Hont et al., 2012; Heslop-Harrison \& Schwarzacher, 2007; Perrier et al., 2011; Simmonds \& Shepherd, 1955). Banana cultivars in the Musa section are subdivided into genomic groups based on the relative contribution of $M$. acuminata (A-genome) and M. balbisiana (B-genome) to the constitution of the banana cultivar, its ploidy or chromosome number (Robinson \& Sauco, 2010). In spite of a rough estimate of 300 distinct edible banana varieties, only a few of them exhibit suitable characteristics for commercial exploitation, such as the sweet banana cultivars 'Gros Michel' and 'Grand Naine' from the Gros Michel and Cavendish subgroups, respectively (Table 1). These two subgroups belong to the $M$. acuminata triploid hybrids (AAA) genomic group (Robinson \& Sauco, 2010). The Cavendish subgroup represents 28\% of locally produced bananas and dominates the global banana export trade ( 90\%). In Africa, East African Highland bananas (AAA) are a relevant group of cultivars for food security and cash crop as they constitute over $80 \%$ of produced bananas in Uganda, Kenya, Tanzania, Rwanda, Burundi and the eastern part of Democratic Republic of Congo (Karamura et al., 1998). The plantain subgroup (AAB), triploid hybrids of M. acuminata and M. balbisiana, is another important subgroup, especially for West Africa, Latin America and the Caribbean, representing 21\% of the global banana production (Ploetz, 2015b). The AAB dessert bananas in the subgroups Pome and Silk, are also popular in Latin America, especially in Brazil where the cultivar 'Prata' is widely grown for national markets (Dita et al., 2013).

Bananas were traditionally dispersed by vegetative propagation using rhizomes, the "suckers" developing at the base of the plant, and since the 1970s as tissue-culture plantlets. The latter enables the rapid roll-out of pathogen-free germplasm (Dore-Swamy et al., 1983; Gowen et al., 1995). However, the downside of both propagating strategies is massive genetic uniformity that contributed to global monocropping of banana and resulted in one of the largest remaining monocultures, prone to rapidly succumb to pathogen and pest epidemics. The major fungal pathogens of bananas are Pseudocercospora fijiensis, causing black leaf streak disease, also known as black Sigatoka, P. musicola, causing yellow Sigatoka; 
Colletotrichum musae causing anthracnose and Fusarium oxysporum f.sp. cubense (Foc), causing Panama disease also known as Fusarium wilt (Ploetz et al., 2015). Important emerging fungal pathogens threatening banana production are Mycosphaerella eumusae, causing Eumusae leaf spot in Southern Asia and Nigeria, and Phyllosticta maculate, causing freckle in the Eastern hemisphere (Jones, 2009).

Table 1. Major banana genomic groups produced for local and export markets.

\begin{tabular}{lll}
\hline Genomic group & Subgroup & Main cultivars \\
\hline AAA & Gros Michel & 'Gros Michel', 'Cocos', 'Highgate' \\
& Cavendish & 'Grand Naine', 'Mons Mari', 'Pisang Masak Hijau', 'Robusta', \\
& 'Williams' \\
& Lujugira & East African Highland bananas: 'Mpologoma', 'Muvubo', \\
& 'Namunwe' \\
& Plantain & 'Giant French', 'False Horn', 'Isla', 'Palillo' \\
AAB & Pome & 'Prata', 'Lady Finger' \\
& Silk & 'Manzano', 'Latundan' \\
& Bluggoe & 'Silver Bluggoe' \\
\hline
\end{tabular}

\section{FUSARIUM OXYSPORUM F.SP. CUBENSE, THE CAUSAL AGENT OF FUSARIUM WILT OF BANANA}

Fusarium oxysporum f.sp. cubense (Foc) is an ascomycete belonging to Fusarium oxysporum species complex (FOSC) in the Fusarium genus (Leslie \& Summerell, 2006). This genus includes some of the most notorious plant pathogens that affect several crops worldwide (Chakrabarti, 2013), and also human pathogens causing infections in immunecompromised patients (Nucci \& Anaissie, 2002). The term 'species complex' for strains in the Fusarium genus covers taxonomically closely related strains that cannot confidently be distinguished (Chen et al., 2016; O'Donnell et al., 2013). The FOSC comprises the largest number of plant pathogenic Fusarium strains which are among the top-10 of fungal plant pathogens due to their scientific and economic impact (Dean et al., 2012). It also contains many cosmopolitan non-pathogenic saprophytes and endophytes (Geiser et al., 2013; Leslie \& Summerell, 2006; Michielse \& Rep, 2009; Steinberg et al., 2016), partly recognized as such since their host specificity has not yet been identified (Alabouvette et al., 2009; Steinberg et al., 2016). In terms of genetic diversity, the FOSC is a monophyletic complex comprising phylogenetically diverse filamentous ascomycetes commonly group in four main clades $(1,2$, 3 and 4) (Laurence et al., 2014; O'Donnell et al., 1998; O'Donnell et al., 2004). For this species complex, a subgrouping system that is based on pathogenicity features rather than taxonomic or phylogenetic descriptions is widely used (Chakrabarti, 2013; Fourie et al., 2011). In this regard, formae speciales (ff.spp.) were adopted to group $F$. oxysporum strains by their pathogenicity on a specific host(s). More than 150 plant pathogenic $F$. oxysporum strains are reported, and $F$. oxysporum strains infecting bananas are referred as forma specialis (f.sp.) cubense (Leslie \& Summerell, 2006; Michielse \& Rep, 2009). A morphological distinction among $F$. oxysporum strains causing disease on different hosts is 
not possible as they show indistinguishable morphological features. Typical morphological characteristics of $F$. oxysporum strains include the presence of oval, elliptical or kidneyshaped microconidia formed on the hyphae, canoe-shaped macroconidia and smooth or rough walled chlamydospores (Fig. 2) (Leslie \& Summerell, 2006).

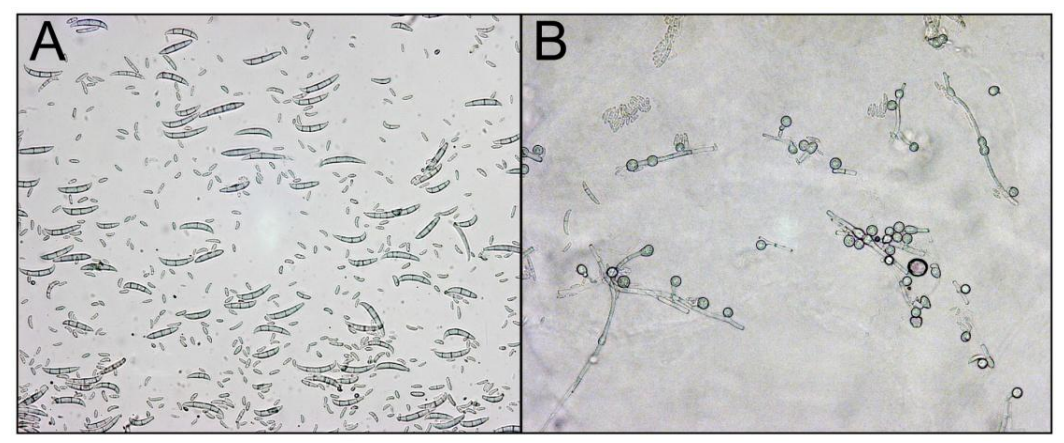

Figure 2. Typical morphological features of Fusarium oxysporum strains: the presence of (A) macroconidia, microconidia and (B) chlamydospores.

\section{Life cycle and disease symptoms}

The life cycle of the soil-borne Foc starts with germinating chlamydospores. These are persistent propagules that can survive in the soil for decades (Buddenhagen, 2009). Their adhesion on root hairs of bananas is driven by a variety of chemical signals from the host (Diener, 2012; Guo et al., 2015; Li et al., 2011; Turra et al., 2015). Hyphal penetration occurs through the tip and elongation zone of lateral roots or through natural wounds in secondary root bases after overcoming the plant defense mechanisms (Di Pietro et al., 2001; Di et al., 2016; Li et al., 2011; Perez-Nadales et al., 2014). Henceforward, Foc continues to colonize the root cortex, until it enters and colonizes the xylem vessels in susceptible cultivars, moving upwards with the xylem sap flow (Di Pietro et al., 2003; Guo et al., 2015; Yadeta \& Thomma, 2013). Deposition of callose, formation of tyloses and gels, accumulation of phenolics and intense mycelium and microconidia production inside the vascular system block the transport of water and nutrients, consequently causing wilting of the host (Beckman, 2000; Okubara \& Paulitz, 2005). Externally, chlorosis of the leaves appears relatively late, often six months after the initial infection (Stover, 1962), and newly emerging leaves are generally shorter and stunted (Fig. 3). No internal or external symptoms are present in the fruit, nevertheless, fruit production is compromised since the plant can die before it sets fruits (Pérez, 2004). Other symptoms are the splitting of the outer leaf sheaths near the soil line, and the red, yellow or brown discoloration of the vascular strands. The latter can be observed in transverse sections of rhizomes, pseudostems and bunch stems (Ghag et al., 2015). Foc reflects the life of a hemibiotroph, with a short biotrophic phase that ultimately leads to the necrotrophic phase, where the host dies and the fungus produces chlamydospores, ready to repeat the disease cycle by infecting the rhizome tissue of suckers or a susceptible host (Chakrabarti, 2013). Additionally, Foc can survive in non-host plants, such as weed, which therefore can be potential sources of inoculum (Hennessy et al., 2005; Salacinas et al., 2018). 


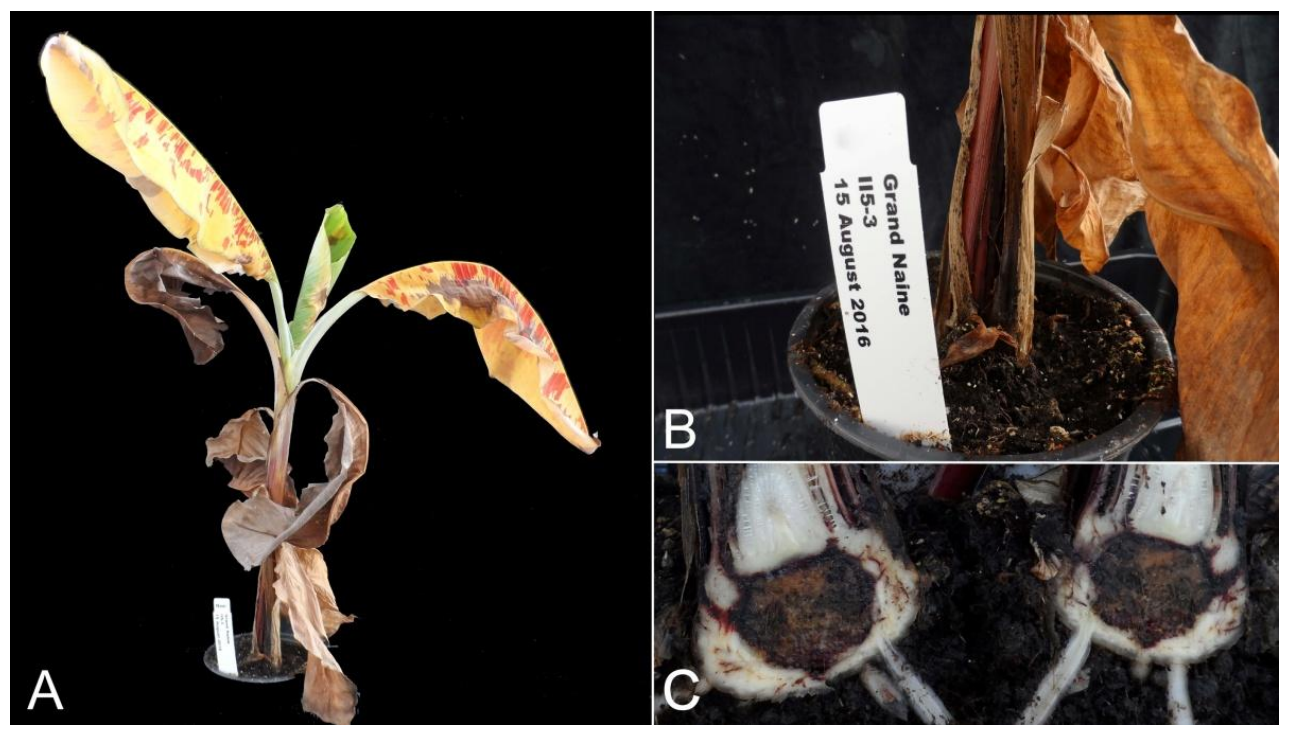

Figure 3. Typical Fusarium wilt symptoms on banana, (A) chlorosis of older leaves, (B) splitting of the outer leaf sheaths near the soil line and $(\mathbf{C})$ internal discoloration of the rhizome.

\section{Classification}

Since Smith (1910) isolated Foc for the first time from wilted banana plants in Cuba, several attempts to classify Foc diversity have been explored with the use of advancing technologies (Baayen et al., 2000; Bentley \& Bassam, 1996; Bentley et al., 1995; Bentley et al., 1998; Boehm et al., 1994; Bogale et al., 2006; Fourie et al., 2009; Groenewald et al., 2006; Koenig et al., 1997; O'Donnell et al., 1998). Foc strains were classified into i) races usually based on field observations of pathogenicity towards specific host cultivars (Stover, 1962), ii) on vegetative compatibility, on which fungal isolates are grouped into unique vegetative compatibility groups (VCGs) (Puhalla, 1985) and iii) by modern molecular techniques that better account for genetic variation and thus provide understanding of the phylogenetic relations and evolution of this pathogen (Bentley et al., 1998; Boehm et al., 1994; Fourie et al., 2009; Groenewald et al., 2006; Koenig et al., 1997).

Races. Foc isolates are classified into three races based on the specific banana cultivars they can infect (Ploetz, 2015a), race 1 is pathogenic on 'Gros Michel' (AAA) and 'Manzano' (AAB), race 2 affects Bluggoe (ABB) and other cooking bananas (AAB). Race 4 is subdivided into subtropical (ST4) and tropical race 4 (TR4). ST4 strains infect Cavendish (AAA) cultivars under subtropical or rather unfavorable agronomic conditions, such as waterlogging and drought stress (Molina et al., 2009; Pegg et al., 1995; Visser et al., 2009); while TR4 is highly pathogenic on Cavendish bananas even in the best agronomic settings and therefore considered as the most threatening strain since it can potentially affect approximately $80 \%$ of the global current banana exports (Butler, 2013; FAO, 2014; Kupferschmidt, 2012; Ploetz et al., 2015). Moreover, the TR4 strain is pathogenic on varieties that are susceptible to race 1 and 2, as well as other banana cultivars (García-Bastidas et al., 2018; Ploetz, 2015b; Ploetz et al., 2015) 
VCGs. Vegetative compatibility, also known as heterokaryon compatibility, is controlled by several vegetative (vic) loci (termed also heterokaryon, het loci), therefore having a multigenic basis. Compatible isolates share a common allele at each vic locus enabling them to develop a stable hyphal fusion (heterokaryon formation), and to exchange nuclear material (Correll, 1991; Leslie, 1990; Leslie et al., 2007). As a result, asexual isolates within the same VCG are considered to be clonally related (Leslie \& Summerell, 2006; Taylor et al., 1999). In Fusarium and other species, the current strategy to identify VCGs begins with the development of nit $\left(\mathrm{NO}_{3}\right.$-non-utilizing) mutants from wild type isolates by exposure to a chlorate-amended culture medium. Later, the resulting mutants are characterized by their ability to grow on media containing different nitrogen sources. Lastly, heterokaryon formation is revealed by dense mycelial growth between otherwise sparsely growing mutants on minimal medium among heterokaryon compatible isolates (Leslie \& Summerell, 2006; Puhalla, 1985). To date, 24 VCGs are described for Foc (Table 2), the highest number of VCGs for any of the formae speciales in the FOSC (Bentley et al., 1995; Katan, 1999; Katan \& Di Primo, 1999; Moore et al., 1993; Ploetz, 2015a). VCGs related to each forma specialis were assigned a 3-digit numerical code (Katan \& Di Primo, 1999; Kistler et al., 1998; Puhalla, 1985). Foc strains are designated the code 012 and comprise VCG0120 through 0126 and 0128 through 01224 (Bentley et al., 1995; Katan, 1999; Katan \& Di Primo, 1999; Moore et al., 1993; Ploetz, 2015a; Somrith et al., 2011). Furthermore, sometimes isolates from different VCGs show cross compatibility and form stable heterokaryons. Hence, such VCGs are grouped into VCG complexes: 0120/15, 0124/5/8/20 and 01213/16 complexes (Ploetz, 2006). Lately, the VCG01213/16 complex is considered as a single group (01213) composed of genetically similar isolates (Bentley et al., 1998).

Genetic diversity. A high level of genetic diversity was identified among reported Foc strains using modern molecular technologies, such as electrophoretic karyotyping (Boehm et al., 1994), restriction fragment length polymorphism (Koenig et al., 1997), random amplified polymorphism (Bentley \& Bassam, 1996; Bentley et al., 1995), DNA amplified fingerprinting (Bentley et al., 1998), amplified fragment length polymorphisms (Baayen et al., 2000; Bogale et al., 2006; Groenewald et al., 2006), microsatellites or short sequence repeats (Bogale et al., 2006) and DNA sequencing (Bogale et al., 2006; Fourie et al., 2009; O'Donnell et al., 1998). Undoubtedly, molecular techniques are the preferred approach to study Foc diversity due to their better resolution, reliability, sensitivity and throughput (Fourie et al., 2011; Lievens et al., 2008). These molecular studies consistently separated Foc isolates from global collections into two major clades or groups (clade 1 and 2) of the FOSC (Table 2), each with five to nine clonal lineages with distinct VCGs. In addition, molecular studies reported that some Foc VCGs were more closely related to other pathogenic $F$. oxysporum strains than to each other, suggesting that Foc has a polyphyletic origin (Baayen et al., 2000; Koenig et al., 1997; O'Donnell et al., 1998; O'Donnell et al., 2004).

Another significant contribution to genetic studies that modern molecular technologies allow is the genome sequencing of multiple Fusarium strains that nowadays are available to the scientific community (https:/www.ncbi.nlm.nih.gov/genome/genomes/707). The genome of a TR4 isolate (II-5: NRRL54006; VCG01213) from Indonesia was sequenced by the Broad Institute, showing a genome size of nearly $46.5 \mathrm{Mb}$. In addition, the Broad Institute developed genome sequences for $F$. oxysporum strains causing wilt diseases in pea (f.sp. pisi), melon 
(f.sp. melonis), cotton (f.sp. vasinfectum), radish (f.sp. raphani), cabbage (f.sp. conglutinans) and tomato (three races of f.sp. lycopersici). Next to the TR4 genome, genomes from a race 1 and 4 isolates were generated by the Beijing Genome Institute (Guo et al., 2014). These genomic data and many on-going sequencing projects of Foc and other FOSC constituents will be crucial to identify pathogenicity genes. This will inevitably contribute to the elucidation of the complex banana-Fusarium interactions, but also facilitate the development of accurate molecular diagnostic for specific fungal genotypes, thereby circumventing laborious and time consuming phenotyping assays (Chakrabarti, 2013; Fraser-Smith et al., 2013; Ma et al., 2013; Michielse \& Rep, 2009; Vlaardingerbroek et al., 2016).

\section{EVOLUTION AND DISTRIBUTION OF FUSARIUM OXYSPORUM F.SP. CUBENSE}

There is a range of mechanisms such as mutations, selection, genetic drift, gene flow, transposons, reproduction and horizontal gene transfer that contribute to the genetic variation of fungal populations (Boddy, 2016; Ma et al., 2013; Ma et al., 2010; McDonald \& Linde, 2002; Möller \& Stukenbrock, 2017; Seidl \& Thomma, 2014, 2017). These mechanisms can lead to changes in phenotypes that support fungal adaptation to environmental changes or a new host (Boddy, 2016; Taylor et al., 1999). In the evolutionary history of Foc, co-evolution with its host in the Indo-Malayan archipelago in Southeast Asia presumably played an important role in shaping its current genetic diversity (Fourie et al., 2009; Fourie et al., 2011; O'Donnell et al., 1998). Foc strains in clade 1 of the FOSC were associated with banana varieties containing pure A genomes (M. acuminata related), while Foc strains in clade 2 were mostly related hosts containing partial and/or pure B genomes (hybrids between M. acuminata and $M$ balbisiana), suggesting that the presence of these two clades contributed to the several independent evolutionary origins of Foc in Southeast Asia (Boehm et al., 1994). The Wallace's line in the Indo-Malayan archipelago appeared to be the eastern boundary for the natural distribution of these two groups (Ploetz \& Pegg, 1997). Importantly, molecular studies based on sequencing of nuclear and mitochondrial genes showed that Foc strains are phylogenetically diverse with independent evolutionary origins (Bentley et al., 1998; Fourie et al., 2009; O'Donnell et al., 1998). Foc strains were dispersed within Southeast Asia and later disseminated to Africa and America mainly through movement of infected plant material (D'Hont et al., 2012; Marin et al., 1998; Nayar, 2010; Perrier et al., 2011; Ploetz, 2015a). Since then, Fusarium wilt was reported in nearly all banana-growing regions, except areas close to the Mediterranean, Melanesia, Somalia and some islands in the South Pacific (Ploetz, 2015a). As expected, the highest VCG diversity is reported in Southeast Asia (Bentley et al., 1998), while only a few genotypes show a pandemic distribution (Table 2 and Fig. 4) (Bentley et al., 1998; Boehm et al., 1994; Fourie et al., 2009; Groenewald et al., 2006; Koenig et al., 1997). Foc isolates belonging to the VCGs 01210,01212 and 01214 seemed to have evolved in areas outside the Indo-Malayan archipelago, since they are phylogenetically distant from other VCGs and have not been reported in Southeast Asia. Hence, it is suggested that these genotypes arose independently from local F. oxysporum populations and evolved the ability to infect the introduced plant hosts (Fourie et al., 2011; Gurr et al., 2011). Also, recent evidence of horizontal genome transfer of host specificity factors in Fusarium strains may explain the emergence of new pathogenic lineages outside Southeast Asia as well as the polyphyletic origin of host specificity in F. oxysporum strains (Ma et al., 2013; Ma et al., 2010). Horizontal 
exchange of genetic material that leads to the identification of lineage specific pathogenicity chromosomes was reported between $F$. oxysporum strains, converting a non-pathogenic strain into a pathogen (Ma et al., 2010).

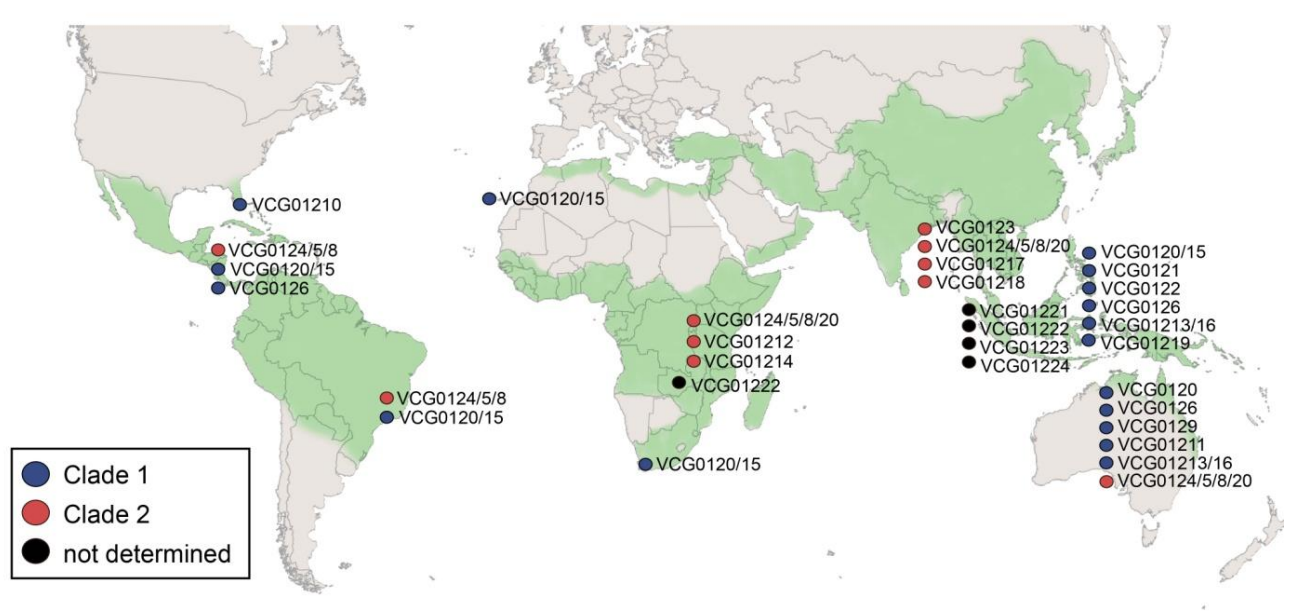

Figure 4. Geographical distribution of vegetative compatibility groups of Fusarium oxysporum f.sp. cubense from all banana-growing regions (green areas) and their relation to clades in the FOSC.

Reproduction is an important factor shaping the evolutionary history of fungal pathogens (Atallah \& Subbarao, 2012; Boddy, 2016; Taylor et al., 1999). Not only Foc strains are genetically distant but they exhibit two strategies to transmit genes to the next generation: clonality and recombination (Taylor et al., 1999). In clonal organisms, genomes of progeny are nearly identical to the parental genome. Under this strategy, clonal fungal populations can be generated by the production of asexual spores (Boddy, 2016; Taylor et al., 1999). Sex in Foc has yet to be discovered and hence, the agreed common reproductive mechanism in Foc genotypes is asexual spore production, which results in low genetic diversity within VCGs (Bentley et al., 1998; Fourie et al., 2009; Groenewald et al., 2006; Taylor et al., 1999). On the other hand, there is evidence for recombination in Foc that is though to be driven by parasexuality, i.e. recombinant genomes result from nuclear exchange between otherwise asexual parents (Atallah \& Subbarao, 2012). Foc isolates related to the VCG0124/5/8/20 complex showed evidence of parasexual recombination, suggesting that genetic exchange may have occurred and generated diversity among these isolates (Taylor et al., 1999). Recombination in Foc strains could potentially occur via sexual reproduction as well. Foc strains typically contain one of both mating types idiomorph alleles (MAT1-1 and MAT1-2) essential for mating, suggesting a heterothallic mating behavior during the Foc evolutionary history (Fourie et al., 2009). Nonetheless, a sexual stage in F. oxysporum strains was never recorded and attempted sexual crossings among $F$. oxysporum strains were not successful (Fourie et al., 2011; Kawabe et al., 2005). In the future, genomic studies on F. oxysporum populations will help to unravel the evolutionary mechanisms and their implications of this relevant pathogen. 
Table 2. Current diversity and geographical distribution of vegetative compatibility groups (VCGs) of Fusarium oxysporum f.sp. cubense (Foc) from all banana-growing regions.

\begin{tabular}{|c|c|c|c|c|}
\hline Clade $^{1}$ & VCG & Race $^{5}$ & Countries & Macro region \\
\hline $\begin{array}{l}\text { Genome size } \\
32-45 \mathrm{Mb}\end{array}$ & $0120 / 15$ & ST4, R1 & $\begin{array}{l}\text { Australia, Brazil, Canary Island, China (Taiwan), Costa } \\
\text { Rica, French Guyana, Guadeloupe, Honduras, } \\
\text { Indonesia, Jamaica, Malaysia, Nigeria, South Africa, } \\
\text { Spain (Madeira Island), The Philippines, USA (Florida) }\end{array}$ & $\begin{array}{l}\text { Africa, Americas, } \\
\text { Southeast Asia, } \\
\text { Oceania }\end{array}$ \\
\hline Chromosome & 0121 & ST4, TR4 & China (Taiwan), Indonesia & Southeast Asia \\
\hline number & 0122 & $\mathrm{R} 2, \mathrm{TR} 4$ & The Philippines & Southeast Asia \\
\hline \multirow[t]{7}{*}{$9-12^{2}$} & $\mathbf{0 1 2 3}^{3}$ & $\mathrm{R} 1$ & $\begin{array}{l}\text { China (Taiwan), Indonesia, Malaysia, Thailand, The } \\
\text { Philippines }\end{array}$ & Southeast Asia \\
\hline & 0126 & $\mathrm{R} 1, \mathrm{ST} 4$ & $\begin{array}{l}\text { Honduras, Indonesia, Spain (Canary Island), The } \\
\text { Philippines }\end{array}$ & $\begin{array}{l}\text { Africa, Americas, } \\
\text { Southeast Asia }\end{array}$ \\
\hline & 0129 & $\mathrm{R} 1, \mathrm{ST} 4$ & Australia & Oceania \\
\hline & $01210^{3}$ & R1 & Cuba, Honduras, USA (Florida) & Americas \\
\hline & 01211 & ST4 & Australia & Oceania \\
\hline & $01213^{4}$ & TR4 & $\begin{array}{l}\text { Australia, China (Taiwan), Indonesia, Malaysia, The } \\
\text { Philippines }\end{array}$ & $\begin{array}{l}\text { Southeast Asia, } \\
\text { Oceania }\end{array}$ \\
\hline & 01219 & n.d. & Indonesia & Southeast Asia \\
\hline $\begin{array}{l}\text { Genome size } \\
40-59 \mathrm{Mb} \\
\text { Chromosome }\end{array}$ & $0124 / 5 / 8 / 20$ & $\begin{array}{ll}\mathrm{R} 1, & \mathrm{R} 2, \\
\mathrm{R}^{6} & \end{array}$ & $\begin{array}{l}\text { Australia, Brazil, Burundi, Comoro Island, Congo, } \\
\text { Cuba, Haiti, Honduras, India, Indonesia, Jamaica, } \\
\text { Kenya, Malawi, Malaysia, Mexico, Nicaragua, Rwanda, } \\
\text { Tanzania, Thailand, The Philippines, Uganda, USA } \\
\text { (Florida), Vietnam, Zaire }\end{array}$ & $\begin{array}{l}\text { Africa, Americas, } \\
\text { Southeast Asia, } \\
\text { Oceania }\end{array}$ \\
\hline number & 01212 & n.d. & Kenya, Tanzania, Uganda & Africa \\
\hline \multirow[t]{3}{*}{$11-14^{2}$} & $\mathbf{0 1 2 1 4}^{3}$ & $\mathrm{R} 2$ & Malawi & Africa \\
\hline & 01217 & $\mathrm{R} 1$ & Malaysia & Southeast Asia \\
\hline & 01218 & $\mathrm{R} 1$ & Indonesia, Malaysia, Thailand & Southeast Asia \\
\hline n.d. & 01221* & n.d. & Thailand & Southeast Asia \\
\hline n.d. & $01222 \%$ & n.d. & Kenya, Malaysia, Thailand, Uganda & $\begin{array}{l}\text { Southeast Asia, } \\
\text { Africa }\end{array}$ \\
\hline n.d. & 01223* & n.d. & Malaysia & Southeast Asia \\
\hline n.d. & 01224* & n.d. & Malaysia & Southeast Asia \\
\hline
\end{tabular}

${ }^{1}$ Clades of the $F$. oxysporum species complex as described by O'Donnell et al. (1998) and O'Donnell et al. (2004). ${ }^{2}$ Electrophoretic karyotyping data on Foc VCGs except for VCGs 0126, 0128, 01211,01212 and 01217 01224 (Boehm et al., 1994). ${ }^{3}$ These VCGs have been occasionally reported on the opposite clade, 0123 (Bentley et al., 1995; Bentley et al., 1998; Fourie et al., 2009; Groenewald et al., 2006), 01210 (Boehm et al., 1994) and 01214 (Koenig et al., 1997). ${ }^{4}$ VCG01213 includes previously named 01216 isolates. ${ }^{5}$ Race designation (race 1 , R1; race 2, R2; race 4, R4) based on Bentley et al. (1998), Boehm et al. (1994), Fourie et al. (2009), FraserSmith et al. (2013), Groenewald et al. (2006) and Koenig et al. (1997). ${ }^{6}$ Only VCG01220 out of this VCG complex is considered race 4 (Fourie et al., 2009). *These VCGs are maintained at the Foc collection of Dr. Randy Ploetz at the Research \& Education Center, Florida, USA. n.d. stands for "not determined". 


\section{THESIS OUTLINE}

In this $\mathrm{PhD}$ thesis, the genetic diversity of Foc, one of the most devastating pathogens of bananas, is explored using a high-resolution genotyping-by sequencing technique called Diversity Array Technology Sequencing, or DArTseq on a global panel of Foc strains from all banana-growing regions. In addition, relevant strains are examined for their pathogenicity and aggressiveness towards essential banana cultivars. Above all, the emerging TR4 strain is given special attention, since this embodies the contemporary major threat to worldwide banana production. Therefore, the genetic diversity among multiple TR4 isolates is analysed in detail and an innovative molecular detection tool is developed.

In Chapter 1, the thesis subject is introduced. The relevance of bananas and its interaction with Foc, namely its life cycle, typical symptoms of the disease and the evolution of this pathogen are summarized. Additionally, approaches to analyse and classify Foc diversity, as well as, their geographical distribution are described.

Chapter 2 has its focus on the emerging and disseminating TR4 strain. This genotype is responsible for severe losses in Cavendish banana production, one of the most important banana cultivars and virtually the only banana group that is being exported. Genomic data are used to demonstrate the genetic similarity among previous and recently reported TR4 isolates from Middle Asia. In addition to this, the genomic data are used to analyse all 24 Foc VCGs, including the previously unstudied VCG01221-01224. Lastly, strategies to deal with Fusarium wilt are discussed, particularly emphasizing the necessity to develop TR4-resistance banana varieties as the best approach to manage this threat.

In Chapter 3, the development of a sensitive, reliable and rapid new detection technology for TR4 is described which was validated under field conditions in The Philippines. It will be of great use in environments where bananas are an important staple food and cash crop but where laboratory conditions are absent or poorly developed.

In Chapter 4, the genetic diversity of a global Foc panel, comprising isolates from all banana-growing areas, is investigated by using DArTseq. Here, new Foc genotypes are revealed that account for an expanding diversity of the pathogen within clades 1, 2 and 3 of the FOSC, which elaborates on the origins of these pathogenic strains. Additionally, DArTseq analyses demonstrate that it is an efficient substitute for lengthy VCG testing to describe genetic diversity in existing or new Foc populations.

In Chapter 5, the resistance of the banana varieties 'Gros Michel' and 'Grand Naine' is investigated by phenotyping them with part of the global Foc panel (23 Foc VCGs). The results challenge the current Foc race concept, confirm the aggressiveness of the TR4 strain, and highlight the differential susceptibility of 'Gros Michel' cultivar compared to 'Grand Naine'.

Lastly in Chapter 6, the results of the thesis are discussed. The implications of the expanded Foc diversity and its geographical distribution, as well as, the deficiencies of Foc classification approaches are debated. Also, future lines of research are discussed that would lead to a better understanding and characterization of Fusarium strains causing the wilt disease of bananas. 


\section{REFERENCES}

Alabouvette, C., Olivain, C., Migheli, Q., \& Steinberg, C. (2009). Microbiological control of soil-borne phytopathogenic fungi with special emphasis on wilt-inducing Fusarium oxysporum. New Phytol, 184(3), 529-544.

Atallah, Z.K., \& Subbarao, K.V. (2012). Population biology of fungal plant pathogens. In M. D. Bolton \& B. P. H. J. Thomma (Eds.), Plant fungal pathogens: methods and protocols (pp. 333-363). Totowa, NJ: Humana Press.

Aurore, G., Parfait, B., \& Fahrasmane, L. (2009). Bananas, raw materials for making processed food products. Trends in Food Sci Tech, 20(2), 78-91.

Baayen, R.P., O'Donnell, K., Bonants, P.J.M., Cigelnik, E., Kroon, L.P.N.M., Roebroeck, E.J.A., \& Waalwijk, C. (2000). Gene genealogies and AFLP analyses in the Fusarium oxysporum complex identify monophyletic and nonmonophyletic formae speciales causing wilt and rot disease. Phytopathology, 90, 891-900.

Beckman, C.H. (2000). Phenolic-storing cells: keys to programmed cell death and periderm formation in wilt disease resistance and in general defence responses in plants? Physiol Mol Plant P, 57(3), 101-110.

Bentley, S., Pegg, K.G., Moore, N.Y., Davis, R.D., \& Buddenhagen, I. (1998). Genetic variation among vegetative compatibility groups of Fusarium oxysporum f.sp. cubense analyzed by DNA fingerprinting. Phytopathology, 88(12), 1283-1293.

Bentley, S., \& Bassam, B.J. (1996). A robust DNA amplification fingerprinting system applied to analysis of genetic variation Fusarium oxysporum f.sp. cubense. J Phytopathol, 144, 207-213.

Bentley, S., Pegg, K.G., \& Dale, J.L. (1995). Genetic variation among a world-wide collection of isolates of Fusarium oxysporum f.sp. cubense analysed by RAPD-PCR fingerprinting. Mycol Res, 99(11), 13781384.

Boddy, L. (2016). Chapter 4 Genetics - Variation, Sexuality, and Evolution The Fungi (pp. 99-139). Boston: Academic Press.

Boehm, E.W.A., Ploetz, R., \& Kistler, H.C. (1994). Statistical analysis of electrophoretic karyotype variation among vegetative compatibility groups of Fusarium oxysporum f.sp. cubense. MPMI, 7(2), 196-207.

Bogale, M., Wingfield, B.D., Wingfield, M.J., \& Steenkamp, E.T. (2006). Characterization of Fusarium oxysporum isolates from Ethiopia using AFLP, SSR and DNA sequence analyses. Fungal Divers, 23, 51-66.

Buddenhagen, I. (2009). Understanding strain diversity in Fusarium oxysporum f.sp. cubense and history of introduction of Tropical Race 4 to better manage banana production. Acta Hort, 828(Proc. IS on Banana Crop Prot., Sust. Prod. \& Impr. Livelihoods), 193-204.

Butler, D. (2013). Fungus threatens top banana. Nature, 504, 195-196.

Chakrabarti, A. (2013). Fusarium oxysporum: a "moving" view of pathogenicity. In B. A. Horwitz, P. K. Mukherjee, M. Mukherjee, \& C. P. Kubicek (Eds.), Genomics of soil- and plant-associated fungi (pp. 157-190). New York Dordrecht London: Springer.

Chen, M., Zeng, J., De Hoog, G.S., Stielow, B., Gerrits Van Den Ende, A.H., Liao, W., \& Lackner, M. (2016). The 'species complex' issue in clinically relevant fungi: A case study in Scedosporium apiospermum. Fungal Biol, 120(2), 137-146.

Correll, J.C. (1991). The relationships between formae speciales, races and vegetative compatibility groups in Fusarium oxysporum. Phytopathology, 81, 1061-1064.

D'Hont, A., Denoeud, F., Aury, J.M., Baurens, F.C., Carreel, F., Garsmeur, O., . . . Wincker, P. (2012). The banana (Musa acuminata) genome and the evolution of monocotyledonous plants. Nature, 488(7410), 213-217.

Dean, R., Van Kan, J.A.L., Pretorius, Z.A., Hammond-Kosack, K.E., Di Pietro, A., Spanu, P.D., . . Foster, G.D. (2012). The Top 10 fungal pathogens in molecular plant pathology. Mol Plant Pathol, 13(4), 414-430.

Di Pietro, A., Madrid, M.P., Caracuel, Z., Delgado-Jarana, J., \& Roncero, M.I. (2003). Fusarium oxysporum: exploring the molecular arsenal of a vascular wilt fungus. Mol Plant Pathol, 4(5), 315-325.

Di Pietro, A., García-Maceira, F.I., Méglecz, E., \& Roncero, M.I.G. (2001). A MAP kinase of the vascular wilt fungus Fusarium oxysporum is essential for root penetration and pathogenesis. Mol Microbiol, 39(5), 1140-1152. 
Di, X., Takken, F.L., \& Tintor, N. (2016). How phytohormones shape interactions between plants and the soilborne fungus Fusarium oxysporum. Front Plant Sci, 7, 1-9.

Diener, A. (2012). Visualizing and quantifying Fusarium oxysporum in the plant host. Mol Plant Microbe In, 25(12), 1531-1541.

Dita, M. A., Garming, H., Van den Bergh, E.B., Staver, C., \& Lescot, T. (2013). Banana in Latin America and the Caribbean: current state, challenges and perspectives Acta Hort, 986(Proc. Int. ISHS-ProMusa Symp. on bananas and plantains: towards sustainable global production and improved uses), 365-380.

Dore-Swamy, R., Srinivasa-Rao, N.K., \& Chacko, E.K. (1983). Tissue-culture propagation of banana. Sci Hortic, 18(3), 247-252.

Ekesa, B.N., Kimiywe, J., Davey, M.W., Dhuique-Mayer, C., Van den Bergh, I., Karamura, D., \& Blomme, G. (2012). Banana and plantain (Musa spp) cultivar preference, local processing techniques and consumption patterns in Eastern Democratic Republic of Congo. Int J Agri Sci, 4(8), 312-319.

FAO. (2014). Technical manual prevention and diagnostic of Fusarium Wilt (Panama disease) of banana caused by Fusarium oxysporum f.sp. cubense Tropical Race 4 (TR4).

FAOSTAT. (2013). FAO statistical database.

Fourie, G., Steenkamp, E.T., Ploetz, R.C., Gordon, T.R., \& Viljoen, A. (2011). Current status of the taxonomic position of Fusarium oxysporum forma specialis cubense within the Fusarium oxysporum complex. Infect Genet Evol, 11(3), 533-542.

Fourie, G., Steenkamp, E.T., Gordon, T.R., \& Viljoen, A. (2009). Evolutionary relationships among the Fusarium oxysporum f.sp. cubense vegetative compatibility groups. Appl Environ Microbiol, 75(14), 4770-4781.

Fraser-Smith, S., Czislowski, E., Meldrum, R.A., Zander, M., O'Neill, W., Balali, G.R., \& Aitken, E.A.B. (2013). Sequence variation in the putative effector gene SIX8 facilitates molecular differentiation of Fusarium oxysporum f.sp. cubense. Plant Pathol, 63(5), 1044-1052.

Frison, E., \& Sharrock, S. (1998). The economic, social and nutritional importance of banana in the world. Paper presented at the Bananas and food security, Douala, Cameroon.

FruitTrop. (2017). Banana-statistics. Fruit Trop, 248, 86-87.

García-Bastidas, F.A., Bakry, F., Irish, B., \& Kema, G.H.J. (2018a). Evidence for wide variation of resistance to Fusarium oxysporum f.sp. cubense tropical race 4 and race 1 generated by vegetative propagation in banana. (PhD Degree), Wageningen University \& Research, Wageningen, The Netherlands.

Geiser, D.M., Aoki, T., Bacon, C.W., Baker, S.E., Bhattacharyya, M.K., Brandt, M.E., . . . Zhang, N. (2013). One fungus, one name: defining the genus Fusarium in a scientifically robust way that preserves longstanding use. Phytopathology, 103(5), 400-408.

Ghag, S.B., Shekhawat, U.K.S., \& Ganapathi, T.R. (2015). Fusarium wilt of banana: biology, epidemiology and management. Int J Pest Manage, 1-14.

Gowen, S., Israeli, Y., Lahav, E., \& Reuveni, O. (1995). In vitro culture of bananas Bananas and plantains (pp. 147-178): Springer Netherlands.

Groenewald, S., Van Den Berg, N., Marasas, W.F., \& Viljoen, A. (2006). The application of high-throughput AFLP's in assessing genetic diversity in Fusarium oxysporum f.sp. cubense. Mycol Res, 110(Pt 3), 297 305.

Guo, L., Yang, L., Liang, C., Wang, G., Dai, Q., \& Huang, J. (2015). Differential colonization patterns of bananas (Musa spp.) by physiological race 1 and race 4 isolates of Fusarium oxysporum f.sp. cubense. $J$ Phytopathol, 1-11.

Gurr, S., Samalova, M., \& Fisher, M. (2011). The rise and rise of emerging infectious fungi challenges food security and ecosystem health. Fungal Biol Rev, 25(4), 181-188.

Häkkinen, M. (2013). Reappraisal of sectional taxonomy in Musa (Musaceae). Taxon, 62(4), 809-813.

Hennessy, C., Walduck, G., Daly, A., \& Padovan, A. (2005). Weed hosts of Fusarium oxysporum f.sp. cubense tropical race 4 in northern Australia. Australas Plant Pathol, 34(1), 115-117.

Heslop-Harrison, J.S., \& Schwarzacher, T. (2007). Domestication, genomics and the future for banana. Ann BotLondon, 100(5), 1073-1084.

Jansen, K. (2006). Banana Wars and the Multiplicity of Conflicts in Commodity Chains. ERLACS, 81, 97-113.

Jones, D.R. (2009). Disease and pest constraints to banana production. Acta Hort, 828(Proc. IS on Banana Crop Prot., Sust. Prod. \& Impr. Livelihoods), 21-36. 
Karamura, E., Frison, E., Karamura, D.A., \& Sharrock, S. (1998). Banana production system in eastern and southern Africa. Paper presented at the Bananas and food security, INIBAP, Montpellier.

Katan, T. (1999). Current status of vegetative compatibility groups in Fusarium oxysporum. Phytoparasitica, 27(1), 51-64.

Katan, T., \& Di Primo, P. (1999). Current status of vegetative compatibility groups in Fusarium oxysporum: Supplement (1999). Phytoparasitica, 27(4), 273-277.

Kawabe, M., Kobayashi, Y., Okada, G., Yamaguchi, I., Teraoka, T., \& Arie, T. (2005). Three evolutionary lineages of tomato wilt pathogen, Fusarium oxysporum f.sp. lycopersici, based on sequences of IGS, $M A T 1$, and pg1, are each composed of isolates of a single mating type and a single or closely related vegetative compatibility group. J Gen Plant Pathol, 71(4), 263-272.

Kistler, H.C., Alabouvette, C., Baayen, R.P., Bentley, S., Brayford, D., Coddington, A., . . . Woo, S. (1998). Systematic numbering of vegetative compatibility groups in the plant pathogenic fungus Fusarium oxysporum. Phytopathology, 88(1), 30-32.

Koenig, R.L., Ploetz, R., \& Kistler, H.C. (1997). Fusarium oxysporum f.sp. cubense consists of a small number of divergent and globally distributed clonal lineages. Phytopathology, 87(9), 915-923.

Koeppel, D. (2008). Banana, the fate of the fruit that changed the world. USA: PLUME.

Kupferschmidt, K. (2012). Attack of the clones. Science, 337, 636-638.

Laurence, M.H., Summerell, B.A., Burgess, L.W., \& Liew, E.C. (2014). Genealogical concordance phylogenetic species recognition in the Fusarium oxysporum species complex. Fungal Biol, 118(4), 374-384.

Leslie, J.F., Anderson, L. L., Bowden, R. L., \& Lee, Y. W. (2007). Inter- and intra-specific genetic variation in Fusarium. Int J Food Microbiol, 119(1-2), 25-32.

Leslie, J.F., \& Summerell, B. (2006). The Fusarium Laboratory Manual: Blackwell Publishing.

Leslie, J.F. (1990). Genetic exchange within sexual and asexual populations of the genus Fusarium. In R. Ploetz (Ed.), Fusarium wilt of banana (pp. 37-48).

Li, C., Chen, S., Zuo, C., Sun, Q., Ye, Q., Yi, G., \& Huang, B. (2011). The use of GFP-transformed isolates to study infection of banana with Fusarium oxysporum f.sp. cubense race 4. Eur J Plant Pathol, 131(2), 327-340.

Lievens, B., Rep, M., \& Thomma, B.P. (2008). Recent developments in the molecular discrimination of formae speciales of Fusarium oxysporum. Pest Manag Sci, 64(8), 781-788.

Ma, L.J., Geiser, D.M., Proctor, R.H., Rooney, A.P., O'Donnell, K., Trail, F., . . Kazan, K. (2013). Fusarium pathogenomics. Annu Rev Microbiol, 67, 399-416.

Ma, L.J., van der Does, H.C., Borkovich, K.A., Coleman, J.J., Daboussi, M.J., Di Pietro, A., . . Rep, M. (2010). Comparative genomics reveals mobile pathogenicity chromosomes in Fusarium. Nature, 464(7287), 367-373.

Marin, D.H., Sutton, T.B., \& Barker, K.R. (1998). Dissemination of bananas in Latin America and the Caribbean and its relationship to the occurrence of Radopholus similis. . Plant Dis, 82(9), 964-974.

McDonald, B.A., \& Linde, C. (2002). The population genetics of plant pathogens and breeding strategies for durable resistance. Euphytica, 124(2), 163-180.

Michielse, C.B., \& Rep, M. (2009). Pathogen profile update: Fusarium oxysporum. Mol Plant Pathol, 10(3), 311-324.

Molina, A.B., Fabregar, E., Sinohin, V.G., Yi, G., \& Viljoen, A. (2009). Recent occurrence of Fusarium oxysporum f.sp. cubense tropical race 4 in Asia. Acta Hort, 828(Proc. IS on Banana Crop Prot., Sust. Prod. \& Impr. Livelihoods), 109-115.

Möller, M., \& Stukenbrock, E.H. (2017). Evolution and genome architecture in fungal plant pathogens. Nat Rev Microbiol, 15, 756.

Moore, N.Y., Pegg, K.G., Allen, R.N., \& Irwin, J.A.G. (1993). Vegetative compatibility and distribution of Fusarium oxysporum f.sp. cubense in Australia. Aust J Exp Agri, 33, 797-802.

Nayar, N. (2010). The Bananas: botany, origin, dispersal (J. Janick Ed.): Wiley-Blackwell.

Nucci, M., \& Anaissie, E. (2002). Cutaneous infection by Fusarium species in healthy and immunocompromised hosts: implications for diagnosis and management. Clin Infect Dis, 35(8), 909-920.

O'Donnell, K., Rooney, A.P., Proctor, R.H., Brown, D.W., McCormick, S.P., Ward, T.J., . . . Geiser, D.M. (2013). Phylogenetic analyses of $R P B 1$ and $R P B 2$ support a middle Cretaceous origin for a clade comprising all agriculturally and medically important fusaria. Fungal Genet Biol, 52, 20-31. 
O'Donnell, K., Sutton, D.A., Rinaldi, M.G., Magnon, K.C., Cox, P.A., Revankar, S.G., . . . Robinson, J.S. (2004). Genetic diversity of human pathogenic members of the Fusarium oxysporum complex inferred from multilocus DNA sequence data and amplified fragment length polymorphism analyses: evidence for the recent dispersion of a geographically widespread clonal lineage and nosocomial origin. $J$ Clin Microbiol, 42(11), 5109-5120.

O'Donnell, K., Kistler, H.C., Cigelnik, E., \& Ploetz, R. (1998). Multiple evolutionary origins of the fungus causing Panama disease of banana: Concordant evidence from nuclear and mitochondrial gene genealogies. Proc Natl Acad Sci USA, 95, 2044-2049.Okubara, P.A., \& Paulitz, T.C. (2005). Root defense responses to fungal pathogens: a molecular perspective. Plant Soil, 274(1), 215-226.

Pareek, S. (2016). Chapter 3 - Nutritional and Biochemical Composition of Banana (Musa spp.) In V. R. Preedy (Ed.), Nutritional Composition of Fruit Cultivars (pp. 49-81). San Diego: Academic Press.

Pegg, K.G., Shivas, R.G., Moore, N.Y., \& Bentley, S. (1995). Characterization of a unique population of Fusarium oxysporum f.sp. cubense causing Fusarium wilt in Cavendish bananas at Carnarvon, Western Australia. Aust J Agric Res, 46, 167-178.

Perez-Nadales, E., Nogueira, M.F., Baldin, C., Castanheira, S., El Ghalid, M., Grund, E., .. . Wendland, J. (2014). Fungal model systems and the elucidation of pathogenicity determinants. Fungal Genet Biol, $70,42-67$.

Pérez, L.V. (2004). Fusarium wilt (Panama disease) of bananas: an updating review of the current knowledge on the disease and its causal agent. Paper presented at the XVI REUNIÓN INTERNACIONAL ACORBAT, Oaxaca, Mexico.

Perrier, X., De Langhe, E., Donohue, M., Lentfer, C., Vrydaghs, L., Bakry, F., . . . Denham, T. (2011). Multidisciplinary perspectives on banana (Musa spp.) domestication. Proc Natl Acad Sci USA, 108(28), 11311-11318.

Ploetz, R.C. (2015a). Fusarium Wilt of Banana. Phytopathology, 105(12), 1512-1521.

Ploetz, R.C. (2015b). Management of Fusarium wilt of banana: a review with special reference to tropical race 4. Crop Prot, 73, 7-15.

Ploetz, R.C., Kema, G.H., \& Ma, L.J. (2015). Impact of diseases on export and smallholder production of banana. Annu Rev Phytopathol, 53, 269-288.

Ploetz, R.C. (2006). Panama disease: An old nemesis rears its ugly head. Part2. The Cavendish era and beyond. Plant Health Progress.

Ploetz, R.C., \& Pegg, K. (1997). Fusarium wilt of banana and Wallace's line: Was the disease originally restricted to his Indo-Malayan region? Australas Plant Pathol, 26, 239-249.

Puhalla, J.E. (1985). Classification of strains of Fusarium oxysporum on the basis of vegetative compatibility. Can J Bot, 63, 179-183.

Robinson, J.C., \& Sauco, G.V. (2010). Bananas and plantains. Wellingford, Oxfordshire, UK: CABI.

Salacinas, M.A., Stoorvogel, J., Mendes, O., Schoen, C., Landeweert, R., Rebuta, A.M., . . . Kema, G.H.J. (2018). Tracing contamination of Fusarium oxysporum f.sp. cubense tropical race 4 in soil, water, weeds and field sanitation by burning in The Philippines. (PhD Degree), Wageningen University \& Research, Wageningen, The Netherlands.

Seidl, M.F., \& Thomma, B.P.H.J. (2017). Transposable elements direct the coevolution between plants and microbes. Trends Genet, 33(11), 842-851.

Seidl, M.F., \& Thomma, B.P.H.J. (2014). Sex or no sex: Evolutionary adaptation occurs regardless. BioEssays, 36(4), 335-345.

Simmonds, N.W., \& Shepherd, K. (1955). Taxonomy and origins of cultivated bananas. J Linn Soc Bot, 55, 302312.

Smith, E.F. (1910). A Cuban banana disease. Science, 31, 754-755.

Somrith, A., Singburaudom, N., \& Piasai, O. (2011). Vegetative Compatibility Groups of Fusarium oxysporum f.sp. cubense. Nat Sci, 45, 451-460.

Steinberg, C., Lecomte, C., Alabouvette, C., \& Edel-Hermann, V. (2016). Root interactions with nonpathogenic Fusarium oxysporum. In C. M. F. Vos \& K. Kazan (Eds.), Belowground Defence Strategies in Plants, Signaling and Communication in Plants (pp. 281-299): Springer International Publishing Switzerland.

Stover, R.H. (1962). Fusarial wilt (Panama disease) of bananas and other Musa species. UK: Commonwealth Mycological Institute 


\section{Chapter 1}

Taylor, J.W., Jacobson, D.J., \& Fisher, M.C. (1999). The evolution of asexual fungi: Reproduction, speciation and classification. Annu Rev Phytopathol, 37, 197-246.

Thornton, P., \& Cramer, L. (2012). Impacts of climate change on the agricultural and aquatic systems and natural resources within the CGIAR's mandate. Paper presented at the CCAFS Working Paper 23. CGIAR Research Program on Climate Change, Agriculture and Food Security (CCAFS), Copenhagen, Denmark.

Turra, D., El Ghalid, M., Rossi, F., \& Di Pietro, A. (2015). Fungal pathogen uses sex pheromone receptor for chemotropic sensing of host plant signals. Nature, 527(7579), 521-524.

Visser, M., Gordon, T., Fourie, G., \& Viljoen, A. (2009). Characterization of South Africa isolates of Fusarium oxysporum f.sp. cubense from Cavendish bananas S Afr J Sci, 106(3/4), 1-6.

Vlaardingerbroek, I., Beerens, B., Schmidt, S.M., Cornelissen, B.J.C., \& Rep, M. (2016). Dispensable chromosomes in Fusarium oxysporum f.sp. lycopersici. Mol Plant Pathol, 17(9), 1455-1466.

Yadeta, K.A., \& Thomma, B.P. (2013). The xylem as battleground for plant hosts and vascular wilt pathogens. Front Plant Sci, 4, 1-12. 



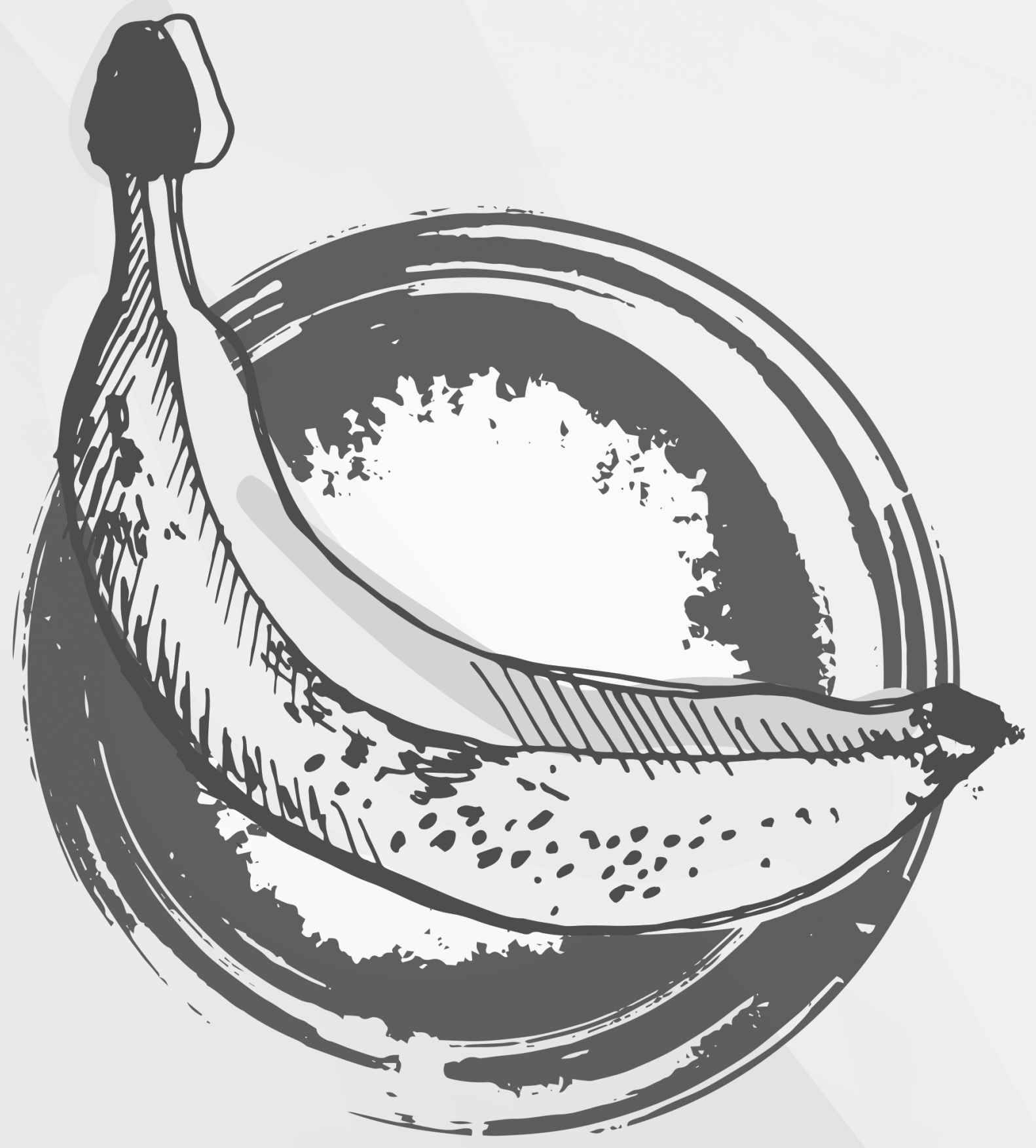




\section{CHAPTER 2}

\section{Worse comes to worst: Bananas and Panama disease - when plant and pathogen clones meet}

Ordóñez, N*., Seidl, M.F*., Waalwijk C., Drenth A., Kilian A., Thomma B.P.H.J., Ploetz R.C., Kema G.H.J. PloS Pathog 11, 1-7.

*These authors contributed equally to this work.
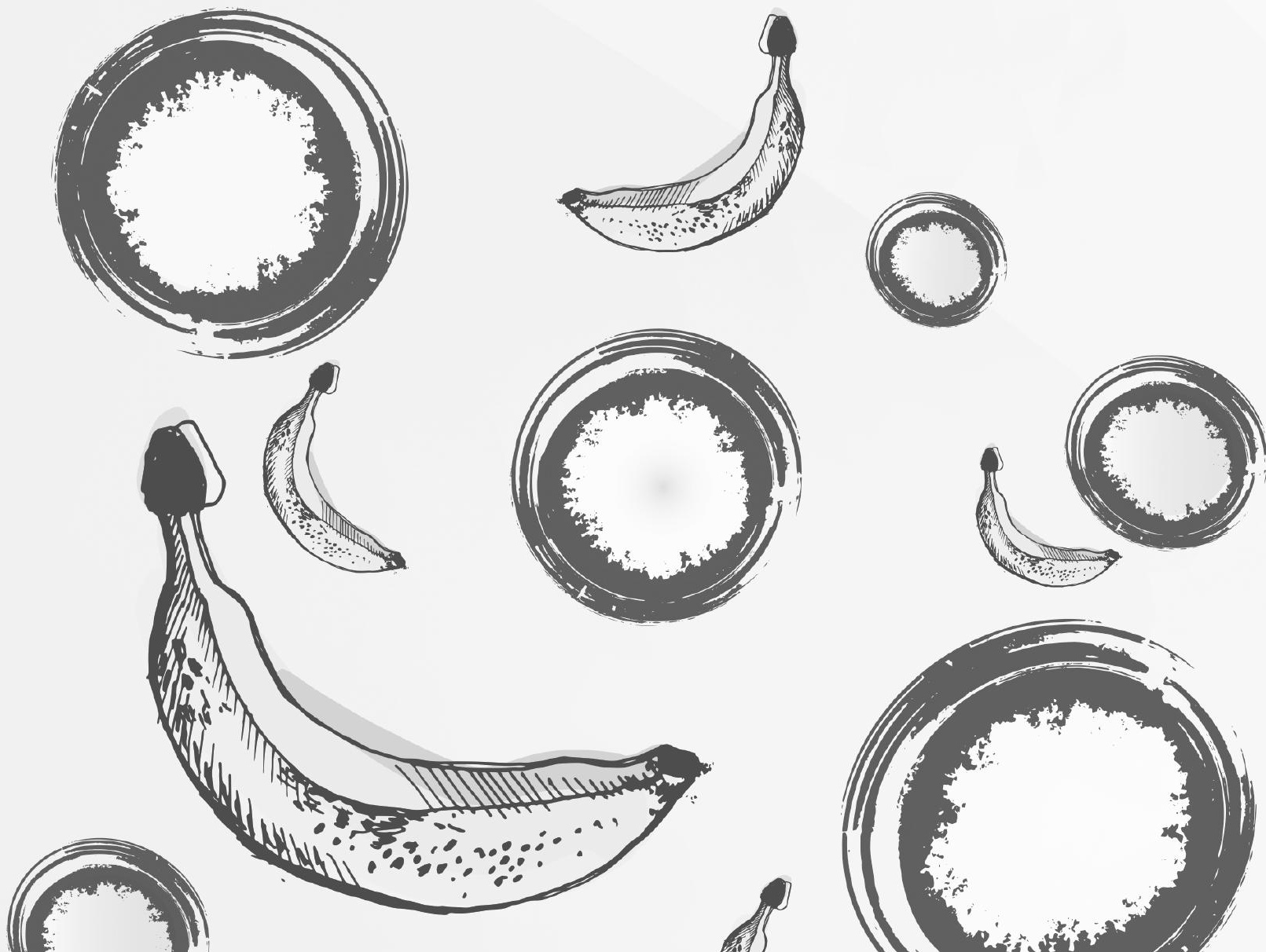


\section{BANANAS: THEIR ORIGIN AND GLOBAL ROLLOUT}

The banana is the most popular fruit in the world and ranks among the top ten food commodities for Southeast Asia, Africa and Latin America (FAOSTAT, 2013). Notably, the crop is largely produced by small-holder farmers, with around $85 \%$ of the global production destined for local markets and only $15 \%$ entering the international trade (FAOSTAT, 2013). Bananas evolved in the Indo-Malayan archipelago thousands of years ago. The majority of all edible varieties developed from specific (inter- and intra-) hybridizations of two seeded diploid Musa species (M. acuminata and M. balbisiana) and subsequent selection of diploid and triploid seedless clones (Perrier et al., 2011; Simmonds \& Shepherd, 1955). Despite rich genetic and phenotypic diversity (D'Hont et al., 2012), only a few clones developed, over time, into global commodities - either as dessert bananas, such as the triploid Cavendish clones, or as important staple foods such as cooking bananas and plantains (D'Hont et al., 2012; Ploetz, 2006). Currently, bananas are widely grown in the (sub) tropics and are consumed in nearly all countries around the world, providing crucial nutrition for millions of people. Edible bananas reproduce asexually through rhizomes, but since the early 1970s, tissue culture has enabled mass production of cultivars (Gowen et al., 1995). This facilitates the rapid rollout of genetically identical plants, which have consumer-preferred traits and outstanding agronomical performance, onto vast acreages around the world. However, the typical vulnerability of monocultures to diseases has taken its toll on banana production over the last century. In 1876, a wilting disease of banana was reported in Australia (Bancroft, 1876), and in 1890, it was observed in the 'Gros Michel' plantation crops of Costa Rica and Panama (Ploetz, 1994; Stover, 1962). There it developed major epidemics in the 1900s that are among the worst in agricultural history (Ploetz, 2005), linking its most prone geographical area to its colloquial name: Panama disease. It was only in 1910 that the soil-borne fungus Fusarium oxysporum f.sp. cubense (Foc) was identified as the causal agent in Cuba, from which the name of the forma specialis was derived (Ploetz, 2005).

\section{GENETIC DIVERSITY OF FUSARIUM OXYSPORUM F.SP. CUBENSE, THE CAUSAL AGENT OF PANAMA DISEASE}

Foc belongs to the Fusarium oxysporum species complex (FOSC): a suite of asexual, morphologically similar, pathogenic and non-pathogenic strains affecting a wide variety of crops (O'Donnell et al., 2009). Foc likely coevolved with its host species Musa in its center of origin (Bentley et al., 1998; Fourie et al., 2009; O'Donnell et al., 1998; Ploetz \& Pegg, 1997). Traditionally, phenotyping has identified three Foc races (1,2 and 4) that cause disease in different subsets of banana and plantain cultivars (Ploetz, 2006; Stover, 1962). However, Foc race designations are cumbersome and hence other methods unveiling genetic diversity were developed. Vegetative compatibility group (VCG) analyses largely divide Foc into 24 unique VCGs (VCG0120 through 0126 and 0128 through 01224) (Bentley et al., 1998; Kistler et al., 1998; Ploetz, 2006). Later, DNA markers revealed the polyphyletic origin of Foc, as some VCGs are taxonomically closer to other $F$. oxysporum formae speciales than to other Foc VCGs (Baayen et al., 2000; Fourie et al., 2009; O'Donnell et al., 1998). Moreover, strains belonging to diverse VCGs infect particular banana cultivars and, hence, were grouped in the same race, suggesting that pathogenicity towards a specific cultivar evolved either convergently (Fourie et al., 2009; O'Donnell et al., 1998; Ploetz, 2006) or resulted from 
horizontal gene transfer among members of the FOSC (Ma et al., 2010). Overall, Foc lineages show a remarkable dichotomy, referred to as types or clades (Bentley et al., 1995; Bentley et al., 1998; Boehm et al., 1994; Fourie et al., 2009; Groenewald et al., 2006; Koenig et al., 1997; O'Donnell et al., 1998). High-resolution genotyping-by sequencing analyses using DArTseq - which generates short sequence reads after a genomewide complexity reduction through restriction enzyme digestion (Cruz et al., 2013) - validate and extend these findings (Fig. 1). Based on genome-wide DArTseq markers, 24 Foc isolates (representing all hitherto known VCGs) split into two groups. These largely corroborate the aforementioned clades, except for VCG0123 (Bentley et al., 1995; Bentley et al., 1998; Fourie et al., 2009; Groenewald et al., 2006), VCG01210 (Boehm et al., 1994), VCG01212 (Bentley et al., 1995) and VCG01214 (Koenig et al., 1997), which were occasionally reported in opposite clades, and VCGs 01221 to 01224 , which were never classified before but now clearly belong to clade 2 (Fig. 1).

Unfortunately, it is not well known which VCGs (the so-called Foc race 1 strains) caused the Panama disease epidemic in 'Gros Michel' and, hence, their geographical dissemination is still unclear (I. Buddenhagen and M. Dita, personal communications). The current epidemic in Cavendish bananas, however, is caused by VCG01213 (Ploetz, 2006), colloquially called tropical race 4 (TR4).

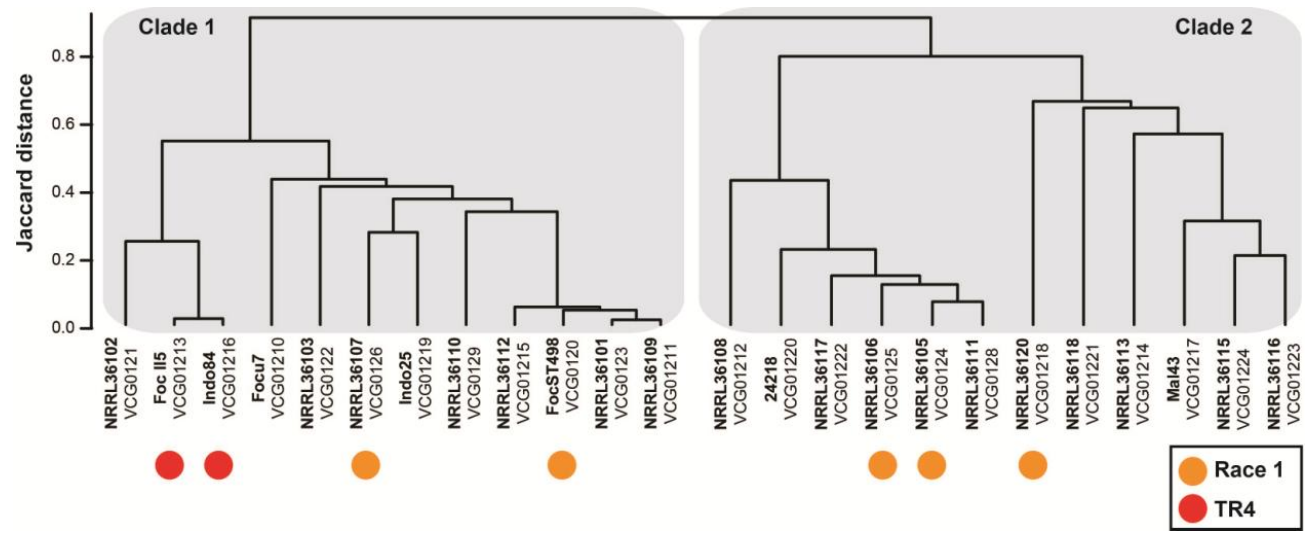

Figure 1. Genetic diversity of the banana pathogen Fusarium oxysporum f.sp. cubense (Foc). Genotyping-bysequencing analyses of the hitherto identified 24 vegetative compatibility groups (VCG) in Foc resulted in 12,978 DArTseq markers that divide Foc into two distinct clades - clade 1 and 2. VCG01216 is considered the same as 01213 (Bentley et al., 1998). The labels for race 1 isolates are based on personal communications with I. Buddenhagen and M. Dita. Although VCG01213 contains all TR4 isolates that cause the current Panama disease epidemic in Cavendish bananas, 0120 - which has also been considered as race 4 (Ploetz, 2006) -and 0124 (Thangavelu \& Mustaffa, 2010) were also recovered from symptomatic Cavendish plants. 


\section{PANAMA DISEASE: HISTORY REPEATS}

Large railway projects in Central America in the late 1800 s facilitated industrial banana production and trade (Ploetz, 2005), which was entirely based on 'Gros Michel' bananas (Stover, 1962). The unparalleled vulnerability of 'Gros Michel' to race 1 strains drove aggressive land-claiming policies in order to continue banana production. However, this did not stop the epidemic as Panama disease was easily entering these new areas through infected planting material. Hence, by the 1960s, the epidemic reached a tipping point with the total collapse of 'Gros Michel' (Ploetz, 1994). Fortunately, there was a remedy: Cavendish bananas - maintained as interesting specimens in botanical gardens in the United Kingdom and in the United Fruit Company collection in Honduras - were identified as resistant substitutes for 'Gros Michel'. A new clone was "born” that, along with the new tissue culture techniques, helped save and globalize banana production (Ploetz, 1994, 2006; Stover, 1962).

However, in the late 1960s, Panama disease emerged in Cavendish bananas in Taiwan, but TR4 was only identified as its cause in 1994 (Buddenhagen, 2009; Pegg et al., 1993; Ploetz, 1994). Surprisingly, this initial outbreak did not awaken the banana industry and awareness levels remained low, despite the lack of any Cavendish replacement that met market demands and the susceptibility of many local banana cultivars to TR4 (Ploetz, 2006) (see also http://panamadisease.org/en/news/26). Thus, TR4 threatens not only the export trade but also regional food provision and local economies.

\section{TROPICAL RACE 4, A SINGLE CLONE, THREATENS GLOBAL BANANA PRODUCTION}

Ever since TR4 destroyed the Cavendish-based banana industry in Taiwan, its trail in Southeast Asia seems unstoppable with incursions and expansions in the Chinese provinces of Guangdong, Fujian, Guangxi and Yunnan as well as on the island of Hainan. Since the 1990s, TR4 has also wiped out Cavendish plantations in Indonesia and Malaysia; between 1997 and 1999, it significantly reduced the banana industry near Darwin in the Northern Territory of Australia. It was first observed in the early 2000s in a newly planted Cavendish banana farm in Davao (on the island of Mindanao, Philippines), where it currently threatens the entire banana export trade (Molina et al., 2009). Since 2013, incursions outside Southeast Asia were reported in Jordan (García-Bastidas et al., 2014), Pakistan and Lebanon (Ordoñez et al., 2016), informally announced in Mozambique and Oman, and just recently noted in the Tully region of Northern Queensland, Australia. By now, TR4 may have affected up to approximately 100,000 hectares, and it is likely that it will disseminate further - either through infected plant material, contaminated soil, tools, footwear or due to flooding and inappropriate sanitation measures (Ploetz, 2006; Ploetz \& Pegg, 2000). Clearly, the current expansion of the Panama disease epidemic is particularly destructive due to the massive monoculture of susceptible Cavendish bananas. 

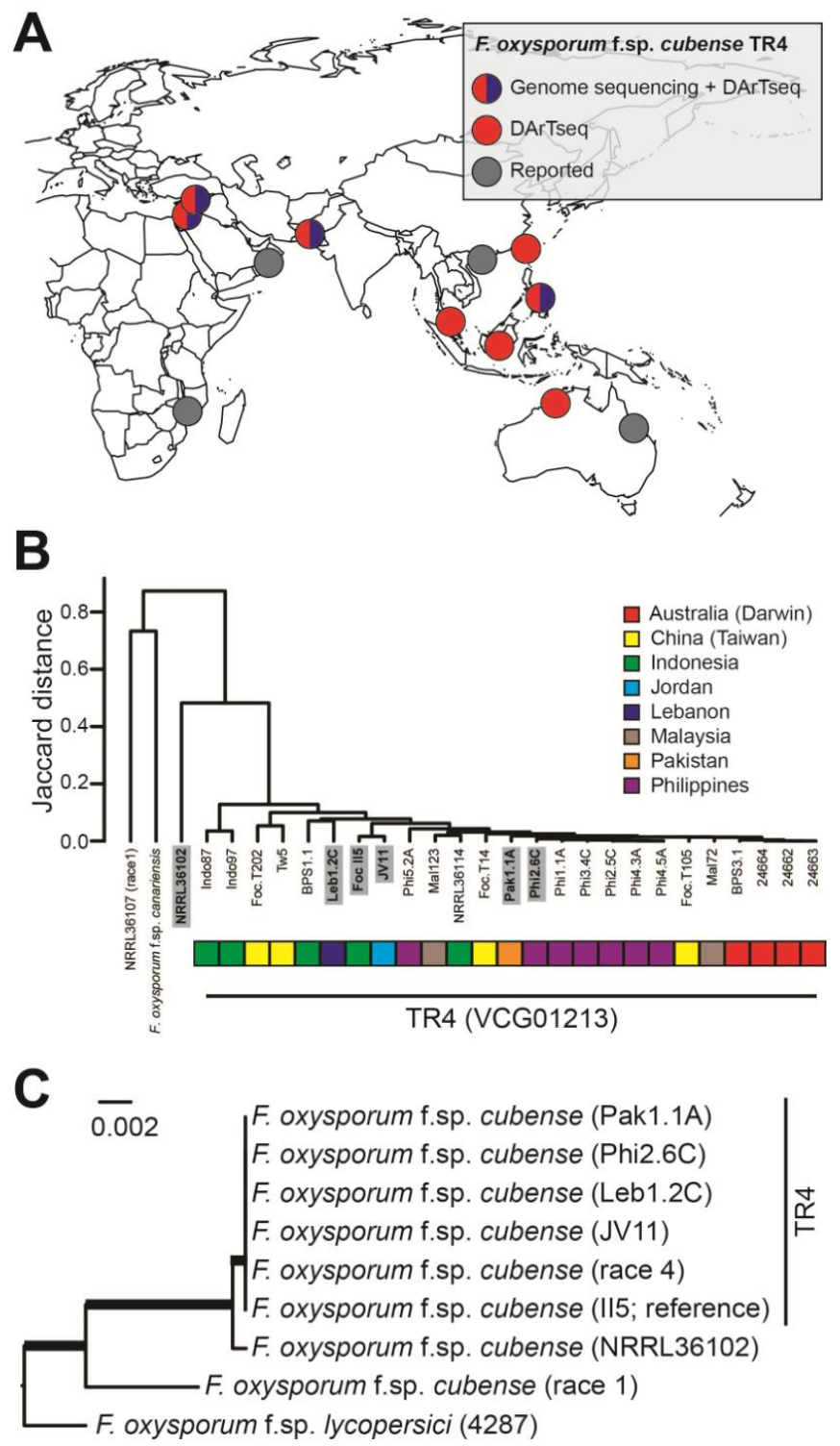

Figure 2. Phylogeography of Fusarium oxysporum f.sp. cubense tropical race 4 (Foc TR4). (A) Geographical locations of proclaimed TR4 incursions in Southeast Asia, Australia, Africa, the Middle East and the Indian subcontinent. Different colors indicate if and how the genetic diversity of collected isolates was assessed. (B) Limited genetic diversity between multiple TR4 isolates from distinct geographical locations revealed by hierarchical clustering, based on 4,298 DArTseq markers. Countries of origin for each of the TR4 isolates are indicated by different colors. (C) Phylogenetic analysis of selected TR4 isolates (highlighted in bold in panel B) and related $F$. oxysporum species, based on whole-genome re-sequencing data. Phylogenetic tree analysis was performed using REALPHY (Bertels et al., 2014), applying the PhyML algorithm for tree constructing (II5 reference genome). The $F$. oxysporum f.sp. lycopersici and the Foc II5 genomes, as well as Foc race 4 and 1 genomes, are publicly available at GenBank (http://www.ncbi.nlm.nih.gov/genome/genomes/707). Robustness of the grouping was assessed by 500 bootstrap replicates, and thick branches indicate maximum support. 
Foc is a haploid asexual pathogen (Stover, 1962) and is therefore expected to have a predominantly clonal population structure (Bentley et al., 1995; Bentley et al., 1998; Boehm et al., 1994; Fourie et al., 2009; Groenewald et al., 2006; Koenig et al., 1997). Comparison of re-sequencing data of TR4 isolates from Jordan, Lebanon, Pakistan and the Philippines with the publicly available reference genome sequence of TR4 isolate II5 (http://www.broadinstitute.org/) indeed shows a very low level of single nucleotide polymorphisms (SNPs) (about $0.01 \%$ ). This, together with a highly similar set of DArTseq markers, suggests that the temporal and spatial dispersal of TR4 is due to a single clone (Fig 2). This finding underscores the need for global awareness and quarantine campaigns in order to protect banana production from another pandemic that particularly affects vulnerable, small-holder farmers.

\section{STRATEGIES FOR SUSTAINABLE PANAMA DISEASE MANAGEMENT}

Any disease management eventually fails in a highly susceptible monoculture. Managing Panama disease with its soil-borne nature, long latency period, and persistence once established is, therefore, impossible without drastic strategy changes. Evidently, exclusion is the primary measure to protect banana production, which requires accurate diagnosis based not only on visual inspection, as this overlooks important aspects of its genetic diversity and epidemiology. New molecular-based diagnostics rapidly detect TR4 in (pre)symptomatic plants (Dita et al., 2010), soil and water and, hence, can be used for surveillance and containment, which are key to avoiding an encounter of TR4 with Cavendish monocultures. Additionally, a thorough understanding of Foc epidemiology and pathology is urgently required, as this facilitates developing effective methods to destroy infected plants and (biological) soil treatments, thus reducing the inoculum quantity. Furthermore, we showed that high-throughput genome analyses unveil Foc population diversity (Fig. 1 and 2), rather than lengthy and cumbersome VCG analyses, which enables resistance deployment strategies. Finally, effective disease management cannot be achieved without adequate disease resistance levels. Cavendish-based somaclones (Hwang \& Ko, 2004) do not satisfy local or international industry demands (apart from the epidemiological risks), as this germplasm is, at most, only partially resistant to TR4 (Ploetz, 2015). Instead, the substantial genetic diversity for TR4 resistance in (wild) banana germplasm, such as accessions of Musa acuminata ssp. malaccensis (D'Hont et al., 2012), can be exploited in breeding programs and/or along with various transformation techniques (Ghag et al., 2014a, 2014b; Paul et al., 2011) to develop a new generation of banana cultivars in conformity with consumer preferences. Developing new banana cultivars, however, requires major investments in research and development and the recognition of the banana as a global staple and cash crop (rather than an orphan crop) that supports the livelihoods of millions of smallholder farmers. Until new, commercially viable, and resistant banana cultivars reach markets, any potential disease management option needs to be scrutinized, thereby lengthening the commercial lifespan of contemporary banana accessions. The current TR4 epidemic and inherent global attention should be the wake-up call for these much needed strategy changes. 


\section{REFERENCES}

Baayen, R.P., O'Donnell, K., Bonants, P.J.M., Cigelnik, E., Kroon, L.P.N.M., Roebroeck, E.J.A., \& Waalwijk, C. (2000). Gene genealogies and AFLP analyses in the Fusarium oxysporum complex identify monophyletic and nonmonophyletic formae speciales causing wilt and rot disease. Phytopathology, 90, 891-900.

Bancroft, J. (1876). Report of the board appointed to enquire into the cause of disease affecting livestock and plants. Votes and Proceedings 1877, 3, 1011-1038.

Bentley, S., Pegg, K.G., Moore, N.Y., Davis, R.D., \& Buddenhagen, I. (1998). Genetic variation among vegetative compatibility groups of Fusarium oxysporum f.sp. cubense analyzed by DNA fingerprinting. Phytopathology, 88(12), 1283-1293.

Bentley, S., Pegg, K.G., \& Dale, J.L. (1995). Genetic variation among a world-wide collection of isolates of Fusarium oxysporum f.sp. cubense analysed by RAPD-PCR fingerprinting. Mycol Res, 99(11), 13781384.

Bertels, F., Silander, O.K., Pachkov, M., Rainey, P.B., \& van Nimwegen, E. (2014). Automated reconstruction of whole-genome phylogenies from short-sequence reads. Mol Biol Evol, 31(5), 1077-1088.

Boehm, E.W.A., Ploetz, R., \& Kistler, H.C. (1994). Statistical analysis of electrophoretic karyotype variation among vegetative compatibility groups of Fusarium oxysporum f.sp. cubense. MPMI, 7(2), 196-207.

Buddenhagen, I. (2009). Understanding strain diversity in Fusarium oxysporum f.sp. cubense and history of introduction of tropical race 4 to better manage banana production. Acta Hort, 828(Proc. IS on Banana Crop Prot., Sust. Prod. \& Impr. Livelihoods), 193-204.

Cruz, V.M., Kilian, A., \& Dierig, D.A. (2013). Development of DArT marker platforms and genetic diversity assessment of the U.S. collection of the new oilseed crop lesquerella and related species. PLoS One, $8(5), 1-13$.

D'Hont, A., Denoeud, F., Aury, J.M., Baurens, F.C., Carreel, F., Garsmeur, O., . . . Wincker, P. (2012). The banana (Musa acuminata) genome and the evolution of monocotyledonous plants. Nature, 488(7410), 213-217.

Dita, M.A., Waalwijk, C., Buddenhagen, I.W., Souza Jr, M.T., \& Kema, G.H.J. (2010). A molecular diagnostic for tropical race 4 of the banana Fusarium wilt pathogen. Plant Pathol, 59(2), 348-357.

FAOSTAT. (2013). FAO statistical database.

Fourie, G., Steenkamp, E. T., Gordon, T. R., \& Viljoen, A. (2009). Evolutionary relationships among the Fusarium oxysporum f.sp. cubense vegetative compatibility groups. Appl Environ Microbiol, 75(14), 4770-4781.

García-Bastidas, F., Ordóñez, N., Konkol, J., Al-Qasim, M., Naser, Z., Abdelwali, M., . . Kema, G.H.J. (2014). First report of Fusarium oxysporum f.sp. cubense tropical race 4 associated with Panama disease of banana outside Southeast Asia. Plant Dis, 98(5), 694-694.

Ghag, S.B., Shekhawat, U.K., \& Ganapathi, T.R. (2014a). Host-induced post-transcriptional hairpin RNAmediated gene silencing of vital fungal genes confers efficient resistance against Fusarium wilt in banana. Plant Biotechnol J, 12(5), 541-553.

Ghag, S.B., Shekhawat, U.K., \& Ganapathi, T.R. (2014b). Native cell-death genes as candidates for developing wilt resistance in transgenic banana plants. AoB Plants, 6, 1-12.

Gowen, S., Israeli, Y., Lahav, E., \& Reuveni, O. (1995). In vitro culture of bananas. Bananas and Plantains (pp. 147-178): Springer Netherlands.

Groenewald, S., Van Den Berg, N., Marasas, W.F., \& Viljoen, A. (2006). The application of high-throughput AFLP's in assessing genetic diversity in Fusarium oxysporum f.sp. cubense. Mycol Res, 110(Pt 3), $297-$ 305.

Guo, L., Han, L., Yang, L., Zeng, H., Fan, D., Zhu, Y., . . Huang, J. (2014). Genome and transcriptome analysis of the fungal pathogen Fusarium oxysporum f.sp. cubense causing banana vascular wilt disease. PLoS One,9(4), 1-17.

Hwang, S.C., \& Ko, W.H. (2004). Cavendish banana cultivars resistant to Fusarium wilt acquired through somaclonal variation in Taiwan somaclonal variation in Taiwan. Plant Dis, 88(6), 580-588. 


\section{Chapter 2}

Kistler, H.C., Alabouvette, C., Baayen, R.P., Bentley, S., Brayford, D., Coddington, A., . . Woo, S. (1998). Systematic numbering of vegetative compatibility groups in the plant pathogenic fungus Fusarium oxysporum. Phytopathology, 88(1), 30-32.

Koenig, R.L., Ploetz, R., \& Kistler, H. C. (1997). Fusarium oxysporum f.sp. cubense consists of a small number of divergent and globally distributed clonal lineages. Phytopathology, 87(9), 915-923.

Ma, L.J., van der Does, H.C., Borkovich, K.A., Coleman, J.J., Daboussi, M.J., Di Pietro, A., . . Rep, M. (2010). Comparative genomics reveals mobile pathogenicity chromosomes in Fusarium. Nature, 464(7287), 367-373.

Molina, A.B., Fabregar, E., Sinohin, V.G., Yi, G., \& Viljoen, A. (2009). Recent occurrence of Fusarium oxysporum f.sp. cubense tropical race 4 in Asia. Acta Hort, 828(Proc. IS on Banana Crop Prot., Sust. Prod. \& Impr. Livelihoods), 109-115.

O'Donnell, K., Gueidan, C., Sink, S., Johnston, P.R., Crous, P.W., Glenn, A., . . Sarver, B.A. (2009). A twolocus DNA sequence database for typing plant and human pathogens within the Fusarium oxysporum species complex. Fungal Genet Biol, 46(12), 936-948.

O'Donnell, K., Kistler, H.C., Cigelnik, E., \& Ploetz, R. (1998). Multiple evolutionary origins of the fungus causing Panama disease of banana: Concordant evidence from nuclear and mitochondrial gene genealogies. Proc Natl Acad Sci USA, 95, 2044-2049.

Ordoñez, N., García-Bastidas, F., Laghari, H.B., Akkary, M.Y., Harfouche, E.N., al Awar, B.N., \& Kema, G.H.J. (2016). First report of Fusarium oxysporum f.sp. cubense tropical race 4 causing Panama Disease in Cavendish Bananas in Pakistan and Lebanon. Plant Dis, 100(1), 209.

Paul, J.Y., Becker, D.K., Dickman, M.B., Harding, R.M., Khanna, H.K., \& Dale, J.L. (2011). Apoptosis-related genes confer resistance to Fusarium wilt in transgenic 'Lady Finger' bananas. Plant Biotechnol J, 9(9), 1141-1148.

Pegg, K.G., Moore, N.Y., \& Sorensen, S. (1993, 14-18 December, 1992). Fusarium wilt in the Asian Pacific region. Paper presented at the Procceedings of an International Symposium on Recent Developments in Banana Cultivation Technology, Pingtun, Taiwan (Los Banos, Laguna, Philippines: TBRI, ASPNET, INIBAP), .

Perrier, X., De Langhe, E., Donohue, M., Lentfer, C., Vrydaghs, L., Bakry, F., . . . Denham, T. (2011). Multidisciplinary perspectives on banana (Musa spp.) domestication. Proc Natl Acad Sci USA, 108(28), 11311-11318.

Ploetz, R.C. (2015). Management of Fusarium wilt of banana: a review with special reference to tropical race 4. Crop Prot, 73, 7-15.

Ploetz, R.C. (2006). Panama disease: An old nemesis rears its ugly head. Part2. The Cavendish era and beyond. Plant Health Progress.

Ploetz, R.C. (2005). Panama Disease: An old nemesis rears its ugly head. Part1: The beginnings of the banana export trades. Plant Health Progress.

Ploetz, R.C., \& Pegg, K.G. (2000). Fusarium wilt. In: Diseases of Banana, Abaca and Enset. Wallingford, UK: CABI Publishing.

Ploetz, R.C., \& Pegg, K. (1997). Fusarium wilt of banana and Wallace's line: Was the disease originally restricted to his Indo-Malayan region? Australas Plant Pathol, 26, 239-249.

Ploetz, R.C. (1994). Panama disease: Return of the first banana menace. Int J Pest Manage, 40(4), 326-336.

Simmonds, N.W., \& Shepherd, K. (1955). Taxonomy and origins of cultivated bananas. J Linn Soc Bot, 55, 302312.

Stover, R.H. (1962). Fusarial wilt (Panama disease) of bananas and other Musa species. UK: Commonwealth Mycological Institute

Thangavelu, R., \& Mustaffa, M.M. (2010). First report on the occurrence of a virulent strain of Fusarium wilt pathogen (Race-1) infecting Cavendish (AAA) group of bananas in India. Plant Dis, 94(11), 1379. 
Supplementary Table 1. Isolate collection at Wageningen University \& Research (WUR) and genome data used in this study.

\begin{tabular}{|c|c|c|c|c|c|c|c|c|}
\hline Isolate code & Other collections & Species & VCG & $\begin{array}{l}\text { Country } \\
\text { of origin }\end{array}$ & $\begin{array}{l}\text { Received } \\
\text { as }\end{array}$ & $\begin{array}{l}\text { Isolated } \\
\text { by }\end{array}$ & $\begin{array}{l}\text { Original } \\
\text { Provider }\end{array}$ & $\begin{array}{l}\text { On } \\
\text { Figure }\end{array}$ \\
\hline FocST498 & Not in others & $\begin{array}{l}\text { Fusarium } \\
\text { oxysporum } \\
\text { f.sp. cubense }\end{array}$ & 0120 & Spain & Isolate & $\begin{array}{l}\text { Not } \\
\text { applicable }\end{array}$ & $\begin{array}{l}\text { C. Waalwijk, } \\
\text { WUR }\end{array}$ & 1 \\
\hline II5 & $\begin{array}{l}\text { ARS Culture } \\
\text { Collection, USA } \\
\text { (NRRL54006) }\end{array}$ & $\begin{array}{l}F . \text { oxysporum } \\
\text { f.sp. cubense }\end{array}$ & 01213 & Indonesia & Isolate & $\begin{array}{l}\text { Not } \\
\text { applicable }\end{array}$ & $\begin{array}{l}\text { C. Waalwijk, } \\
\text { WUR }\end{array}$ & $\begin{array}{l}1,2 \mathrm{~B} \\
\text { and } 2 \mathrm{C}\end{array}$ \\
\hline Focu7 & $\begin{array}{l}\text { American Type } \\
\text { Culture Collection } \\
\text { (ATCC76244) }\end{array}$ & $\begin{array}{l}F . \text { oxysporum } \\
\text { f.sp. cubense }\end{array}$ & 01210 & USA & Isolate & $\begin{array}{l}\text { Not } \\
\text { applicable }\end{array}$ & $\begin{array}{l}\text { Université } \\
\text { Paris-Sud, } \\
\text { France }\end{array}$ & 1 \\
\hline Indo84 & $\begin{array}{l}\text { Ecosciences } \\
\text { Precinct, Brisbane } \\
\text { Australia }\end{array}$ & $\begin{array}{l}F . \text { oxysporum } \\
\text { f.sp. cubense }\end{array}$ & 01216 & Indonesia & Isolate & $\begin{array}{l}\text { Not } \\
\text { applicable }\end{array}$ & $\begin{array}{l}\text { W. O'Neil, } \\
\text { Australia }\end{array}$ & 1 \\
\hline NRRL36101 & $\begin{array}{l}\text { ARS Culture } \\
\text { Collection, USA } \\
\text { (NRRL36101) }\end{array}$ & $\begin{array}{l}\text { F. oxysporum } \\
\text { f.sp. cubense }\end{array}$ & 0123 & Australia & Isolate & $\begin{array}{l}\text { Not } \\
\text { applicable }\end{array}$ & $\begin{array}{l}\text { K. O'Donnell, } \\
\text { USA }\end{array}$ & 1 \\
\hline NRRL36102 & $\begin{array}{l}\text { ARS Culture } \\
\text { Collection, USA } \\
\text { (NRRL36102) }\end{array}$ & $\begin{array}{l}F . \text { oxysporum } \\
\text { f.sp. cubense }\end{array}$ & 0121 & China & Isolate & $\begin{array}{l}\text { Not } \\
\text { applicable }\end{array}$ & $\begin{array}{l}\text { K. O'Donnell, } \\
\text { USA }\end{array}$ & $\begin{array}{l}1,2 \mathrm{~B} \\
\text { and } 2 \mathrm{C}\end{array}$ \\
\hline NRRL36103 & $\begin{array}{l}\text { ARS Culture } \\
\text { Collection, USA } \\
\text { (NRRL36103) }\end{array}$ & $\begin{array}{l}F . \text { oxysporum } \\
\text { f.sp. cubense }\end{array}$ & 0122 & Philippines & Isolate & $\begin{array}{l}\text { Not } \\
\text { applicable }\end{array}$ & $\begin{array}{l}\text { K. O'Donnell, } \\
\text { USA }\end{array}$ & 1 \\
\hline NRRL36105 & $\begin{array}{l}\text { ARS Culture } \\
\text { Collection, USA } \\
\text { (NRRL36105) }\end{array}$ & $\begin{array}{l}F . \text { oxysporum } \\
\text { f.sp. cubense }\end{array}$ & 0124 & Honduras & Isolate & $\begin{array}{l}\text { Not } \\
\text { applicable }\end{array}$ & $\begin{array}{l}\text { K. O'Donnell, } \\
\text { USA }\end{array}$ & 1 \\
\hline NRRL36106 & $\begin{array}{l}\text { ARS Culture } \\
\text { Collection, USA } \\
\text { (NRRL36106) }\end{array}$ & $\begin{array}{l}F . \text { oxysporum } \\
\text { f.sp. cubense }\end{array}$ & 0125 & Australia & Isolate & $\begin{array}{l}\text { Not } \\
\text { applicable }\end{array}$ & $\begin{array}{l}\text { K. O'Donnell, } \\
\text { USA }\end{array}$ & $\begin{array}{l}1 \text { and } \\
2 \mathrm{~B}\end{array}$ \\
\hline NRRL36107 & $\begin{array}{l}\text { ARS Culture } \\
\text { Collection, USA } \\
\text { (NRRL36107) }\end{array}$ & $\begin{array}{l}F . \text { oxysporum } \\
\text { f.sp. cubense }\end{array}$ & 0126 & Honduras & Isolate & $\begin{array}{l}\text { Not } \\
\text { applicable }\end{array}$ & $\begin{array}{l}\text { K. O'Donnell, } \\
\text { USA }\end{array}$ & 1 \\
\hline NRRL36108 & $\begin{array}{l}\text { ARS Culture } \\
\text { Collection, USA } \\
\text { (NRRL36108) }\end{array}$ & $\begin{array}{l}F . \text { oxysporum } \\
\text { f.sp. cubense }\end{array}$ & 01212 & Tanzania & Isolate & $\begin{array}{l}\text { Not } \\
\text { applicable }\end{array}$ & $\begin{array}{l}\text { K. O'Donnell, } \\
\text { USA }\end{array}$ & 1 \\
\hline NRRL36109 & $\begin{array}{l}\text { ARS Culture } \\
\text { Collection, USA } \\
\text { (NRRL36109) }\end{array}$ & $\begin{array}{l}F . \text { oxysporum } \\
\text { f.sp. cubense }\end{array}$ & 01211 & Australia & Isolate & $\begin{array}{l}\text { Not } \\
\text { applicable }\end{array}$ & $\begin{array}{l}\text { K. O'Donnell, } \\
\text { USA }\end{array}$ & 1 \\
\hline NRRL36110 & $\begin{array}{l}\text { ARS Culture } \\
\text { Collection, USA } \\
\text { (NRRL36110) }\end{array}$ & $\begin{array}{l}F . \text { oxysporum } \\
\text { f.sp. cubense }\end{array}$ & 0129 & Australia & Isolate & $\begin{array}{l}\text { Not } \\
\text { applicable }\end{array}$ & $\begin{array}{l}\text { K. O'Donnell, } \\
\text { USA }\end{array}$ & 1 \\
\hline NRRL36111 & $\begin{array}{l}\text { ARS Culture } \\
\text { Collection, USA } \\
\text { (NRRL36111) }\end{array}$ & $\begin{array}{l}F . \text { oxysporum } \\
\text { f.sp. cubense }\end{array}$ & 0128 & Australia & Isolate & $\begin{array}{l}\text { Not } \\
\text { applicable }\end{array}$ & $\begin{array}{l}\text { K. O'Donnell, } \\
\text { USA }\end{array}$ & 1 \\
\hline NRRL36112 & $\begin{array}{l}\text { ARS Culture } \\
\text { Collection, USA } \\
\text { (NRRL36112) }\end{array}$ & $\begin{array}{l}F . \text { oxysporum } \\
\text { f.sp. cubense }\end{array}$ & 01215 & $\begin{array}{l}\text { South } \\
\text { Africa }\end{array}$ & Isolate & $\begin{array}{l}\text { Not } \\
\text { applicable }\end{array}$ & $\begin{array}{l}\text { K. O'Donnell, } \\
\text { USA }\end{array}$ & 1 \\
\hline NRRL36113 & $\begin{array}{l}\text { ARS Culture } \\
\text { Collection, USA } \\
\text { (NRRL36113) }\end{array}$ & $\begin{array}{l}F . \text { oxysporum } \\
\text { f.sp. cubense }\end{array}$ & 01214 & Malawi & Isolate & $\begin{array}{l}\text { Not } \\
\text { applicable }\end{array}$ & $\begin{array}{l}\text { K. O'Donnell, } \\
\text { USA }\end{array}$ & 1 \\
\hline NRRL36115 & $\begin{array}{l}\text { ARS Culture } \\
\text { Collection, USA } \\
\text { (NRRL36115) }\end{array}$ & $\begin{array}{l}F . \text { oxysporum } \\
\text { f.sp. cubense }\end{array}$ & 01224 & Malaysia & Isolate & $\begin{array}{l}\text { Not } \\
\text { applicable }\end{array}$ & $\begin{array}{l}\text { K. O'Donnell, } \\
\text { USA }\end{array}$ & 1 \\
\hline NRRL36116 & $\begin{array}{l}\text { ARS Culture } \\
\text { Collection, USA } \\
\text { (NRRL36116) }\end{array}$ & $\begin{array}{l}F . \text { oxysporum } \\
\text { f.sp. cubense }\end{array}$ & 01223 & Malaysia & Isolate & $\begin{array}{l}\text { Not } \\
\text { applicable }\end{array}$ & $\begin{array}{l}\text { K. O'Donnell, } \\
\text { USA }\end{array}$ & 1 \\
\hline NRRL36117 & $\begin{array}{l}\text { ARS Culture } \\
\text { Collection, USA } \\
\text { (NRRL36117) }\end{array}$ & $\begin{array}{l}F . \text { oxysporum } \\
\text { f.sp. cubense }\end{array}$ & 01222 & Malaysia & Isolate & $\begin{array}{l}\text { Not } \\
\text { applicable }\end{array}$ & $\begin{array}{l}\text { K. O'Donnell, } \\
\text { USA }\end{array}$ & 1 \\
\hline NRRL36118 & $\begin{array}{l}\text { ARS Culture } \\
\text { Collection, USA } \\
\text { (NRRL36118) }\end{array}$ & $\begin{array}{l}F . \text { oxysporum } \\
\text { f.sp. cubense }\end{array}$ & 01221 & Thailand & Isolate & $\begin{array}{l}\text { Not } \\
\text { applicable }\end{array}$ & $\begin{array}{l}\text { K. O'Donnell, } \\
\text { USA }\end{array}$ & 1 \\
\hline
\end{tabular}




\begin{tabular}{|c|c|c|c|c|c|c|c|c|}
\hline Isolate code & Other collections & Species & VCG & $\begin{array}{l}\text { Country } \\
\text { of origin }\end{array}$ & $\begin{array}{l}\text { Received } \\
\text { as }\end{array}$ & $\begin{array}{l}\text { Isolated } \\
\text { by }\end{array}$ & $\begin{array}{l}\text { Original } \\
\text { Provider }\end{array}$ & $\begin{array}{l}\text { On } \\
\text { Figure }\end{array}$ \\
\hline NRRL36120 & $\begin{array}{l}\text { ARS Culture } \\
\text { Collection, USA } \\
\text { (NRRL36120) }\end{array}$ & $\begin{array}{l}\text { F. oxysporum } \\
\text { f.sp. cubense }\end{array}$ & 01218 & Thailand & Isolate & $\begin{array}{l}\text { Not } \\
\text { applicable }\end{array}$ & $\begin{array}{l}\text { K. O'Donnell, } \\
\text { USA }\end{array}$ & 1 \\
\hline 24218 & $\begin{array}{l}\text { Ecosciences } \\
\text { Precinct, Brisbane } \\
\text { Australia }\end{array}$ & $\begin{array}{l}\text { F. oxysporum } \\
\text { f.sp. cubense }\end{array}$ & 01220 & Australia & Isolate & $\begin{array}{l}\text { Not } \\
\text { applicable }\end{array}$ & $\begin{array}{l}\text { A. Drenth, } \\
\text { Australia }\end{array}$ & 1 \\
\hline Mal43 & $\begin{array}{l}\text { Ecosciences } \\
\text { Precinct, Brisbane } \\
\text { Australia }\end{array}$ & $\begin{array}{l}\text { F. oxysporum } \\
\text { f.sp. cubense }\end{array}$ & 01217 & Malaysia & Isolate & $\begin{array}{l}\text { Not } \\
\text { applicable }\end{array}$ & $\begin{array}{l}\text { A. Drenth, } \\
\text { Australia }\end{array}$ & 1 \\
\hline Indo25 & $\begin{array}{l}\text { Ecosciences } \\
\text { Precinct, Brisbane } \\
\text { Australia }\end{array}$ & $\begin{array}{l}\text { F. oxysporum } \\
\text { f.sp. cubense }\end{array}$ & 01219 & Indonesia & Isolate & $\begin{array}{l}\text { Not } \\
\text { applicable }\end{array}$ & $\begin{array}{l}\text { A. Drenth, } \\
\text { Australia }\end{array}$ & 1 \\
\hline JV11 & Not in others & $\begin{array}{l}\text { F. oxysporum } \\
\text { f.sp. cubense }\end{array}$ & 01213 & Jordan & $\begin{array}{l}\text { Banana } \\
\text { tissue }\end{array}$ & $\begin{array}{l}\text { Nadia } \\
\text { Ordonez, } \\
\text { WUR }\end{array}$ & R. Ploetz, USA & $\begin{array}{l}2 \mathrm{~B} \text { and } \\
2 \mathrm{C}\end{array}$ \\
\hline BPS1.1 & Not in others & $\begin{array}{l}\text { F. oxysporum } \\
\text { f.sp. cubense }\end{array}$ & 01213 & Indonesia & Isolate & $\begin{array}{l}\text { Not } \\
\text { applicable }\end{array}$ & $\begin{array}{l}\text { I. } \\
\text { Buddenhagen, } \\
\text { USA }\end{array}$ & $2 \mathrm{~B}$ \\
\hline BPS3.1 & Not in others & $\begin{array}{l}\text { F. oxysporum } \\
\text { f.sp. cubense }\end{array}$ & 01213 & Australia & Isolate & $\begin{array}{l}\text { Not } \\
\text { applicable }\end{array}$ & $\begin{array}{l}\text { I. } \\
\text { Buddenhagen, } \\
\text { USA }\end{array}$ & $2 \mathrm{~B}$ \\
\hline Foc.T105 & $\begin{array}{l}\text { Collection Dr. Pi- } \\
\text { Fang Linda } \\
\text { Chang, Taiwan }\end{array}$ & $\begin{array}{l}\text { F. oxysporum } \\
\text { f.sp. cubense }\end{array}$ & 01213 & Taiwan & Isolate & $\begin{array}{l}\text { Not } \\
\text { applicable }\end{array}$ & $\begin{array}{l}\text { J. W. Huang, } \\
\text { Taiwan }\end{array}$ & $2 \mathrm{~B}$ \\
\hline Foc.T14 & $\begin{array}{l}\text { Collection Dr. Pi- } \\
\text { Fang Linda } \\
\text { Chang, Taiwan }\end{array}$ & $\begin{array}{l}\text { F. oxysporum } \\
\text { f.sp. cubense }\end{array}$ & 01213 & Taiwan & Isolate & $\begin{array}{l}\text { Not } \\
\text { applicable }\end{array}$ & $\begin{array}{l}\text { Taitung } \\
\text { District } \\
\text { Agricultural } \\
\text { Research and } \\
\text { Extension } \\
\text { Station }\end{array}$ & $2 \mathrm{~B}$ \\
\hline Foc.T202 & $\begin{array}{l}\text { Collection Dr. Pi- } \\
\text { Fang Linda } \\
\text { Chang, Taiwan }\end{array}$ & $\begin{array}{l}\text { F. oxysporum } \\
\text { f.sp. cubense }\end{array}$ & 01213 & Taiwan & Isolate & $\begin{array}{l}\text { Not } \\
\text { applicable }\end{array}$ & $\begin{array}{l}\text { J. W. Huang, } \\
\text { Taiwan }\end{array}$ & $2 \mathrm{~B}$ \\
\hline Indo87 & $\begin{array}{l}\text { Ecosciences } \\
\text { Precinct, Brisbane } \\
\text { Australia }\end{array}$ & $\begin{array}{l}\text { F. oxysporum } \\
\text { f.sp. cubense }\end{array}$ & 01213 & Indonesia & Isolate & $\begin{array}{l}\text { Not } \\
\text { applicable }\end{array}$ & $\begin{array}{l}\text { W. O'Neil, } \\
\text { Australia }\end{array}$ & $2 \mathrm{~B}$ \\
\hline Indo97 & $\begin{array}{l}\text { Ecosciences } \\
\text { Precinct, Brisbane } \\
\text { Australia }\end{array}$ & $\begin{array}{l}\text { F. oxysporum } \\
\text { f.sp. cubense }\end{array}$ & 01213 & Indonesia & Isolate & $\begin{array}{l}\text { Not } \\
\text { applicable }\end{array}$ & $\begin{array}{l}\text { W. O'Neil, } \\
\text { Australia }\end{array}$ & $2 \mathrm{~B}$ \\
\hline Mal123 & $\begin{array}{l}\text { Ecosciences } \\
\text { Precinct, Brisbane } \\
\text { Australia }\end{array}$ & $\begin{array}{l}\text { F. oxysporum } \\
\text { f.sp. cubense }\end{array}$ & 01213 & Malaysia & Isolate & $\begin{array}{l}\text { Not } \\
\text { applicable }\end{array}$ & $\begin{array}{l}\text { W. O'Neil, } \\
\text { Australia }\end{array}$ & $2 \mathrm{~B}$ \\
\hline Mal72 & $\begin{array}{l}\text { Ecosciences } \\
\text { Precinct, Brisbane } \\
\text { Australia }\end{array}$ & $\begin{array}{l}\text { F. oxysporum } \\
\text { f.sp. cubense }\end{array}$ & 01213 & Malaysia & Isolate & $\begin{array}{l}\text { Not } \\
\text { applicable }\end{array}$ & $\begin{array}{l}\text { W. O'Neil, } \\
\text { Australia }\end{array}$ & $2 \mathrm{~B}$ \\
\hline NRRL36114 & $\begin{array}{l}\text { ARS Culture } \\
\text { Collection, USA } \\
\text { (NRRL36114) }\end{array}$ & $\begin{array}{l}\text { F. oxysporum } \\
\text { f.sp. cubense }\end{array}$ & 01213 & Indonesia & Isolate & $\begin{array}{l}\text { Not } \\
\text { applicable }\end{array}$ & $\begin{array}{l}\text { K. O'Donnell, } \\
\text { USA }\end{array}$ & $2 \mathrm{~B}$ \\
\hline Tw5 & $\begin{array}{l}\text { Ecosciences } \\
\text { Precinct, Brisbane } \\
\text { Australia }\end{array}$ & $\begin{array}{l}\text { F. oxysporum } \\
\text { f.sp. cubense }\end{array}$ & 01213 & Taiwan & Isolate & $\begin{array}{l}\text { Not } \\
\text { applicable }\end{array}$ & $\begin{array}{l}\text { W. O'Neil, } \\
\text { Australia }\end{array}$ & $2 \mathrm{~B}$ \\
\hline Phil.1A & Not in others & $\begin{array}{l}\text { F. oxysporum } \\
\text { f.sp. cubense }\end{array}$ & 01213 & Philippines & $\begin{array}{l}\text { Banana } \\
\text { tissue }\end{array}$ & $\begin{array}{l}\text { N. } \\
\text { Ordonez, } \\
\text { WUR }\end{array}$ & $\begin{array}{l}\text { L.M. Bacus, } \\
\text { Philippines }\end{array}$ & $2 \mathrm{~B}$ \\
\hline Phi2.5C & Not in others & $\begin{array}{l}\text { F. oxysporum } \\
\text { f.sp. cubense }\end{array}$ & 01213 & Philippines & $\begin{array}{l}\text { Banana } \\
\text { tissue }\end{array}$ & $\begin{array}{l}\mathrm{N} . \\
\text { Ordonez }\end{array}$ & $\begin{array}{l}\text { L.M. Bacus, } \\
\text { Philippines }\end{array}$ & $2 \mathrm{~B}$ \\
\hline Phi2.6C & Not in others & $\begin{array}{l}\text { F. oxysporum } \\
\text { f.sp. cubense }\end{array}$ & 01213 & Philippines & $\begin{array}{l}\text { Banana } \\
\text { tissue }\end{array}$ & $\begin{array}{l}\mathrm{N} . \\
\text { Ordonez }\end{array}$ & $\begin{array}{l}\text { L.M. Bacus, } \\
\text { Philippines }\end{array}$ & $\begin{array}{l}2 \mathrm{~B} \text { and } \\
2 \mathrm{C}\end{array}$ \\
\hline Leb1.2C & Not in others & $\begin{array}{l}\text { F. oxysporum } \\
\text { f.sp. cubense }\end{array}$ & 01213 & Lebanon & $\begin{array}{l}\text { Banana } \\
\text { tissue }\end{array}$ & $\begin{array}{l}\mathrm{N} . \\
\text { Ordonez }\end{array}$ & $\begin{array}{l}\text { M. Akkary, } \\
\text { Lebanon }\end{array}$ & $\begin{array}{l}2 \mathrm{~B} \text { and } \\
2 \mathrm{C}\end{array}$ \\
\hline Phi3.4C & Not in others & $\begin{array}{l}\text { F. oxysporum } \\
\text { f.sp. cubense }\end{array}$ & 01213 & Philippines & $\begin{array}{l}\text { Banana } \\
\text { tissue }\end{array}$ & $\begin{array}{l}\mathrm{N} . \\
\text { Ordonez }\end{array}$ & $\begin{array}{l}\text { A.F. Penalosa, } \\
\text { LM Bacus, } \\
\text { Philippines }\end{array}$ & $2 \mathrm{~B}$ \\
\hline
\end{tabular}


Plant and pathogen clones meet, TR4

\begin{tabular}{|c|c|c|c|c|c|c|c|c|}
\hline Isolate code & Other collections & Species & VCG & $\begin{array}{l}\text { Country } \\
\text { of origin }\end{array}$ & $\begin{array}{l}\text { Received } \\
\text { as }\end{array}$ & $\begin{array}{l}\text { Isolated } \\
\text { by }\end{array}$ & $\begin{array}{l}\text { Original } \\
\text { Provider }\end{array}$ & $\begin{array}{l}\text { On } \\
\text { Figure }\end{array}$ \\
\hline Phi4.3A & Not in others & $\begin{array}{l}F . \text { oxysporum } \\
\text { f.sp. cubense }\end{array}$ & 01213 & Philippines & $\begin{array}{l}\text { Banana } \\
\text { tissue }\end{array}$ & $\begin{array}{l}\text { N. } \\
\text { Ordonez }\end{array}$ & $\begin{array}{l}\text { A.F. Penalosa, } \\
\text { Philippines }\end{array}$ & 2B \\
\hline Phi4.5A & Not in others & $\begin{array}{l}F . \text { oxysporum } \\
\text { f.sp. cubense }\end{array}$ & 01213 & Philippines & $\begin{array}{l}\text { Banana } \\
\text { tissue }\end{array}$ & $\begin{array}{l}\text { N. } \\
\text { Ordonez }\end{array}$ & $\begin{array}{l}\text { A.F. Penalosa, } \\
\text { Philippines }\end{array}$ & $2 \mathrm{~B}$ \\
\hline 24662 & $\begin{array}{l}\text { Ecosciences } \\
\text { Precinct, Brisbane } \\
\text { Australia }\end{array}$ & $\begin{array}{l}F . \text { oxysporum } \\
\text { f.sp. cubense }\end{array}$ & 01213 & Australia & Isolate & $\begin{array}{l}\text { Not } \\
\text { applicable }\end{array}$ & $\begin{array}{l}\text { A. Drenth, } \\
\text { Australia }\end{array}$ & $2 \mathrm{~B}$ \\
\hline 24663 & $\begin{array}{l}\text { Ecosciences } \\
\text { Precinct, Brisbane } \\
\text { Australia }\end{array}$ & $\begin{array}{l}F . \text { oxysporum } \\
\text { f.sp. cubense }\end{array}$ & 01213 & Australia & Isolate & $\begin{array}{l}\text { Not } \\
\text { applicable }\end{array}$ & $\begin{array}{l}\text { A. Drenth, } \\
\text { Australia }\end{array}$ & $2 \mathrm{~B}$ \\
\hline 24664 & $\begin{array}{l}\text { Ecosciences } \\
\text { Precinct, Brisbane } \\
\text { Australia }\end{array}$ & $\begin{array}{l}\text { F. oxysporum } \\
\text { f.sp. cubense }\end{array}$ & 01213 & Australia & Isolate & $\begin{array}{l}\text { Not } \\
\text { applicable }\end{array}$ & $\begin{array}{l}\text { A. Drenth, } \\
\text { Australia }\end{array}$ & $2 \mathrm{~B}$ \\
\hline Pak1.1A & Not in others & $\begin{array}{l}F . \text { oxysporum } \\
\text { f.sp. cubense }\end{array}$ & 01213 & Pakistan & $\begin{array}{l}\text { Banana } \\
\text { tissue }\end{array}$ & $\begin{array}{l}\text { N. } \\
\text { Ordonez }\end{array}$ & $\begin{array}{l}\text { H.B. Laghari, } \\
\text { Pakistan }\end{array}$ & $\begin{array}{l}2 \mathrm{~B} \text { and } \\
2 \mathrm{C}\end{array}$ \\
\hline Phi5.2A & Not in others & $\begin{array}{l}F . \text { oxysporum } \\
\text { f.sp. cubense }\end{array}$ & 01213 & Philippines & $\begin{array}{l}\text { Banana } \\
\text { tissue }\end{array}$ & $\begin{array}{l}\text { N. } \\
\text { Ordonez }\end{array}$ & $\begin{array}{l}\text { N. Ordonez, } \\
\text { WUR }\end{array}$ & $2 \mathrm{~B}$ \\
\hline $\begin{array}{l}\text { F.oxysporum } \\
\text { f.sp. } \\
\text { canariensis }\end{array}$ & $\begin{array}{l}\text { Royal Botanical } \\
\text { Garden, Australia }\end{array}$ & $\begin{array}{l}\text { F.oxysporum } \\
\text { f.sp. } \\
\text { canariensis }\end{array}$ & $\begin{array}{l}\text { Not } \\
\text { applicable }\end{array}$ & Spain & Isolate & $\begin{array}{l}\text { Not } \\
\text { applicable }\end{array}$ & $\begin{array}{l}\text { C. Waalwijk, } \\
\text { WUR }\end{array}$ & $2 \mathrm{~B}$ \\
\hline
\end{tabular}

Supplementary Table 2. Genome data used in this study.

\begin{tabular}{|c|c|c|c|c|}
\hline Data & Origin/Reference & Source & Isolates & on Figure \\
\hline DArTseq markers & WUR & WUR & All in Fig. 1 and 2B & 1 and $2 B$ \\
\hline Resequence & WUR & WUR & Pak1.1A, Phi2.6C, Leb1.2C, JV11 and NRRL36102 & $2 \mathrm{C}$ \\
\hline Sequence assembly & Guo et al., 2013 & Public GenBank & $\begin{array}{l}\text { race } 4(\text { AMGQ00000000) and race } 1 \\
(\text { AMGP00000000) }\end{array}$ & $2 \mathrm{C}$ \\
\hline Sequence assembly & $\begin{array}{l}\text { Broad Institute and } \\
\text { MIT }\end{array}$ & $\begin{array}{l}\text { Public Fusarium Comparative } \\
\text { database }\end{array}$ & Fol (4287) and II5; reference & $2 \mathrm{C}$ \\
\hline
\end{tabular}




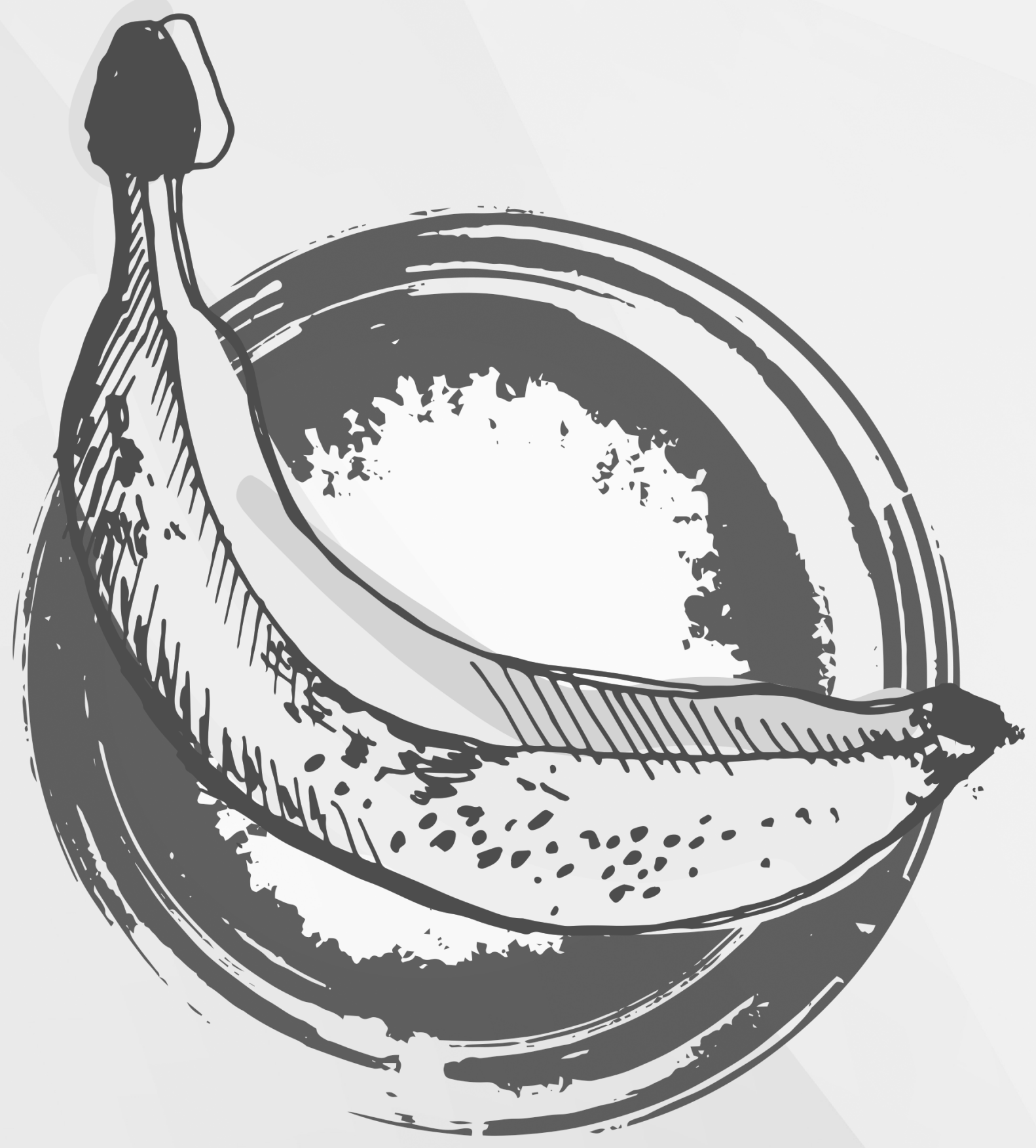




\section{CHAPTER 3}

A Loop-Mediated Isothermal Amplification assay based on unique markers derived from genotyping by sequencing data for rapid in-plant diagnosis of Fusarium oxysporum f.sp. cubense tropical race 4 in banana

Ordóñez, N*., Salacinas, M*., Mendes, O., Seidl, M.F., Meijer, H.J.G., Schoen, C.*, \& Kema, G.H.J. (Accepted manuscript).

*These authors contributed equally to this work. "Corresponding authors.
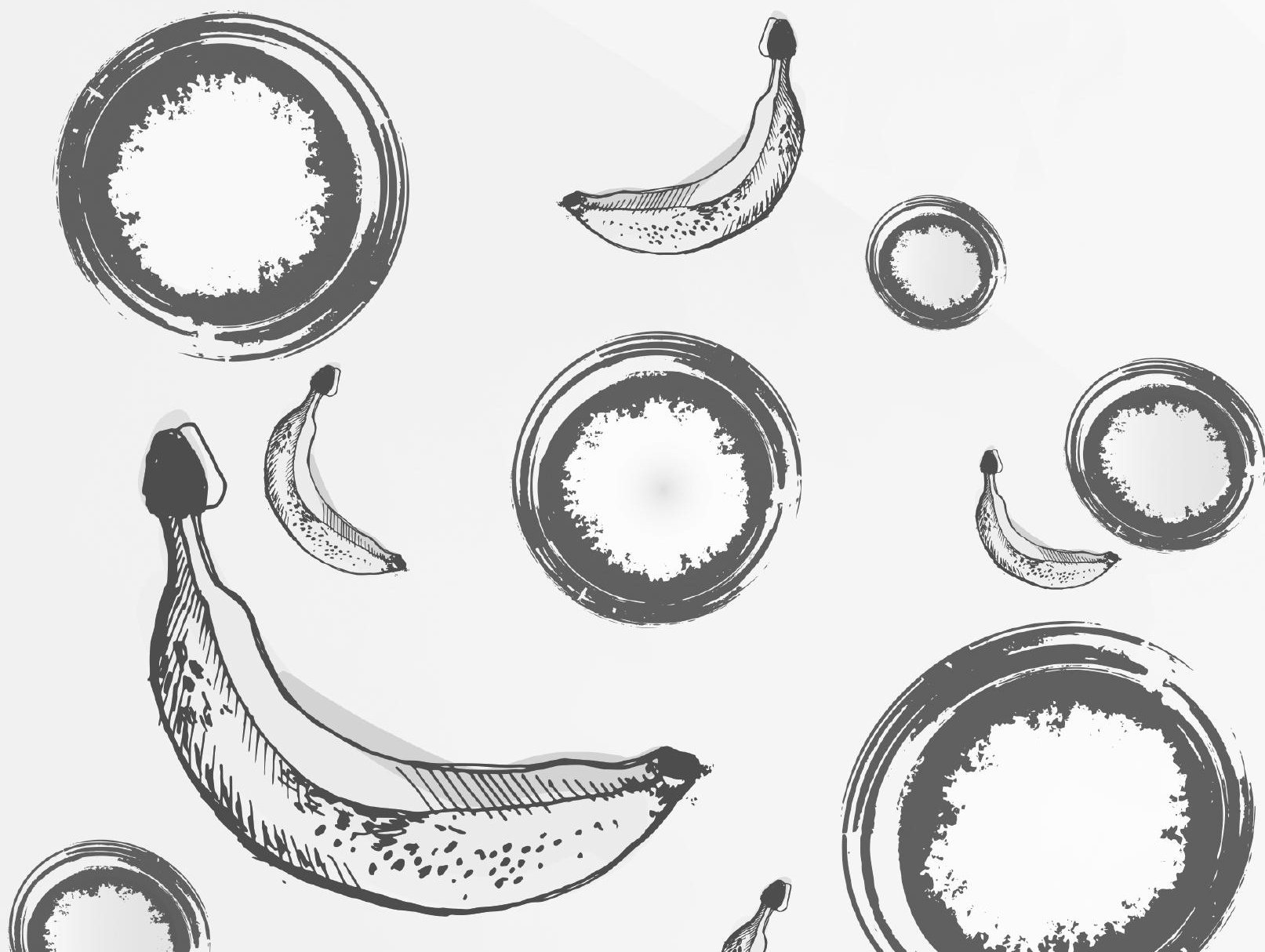


\section{ABSTRACT}

The socio-economic impact of Fusarium oxysporum f.sp. cubense tropical race 4 (Foc TR4) is escalating as this fungal pathogen spreads to new banana-growing areas. Hence, the development of simple, reliable and rapid detection technologies is indispensable for implementing quarantine measures. Here, we develop a versatile Loop-Mediated Isothermal Amplification (LAMP) assay that is applicable under field and laboratory conditions. DNA markers unique to TR4 isolates were obtained by Diversity Arrays Technology sequencing (DArTseq), a genotyping by sequencing technology that was conducted on 27 Foc isolates, including the reported 24 Foc vegetative compatibility groups (VCGs) and three TR4 isolates. The developed LAMP TR4 assay was successfully tested using 22 TR4 isolates and 45 non-target fungal and bacterial isolates as well as on infected plants under greenhouse and field conditions. The detection limit was $1 \mathrm{pg} / \mu 1$ pure TR4 DNA or $10^{2}$ copies plasmid localized TR4 unique sequence (SeqA) per reaction, which was not affected by background DNA in complex samples. The LAMP TR4 assay offers a powerful tool for the routine and unambiguous identification of banana plants infected with TR4, contributing to advanced diagnosis in field situations and monitoring of Fusarium wilt.

\section{INTRODUCTION}

The soil-borne fungus Fusarium oxysporum f.sp. cubense (Foc), the causal agent of Fusarium wilt or Panama disease on bananas (Musa spp.), is currently posing a serious threat to global banana production (Ploetz, 2015b). Foc disseminates through transport of contaminated plants, human migration as well as infested soil and water (Ploetz, 2005, 2006). It has the historical legacy as one of the most destructive plant pathogens recorded as it demised 'Gros Michel' banana plantations in Latin America, leading to the contemporary monocultures that heavily rely on resistant Cavendish bananas (Ploetz, 2015a; Ploetz et al., 2015a; Stover, 1962). Foc race 1 strains were responsible for this first epidemic (Ploetz, 2006). Currently, however, another pathogenic Foc genotype, colloquially called tropical race 4 (TR4), strikes Cavendish plantations as well as manifold local banana varieties causing devastation in many producing areas (García-Bastidas et al., 2018b; Ploetz, 2006, 2015a, 2015b). Contrary to the past, there is no commercially acceptable banana germplasm to replace Cavendish (Ploetz, 2015b) other than the widely promoted Cavendish somaclones that are less susceptible to TR4 (Hwang \& Ko, 2004). As a consequence, food security and local economies are threatened in banana producing countries.

Tropical race 4 strain was initially detected and restrained in a few Southeast Asian countries (Buddenhagen, 2009; Molina et al., 2009). However, this strain meanwhile spread to banana production areas in the Middle East, the Indian sub-continent, Africa and in Northeast Australia and continued its dissemination within Southeast Asia (Chittarath et al., 2017; García-Bastidas et al., 2014; Hung et al., 2017; Mostert et al., 2017; Ordóñez et al., 2016; Ordóñez et al., 2015; Zheng et al., 2018). The spread might be a consequence of unawareness as well as to the fact that external Fusarium wilt symptoms of bananas do not reveal the causal Foc strains. Since race 1 is omnipresent (Ploetz, 2015a), TR4 can easily slip in and affect race 1 susceptible banana germplasm and be left unattended until it affects Cavendish clones. Therefore, any suspicious wilting symptoms in Cavendish bananas should be properly and 
timely addressed, which should be followed by containment, precise sampling and rapid identification of the causal strains. Traditionally, TR4 diagnosis relied on visual disease inspections of internal and external symptoms on susceptible banana cultivars, and timeconsuming vegetative compatibility group (VCG) testing. However, these methods are prone to false positives/negatives and in the case of VCG testing cause significant delays on TR4 diagnosis (García-Bastidas et al., 2014; Leslie \& Summerell, 2006; Molina et al., 2009). Considering that exclusion is the best approach to deal with TR4 and in the absence of longterm successful disease control (Ploetz, 2015b), early and reliable detection of TR4 is vital. In recent years, a DNA-based method succeeded in rapidly identifying TR4 in (pre) symptomatic banana plants (Dita et al., 2010). This PCR-based methodology was applied in all recent TR4 incursions (Chittarath et al., 2017; García-Bastidas et al., 2014; Hung et al., 2017; Ordóñez et al., 2016; Ploetz, 2015a; Zheng et al., 2018). However, it relies on the expertise and accuracy of individuals performing the diagnosis and equipment that is only used under laboratory conditions. Therefore, a robust and reliable molecular identification tool that is easily applicable in field situations is desirable. The feasibility of molecular diagnostic development depends largely on the availability of genome data for both the target and non-target organisms. This allows the identification of unique genomic sequences, specific for the target organism. For F. oxysporum strains, sequencing projects to reveal the genetic composition of its fungal members started, but genomic data on the large diversity of Foc genotypes is still limited (https://www.ncbi.nlm.nih.gov/genome/genomes/707). Despite the presumed exclusive asexual reproduction of Foc, its polyphyletic origin resulted in no less than 24 VCGs (VCG0120-0126 and 0128-01224) (Bentley et al., 1998; Kistler et al., 1998; Ploetz, 2005), which includes VCG01213 that represents the TR4 clone (Ordóñez et al., 2015). The VCG01216 is genetically similar to VCG01213 and thus currently grouped under VCG01213 (Bentley et al., 1998).

In this study, we explored Diversity Arrays Technology sequencing (DArTseq) to identify unique TR4 genomic markers to overcome the current lack of data among Foc VCGs. DArTseq is a new high-throughput genotyping technology that is applied to address diversity analyses (Alves et al., 2014; Cruz et al., 2013). The technology combines a reduction of genome complexity with in silico- hybridization and next-generation sequencing platforms based on polymorphism detection at several hundred genomic loci that result in thousands of DArTseq in-silico markers and single nucleotide polymorphisms (Cruz et al., 2013). All 24 Foc VCGs were subjected to DArTseq to select unique TR4 sequences. These genomic sequences were explored for primer design to develop a Loop-Mediated Isothermal Amplification (LAMP) assay, which is a cost-effective and robust technology that is suitable for detection of plant pathogens under field conditions (Bühlmann et al., 2013; Harper et al., 2010; Notomi et al., 2000; Tomlinson \& Boonham, 2015). Here, we validated the developed LAMP TR4 assay performing specificity, sensitivity and reproducibility tests. Finally, we evaluated its accuracy in identifying TR4 for in-plant diagnosis in the field. 


\section{MATERIAL AND METHODS}

\section{Microbial isolates}

In this study, 50 Foc isolates were used (Table 1), including one or more isolates per known VCG and 22 TR4 isolates including isolates from Jordan (García-Bastidas et al., 2014), Lebanon and Pakistan (Ordóñez et al., 2016), which were confirmed to belong to VCG01213 by VCG testing (see Chapter 4). In addition, 16 other Fusarium spp. were included in this study as well as Ralstonia solanacearum as a soil-borne banana wilting outgroup (Table 1). This sample was isolated from a Moko diseased Cavendish banana in the southern Philippines. All fungal isolates, grown from monosporic isolations are maintained in $15 \%$ DMSO in liquid nitrogen in the collection of Wageningen University \& Research (WUR), The Netherlands.

Table 1. The 22 TR4 target and 45 non-target fungal and bacterial isolates used in the development of the LAMP TR4 assay.

\begin{tabular}{|c|c|c|c|c|c|}
\hline Isolate code & Species & VCG & Host & Country & Provider \\
\hline \multicolumn{6}{|l|}{ Target-TR4 } \\
\hline 24662 & Fusarium oxysporum f.sp. cubense & $01213 / 16$ & Cavendish & Australia & A. Drenth, Australia \\
\hline 24663 & $F$. oxysporum f.sp. cubense & $01213 / 16$ & Cavendish & Australia & A. Drenth, Australia \\
\hline 24664 & F. oxysporum f.sp. cubense & $01213 / 16$ & Cavendish & Australia & A. Drenth, Australia \\
\hline BPS1.1 & F. oxysporum f.sp. cubense & 01213 & Cavendish & Indonesia & I.W. Buddenhagen, USA \\
\hline BPS3.1 & F. oxysporum f.sp. cubense & 01213 & Cavendish & Australia & I.W. Buddenhagen, USA \\
\hline Foc.T105 & F. oxysporum f.sp. cubense & 01213 & Cavendish & China & P.F.L. Chang, Taiwan \\
\hline II $^{1,2}$ & F. oxysporum f.sp. cubense & 01213 & Pisang Manurung & Indonesia & C. Kistler, USA \\
\hline Indo $84^{1}$ & F. oxysporum f.sp. cubense & 01216 & Williams & Indonesia & W. O'Neil, Australia \\
\hline Indo87 & F. oxysporum f.sp. cubense & $01213 / 16$ & Pisang Raja Serah & Indonesia & W. O'Neil, Australia \\
\hline JV1 $11^{1}$ & F. oxysporum f.sp. cubense & 01213 & Cavendish & Jordan & R.C. Ploetz, USA \\
\hline Leb1.1A & F. oxysporum f.sp. cubense & 01213 & Cavendish & Lebanon & $\begin{array}{l}\text { N. Ordóñez }{ }^{3} \text {, Netherlands; } \\
\text { M.Y. Akkary, D. Freres, } \\
\text { Lebanon }\end{array}$ \\
\hline Leb1.2C & F. oxysporum f.sp. cubense & 01213 & Cavendish & Lebanon & $\begin{array}{l}\text { N. Ordóñez }{ }^{3} \text {, Netherlands; } \\
\text { M.Y. Akkary, D. Freres, } \\
\text { Lebanon }\end{array}$ \\
\hline Mal123 & F. oxysporum f.sp. cubense & 01213 & Williams & Malaysia & W. O'Neil, Australia \\
\hline NRRL36114 & F. oxysporum f.sp. cubense & 01213 & Pisang Manurung & Indonesia & K. O'Donnell, USA \\
\hline Pak1.1A & F. oxysporum f.sp. cubense & 01213 & Cavendish & Pakistan & $\begin{array}{l}\text { N. Ordóñez }{ }^{3} \text {, Netherlands; } \\
\text { H.B. Laghari, Pakistan }\end{array}$ \\
\hline Phil.1A & F. oxysporum f.sp. cubense & 01213 & Williams & Philippines & $\begin{array}{l}\text { N. Ordóñez }{ }^{3} \text {, Netherlands; } \\
\text { L.M. Bacus, Philippines }\end{array}$ \\
\hline Phi2.5C & F. oxysporum f.sp. cubense & 01213 & GCTVC218 & Philippines & $\begin{array}{l}\text { N. Ordóñez }{ }^{3} \text {, Netherlands; } \\
\text { L.M. Bacus, Philippines }\end{array}$ \\
\hline Phi3.4C & F. oxysporum f.sp. cubense & 01213 & Williams & Philippines & $\begin{array}{l}\text { N. Ordóñez }{ }^{3} \text {, Netherlands; } \\
\text { A.F. Penalosa, L.M. Bacus, } \\
\text { Philippines }\end{array}$ \\
\hline Phi4.5A & F. oxysporum f.sp. cubense & 01213 & UNIC4 & Philippines & $\begin{array}{l}\text { N. Ordóñez }{ }^{3} \text {, Netherlands; } \\
\text { A.F. Penalosa, L.M. Bacus, } \\
\text { Philippines }\end{array}$ \\
\hline Phi5.2A & F. oxysporum f.sp. cubense & 01213 & Grand Naine & Philippines & N. Ordóñez ${ }^{3}$, Netherlands \\
\hline RPML47 & F. oxysporum f.sp. cubense & $01213 / 16$ & Pisang awak legor & Malaysia & R.C. Ploetz, USA \\
\hline STSUM2 & $F$. oxysporum f.sp. cubense & 01213 & Pisang Kepok & Indonesia & R.C. Ploetz, USA \\
\hline \multicolumn{6}{|c|}{ Non-target isolates } \\
\hline FocST498 ${ }^{1}$ & F. oxysporum f.sp. cubense & 0120 & Dwarf Cavendish & Spain & J. Hernandez, Spain \\
\hline NRRL25603 & F. oxysporum f.sp. cubense & $0120 / 15$ & Cavendish & Australia & K. O'Donnell, USA \\
\hline NRRL36102 ${ }^{1}$ & F. oxysporum f.sp. cubense & 0121 & Cavendish & China & K. O'Donnell, USA \\
\hline NRRL36103 ${ }^{1}$ & F. oxysporum f.sp. cubense & 0122 & Cavendish & Philippines & K. O'Donnell, USA \\
\hline F9129 & F. oxysporum f.sp. cubense & 0123 & Latundan & China & R.C. Ploetz, USA \\
\hline NRRL36105 ${ }^{1}$ & F. oxysporum f.sp. cubense & 0124 & Blugoe & Honduras & K. O'Donnell, USA \\
\hline Foc_R $2^{1}$ & F. oxysporum f.sp. cubense & 0124 & Plantain Monthan & Brazil & $\begin{array}{l}\text { M.A. Dita, EMBRAPA, } \\
\text { Brazil }\end{array}$ \\
\hline NRRL36106 ${ }^{1}$ & F. oxysporum f.sp. cubense & 0125 & Lady finger & Australia & K. O'Donnell, USA \\
\hline
\end{tabular}




\begin{tabular}{|c|c|c|c|c|c|}
\hline Isolate code & Species & VCG & Host & Country & Provider \\
\hline NRRL36107 $^{1}$ & F. oxysporum f.sp. cubense & 0126 & Maqueño & Honduras & K. O'Donnell, USA \\
\hline NRRL36111 ${ }^{1}$ & F. oxysporum f.sp. cubense & 0128 & Bluggoe & Australia & K. O'Donnell, USA \\
\hline NRRL36110 ${ }^{1}$ & F. oxysporum f.sp. cubense & 0129 & Mons & Australia & K. O'Donnell, USA \\
\hline Focu $7^{1}$ & F. oxysporum f.sp. cubense & 01210 & Apple & USA & $\begin{array}{l}\text { M.J. Daboussi, Université } \\
\text { Paris -Sud, France }\end{array}$ \\
\hline NRRL36109 ${ }^{1}$ & F. oxysporum f.sp. cubense & 01211 & SH3142 & Australia & K. O'Donnell, USA \\
\hline NRRL36108 ${ }^{1}$ & F. oxysporum f.sp. cubense & 01212 & Ney Poovan & Tanzania & K. O'Donnell, USA \\
\hline NRRL36113 $^{1}$ & F. oxysporum f.sp. cubense & 01214 & Harare & Malawi & K. O'Donnell, USA \\
\hline NRRL25609 & F. oxysporum f.sp. cubense & 01214 & Harare & Malawi & K. O'Donnell, USA \\
\hline NRRL36112 $^{1}$ & F. oxysporum f.sp. cubense & 01215 & Cavendish & South Africa & K. O'Donnell, USA \\
\hline $\mathrm{Mal}^{4} 3^{1}$ & F. oxysporum f.sp. cubense & 01217 & Pisang Rastali & Malaysia & A. Drenth, Australia \\
\hline NRRL36120 ${ }^{1}$ & F. oxysporum f.sp. cubense & 01218 & Kluai nam wa & Thailand & K. O'Donnell, USA \\
\hline Indo $25^{1}$ & F. oxysporum f.sp. cubense & 01219 & Pisang Ambon & Indonesia & A. Drenth, Australia \\
\hline 242181 & F. oxysporum f.sp. cubense & 01220 & Cavendish & Australia & A. Drenth, Australia \\
\hline NRRL36118 ${ }^{1}$ & F. oxysporum f.sp. cubense & 01221 & Kluai nam wa & Thailand & K. O'Donnell, USA \\
\hline NRRL3611 $7^{1}$ & F. oxysporum f.sp. cubense & 01222 & Pisang awak legor & Malaysia & K. O'Donnell, USA \\
\hline NRRL36116 ${ }^{1}$ & F. oxysporum f.sp. cubense & 01223 & Pisang keeling & Malaysia & K. O'Donnell, USA \\
\hline NRRL3611 $5^{1}$ & F. oxysporum f.sp. cubense & 01224 & Pisang ambon & Malaysia & K. O'Donnell, USA \\
\hline Foc_R $1^{1}$ & F. oxysporum f.sp. cubense & n.d. & Maçã & Brazil & $\begin{array}{l}\text { M. Dita, C. Waalwijk, } \\
\text { Netherlands }\end{array}$ \\
\hline KDM1.2A & F. oxysporum f.sp. cubense & n.d. & Bokoboko & Kenya & $\begin{array}{l}\text { N. Ordóñez }{ }^{3} \text {, Netherlands; } \\
\text { C.M. Muriuki, Del Monte, } \\
\text { Kenya }\end{array}$ \\
\hline Mal1.5B & F. oxysporum f.sp. cubense & n.d. & Banana (Musa sp.) & Malawi & $\begin{array}{l}\text { G. Kema, N. Ordóñez }{ }^{3} \text {, } \\
\text { Netherlands }\end{array}$ \\
\hline 0.1879 & F. oxysporum f.sp. melongenae & n.d. & Eggplant & n.d. & C. Waalwijk, Netherlands \\
\hline $0.1954^{1}$ & F. oxysporum f.sp. canariensis & n.d. & Palm & n.d. & C. Waalwijk, Netherlands \\
\hline CBS196.65 & F. oxysporum f.sp. narcissi & n.d. & Narcissus & n.d. & C. Waalwijk, Netherlands \\
\hline Fo47 & F. oxysporum & n.d. & Non-pathogenic & n.d. & C. Waalwijk, Netherlands \\
\hline Fol4287 & F. oxysporum f.sp. lycopersici & n.d. & Tomato & n.d. & S.M. Schmidt, Netherlands \\
\hline Fop.08.1 & F. oxysporum f.sp. passiflora & n.d. & Passion fruit & n.d. & C. Waalwijk, Netherlands \\
\hline NRRL25433 & F. oxysporum f.sp. vasinfectum & n.d. & Cotton & n.d. & S.M. Schmidt, Netherlands \\
\hline $\begin{array}{l}\text { NRRL26035/ } \\
\text { IPO99.03 }\end{array}$ & F. oxysporum f.sp. canariensis & n.d. & Palm & n.d. & C. Waalwijk, Netherlands \\
\hline $\begin{array}{l}\text { NRRL26381/ } \\
\text { CL57 }\end{array}$ & F. oxysporum f.sp. radicis-lycopersici & n.d. & Tomato & n.d. & S.M. Schmidt, Netherlands \\
\hline $\begin{array}{l}\text { NRRL26406/ } \\
\text { Fom001 }\end{array}$ & F. oxysporum f.sp. melonis & n.d. & Melon & n.d. & S.M. Schmidt, Netherlands \\
\hline $\begin{array}{l}\text { NRRL26761/ } \\
\text { IPO99.04 }\end{array}$ & F. oxysporum f.sp. phaseoli & n.d. & Bean & n.d. & C. Waalwijk, Netherlands \\
\hline $\begin{array}{l}\text { NRRL28781/ } \\
\text { IPO99.02 }\end{array}$ & F. oxysporum f.sp. erythroxyli & n.d. & Coca & n.d. & C. Waalwijk, Netherlands \\
\hline $\begin{array}{l}\text { NRRL37622/ } \\
\text { HDV247 }\end{array}$ & F. oxysporum f.sp. pisi & n.d. & Pea & n.d. & S.M. Schmidt, Netherlands \\
\hline $\begin{array}{l}\text { NRRL54005/ } \\
\text { PHW815 }\end{array}$ & F. oxysporum f.sp. raphani & n.d. & Radish & n.d. & S.M. Schmidt, Netherlands \\
\hline $\begin{array}{l}\text { NRRL54008/ } \\
\text { PHW808 }\end{array}$ & F. oxysporum f.sp. conglutinans & n.d. & Cabbage & n.d. & S.M. Schmidt, Netherlands \\
\hline CBS221.76 & Fusarium fujikuroi & n.a. & Rice & n.d. & C. Waalwijk, Netherlands \\
\hline Moko & Ralstonia solanacearum & n.a. & Banana (Musa sp.) & n.d. & M. Salacinas, Netherlands \\
\hline
\end{tabular}

${ }^{1}$ Fungal isolates analysed using DArTseq. ${ }^{2}$ TR4 reference isolate. ${ }^{3}$ Providers sent tissue sample to our facilities and the strain isolation was performed at Wageningen University \& Research. n.a. stands for "not applicable". n.d. stands for "not determined".

\section{DNA extraction from fungal and bacterial isolates}

For DNA extraction, a single-spore culture of each isolate was grown in $70 \mathrm{~mL}$ potato dextrose broth (Difco ${ }^{\mathrm{TM}}$, USA) in Erlenmeyer flasks and incubated by shaking (New Brunswick $^{\mathrm{TM}}$, Germany) at $125 \mathrm{rpm}$ at $25^{\circ} \mathrm{C}$ for 5-6 days. The mycelium was harvested by filtering the inoculum through a sterile cheese cloth and washed at least twice with sterile water. R. solanacearum was grown on Kelman's tetrazolium chloride agar (Kelman, 1954). The filtered mycelium and $1 \mathrm{~mL}$ bacterial suspension were lyophilized in $2 \mathrm{~mL}$ Eppendorf tubes containing glass beads. DNA was extracted from the freeze-dried material by adding 1 mL DNA extraction buffer (200 mM Tris-HCl, $\mathrm{pH} 8 ; 250 \mathrm{mM} \mathrm{NaCl} ; 25 \mathrm{mM}$ EDTA, pH 8; 
$0.5 \%$ SDS) and a vigorous vortex step, followed by phenol-chloroform extraction (Sambrook et al., 1989). Isolated DNA was diluted in $0.1 \mathrm{X}$ TE buffer and stored at $-20^{\circ} \mathrm{C}$ until use. DNA concentration was measured using Quant-i ${ }^{\mathrm{TM}}$ PicoGreen ${ }^{\circledR}$ dsDNA Reagent and Kit (Life Technologies, USA), according to manufacturer's instructions on a Tecan Infinite ${ }^{\circledR} 200$ PRO monochromator (Tecan, Männedorf, Switzerland) at $\lambda \operatorname{ex~} 485 \mathrm{~nm}$ and $\lambda \operatorname{em} 535 \mathrm{~nm}$. DNA of 27 Foc isolates, including 23 Foc VCGs with three TR4 isolates (II5, JV11 and Indo84), and one $F$. oxysporum f.sp. canariensis isolate (Table 1) was adjusted to $50 \mathrm{ng} / \mu \mathrm{l}$ and subjected to genotyping by sequencing through DArTseq analyses at Diversity Arrays Technology Pty Ltd. (Canberra, Australia; http://www.triticarte.com.au/).

\section{Pipeline based on DArTseq in-silico markers}

The DArTseq in-silico markers consisted of short markers of around $69 \mathrm{bp}$ that were processed following the pipeline indicated in Figure 1. This pipeline includes the use of public and private genomic databases. The NCBI public database comprises nucleotide information for different Fusarium spp. (http://www.ncbi.nlm.nih.gov/genome/genomes/707). The Empresa Brasileira de Pesquisa Agropecuária (Embrapa) private database (http://www.lba.cnptia.embrapa.br/fusarium/index.tml; Embrapa, Brasilia, Brazil) contains transcriptome data from race 1 (Foc_R1), race 2 (Foc_R2; VCG0124), subtropical race 4 (FocST498; VCG0120) and tropical race 4 (II5; VCG01213) isolates (Table 1). Firstly, DArTseq in-silico markers that were only present among the three TR4 isolates (II5, JV11 and Indo84) but absent from the other strains were selected (Fig. 1 step 1). Then, TR4 unique markers that aligned only with the II5 (isolate 54006) genome at NCBI when using the basic local alignment search tool (BLAST) were selected (Fig. 1 steps 2-3). Later, these short markers were subsequently expanded using the II5 genome by more than $200 \mathrm{bp}$ up- and downstream (Fig. 1 step 4$)$. These larger sequences ( $\sim 500 \mathrm{bp})$ were blasted against genomic data present in both databases and sequences aligning with the II5 genome were used for further analyses (Fig. 1 steps 5-6).

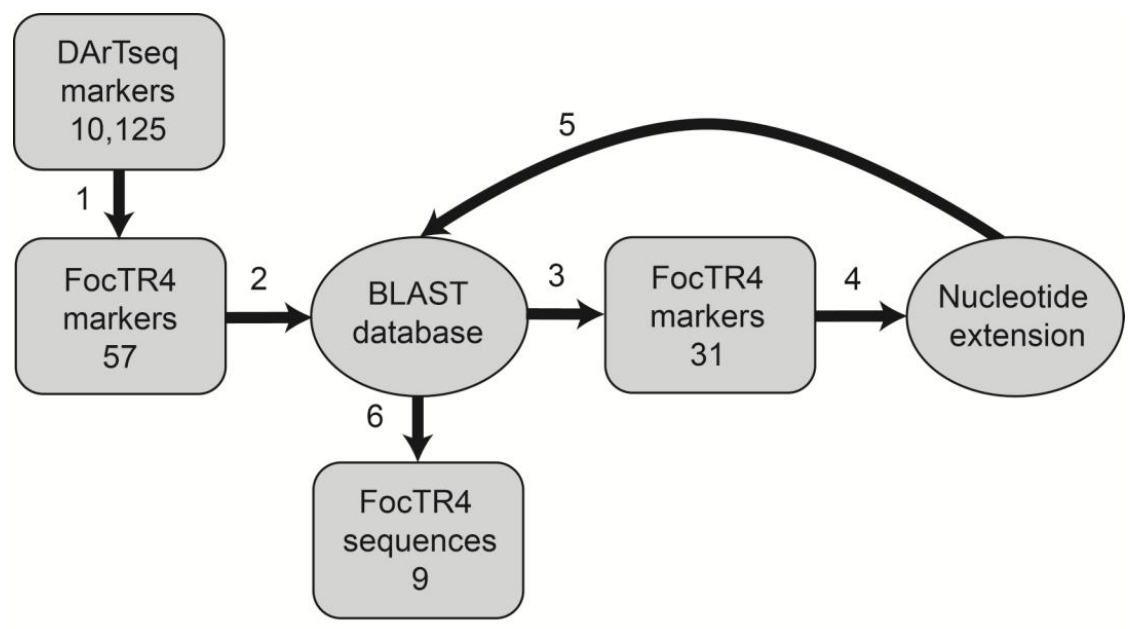

Figure 1. Pipeline used to identify unique TR4 sequences based on DArTseq in-silico markers. Numbers next to arrows indicate the order of the steps involved in the selection process. 


\section{PCR conditions to select TR4 unique sequences}

Identified DArTseq-based TR4 unique sequences (Fig. 1 step 6) were further analysed by designing PCR primers at their flanking sequences using software Primer3Plus (Version: 2.3.6). The designed primers were initially tested for all reported 24 Foc VCGs with II5 isolate as a representative of VCG01213. PCR amplifications were performed in $20 \mu 1$ reaction volumes, by mixing $1 \mu \mathrm{l}$ template DNA $(1 \mathrm{ng})$ with $0.4 \mu \mathrm{M}$ of each primer: $120 \mu \mathrm{M}$ of dATP, dCTP, dGTP and dTTP; 2U of Taq DNA polymerase (Roche); and 1X PCR reaction buffer (Roche). DNA was amplified with an initial denaturation step at $95^{\circ} \mathrm{C}$ for 5 minutes (min), followed by 30 cycles of $95^{\circ} \mathrm{C}$ for $1 \mathrm{~min}$, annealing temperature for $1 \mathrm{~min}$ and $72^{\circ} \mathrm{C}$ for 30 seconds (s); and a final extension step at $72^{\circ} \mathrm{C}$ for $10 \mathrm{~min}$. The annealing temperature was determined by Primer3Plus (Untergasser et al., 2007; Version: 2.3.6) for each tested pair of primers. Aliquots $(12 \mu \mathrm{l})$ of each PCR product were analysed by agarose gel electrophoresis to check for predicted size products. A primer set that showed a unique band for II5 isolate was selected and later tested on 22 TR4 isolates (Table 1), using the same PCR conditions. The resulting amplicons were sequenced by Macrogen (Macrogen Inc., Belgium) and analysed using CLC Main Workbench 6 program (CLC bio, Aarhus, Denmark).

\section{LAMP TR4 primer design and reaction}

For a selected TR4 unique sequence (SeqA), LAMP primers were designed using software Primer Explorer V4 (http://primerexplorer.jp/e/; Eiken Chemical Co. Ltd., Tokyo, Japan) (Fig. 2 and Table 2). LAMP primers consist of four to six primers that recognize six to eight regions of the target DNA and provides very high specificity (Nagamine et al., 2002; Notomi et al., 2000). The forward inner primer (FIP) is composed of F1c (the complementary sequence of F1) and F2, and the backward inner primer (BIP) is composed of B1c (the complementary sequence of B1) and B2. The primer set F3/B3 served as an outer primer and was used for the LAMP initiation reaction. The LoopF forward primers and the LoopB backward primers were developed to accelerate the LAMP reaction. The specificity of the developed LAMP TR4 primers was checked in-silico using BLAST at NCBI against other fungi and plant sequences. The LAMP TR4 reaction was performed according to the instructions of the Isothermal Master Mix ISO-001 kit (Optigene Limited, UK). Reactions were performed in a final volume of $25 \mu \mathrm{L}$ consisting of $15 \mu 1$ Master Mix ISO-00, $2 \mu 1$ primer mix $(0.8 \mu \mathrm{M}$ of each FIP and BIP primer, $0.2 \mu \mathrm{M}$ of each F3 and B3 primer, and 0.4 $\mu \mathrm{M}$ of each LF and LB primers), $1 \mathrm{ng}$ of template DNA and nuclease-free water. The reactions were carried out at $65^{\circ} \mathrm{C}$ for 30 min followed by an annealing step ramping at $0.5^{\circ} \mathrm{C} / \mathrm{s}$ from $98^{\circ} \mathrm{C}$ to $80^{\circ} \mathrm{C}$. For each LAMP reaction, TR4 (II5) DNA was used as a positive control and nuclease-free water as negative control. All LAMP reactions were run in the Genie II instrument (Optigene Ltd., UK) that allows 16 simultaneous reactions. The criteria for positive signals were based on two parameters: Time of positivity (Tp) stated in min:s and melting temperature $(\mathrm{Tm})$ stated in ${ }^{\circ} \mathrm{C}$. The $\mathrm{Tp}$ is calculated as the time at which the maximum increase of fluorescence is reached. The $\mathrm{Tm}$ is the temperature at which half of the LAMP products are in the single-stranded state. This temperature is specific and unique for each LAMP product and allows discrimination for unspecific amplification. 
Chapter 3

Table 2. LAMP primers designed in this study.

\begin{tabular}{cll}
\hline Target & LAMP Primers & 5'- 3' primer sequence \\
\hline & SeqA_F3 & AATAGTAAAGATGCTGAACTTCT \\
& SeqA_B3 & ACTCTTGTGAGAGGTCGA \\
TR4 & SeqA_FIP & TGGGAGGAAGAACTTTCTAGTAT- \\
(VCG01213) & GAGAAAGGATAAGGGATGTAATGTTG \\
& SeqA_BIP & TTGCTCAATTTCCTTGTGTTTCG- \\
& SeqA_Loop F & ACGATTCACGATAGTAGAGTT \\
& SeqA_Loop B & TCTTCTTCTTCGCCGTACCTCATCA \\
\hline & MusaCox_F3 & GCCTGGATCCGGTATCATA \\
Banana cox & MusaCox_B3 & TTGAATTGTATCGAACCTCCC \\
gene & MusaCox_FIP & CGTATCAACGTCTAAGCCCACATGCCATGATCAGTATAGGTGT \\
(Musa spp.). & MusaCox_BIP & TGCCTACTTCACCGCTGCCACATAGTAGCGATCCAACTAA \\
& MusaCox_Loop F & GATGAGCCCAAACAAGAAATCC \\
& MusaCox_Loop B & CCATGATCATAGCTGTCCCTAC \\
\hline
\end{tabular}

\section{Specificity, sensitivity and reproducibility tests}

The developed LAMP TR4 assay was tested for specificity, sensitivity and reproducibility following the reaction conditions described above in order to validate its efficiency in detecting pure TR4 DNA samples. The specificity of the assay was evaluated using 22 target TR4 DNAs and 45 non-target fungal and bacterial DNAs (Table 1). The sensitivity test was run twice using a dilution series of $1000,100,10,1,0.1$ and $0.01 \mathrm{pg} / \mu \mathrm{of}$ pure TR4 (II5) DNA. The dilution series was tested in the presence and absence of pure DNA ( $1 \mathrm{ng} / \mu \mathrm{l})$ from 'Grand Naine' banana cultivar. Additionally, plasmid DNA containing selected $\sim 500$ bp sequence (SeqA) was synthesized (IDT, Belgium) to further determine the sensitivity of the developed assay. Picogreen quantified plasmid DNA was diluted from $10^{9}$ to $10^{0}$ copies/ $\mu$ l. Finally for the reproducibility test, the LAMP TR4 assay was repeated five times using $1 \mu \mathrm{l}$ of TR4 (II5) DNA (1 ng) as a positive control and Foc_R1 DNA (1 ng) and nuclease-free water as negative controls.

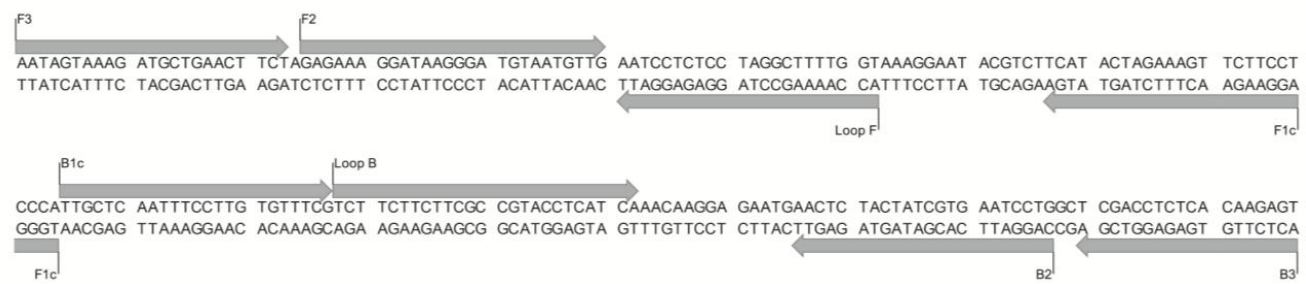

Figure 2. Unique TR4 sequence (SeqA) showing the location of developed LAMP TR4 primers: F3, B3, FIP (F1c-F2), BIP (B1c-B2), Loop F and B. The arrows indicate the 5' to 3' direction of extension. 


\section{Testing of LAMP TR4 assay for in-plant diagnosis}

A simple, rapid and inexpensive procedure was developed to quickly release DNA from plant tissue for TR4 detection with a minimum of equipment. Firstly, plant tissue was cut into small cubes and placed in a $5 \mathrm{ml}$ extraction tube containing one steel ball (Optigene Limited, UK) and $1 \mathrm{ml}$ epicentre buffer (Quick Extract RNA extraction solution) with Chelex 100 resin. The tube was vigorously shaken by hand for $1 \mathrm{~min}$ to homogenize the solution and incubated at $95^{\circ} \mathrm{C}$ in a water bath for $20 \mathrm{~min}$. After short mixing, the solution was left at room temperature for 1 min. Finally, it was diluted 15 times using Optigene dilution buffer (Optigene Limited, UK) and $5 \mu 1$ of this solution was added to the LAMP TR4 reaction vial. Feasibility trials with the LAMP TR4 assay were conducted on 'Grand Naine' plants artificially (WUR greenhouse, The Netherlands) and naturally infected (Mindanao, The Philippines) with TR4. At WUR two months old plants were inoculated with $10^{6}$ conidia/ml TR4 (II5) inoculum following the García-Bastidas et al. (2018a) protocol. Water inoculated plants were used as negative control. Rhizome tissue was recovered eight weeks after inoculation (wai) and stored at $-20^{\circ} \mathrm{C}$ until use. In The Philippines, the LAMP TR4 assay was tested using rhizome and pseudostem tissue of 'Grand Naine' plants collected from a naturally

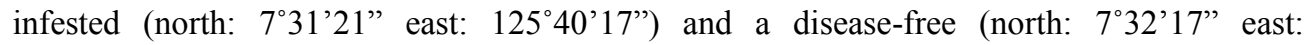
$\left.125^{\circ} 39^{\prime} 44^{\prime \prime}\right)$ banana plantation in Davao del Norte. All plant samples were tested in parallel with the LAMP MusaCox assay as an extraction and internal control. The LAMP banana primers (Table 2) were designed on the dwarf banana (Musa acuminata) mitochondrial cytochrome oxidase (coxl) gene exons 1-2 (AJ247609 at NCBI) using software Primer Explorer V4 (http://primerexplorer.jp/e/; Eiken Chemical Co. Ltd., Tokyo, Japan). This primer set gave a positive signal for DNA obtained from 'Grand Naine' and many other banana cultivars (data not shown). The reaction conditions of the LAMP MusaCox assay were the same as described for LAMP TR4 assay. To test the robustness of the developed LAMP assays for in-plant diagnosis, we performed the simple procedure to obtain DNA as described above two to three times for each evaluated tissue sample. The obtained solutions were run twice following the conditions of our developed LAMP TR4 assay.

\section{RESULTS}

\section{DArTseq pipeline outputs}

From an initial DArTseq platform containing 15,905 DArTseq in-silico markers, 10,125 high quality markers were obtained that passed the stringent quality criteria (call rate $>0.66$, reproducibility $=100$ and $\mathrm{Q}$ value $>2.7$ ). Following the selection pipeline (Fig. 1), we acquired 57 TR4 unique markers based on the three chosen isolates (II5, JV11 and Indo84) (Fig. 1 step 1; Fig. 3). BLAST analysis reduced this to 31 unique markers that blasted to the TR4 II5 reference genome (Fig. 1 steps 2-3). Subsequently, the marker borders were expanded ( $\sim 500 \mathrm{bp})$ using the II5 genome. Finally, nine sequences remained TR4 unique when blasted against fungal genomes from both databases (Fig. 1 steps 4-6). 


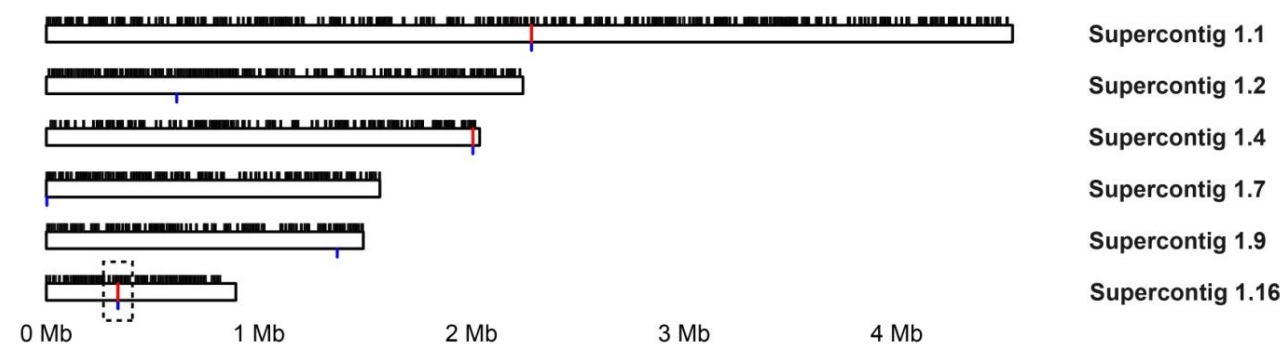

Figure 3. Distribution of the 10,125 DArTseq in-silico markers along the largest contigs of the Fusarium oxysporum f.sp. cubense TR4 II5 genome available at NCBI are shown in balck, while some of the 31 markers present only within TR4 isolates after blasting on the genome databases are shown in blue and nine remained unique markers after extenstion are shown in red. The location of SeqA TR4 sequence is highlighted on Supercontig 1.16 .

\section{PCR selection of a TR4 unique sequence}

To choose among the nine TR4 sequences, primer sets linked to these nine sequences were validated on the 24 Foc VCGs. In most cases, the primer sets specifically amplified a unique band for the II5 isolate (VCG01213) but not for the other Foc VCGs (Fig. 4). Primers set (SeqA) was selected and tested on 22 TR4 isolates, generating a product with the same band size. These amplicons were sequenced, revealing that all nucleotide sequences were identical (data not shown). Thus, the proposed pipeline (Fig. 1) and further PCR analyses established the identification of a TR4 unique sequence of around $>500 \mathrm{bp}$ corresponding to supercont1.16 (336895-337463+), on which LAMP primers were designed. This sequence was confirmed to be single copy, non-coding and non-repetitive based on the annotated II5 genome, available at http://www.broadinstitute.org/annotation/genome/fusarium_group/Featu reSearch.html).

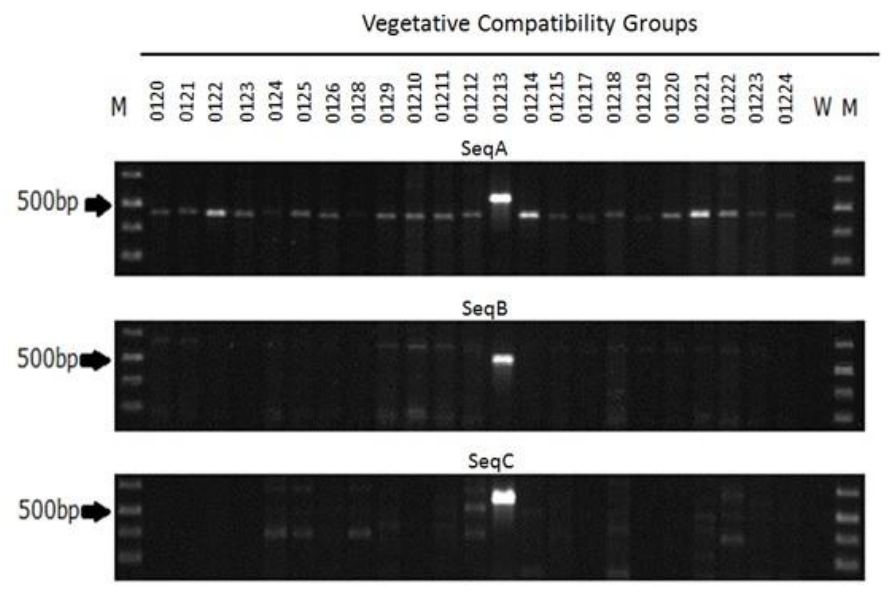

Figure 4. TR4 amplicons ( $\sim 500 \mathrm{bp}$ each) from three unique TR4 sequences (from top to bottom: SeqA, SeqB and SeqC). The PCR primer sets were tested against all reported Foc VCGs. M stands for "molecular marker". W stands for "Water". 


\section{Specificity, sensitivity and reproducibility tests}

To assess for specificity, the LAMP TR4 assay was tested on known TR4 isolates as well as on other Foc and non-Foc strains. In all cases, the TR4 isolates yielded a positive signal; while all non-targets, including the other Foc VCGs, tested negative. We expanded the LAMP analysis by including the previously published LAMP TR4 assay following their suggested reaction conditions (Zhang et al., 2013). For the tested Foc strains, this LAMP TR4 assay resulted in positive signals to Foc isolates other than TR4, suggesting that they are not TR4 specific (Table 3 and Supplementary Table 1). LAMP assays should be highly sensitive in order to detect DNA from plant tissues. The LAMP sensitivity test shows that our LAMP TR4 assay can detect up to $1 \mathrm{pg} / \mu 1$ pure TR4 DNA $\left(\mathrm{Tp}=14: 52 \mathrm{~min}\right.$ and $\left.\mathrm{Tm}=83.4^{\circ} \mathrm{C}\right)$. It is not prone to the presence of irrelevant DNA since the presence or absence of $1 \mathrm{ng} / \mu \mathrm{l}$ background banana DNA neither affected the amplification efficiency nor generated background signals. The sensitivity was evaluated by adding plasmid DNA containing the SeqA sequence. Our LAMP assay was found to be very sensitive and able to generate an amplicon with a detection limit of $10^{2}$ copies (average $\mathrm{Tp}=15: 20 \mathrm{~min}$ and $\mathrm{Tm}=83.4^{\circ} \mathrm{C}$; Fig. 5). The robustness of our LAMP TR4 was shown by producing consistent results with the presence of 1 ng pure TR4 DNA (II5) per reaction (average $\mathrm{Tp}=13: 40 \mathrm{~min}$ and $\mathrm{Tm}=83.4^{\circ} \mathrm{C}$ ). For the negative control samples (Foc_R1 and nuclease-free water), no Tp or Tm was obtained.

Table 3. Specificity comparison of previously published LAMP TR4 primers (Zhang et al., 2013) and the newly developed LAMP TR4 primers on a set of TR4 isolates, and non-target Foc and other fungal and bacterial strains.

\begin{tabular}{lcc}
\hline Isolates $^{1}$ & $\begin{array}{c}\text { LAMP TR4 } \\
\text { this study }\end{array}$ & $\begin{array}{c}\text { LAMP TR4 } \\
\text { (Zhang et al., 2013) }\end{array}$ \\
\hline TR4 (VCG01213) & $22 / 22$ & $2 / 2^{2}$ \\
All other Foc VCGs & $0 / 28$ & $22 / 22^{3}$ \\
Non - Foc & $0 / 17$ & Not tested \\
\hline
\end{tabular}

${ }^{1}$ Isolates listed in Table 1. ${ }^{2}$ Isolates II5 and Indo84 were tested. ${ }^{3}$ Four other Foc VCGs (Foc_R1, Foc_R2, NRRL36103 and NRRL36113) were not tested.

\section{Feasibility of LAMP TR4 assay for in-plant diagnosis}

The developed LAMP TR4 assay successfully detected the presence of TR4 in plant tissue from TR4 infected plants under greenhouse at WUR (average Tp $=16: 06 \mathrm{~min}$ and Tm $=82.9^{\circ} \mathrm{C}$ ) and field conditions in The Philippines (average $\mathrm{Tp}=19: 26 \mathrm{~min}$ and $\mathrm{Tm}=83.0^{\circ} \mathrm{C}$ ) (Table 4). In healthy control plants, TR4 was never detected. Under field conditions, LAMP TR4 assays were performed in banana plantations as proof of the simple requirements to run the assay. All plant tissue samples were positive for the LAMP MusaCox assay (average Tp $=14: 23$ and $\mathrm{Tm}=86.0^{\circ} \mathrm{C}$ ). The $\mathrm{Tm}$ was specific and unique for TR4 and coxl products, corresponding to $82.9^{\circ} \mathrm{C}$ and $86.0^{\circ} \mathrm{C}$ respectively. This temperature difference allows discrimination between the two amplicons generated in the same reaction. In summary, the LAMP TR4 assay proved to be successful in detecting TR4 in the artificially as well as in the naturally TR4 infected plants, showing that this assay is feasible for in-plant diagnosis in an undemanding setting in the field. 


\section{Chapter 3}

Table 4. Performance of the developed LAMP assays on 'Grand Naine' banana tissues collected from artificially and naturally TR4 symptomatic plants at WUR, The Netherlands and in The Philippines. Tp stands for "time of positivity". Tm stands for "melting temperature".

\begin{tabular}{|c|c|c|c|c|c|c|}
\hline \multirow[t]{2}{*}{ Location } & \multirow[t]{2}{*}{ Sample } & \multirow[t]{2}{*}{ Replicate } & \multicolumn{2}{|c|}{$\begin{array}{l}\text { LAMP } \\
\text { TR4 assay }\end{array}$} & \multicolumn{2}{|c|}{$\begin{array}{l}\text { LAMP } \\
\text { MusaCox assay }\end{array}$} \\
\hline & & & Tp & Tm & $\mathbf{T p}$ & $\mathbf{T m}$ \\
\hline \multirow{16}{*}{$\begin{array}{l}\text { Greenhouse } \\
\text { (WUR, } \\
\text { Netherlands) }\end{array}$} & \multirow{4}{*}{$\begin{array}{l}\text { Healthy } \\
\text { rhizome } 1\end{array}$} & Extraction 1- Replicate 1 & - & - & $10: 15$ & 86.3 \\
\hline & & Extraction 1- Replicate 2 & - & - & 10:15 & 86.2 \\
\hline & & Extraction 2-Replicate 1 & - & - & 11:00 & 86.1 \\
\hline & & Extraction 2- Replicate 2 & - & - & $11: 15$ & 86.1 \\
\hline & \multirow{4}{*}{$\begin{array}{l}\text { Healthy } \\
\text { rhizome } 2\end{array}$} & Extraction 1- Replicate 1 & - & - & $10: 15$ & 86.0 \\
\hline & & Extraction 1- Replicate 2 & - & - & 10:00 & 86.1 \\
\hline & & Extraction 2- Replicate 1 & - & - & 10:15 & 86.3 \\
\hline & & Extraction 2-Replicate 2 & - & - & $10: 15$ & 86.2 \\
\hline & \multirow{4}{*}{$\begin{array}{l}\text { Infected } \\
\text { rhizome } 1\end{array}$} & Extraction 1- Replicate 1 & $14: 30$ & 83.1 & $10: 45$ & 86.0 \\
\hline & & Extraction 1- Replicate 2 & $14: 30$ & 83.1 & $10: 45$ & 86.0 \\
\hline & & Extraction 2-Replicate 1 & $15: 00$ & 83.0 & $11: 30$ & 86.0 \\
\hline & & Extraction 2- Replicate 2 & 15:00 & 83.0 & $11: 15$ & 86.0 \\
\hline & \multirow{4}{*}{$\begin{array}{l}\text { Infected } \\
\text { rhizome } 2\end{array}$} & Extraction 1- Replicate 1 & 18:00 & 83.0 & $11: 30$ & 85.9 \\
\hline & & Extraction 1- Replicate 2 & $17: 30$ & 83.0 & 11:30 & 85.9 \\
\hline & & Extraction 2-Replicate 1 & $17: 30$ & 83.0 & $12: 15$ & 85.9 \\
\hline & & Extraction 2- Replicate 2 & $17: 30$ & 82.7 & $12: 00$ & 85.9 \\
\hline \multirow{24}{*}{$\begin{array}{l}\text { Field } \\
\text { (Philippines) }\end{array}$} & \multirow{6}{*}{$\begin{array}{l}\text { Healthy } \\
\text { rhizome }\end{array}$} & Extraction 1- Replicate 1 & - & - & 19:30 & 86.0 \\
\hline & & Extraction 1- Replicate 2 & - & - & $18: 30$ & 86.1 \\
\hline & & Extraction 2-Replicate 1 & - & - & 17:00 & 86.2 \\
\hline & & Extraction 2- Replicate 2 & - & - & $17: 15$ & 86.1 \\
\hline & & Extraction 3-Replicate 1 & - & - & $17: 45$ & 86.0 \\
\hline & & Extraction 3-Replicate 2 & - & - & 23:00 & 85.9 \\
\hline & \multirow{6}{*}{$\begin{array}{l}\text { Healthy } \\
\text { pseudostem }\end{array}$} & Extraction 1- Replicate 1 & - & - & 22:00 & 86.0 \\
\hline & & Extraction 1- Replicate 2 & - & - & $21: 45$ & 86.1 \\
\hline & & Extraction 2-Replicate 1 & - & - & $22: 45$ & 86.1 \\
\hline & & Extraction 2- Replicate 2 & - & - & 23:00 & 86.1 \\
\hline & & Extraction 3-Replicate 1 & - & - & 23:00 & 86.1 \\
\hline & & Extraction 3-Replicate 2 & - & - & $22: 45$ & 86.1 \\
\hline & \multirow{6}{*}{$\begin{array}{l}\text { Infected } \\
\text { rhizome }\end{array}$} & Extraction 1- Replicate 1 & 23:00 & 82.9 & 13:30 & 86.1 \\
\hline & & Extraction 1- Replicate 2 & 19.45 & 83.1 & $13: 30$ & 86.2 \\
\hline & & Extraction 2-Replicate 1 & $18: 30$ & 83.1 & $14: 15$ & 86.2 \\
\hline & & Extraction 2- Replicate 2 & $21: 45$ & 83.1 & $14: 15$ & 86.2 \\
\hline & & Extraction 3-Replicate 1 & $18: 30$ & 83.1 & 14:00 & 86.2 \\
\hline & & Extraction 3-Replicate 2 & 19:15 & 83.1 & $14: 30$ & 86.2 \\
\hline & \multirow{6}{*}{$\begin{array}{l}\text { Infected } \\
\text { pseudostem }\end{array}$} & Extraction 1- Replicate 1 & $16: 15$ & 83.1 & 14:00 & 86.1 \\
\hline & & Extraction 1- Replicate 2 & $17: 45$ & 83.1 & $17: 45$ & 86.1 \\
\hline & & Extraction 2- Replicate 1 & $17: 15$ & 83.3 & 15:00 & 86.1 \\
\hline & & Extraction 2-Replicate 2 & $22: 15$ & 83.1 & 15:00 & 86.1 \\
\hline & & Extraction 3-Replicate 1 & $20: 15$ & 83.0 & 15:00 & 86.2 \\
\hline & & Extraction 3-Replicate 2 & $18: 45$ & 83.0 & 18:00 & 86.0 \\
\hline
\end{tabular}


A

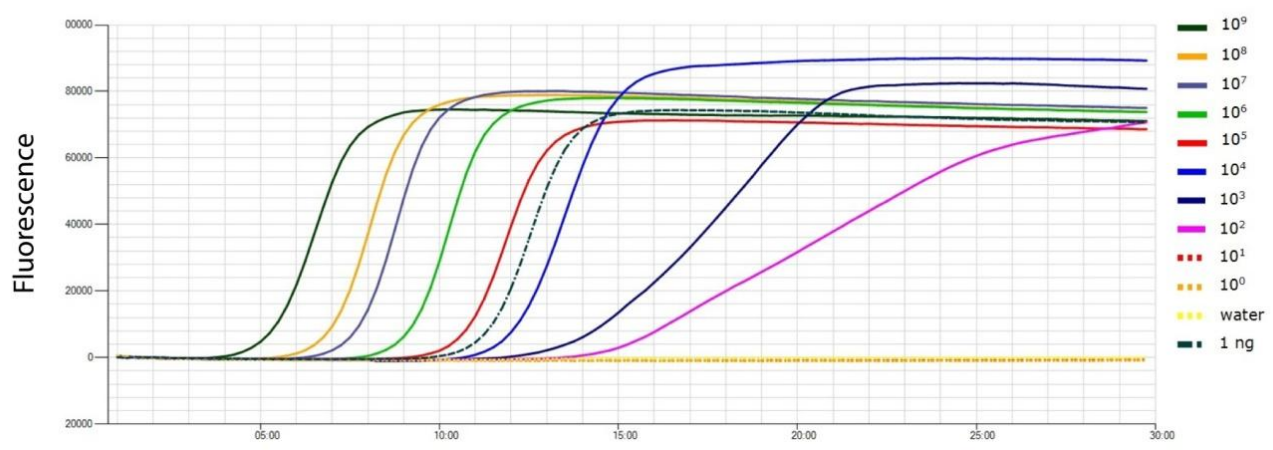

B

Time (min)
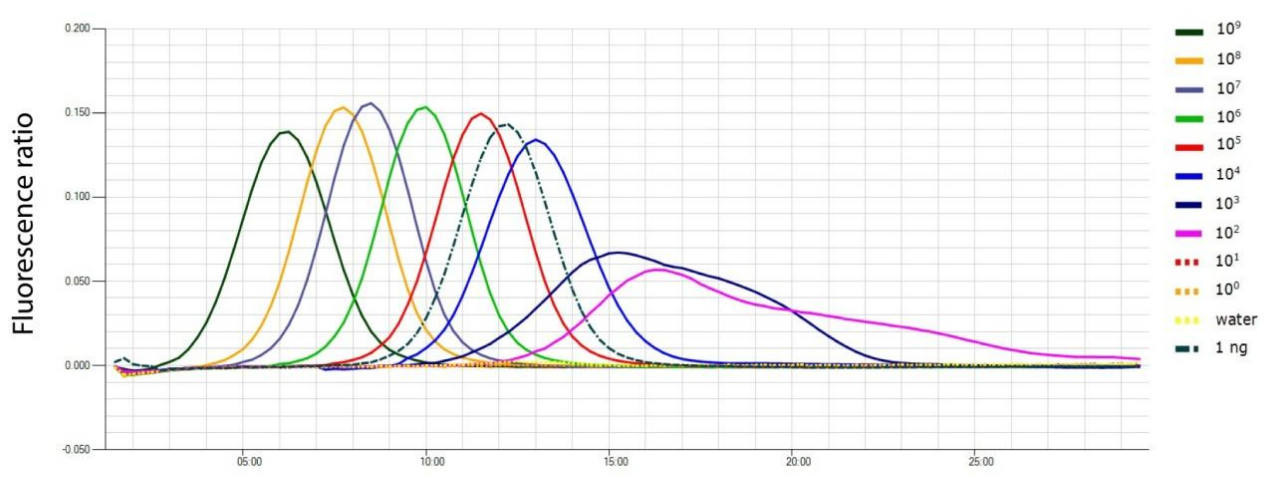

Time (min)

C

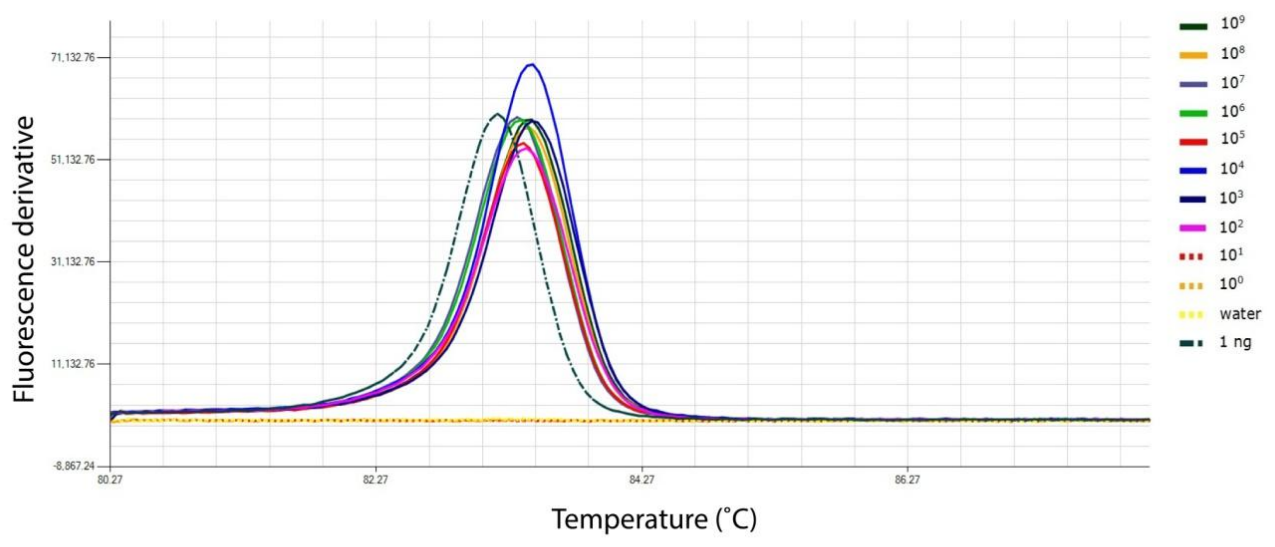

Figure 5. Sensitivity of the LAMP TR4 assay on the dilution series $\left(10^{9}\right.$ to $10^{0}$ copies per reaction) of the plasmid DNA containing the SeqA sequence. In each run, $1 \mathrm{ng}$ of pure TR4 II5 DNA and nuclease-free water were included as positive and negative control, respectively. (A) Amplification curves, (B) time of positivity (Tp) and (C) melting temperature (Tm). 


\section{DISCUSSION}

Crop losses due to the incidence of pests can significantly threaten food security (Bebber \& Gurr, 2014; Fisher et al., 2016; Gurr et al., 2011). Estimates of potential and actual losses due to plant pests despite the current crop protection practices varied from $50 \%$ in wheat to more than $80 \%$ in cotton production (Oerke, 2005). Currently in bananas, the emerging TR4 strain causing Fusarium wilt may potentially develop into a pandemic (Butler, 2013; Kema \& Weise, 2013; Kupferschmidt, 2012; Ordóñez et al., 2015; Pearce, 2003) as it occurred during the first outbreak of the disease in Latin America (Ploetz, 1994; Stover, 1962). The Foc genotype responsible for the current outbreak on bananas corresponds to VCG01213 (Molina et al., 2009; Ordóñez et al., 2015; Ploetz, 2015a, 2015b) and has disseminated, since its first encounter with Cavendish in Taiwan (Ploetz, 2006), within and outside of Southeast Asia (Chittarath et al., 2017; García-Bastidas et al., 2014; Hung et al., 2017; Mostert et al., 2017; Ordóñez et al., 2016; Ordóñez et al., 2015; Zheng et al., 2018), affecting by now an estimated $>100,000$ ha. of banana plantations (Ordóñez et al., 2015). As there is no known effective and long-term control of the disease, global awareness among banana-growing countries are directed towards prevention of further spread of the pathogen (FAO, 2014), which requires accurate diagnosis. In this study, we developed a LAMP assay that enables on-site diagnosis of TR4 in the field. Diagnosis of plant pathogens is the cornerstone of effective disease control and prevention (Schaad et al., 2003). For molecularbased diagnostic development, targeting of unique genome sequences is essential. Thus in the current study, we used DArTseq to identify TR4 specific sequences that were fully absent from other Foc VCGs. The sequence extension upon selection of our DArTseq markers benefitted from available Foc genomes that aided the development of our LAMP TR4 assay. Since there is not public genomic data on all 24 reported Foc VCGs, our selected sequence (SeqA) was further tested via PCR reactions on isolates representing each of these genotypes. Currently, there are four publicy available Foc genomes that correspond to two TR4 isolates (VCG01213) and two isolates of unknown VCG. Also, 94 genomes corresponding to $F$. oxysporum strains pathogenic to hosts other than bananas are available (http://www.ncbi.nlm.nih.gov/genome/genomes/707). Here, our extended TR4 sequence (SeqA) proved to be specific to TR4 genomes available on the two databases used in this study. Certainly, whole-sequencing projects on a larger suite of Foc genotypes and other polyphyletic fungal members of the Fusarium oxysporum species complex (FOSC) will facilitate the development and improvement of molecular-based diagnostic tools for Foc genotypes.

Specificity of molecular-based diagnostics is indispensable to ensure an accurate diagnosis of pathogens, thus ideally development of diagnostic tools must include a diverse set of relevant isolates. The comparison of our developed LAMP TR4 assay to the previously developed LAMP TR4 assay (Zhang et al., 2013) showed that the latter cannot discriminate TR4 (VCG01213) from other Foc VCGs, despite carefully following the described protocol. Since the B3 and F3 LAMP primers (Zhang et al., 2013) are the same as the PCR primers for TR4 (Dita et al., 2010), the unspecificity of this LAMP assay likely is due to other components of this LAMP assay (LoopF, LoopB, B2, F2, F1c and B1c). Moreover, our assay is grounded in the widest possible genetic diversity of Foc, whereas the LAMP assay of Zhang et al. (2013) was developed on a single TR4 isolate and just five other Foc isolates. In 
our study, the new LAMP TR4 assay was highly specific to TR4. Non-target species, including $R$. solanacearum, a pathogen bacteria that causes similar wilting symptoms on bananas are those elicited by Foc strains (Blomme et al., 2017; Kubota et al., 2008), did not result in an amplicon. The sensitivity of our LAMP assay is excellent as it detects volumes as low as $1 \mathrm{pg} / \mu 1$ or $10^{2}$ copies of plasmid DNA per reaction and from $1 \mathrm{ng}$ pure TR4 DNA with an excellent reproducibility and amplification efficiency despite the presence of background DNA. This corroborates with a previous report stating that LAMP assays are less influenced by non-target DNA compared to other molecular diagnostics (Kaneko et al., 2007). In LAMP assays, target genome sequences can be detected faster than with other molecular diagnostics (Notomi et al., 2000). Diagnosis of TR4 in suspicious plan samples following a simple and quick DNA extraction procedure was completed in $30 \mathrm{~min}$ for 12 samples in parallel. Hence, this new LAMP is a ready to use and on-site solution for routine TR4 diagnosis that supports the implementation of cordoning and quarantine strategies.

Contrary to LAMP, PCR-based molecular diagnostics for TR4 VCG01213 (Dita et al., 2010; Li et al., 2013a, Li et al., 2013b) require advanced laboratory facilities and expertise. In banana, the most important pathogens such as bunchy top virus (Peng et al., 2012a), cucumber mosaic virus (Peng et al., 2012b), streak virus (Peng et al., 2012c) and the Moko pathogen $R$. solanacearum (Kubota et al., 2008) can now be detected using LAMP technology. These assays are particularly relevant to reduce the time between the introduction of a pathogen and its detection. Usually, considerable time elapses between the incursion of a plant pathogen and its diagnosis, generating greater economic losses (Stack et al., 2006). In Jordan, Fusarium wilt symptoms on Cavendish plants were first observed in 2006, but TR4 was only diagnosed after eight years (García-Bastidas et al., 2014), in the meantine TR4 spread to new farms in the country and some banana farms are nowadays abandoned (Ploetz et al., 2015b). Similarly in Taiwan, TR4 was identified only in 1994 as the strain responsible for wilting in Cavendish observed in the 1960s, nowadays TR4 is widely spread in the country (Molina et al., 2009; Zheng et al., 2018). A global analysis of crop pathogen distributions showed that a country's ability to monitor and report accurately its pathogen load increases with per capita gross domestic product, its research capacity and expenditure (Bebber et al., 2014). Since LAMP assays require low cost materials and non-experienced personnel, the LAMP TR4 assay was pioneered for three years in the Philippines to test its rapid implementation in resource poor environments for on-site detection and the cordoning of TR4 to minimize economic losses (Frison \& Sharrock, 1998; IOM, 2007). Indeed, in these farms, new incursions are being identified and correctly diagnosed thereby supporting immediate quarantine actions. We conclude that the developed LAMP technology is of great value and provide immediate information on TR4 hotspots and, most importantly, the ability to set off routine surveillance and eradication plans.

\section{ACKNOWLEDGMENTS}

This research is funded by the Interdisciplinary Research and Education Fund (INREF) of Wageningen University \& Research (WUR), Wageningen, The Netherlands. Banana research at WUR is supported by the Dutch Dioraphte Foundation endowed chair in Tropical Phytopathology of GHJK at the WUR-Laboratory of Phytopathology. Research in 
Chapter 3

the laboratory of M.F.S. is supported by the Research Council Earth and Life Science (ALW) of The Netherlands Organization of Scientific Research (NWO). NEH-Philippines generously supported field experimentation and Tadeco-Philippines provided Moko isolates from Cavendish banana. We thank Rahan Meristem, Israel, for providing all greenhouse plants for experimentation and Nani Maryani for making infected plants available for this project. UNIFARM, WUR, The Netherlands is greatly acknowledged for greenhouse maintenance and plant care. 


\section{REFERENCES}

Alves, A., Pereira, V., Leão, A., Formigheri, E., de Capdeville, G., \& Souza Junior, M. (2014). Advancing palm genomics by developing a high-density battery of molecular markers for Elaeis oleifera for future downstream applications. BMC Proceedings, 8(Suppl 4), P96.

Bebber, D.P., Holmes, T., Smith, D., \& Gurr, S J. (2014). Economic and physical determinants of the global distributions of crop pests and pathogens. New Phytol, 202(3), 901-910.

Bebber, D.P., Ramotowski, M.A.T., \& Gurr, S.J. (2013). Crop pests and pathogens move polewards in a warming world. Nat Clim Change, 3, 985.

Bentley, S., Pegg, K.G., Moore, N.Y., Davis, R.D., \& Buddenhagen, I. (1998). Genetic variation among vegetative compatibility groups of Fusarium oxysporum f.sp. cubense analyzed by DNA fingerprinting. Phytopathology, 88(12), 1283-1293.

Blomme, G., Dita, M., Jacobsen, K.S., Pérez Vicente, L., Molina, A., Ocimati, W., . . Prior, P. (2017). Bacterial diseases of bananas and Enset: Current state of knowledge and integrated approaches toward sustainable management. Front Plant Sci, 8(1290), 1-25.

Buddenhagen, I. (2009). Understanding strain diversity in Fusarium oxysporum f.sp. cubense and history of introduction of Tropical Race 4 to better manage banana production. Acta Hort, 828(Proc. IS on Banana Crop Prot., Sust. Prod. \& Impr. Livelihoods), 193-204.

Bühlmann, A., Pothier, J.F., Rezzonico, F., Smits, T.H.M., Andreou, M., Boonham, N., . . . Frey, J.E. (2013). Erwinia amylovora loop-mediated isothermal amplification (LAMP) assay for rapid pathogen detection and on-site diagnosis of fire blight. J Microbiol Methods, 92(3), 332-339.

Butler, D. (2013). Fungus threatens top banana. Nature, 504, 195-196.

Chittarath, K., Mostert, D., Crew, K.S., Viljoen, A., Kong, G., Molina, G., \& Thomas, J.E. (2017). First report of Fusarium oxysporum f.sp. cubense tropical race 4 (VCG 01213/16) associated with Cavendish bananas in Laos. Plant Dis, 449.

Cruz, V.M., Kilian, A., \& Dierig, D.A. (2013). Development of DArT marker platforms and genetic diversity assessment of the U.S. collection of the new oilseed crop lesquerella and related species. PLoS One, $8(5), 1-13$.

Dita, M.A., Waalwijk, C., Buddenhagen, I.W., Souza Jr, M.T., \& Kema, G.H.J. (2010). A molecular diagnostic for tropical race 4 of the banana Fusarium wilt pathogen. Plant Pathol, 59(2), 348-357.

FAO. (2014). Technical manual prevention and diagnostic of Fusarium Wilt (Panama disease) of banana caused by Fusarium oxysporum f.sp. cubense Tropical Race 4 (TR4).

Fisher, M.C., Gow, N.A., \& Gurr, S.J. (2016). Tackling emerging fungal threats to animal health, food security and ecosystem resilience. Philos Trans R Soc Lond B Biol Sci, 371(1709).

Frison, E., \& Sharrock, S. (1998). The economic, social and nutritional importance of banana in the world. Paper presented at the Bananas and food security, Douala, Cameroon.

García-Bastidas, F.A., van der Veen, A.J.T., Nakasato-Tagami, G., Meijer, H.J.G., Arango-Isaza, R.E., \& Kema, G.H.J. (2018a). An improved spore production protocol facilitates a high throughput phenotyping assay for the banana - Fusarium oxysporum f.sp. cubense pathosystem. (PhD Degree), Wageningen University \& Research, Wageningen, The Netherlands.

García-Bastidas, F.A., Bakry, F., Irish, B., \& Kema, G.H.J. (2018b). Evidence for wide variation of resistance to Fusarium oxysporum f.sp. cubense tropical race 4 and race 1 generated by vegetative propagation in banana. (PhD Degree), Wageningen University \& Research, Wageningen, The Netherlands.

García-Bastidas, F., Ordóñez, N., Konkol, J., Al-Qasim, M., Naser, Z., Abdelwali, M., . . Kema, G.H.J. (2014). First report of Fusarium oxysporum f.sp. cubense tropical race 4 associated with Panama disease of banana outside Southeast Asia. Plant Dis, 98(5), 694.

Gurr, S., Samalova, M., \& Fisher, M. (2011). The rise and rise of emerging infectious fungi challenges food security and ecosystem health. Fungal Biol Rev, 25(4), 181-188.

Harper, S.J., Ward, L.I., \& Clover, G.R.G. (2010). Development of LAMP and Real-Time PCR methods for the rapid detection of Xylella fastidiosa for quarantine and field applications. Phytopathology, 100(12), 1282-1288.

Hung, T.N., Hung, N.Q., Mostert, D., Viljoen, A., Chao, C.P., \& Molina, G. (2017). First report of Fusarium wilt on Cavendish bananas, caused by Fusarium oxysporum f.sp. cubense tropical race 4 (VCG 01213/16), in Vietnam. Plant Dis, 448. 
Hwang, S.C., \& Ko, W.H. (2004). Cavendish banana cultivars resistant to Fusarium wilt acquired through somaclonal variation in Taiwan somaclonal variation in Taiwan. Plant Dis, 88(6), 580-588.

IOM. (2007). Global Infectious Disease Surveillance and Detection: Assessing the Challenges-Finding Solutions, Workshop Summary. Washington (DC): National Academies Press (US).

Kaneko, H., Kawana, T., Fukushima, E., \& Suzutani, T. (2007). Tolerance of loop-mediated isothermal amplification to a culture medium and biological substances. J Biochem Bioph Meth, 70(3), 499-501.

Kelman, A. (1954). The relationship of pathogenicity in Pseudomonas solanacearum to colony appearance on a tetrazolium medium. Phytopathology, 64, 693-695.

Kema, G.H.J., \& Weise, S. (2013). Pathogens: Appeal for funds to fight banana blight. Nature, 504(7479), 218.

Kistler, H.C., Alabouvette, C., Baayen, R.P., Bentley, S., Brayford, D., Coddington, A., . . . Woo, S. (1998). Systematic numbering of vegetative compatibility groups in the plant pathogenic fungus Fusarium oxysporum. Phytopathology, 88(1), 30-32.

Kubota, R., Vine, B.G., Alvarez, A.M., \& Jenkins, D.M. (2008). Detection of Ralstonia solanacearum by LoopMediated Isothermal Amplification. Phytopathology, 98(9), 1045-1051.

Kupferschmidt, K. (2012). Attack of the clones. Science, 337, 636-638.

Leslie, J.F., \& Summerell, B. (2006). The Fusarium Laboratory Manual: Blackwell Publishing.

Li, M.H., Shi, J.X., Xie, X.L., Leng, Y.Q., Wang, H.F., Xi, P.G., . . Jiang, Z.D. (2013a). Identification and application of a unique genetic locus in diagnosis of Fusarium oxysporum f.sp cubense tropical race 4. Canadian Journal of Plant Pathology, 35(4), 482-493.

Li, C.Y., Mostert, G., Zuo, C.W., Beukes, I., Yang, Q.S., Sheng, O., . . . Yi, G.J. (2013b). Diversity and distribution of the banana wilt pathogen Fusarium oxysporum f.sp. cubense in China. Fungal Genom Biol, 3(2), 1-6.

Molina, A.B., Fabregar, E., Sinohin, V.G., Yi, G., \& Viljoen, A. (2009). Recent occurrence of Fusarium oxysporum f.sp. cubense tropical race 4 in Asia. Acta Hort, 828(Proc. IS on Banana Crop Prot., Sust. Prod. \& Impr. Livelihoods), 109-115.

Mostert, D., Molina, A.B., Daniells, J., Fourie, G., Hermanto, C., Chao, C. P., . . . Viljoen, A. (2017). The distribution and host range of the banana Fusarium wilt fungus, Fusarium oxysporum f.sp. cubense, in Asia. PLoS One, 12(7), 1-24.

Nagamine, K., Kuzuhara, Y., \& Notomi, T. (2002). Isolation of single-stranded DNA from Loop-Mediated Isothermal Amplification products. Biochem Bioph Res Co, 290(4), 1195-1198.

Notomi, T., Okayama, H., Masubuchi, H., Yonekawa, T., Watanabe, K., Amino, N., \& Hase, T. (2000). Loopmediated isothermal amplification of DNA. Nucleic Acids Res, 28(12), e63.

Oerke, E. C. (2005). Crop losses to pests. J Agri Sci, 144(1), 31-43.

Ordóñez, N., García-Bastidas, F., Laghari, H.B., Akkary, M.Y., Harfouche, E.N., al Awar, B.N., \& Kema, G. H. J. (2016). First report of Fusarium oxysporum f.sp. cubense tropical race 4 causing Panama disease in Cavendish bananas in Pakistan and Lebanon. Plant Dis, 100(1), 209.

Ordóñez, N., Seidl, M.F., Waalwijk, C., Drenth, A., Kilian, A., Thomma, B.P., . . Kema, G.H. (2015). Worse comes to worst: Bananas and Panama disease-when plant and pathogen clones meet. PLoS Pathog, 11(11), 1-7.

Pearce, F. (2003). Going bananas. New Sci, 177, 27.

Peng, J., Zhang, J., Xia, Z., Li, Y., Huang, J., \& Fan, Z. (2012a). Rapid and sensitive detection of Banana bunchy top virus by loop-mediated isothermal amplification. $J$ Virol Methods, 185(2), 254-258.

Peng, J., Shi, M., Xia, Z., Huang, J., \& Fan, Z. (2012b). Detection of cucumber mosaic virus isolates from banana by one-step reverse transcription loop-mediated isothermal amplification. Arch Virol, 157(11), 2213-2217.

Peng, J., Fan, Z., \& Huang, J. (2012c). Rapid detection of banana streak virus by Loop-mediated Isothermal Amplification Assay in South China. J Phytopathol, 160(5), 248-250.

Ploetz, R.C. (2015a). Fusarium wilt of Banana. Phytopathology, 105(12), 1512-1521.Ploetz, R.C. (1994). Panama disease: Return of the first banana menace. Int J Pest Manage, 40(4), 326-336.

Ploetz, R.C. (2015b). Management of Fusarium wilt of banana: a review with special reference to tropical race 4. Crop Prot, 73, 7-15.

Ploetz, R.C., Kema, G. H., \& Ma, L. J. (2015a). Impact of diseases on export and smallholder production of banana. Annu Rev Phytopathol, 53, 269-288. 
Ploetz, R.C., Freeman, S., Konkol, J., Al-Abed, A., Naser, Z., Shalan, K., . . Israeli, Y. (2015b). Tropical race 4 of Panama disease in the Middle East. Phytoparasitica, 1-11.

Ploetz, R.C. (2006). Panama disease: An old nemesis rears its ugly head. Part2. The Cavendish era and beyond. Plant Health Progress.

Ploetz, R.C. (2005). Panama Disease: An old nemesis rears its ugly head. Part1: The beginnings of the banana export trades. Plant Health Progress.

Sambrook, J., Fritsch, E.F., \& Maniatis, T. (1989). Molecular cloning: A laboratory manual. (2nd. ed. ed.). New York: Cold Spring Harbour Press.

Schaad, N.W., Frederick, R.D., Shaw, J., Schneider, W. L., Hickson, R., Petrillo, M. D., \& Luster, D. G. (2003). Advances in molecular-based diagnostics in meeting crop biosecurity and phytosanitary issues. Annu Rev Phytopathol, 41, 305-324.

Stack, J., Cardwell, K., Hammerschmidt, R., Byrne, J., Loria, R., Snover-Clift, K., . . . Luke, E. (2006). The National Plant Diagnostic Network. Plant Dis, 90(2), 128-136.

Stover, R.H. (1962). Fusarial wilt (Panama disease) of bananas and other Musa species. UK: Commonwealth Mycological Institute.

Tomlinson, J., \& Boonham, N. (2015). Real-Time LAMP for Chalara fraxinea diagnosis. Methods Mol Biol, $1302,75-83$.

Untergasser, A., Nijveen, H., Rao, X., Bisseling, T., Geurts, R., \& Leunissen, J.A.M. (2007). Primer3Plus, an enhanced web interface to Primer3. Nucleic Acids Res, 35(suppl_2), W71-W74.

Zhang, X., Zhang, H., Pu, J., Qi, Y., Yu, Q., Xie, Y., \& Peng, J. (2013). Development of a real-time fluorescence loop-mediated isothermal amplification assay for rapid and quantitative detection of Fusarium oxysporum f.sp. cubense tropical race 4 in soil. PLoS One, 8(12), 1-10.

Zheng, S., García-Bastidas, F.A., Li, X., Zheng, L., Bai, T. T., Xu, S., . . . Kema, G.H.J. (2018). New geographical insights of the latest expansion of Fusarium oxysporum f.sp. cubense tropical race 4 into the Greater Mekong subregion. Front Plant Sci, 9(457), 1-9. 


\section{Chapter 3}

Supplemtary Table 1. Response of TR4 and non-TR4 isolates to the developed LAMP TR4 assay. Positive results for LAMP TR4 assays are indicated as "+", while negative results are indicated as "-.". n.d.stands for "not determined". n.a. stands for "not applicable". n.t. stands for "not tested".

\begin{tabular}{|c|c|c|c|c|}
\hline Isolate code & Species & VCG & $\begin{array}{l}\text { LAMP TR4 } \\
\text { this study }\end{array}$ & $\begin{array}{l}\text { LAMP TR4 } \\
\text { (Zhang et al., 2013) }\end{array}$ \\
\hline \multicolumn{5}{|l|}{ TR4 isolates } \\
\hline 24662 & Fusarium oxysporum f.sp. cubense & $01213 / 16$ & + & n.t. \\
\hline 24663 & F. oxysporum f.sp. cubense & $01213 / 16$ & + & n.t. \\
\hline 24664 & F. oxysporum f.sp. cubense & $01213 / 16$ & + & n.t. \\
\hline BPS1.1 & F. oxysporum f.sp. cubense & 01213 & + & n.t. \\
\hline BPS3.1 & F. oxysporum f.sp. cubense & 01213 & + & n.t. \\
\hline Foc.T105 & F. oxysporum f.sp. cubense & 01213 & + & n.t. \\
\hline II5 & F. oxysporum f.sp. cubense & 01213 & + & + \\
\hline Indo84 & F. oxysporum f.sp. cubense & 01216 & + & + \\
\hline Indo87 & F. oxysporum f.sp. cubense & $01213 / 16$ & + & n.t. \\
\hline JV11 & F. oxysporum f.sp. cubense & 01213 & + & n.t. \\
\hline Leb1.1A & F. oxysporum f.sp. cubense & 01213 & + & n.t. \\
\hline Leb1.2C & F. oxysporum f.sp. cubense & 01213 & + & n.t. \\
\hline Mal123 & F. oxysporum f.sp. cubense & 01213 & + & n.t. \\
\hline NRRL36114 & F. oxysporum f.sp. cubense & 01213 & + & n.t. \\
\hline Pak1.1A & F. oxysporum f.sp. cubense & 01213 & + & n.t. \\
\hline Phil.1A & F. oxysporum f.sp. cubense & 01213 & + & n.t. \\
\hline Phi2.5C & F. oxysporum f.sp. cubense & 01213 & + & n.t. \\
\hline Phi3.4C & F. oxysporum f.sp. cubense & 01213 & + & n.t. \\
\hline Phi4.5A & F. oxysporum f.sp. cubense & 01213 & + & n.t. \\
\hline Phi5.2A & F. oxysporum f.sp. cubense & 01213 & + & n.t. \\
\hline RPML47 & F. oxysporum f.sp. cubense & $01213 / 16$ & + & n.t. \\
\hline STSUM2 & F. oxysporum f.sp. cubense & 01213 & + & n.t. \\
\hline \multicolumn{5}{|l|}{ Non - TR4 isolates } \\
\hline FocST498 & F. oxysporum f.sp. cubense & 0120 & - & + \\
\hline NRRL25603 & F. oxysporum f.sp. cubense & $0120 / 15$ & - & + \\
\hline NRRL36102 & F. oxysporum f.sp. cubense & 0121 & - & + \\
\hline NRRL36103 & F. oxysporum f.sp. cubense & 0122 & - & n.t. \\
\hline F9129 ${ }^{1}$ & F. oxysporum f.sp. cubense & 0123 & - & + \\
\hline NRRL36105 & F. oxysporum f.sp. cubense & 0124 & - & + \\
\hline Foc_R2 & F. oxysporum f.sp. cubense & 0124 & - & n.t. \\
\hline NRRL36106 & F. oxysporum f.sp. cubense & 0125 & - & + \\
\hline NRRL36107 ${ }^{1}$ & F. oxysporum f.sp. cubense & 0126 & - & + \\
\hline NRRL36111 & F. oxysporum f.sp. cubense & 0128 & - & + \\
\hline NRRL36110 & F. oxysporum f.sp. cubense & 0129 & - & + \\
\hline Focu $7^{1}$ & F. oxysporum f.sp. cubense & 01210 & - & + \\
\hline NRRL36109 & F. oxysporum f.sp. cubense & 01211 & - & + \\
\hline NRRL36108 & F. oxysporum f.sp. cubense & 01212 & - & + \\
\hline NRRL36113 & F. oxysporum f.sp. cubense & 01214 & - & n.t. \\
\hline NRRL25609 & F. oxysporum f.sp. cubense & 01214 & - & + \\
\hline NRRL36112 & F. oxysporum f.sp. cubense & 01215 & - & + \\
\hline Mal43 & F. oxysporum f.sp. cubense & 01217 & - & + \\
\hline NRRL36120 & F. oxysporum f.sp. cubense & 01218 & - & + \\
\hline Indo25 & F. oxysporum f.sp. cubense & 01219 & - & + \\
\hline 242181 & F. oxysporum f.sp. cubense & 01220 & - & + \\
\hline NRRL36118 & F. oxysporum f.sp. cubense & 01221 & - & + \\
\hline NRRL36117 & F. oxysporum f.sp. cubense & 01222 & - & + \\
\hline NRRL36116 & F. oxysporum f.sp. cubense & 01223 & - & + \\
\hline NRRL36115 & F. oxysporum f.sp. cubense & 01224 & - & + \\
\hline Foc $R 1$ & F. oxysporum f.sp. cubense & n.d. & - & n.t. \\
\hline $\mathrm{KDM} 1.2 \mathrm{~A}$ & F. oxysporum f.sp. cubense & n.d. & - & n.t. \\
\hline Mal1.5B & F. oxysporum f.sp. cubense & n.d. & - & n.t. \\
\hline 0.1879 & F. oxysporum f.sp. melongenae & n.d. & - & n.t. \\
\hline 0.1954 & F. oxysporum f.sp. canariensis & n.d. & - & n.t. \\
\hline CBS196.65 & F. oxysporum f.sp. narcissi & n.d. & - & n.t. \\
\hline Fo47 & F. oxysporum & n.d. & - & n.t. \\
\hline Fol4287 & F. oxysporum f.sp. lycopersici & n.d. & - & n.t. \\
\hline Fop.08.1 & F. oxysporum f.sp. passiflora & n.d. & - & n.t. \\
\hline NRRL25433 & F. oxysporum f.sp. vasinfectum & n.d. & - & n.t. \\
\hline NRRL26035/ & F. oxysporum f.sp. canariensis & n.d. & - & n.t. \\
\hline IPO99.03 & & & & \\
\hline NRRL26381/ CL57 & F. oxysporum f.sp. radicis-lycopersici & n.d. & - & n.t. \\
\hline
\end{tabular}




\begin{tabular}{|c|c|c|c|c|}
\hline Isolate code & Species & VCG & $\begin{array}{l}\text { LAMP TR4 } \\
\text { this study }\end{array}$ & $\begin{array}{l}\text { LAMP TR4 } \\
\text { (Zhang et al., 2013) }\end{array}$ \\
\hline NRRL26406/ Fom001 & F. oxysporum f.sp. melonis & n.d. & - & n.t. \\
\hline $\begin{array}{l}\text { NRRL26761/ } \\
\text { IPO99.04 }\end{array}$ & F. oxysporum f.sp. phaseoli & n.d. & - & n.t. \\
\hline $\begin{array}{l}\text { NRRL28781/ } \\
\text { IPO99.02 }\end{array}$ & F. oxysporum f.sp. erythroxyli & n.d. & - & n.t. \\
\hline NRRL37622/ HDV247 & F. oxysporum f.sp. pisi & n.d. & - & n.t. \\
\hline NRRL54005/ PHW815 & F. oxysporum f.sp. raphani & n.d. & - & n.t. \\
\hline NRRL54008/ PHW808 & F. oxysporum f.sp. conglutinans & n.d. & - & n.t. \\
\hline CBS221.76 & Fusarium fujikuroi & n.a. & - & n.t. \\
\hline Moko & Ralstonia solanacearum & n.a. & - & n.t. \\
\hline
\end{tabular}
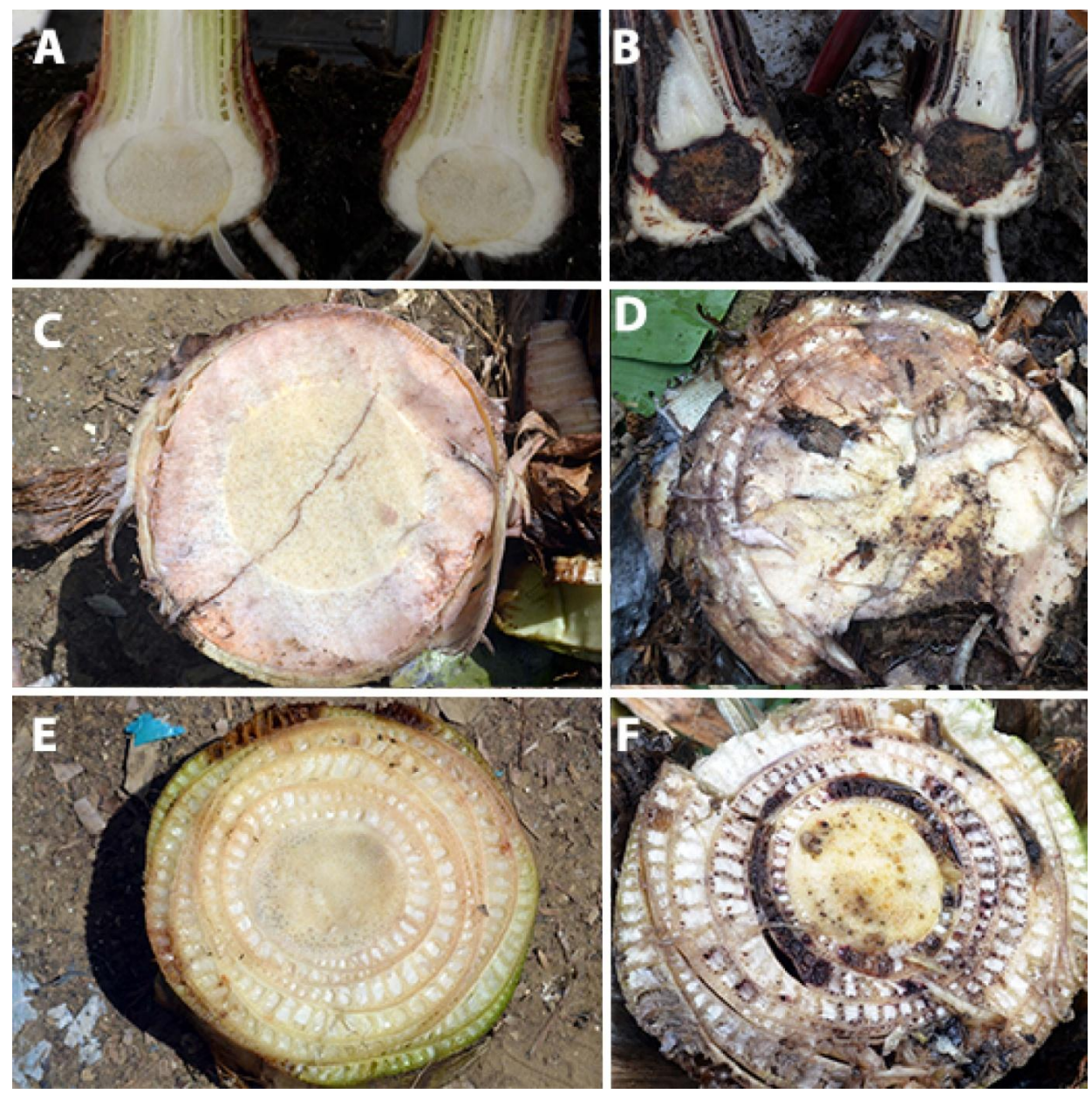

Supplementary Figure 1. 'Grand Naine' samples evaluated using the developed LAMP TR4 and MusaCox assays. (A) Healthy (water-control) and (B) infected rhizome under greenhouse conditions at WUR, The Netherlands; (C) healthy and (D) infected rhizome and (E) healthy and (F) infected pseudostem in field conditions in The Philippines. 


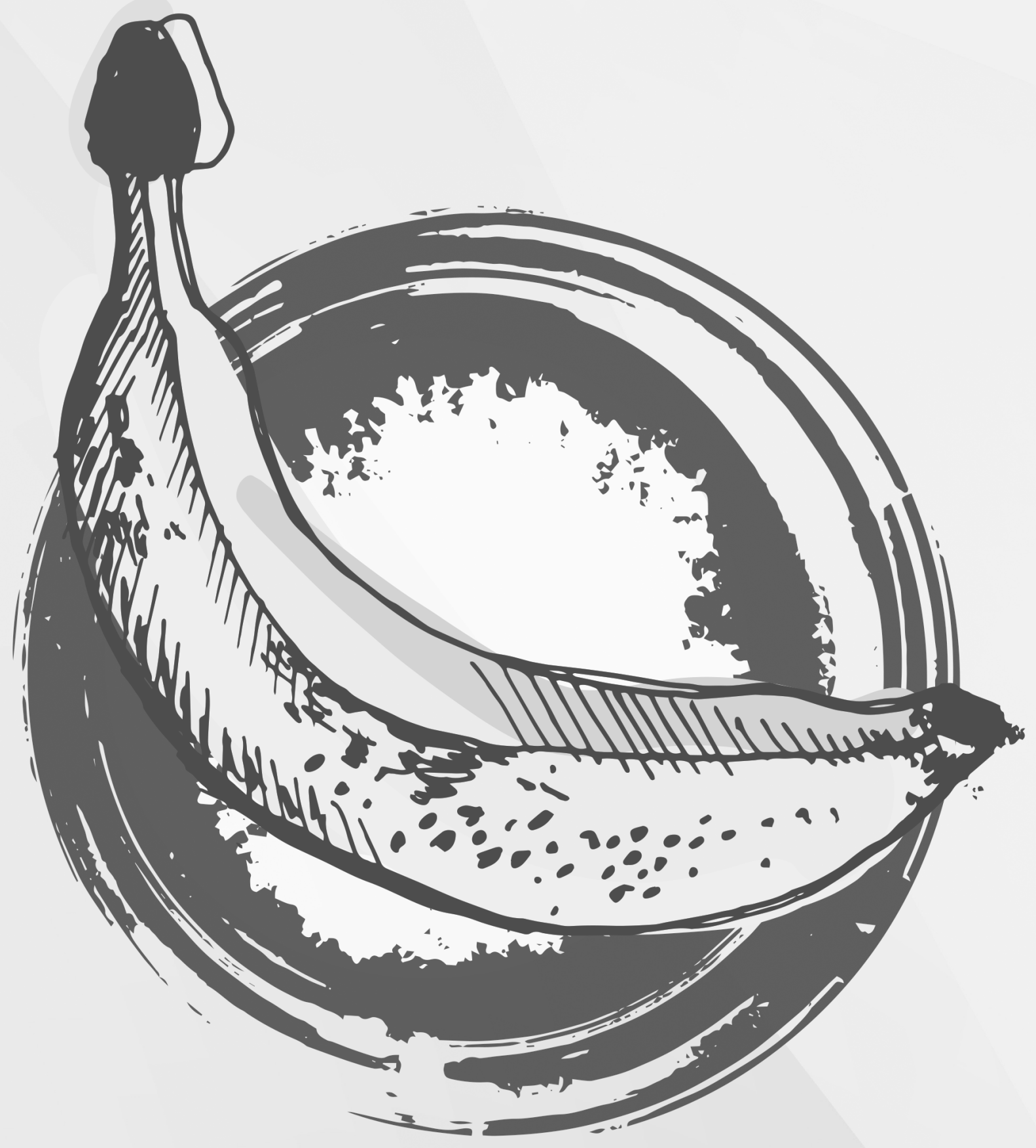




\section{CHAPTER 4}

The phylogeography of the banana Fusarium wilt pathogen Fusarium oxysporum f.sp. cubense

Ordóñez, N., Seidl, M.F., Dita, M., Chaves, N., Roman C., Drenth, A., Ploetz, R.C., Waalwijk, C., Papagiannaki, E., Islam, S., Pérez, L.V., Meijer, H.J.G., Kema, G.H.J. (Manuscript to be submitted).
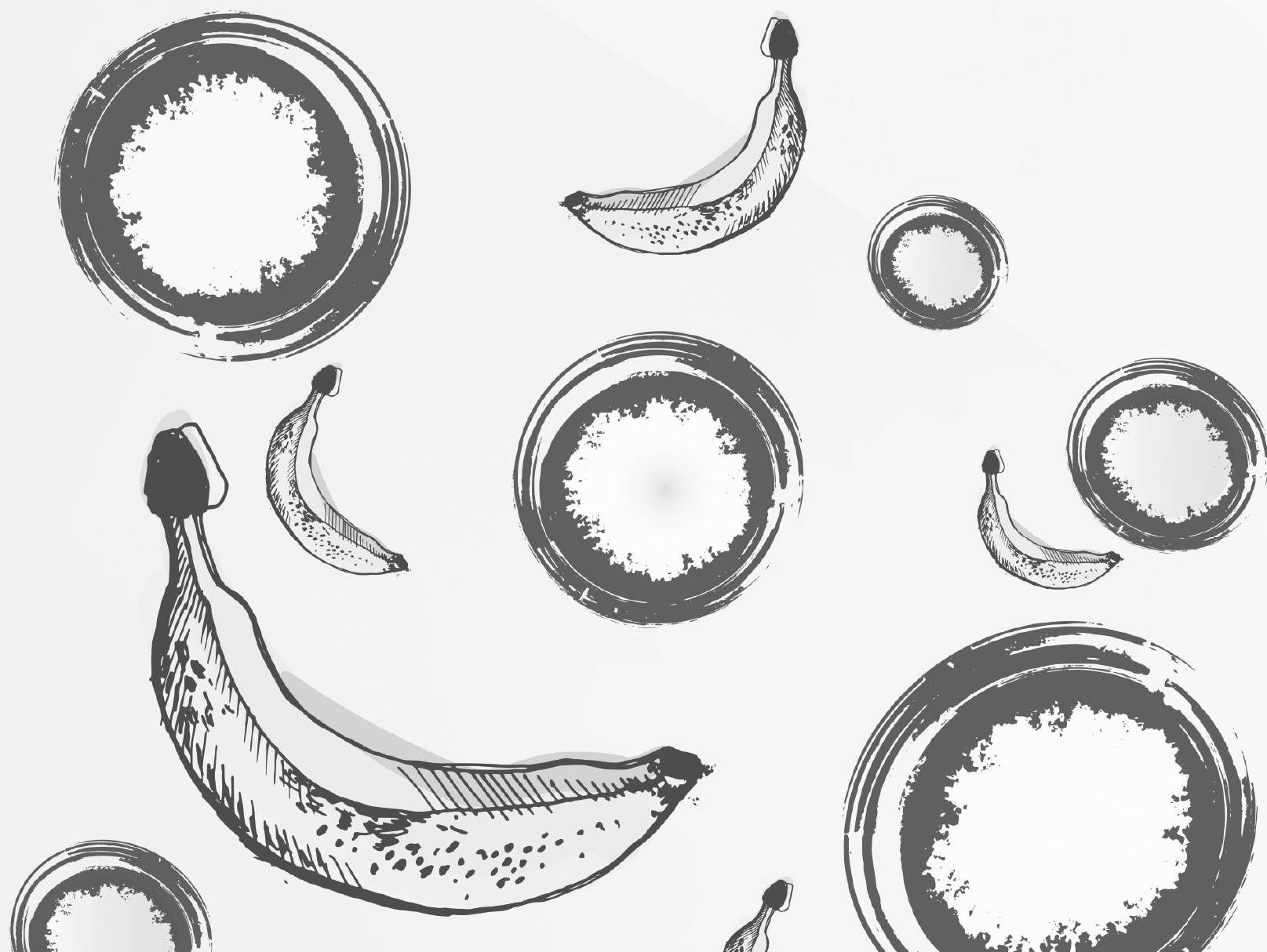


\section{ABSTRACT}

Fusarium wilt, caused by the soil-borne fungus Fusarium oxysporum f.sp. cubense (Foc), is one of the most damaging fungal diseases on bananas (Musa spp.). Foc comprises genetically diverse strains usually grouped into vegetative compatibility groups (VCGs). In this study, we explore the genetic diversity among Foc isolates collected from bananagrowing regions around the world by genotyping-by-sequencing using Diversity Array Technology sequencing (DArTseq). The collection includes 152 Foc isolates of known VCGs, 131 Foc isolates of unknown VCG, $13 F$. oxysporum isolates pathogenic on other host plants and a non-pathogenic $F$. oxysporum isolate. With the use of 25,282 DArTseq markers, genetic distance analyses group all isolates into three clades in the $F$. oxysporum species complex (FOSC), showing a robust genetic resolution of diversity among Foc isolates within VCGs. The 24 known VCGs were associated with either clade 1 or 2 . Importantly, here we also identify Foc isolates that associate with clade 3 and are evidence for the emergence of Foc strains outside the banana center of origin. DArTseq proves to be a practical approach to efficiently assign VCGs without the need for laborious VCG testing. We distinguish 20 new VCGs spread over the three clades mainly derived from recent sampling campaigns in Latin America. Our results provide a better understanding of the phylogeography of Foc with implications for other $F$. oxysporum strains in the FOSC, and highlight that currently unknown Foc isolates remain to be discovered.

\section{INTRODUCTION}

Fusarium oxysporum f.sp. cubense (Foc) is the causal agent of Panama disease, a fungal disease that is also known as Fusarium wilt, which causes severe losses in banana production (Ploetz et al., 2015). Bananas (Musa spp.) are an essential staple food for developing countries, particularly in Africa, and supply a substantial economic income for small and large producers. Bananas originated in the Indo-Malayan archipelago and were transported to Africa and America, during multiple events that occurred over millennia (D'Hont et al., 2012; Marin et al., 1998; Perrier et al., 2011; Simmonds \& Shepherd, 1955). Global dissemination of bananas was accompanied by the spread of its pests and pathogens (Marin et al., 1998). Fusarium wilt of banana was firstly recorded in Australia in 1876 (Smith, 1910). Nowadays, the disease affects nearly all banana plantations in the tropics and subtropics (Ploetz et al., 2015), except for areas close to the Mediterranean, Melanesia, Somalia and some islands in the South Pacific (Ploetz \& Pegg, 2000).

The soil-borne fungus Foc disseminates primarily through infected plant material, in addition to contaminated soil, tools and irrigation water (Ploetz, 2015). Foc initially enters through the roots and progresses into the rhizome and vascular tissue in susceptible Musa spp. The xylem eventually gets occluded by fungal biomass and tyloses, impeding water and nutrient transport, which leads to wilting of the leaves and finally, the plant collapses (Supplementary Fig. 1) (Di Pietro et al., 2001; Guo et al., 2015; C. Li et al., 2011). Once a banana plantation is infested, there are no strategies to successfully eradicate Foc, as resting structures of the fungus -so called chlamydospores- can survive in the soil for decades. Drastic losses in banana plantations may occur from an initially restricted number of infected 
plants since dead hosts contribute to increasing inoculum levels in the soil (Buddenhagen, 2009).

Notwithstanding its assumed asexuality, Foc comprises genetically diverse strains that belong to the Fusarium oxysporum species complex (FOSC) (Michielse \& Rep, 2009). Strains in the FOSC are morphologically indistinguishable, with cosmopolitan non-pathogenic and plant pathogenic strains that are grouped into formae speciales (ff.spp.) in regard to their capacity to cause disease on a specific host plant or related hosts (Baayen et al., 2000; Dean et al., 2012; Leslie \& Summerell, 2006). Based on phylogenetic studies, four main clades (1-4) are defined in the FOSC (Baayen et al., 2000; Laurence et al., 2014; O'Donnell et al., 1998a; O'Donnell et al., 2004) and Foc strains are consistently placed in clade 1 and 2 (Bentley, Pegg et al., 1998; Bogale et al., 2006; Fourie et al., 2009; Groenewald et al., 2006; Koenig et al., 1997). Notably, certain Foc strains are more closely related to other formae speciales than to each other (Baayen et al., 2000; Koenig et al., 1997; O'Donnell et al., 1998a), suggesting multiple independent evolutionary origins (O'Donnell et al., 1998a). Foc strains contain one of both mating type idiomorphs (MAT1-1 or MAT1-2) which are essential for mating in many other fungal species (Leslie \& Summerell, 2006), but a sexual cycle was never reported (Fourie et al., 2009; Fourie et al., 2011).

Initially, Foc strains were classified in terms of their pathogenicity towards a set of different banana cultivars into three different races, namely race 1,2 and 4. The latter is subdivided into subtropical race 4 (ST4) and tropical race 4 (TR4) based on their pathogenicity towards Cavendish banana cultivars under subtropical or in both tropical and subtropical conditions, respectively (Ploetz, 2015). Another approach to classify Foc isolates and other $F$. oxysporum strains is based on vegetative compatibility, also referred to as heterokaryon formation, a trait governed by the vic or het loci (Correll, 1991; Leslie, 1990; Leslie et al., 2007; Puhalla, 1985). When two fungal isolates share identical alleles at their vic locus, they can anastomose and fuse to form a stable heterokaryon, showing a dense mycelial growth between otherwise sparsely growing nitrate non-utilising (nit) mutants, which places them in the same vegetative compatibility group (VCG) (Leslie \& Summerell, 2006). Based on vegetative compatibility, Foc is subdivided into 24 VCGs named from VCG0120 through 0126 and from 0128 through 01224 . Since some isolates from different VCGs frequently form stable heterokaryons, some VCGs are combined into VCG complexes: 0120/15, 0124/5/8/20 and 01213/16 (Bentley et al., 1995; Katan, 1999; Katan \& Di Primo, 1999; Moore et al., 1993; Ploetz, 2006, 2015). Lately, the VCG01213/16 complex is considered as a single group (01213) composed of genetically similar isolates (Bentley et al., 1998). Interestingly, there is accumulating evidence on the presence of Foc isolates that are not compatible with known VCGs (Araújo et al., 2017; Bentley et al., 1998; Karangwa et al., 2018; Mostert et al., 2017). As vegetative compatibility does not provide in-depth insights into genetic relatedness (Fourie et al., 2011; Leslie \& Summerell, 2006), genetic variation among Foc VCGs and to other nonFoc strains remained unclear. Other disadvantages associated with vegetative compatibility are heterokaryon self-incompatibility that may occur in $1-2 \%$ of recovered field isolates (Leslie, 1990) and the demanding laboratory procedures to perform the test (Fourie et al., 2011). Lately, the use of molecular markers (such as microsatellites or Amplified Restriction Fragment Length Polymorphisms-AFLP) helped to circumvent these challenges by simplifying the VCG testing procedure as well as revealing the genetic variation within and 
among Foc VCGs and between Foc strains to other $F$. oxysporum strains in the FOSC (Bentley et al., 1998; Bogale et al., 2006; Fourie et al., 2009; Groenewald et al., 2006; Koenig et al., 1997; O'Donnell et al., 1998a). Thus, a molecular-based technology that rapidly facilitates VCG assignment and offers a high-resolution genotyping is desirable in order to accurately characterize not only Foc populations but any other $F$. oxysporum population. Genetic information combined with geographic distribution of Foc can elaborate on its phylogeography by revealing the origin and dissemination tracks of its genotypes (Avise et al., 1987; McDonald \& Linde, 2002; Summerell et al., 2010; Zheng et al., 2018).

In this study, we explore genotyping by sequencing on a global collection of 283 Foc isolates using thousands of in-silico markers generated with Diversity Array Technology sequencing (DArTseq) enabling a high resolution diversity analysis in the FOSC and across the constituent Foc VCGs. DArTseq targets thousands of genome-wide marker loci, thereby increasing genome coverage compared to other approaches such as RFLP, AFLP and microsatellites (Alves et al., 2014; Cruz et al., 2013; Jaccoud et al., 2001; Sharma et al., 2014; Maryani et al., 2018a). Also, we explored the capacity of DArTseq to assign VCGs to uncharacterized Foc isolates such as those from recent field samplings in Costa Rica and Peru, which are usually underrepresented in Foc collections. Lastly, we report a phylogeography of Foc that now extends into three clades and hence contributes to a better understanding of its diversity.

\section{MATERIALS AND METHODS}

\section{Fungal global collection}

We analysed a $F$. oxysporum collection that included Foc isolates recovered from Fusarium wilt symptomatic banana plants from all geographic regions where bananas are grown. All isolates (Supplementary Table 1, 2 and 3), grown from monosporic isolations, are stored in $15 \%$ DMSO in liquid nitrogen in the collection of Wageningen University \& Research, The Netherlands.

\section{DNA extraction and PCR reactions}

Fungal isolates were inoculated in $70 \mathrm{~mL}$ potato dextrose broth (PDB) (Difco ${ }^{\mathrm{TM}}$, USA) in $100 \mathrm{~mL}$ flasks and incubated by shaking at $125 \mathrm{rpm}$ and $25^{\circ} \mathrm{C}$ for $5-6$ days. The mycelium was harvested by filtering the inoculum through sterile cheesecloth and washed at least twice with sterile water. The harvested mycelium was freeze-dried in a $2 \mathrm{~mL}$ Eppendorf tube. DNA extraction consisted of adding $1 \mathrm{~mL}$ DNA extraction buffer (200 mM Tris- $\mathrm{HCl}$, pH 8; $250 \mathrm{mM} \mathrm{NaCl} ; 25 \mathrm{mM}$ EDTA, pH 8; 0.5\% SDS) to the lyophilized mycelium, followed by a vigorous vortex step and phenol-chloroform extraction (Sambrook et al., 1989). Isolated DNA was diluted in $0.1 \mathrm{X}$ TE buffer and stored at $-20^{\circ} \mathrm{C}$ until use. DNA concentrations were determined using a Quant-iT ${ }^{\mathrm{TM}}$ PicoGreen $^{\circledR}$ dsDNA Reagent and Kit (Life Technologies, USA), according to the manufacturer's instructions on a Tecan Infinite ${ }^{\circledR} 200$ PRO monochromator (Tecan, Männedorf, Switzerland) at $\lambda$ ex $485 \mathrm{~nm}$ and $\lambda \mathrm{em} 535 \mathrm{~nm}$. DNAs were adjusted to $50 \mathrm{ng} / \mu 1$ for DArTseq analyses at Diversity Arrays Technology Pty Ltd. (Canberra, Australia; http://www.triticarte.com.au/); and to $5 \mathrm{ng} / \mu \mathrm{l}$ for PCRs. Since data 
resulting from modern genotyping tools, such as DArTseq, contain thousands of markers, small biases can easily become strongly significant patterns (Meirmans, 2015). To avoid this, DNAs were randomized in 96-well plates along with biological (several independent mycelia cultures and DNA extractions) and technical replicates (several DNA extractions from the same harvested mycelium) for DArTseq analyses.

Three PCRs were performed using $10 \mathrm{ng}$ of total fungal DNA per $20 \mu \mathrm{l}$ PCR reaction. Firstly, F. oxysporum primers were used (Edel et al., 2000) to confirm the identity of the isolates, ruling out the presence of unrelated fungi especially among uncharacterized isolates. In addition, two mating type (MAT1-1 and MAT1-2) primer sets (Fourie et al., 2009) were used to further characterize the isolates. PCR conditions were set according to the above references, except for the annealing temperature of $F$. oxysporum primers that was adjusted to $62^{\circ} \mathrm{C}$ (van Brunschot, 2006). Aliquots $(10 \mu \mathrm{l})$ of each PCR reaction were analysed by $1.2 \%$ agarose gel electrophoresis to determine the amplicon size.

\section{Genotyping by sequencing analyses}

DArTseq is a high-throughput technology that effectively assesses genetic diversity by combining the reduction of genome complexity with in-silico hybridization and nextgeneration sequencing platforms (Cruz et al., 2013; Kilian, 2003). An initial DArTseq platform containing polymorphic markers for the entire $F$. oxysporum collection was analysed. DArTseq markers are scored as binary data (1/0), indicating the presence or absence of a marker in each sample (Jaccoud et al., 2001). A binary DArTseq marker matrix was used to calculate the Dice distance among unequivocally $1 / 0$ polymorphic markers and to construct a dendrogram by hierarchical average clustering using the dist, package (proxy) (Meyer \& Buchta, 2017) and the hclust functions in R (RCoreTeam, 2017). Similarly, a subset binary matrix containing markers that were always stated as $1 / 0$ among all isolates was used to calculate the Jaccard and Hamming distances among selected isolates in R, package (vegan) (Oksanen et al., 2017). The Dice, Jaccard and Hamming distances indicate the dissimilarity among individuals in a population (Chao et al., 2005; Dalirsefat et al., 2009; Weik, 2001). The Jaccard and Dice distances are equivalent, except that double weight is given to positive cooccurrences in the Dice distance (Dalirsefat et al., 2009). The Hamming distance calculates the number of positions at which the corresponding markers are different (mismatch) between selected individuals (Weik, 2001). Jaccard and Dice distance values range from 0 to 1 for which distances close to 0 represent individuals that share similar marker profiles and hence contain fewer mismatches among their markers, resulting in Hamming values close to 0 .

\section{Vegetative compatibility group testing}

Vegetative compatibility was assessed as described previously (Puhalla, 1985). Briefly, nit mutants from selected wild-type isolates were generated on minimal medium (MM) amended with $1.5-2 \% \mathrm{KClO}_{3}$, and incubated for $7-14$ days at $25^{\circ} \mathrm{C}$ in darkness. Subsequently, the nit mutants were identified as nit1, nit3 or NitM based on their ability to grow on four media containing different nitrogenous compounds as the sole nitrogen source (Leslie \& Summerell, 2006). Two VCG approaches were performed to check for compatibility. Firstly, one isolate from each VCG was tested for cross-compatibility among the 24 VCGs. Secondly, VCG testing was performed to corroborate DArTseq VCG 
designation for 31 isolates. In all pairing tests, at least two nit1 and/or nit3 mutants of a selected isolate were paired on MM with all 24 NitM VCG testers in the first approach and for the DArTseq-based NitM VCG testers in the second approach. Positive compatibility events were visually recorded as dense mycelium growth among tested nit mutants.

\section{RESULTS}

\section{Genetic diversity of Fusarium oxysporum f.sp. cubense within the FOSC}

With 24 known VCGs, Foc is one of the most diverse plant pathogens in the FOSC and is prevalent in nearly all banana-growing areas worldwide. To provide a global overview of Foc diversity and distribution, we analysed a collection of 296 F. oxysporum isolates, including 152 Foc isolates with known VCGs (Supplementary Table 1), 131 Foc isolates with unknown VCGs (Supplementary Table 2), 13 F. oxysporum isolates pathogenic to non-banana host and a non-pathogenic F. oxysporum isolate (Supplementary Table 3). The Foc isolates included all 24 VCGs, with 14 VCGs represented by more than one isolate, and covered all tropical and subtropical regions where bananas are cultivated for domestic and/or international markets. The Foc isolates of unknown VCG were mostly collected from Fusarium wilt symptomatic banana plants in Costa Rica (N. Chaves, personal communication) and Peru (Roman, 2012). By performing PCR with F. oxysporum diagnostic primers (Edel et al., 2000), we confirmed that all isolates could be identified as $F$. oxysporum. This is particularly relevant for isolates recently sampled and of yet unknown VCGs, since multiple Fusarium spp. can be recovered from banana tissue (Karangwa et al., 2018; Zeng et al., 2013; Maryani et al., 2018a).

To determine to which clades of the FOSC our 296 F. oxysporum isolates belong and to explore the extent of the genetic variation in our global collection, we performed DArTseq, yielding 25,282 polymorphic markers for all isolates. First, we calculated genetic distances of the technical and biological replicates of 39 randomly selected isolates. The average Jaccard and Hamming distances of a total of 108 replicates were 0.02 and 3.5, respectively, hence considered negligible (Supplementary Table 4). Thus, low Jaccard and Hamming distances from either technical or biological replicates validated DArTseq as a robust, reliable and reproducible approach to detect polymorphic markers present in any given Foc population. Next, we performed hierarchical cluster analyses using Dice as a distances measure based on all markers. Our fungal isolates grouped into three major clades (clade 1,2 and 3) that were established using isolates that are consistently grouped within each of these clades in the FOSC (Fig. 1 and Supplementary Fig. 2) (Baayen et al., 2000; Fourie et al., 2009; Laurence et al., 2012; Laurence et al., 2014; O'Donnell et al., 1998a; O'Donnell et al., 2004). Distribution of Foc VCGs between clades 1 and 2 was the same as previously reported (Ordóñez et al., 2015), except for VCG0123 that is now placed in clade 2. In our collection, three other VCG0123 isolates (F9129, NRRL26022 and Mal5) assisted in the placement of VCG0123 in clade 2. The NRR36101 isolate previously reported as VCG0123 (Dita et al., 2010; Ordóñez et al., 2015) was instead confirmed to belong to VCG0120 based on their similar DArTseq marker profile (Fig. 1 and Supplementary Fig. 2) and vegetative compatibility to VCG0120/15 isolates (Supplementary Table 1). Interestingly, we showed evidence that Foc 
isolates also cluster in clade 3 . These corresponded to 23 isolates pathogenic on banana cultivars under field conditions, including isolate Foc_R1 under greenhouse conditions (García-Bastidas et al., 2018; Maryani et al., 2018b). In addition, a microscopic characterization of selected clade 3 isolates (BPI09.05, Foc_R1, Foc8, Foc16, Mal1.5b, P20a, P26, P65, P93 and Phi6.6a) showed that these produce chlamydospores and sporodochia under in-vitro conditions, typical morphological features for $F$. oxysporum strains (Supplementary Fig. 3). Although microscopic characterization of F. oxysporum isolates is taxonomically not very relevant as they are morphologically largely indistinguishable, this approach is still routinely used as an in-vitro characterization (Leslie \& Summerell, 2006). Lastly, the $F$. oxysporum isolates pathogenic to non-banana hosts and the non-pathogenic $F$. oxysporum isolate grouped closely with Foc isolates in all three clades (Fig. 1 and Supplementary Fig. 2). In summary, our collection is one of the largest Foc panels studied comprising a global collection, which is divided in groups that are placed in clade 1, 2 and 3 of the FOSC.

To determine the extent of genetic variation provided by DArTseq among and within reported Foc VCGs, we calculated genetic distances in a subset of 7,740 markers that were always stated as 1/0 in all isolates. Firstly, we performed VCG tests among Foc isolates representing each of the 24 VCGs to check for cross-compatibility. Previous Foc studies indicated that cross-compatibility only occurred between genetically similar isolates, typically among isolates in the VCG0120/15 and 0124/5/8/20 complexes (Baayen et al., 2000; Bentley et al., 1998; Bogale et al., 2006; Fourie et al., 2009; Groenewald et al., 2006; Koenig et al., 1997; O'Donnell et al., 1998a). In our study, we did not only corroborate cross-compatibility for isolates in the VCG0120/15 and 0124/5/8/20 complexes, but additionally detected crosscompatibility of VCG01211 (NRRL36109) and 01222 (NRRL36117) to isolates from the VCG0120/15 and 0124/5/8/20 complexes, respectively (Table 1). Recent studies also confirm cross-compatibility between VCG01222 and the 0124/5/8/20 complex (Karangwa et al., 2018; Mostert et al., 2017). In our study, no other Foc VCGs showed cross-compatibility, thus these remain as unique VCG entities. All tested Foc isolates that were cross-compatible grouped closely with isolates of their corresponding VCG complex (Fig. 1 and Supplementary Fig. 2). As a consequence, we included VCG01211 and 01222 to their corresponding VCG complexes as VCG0120/11*/15 and 0124/5/8/20/22* complexes. Genetic analyses on the 24 VCGs from our collection demonstrated that vegetative incompatible/unique VCGs exhibit high genetic distances among them, with total Jaccard/Hamming distances of 0.90/320.6 (Supplementary Table 5 and 6). On the other hand, genetic distances among isolates within cross-compatible and unique VCG were always low. Foc isolates within the cross-compatible VCG0120/11*/15 and 0124/5/8/20/22* complexes showed average Jaccard/Hamming distances of 0.18/6.4 and $0.32 / 27.2$, respectively. For the here reported cross-compatibility between VCG01211 and 01222 to isolates from the VCG0120/15 and 0124/5/8/20 complexes, we also observed low genetic distance values. The Jaccard distance between the cross-compatible NRRL36109 (VCG01211) and VCG0120 (ST4) isolates was 0.23 resulting from a difference of only nine markers. Likewise, the NRRL36117 isolate (VCG01222), which is cross-compatible with the NRRL36105 (VCG0124) and NRRL36106 (VCG0125) isolates, is closely related to these two VCGs, with average Jaccard/Hamming distances of 0.28/22.5 (Supplementary Table 5 and 6). These findings further support our proposal to include these VCGs to former VCGs 
complexes. Foc isolates in unique VCGs that were not cross-compatible with other VCGs showed low genetic distances with average Jaccard/Hamming distances of 0.13/20.1. Unfortunately, we only had single isolates of VCGs 0122, 01211, 01218, 01221, 01222, 01223 and 01224 , hence could not be analysed. Isolates within each of the cross-compatible and unique VCGs contained either the MAT1-1 or MAT1-2 idiomorphs (Table 2 and Supplementary Fig. 4), which supports the low genetic dissimilarity based on DArTseq markers. In summary, Foc isolates are genetically closely related within unique VCGs and VCG complexes. Conversely, genetic distances among vegetatively incompatible isolates and unique VCGs were always higher than those recorded within VCGs.

Table 1. Vegetative compatibility group (VCG) testing among the 24 reported VCGs for Fusarium oxysporum f.sp. cubense (Foc). The selected isolates for VCG testing were Foc19508 (0120), NRRL36102 (0121), NRRL36103 (0122), F9129 (0123), NRRL36105 (0124), NRRL36106 (0125), NRRL36107 (0126), NRRL36111 (0128), N5443 (VCG0129), Focu7 (01210), NRRL36109 (01211), NRRL36108 (01212), II5 (01213), NRRL36113 (01214), NRRL36112 (01215), Mal43 (01217), NRRL36120 (01218), Indo25 (01219), 24218 (01220), NRRL36118 (01221), NRRL36117 (01222), NRRL36116 (01223) and NRRL36115 (01224). Positive heterokaryon formation is indicated as “+”. Negative interactions are indicated as “-”. All selected isolates were self-compatible.

\begin{tabular}{|c|c|c|c|c|c|c|c|c|c|c|c|c|c|c|c|c|c|c|c|c|c|c|c|}
\hline VCG & 0 & 1 & 2 & 3 & 4 & 5 & 6 & 8 & 9 & 10 & 11 & 12 & 13 & 14 & 15 & 17 & 18 & 19 & 20 & 21 & 22 & 23 & 24 \\
\hline 0 & + & & & & & & & & & & & & & & & & & & & & & & \\
\hline 1 & - & + & & & & & & & & & & & & & & & & & & & & & \\
\hline 2 & - & - & + & & & & & & & & & & & & & & & & & & & & \\
\hline 3 & - & - & - & + & & & & & & & & & & & & & & & & & & & \\
\hline 4 & - & - & - & - & + & & & & & & & & & & & & & & & & & & \\
\hline 5 & - & - & - & - & + & + & & & & & & & & & & & & & & & & & \\
\hline 6 & - & - & - & - & - & - & + & & & & & & & & & & & & & & & & \\
\hline 8 & - & - & - & - & - & - & - & + & & & & & & & & & & & & & & & \\
\hline 9 & - & - & - & - & - & - & - & - & + & & & & & & & & & & & & & & \\
\hline 10 & - & - & - & - & - & - & - & - & - & + & & & & & & & & & & & & & \\
\hline 11 & + & - & - & - & - & - & - & - & - & - & + & & & & & & & & & & & & \\
\hline 12 & - & - & - & - & - & - & - & - & - & - & - & + & & & & & & & & & & & \\
\hline 13 & - & - & - & - & - & - & - & - & - & - & - & - & + & & & & & & & & & & \\
\hline 14 & - & - & - & - & - & - & - & - & - & - & - & - & - & + & & & & & & & & & \\
\hline 15 & + & - & - & - & - & - & - & - & - & - & - & - & - & - & + & & & & & & & & \\
\hline 17 & - & - & - & - & - & - & - & - & - & - & - & - & - & - & - & + & & & & & & & \\
\hline 18 & - & - & - & - & - & - & - & - & - & - & - & - & - & - & - & - & + & & & & & & \\
\hline 19 & - & - & - & - & - & - & - & - & - & - & - & - & - & - & - & - & - & + & & & & & \\
\hline 20 & - & - & - & - & - & - & - & + & - & - & - & - & - & - & - & - & - & - & + & & & & \\
\hline 21 & - & - & - & - & - & - & - & - & - & - & - & - & - & - & - & - & - & - & - & + & & & \\
\hline 22 & - & - & - & - & + & + & - & - & - & - & - & - & - & - & - & - & - & - & - & - & + & & \\
\hline 23 & - & - & - & - & - & - & - & - & - & - & - & - & - & - & - & - & - & - & - & - & - & + & \\
\hline 24 & - & - & - & - & - & - & - & - & - & - & - & - & - & - & - & - & - & - & - & - & - & - & + \\
\hline
\end{tabular}




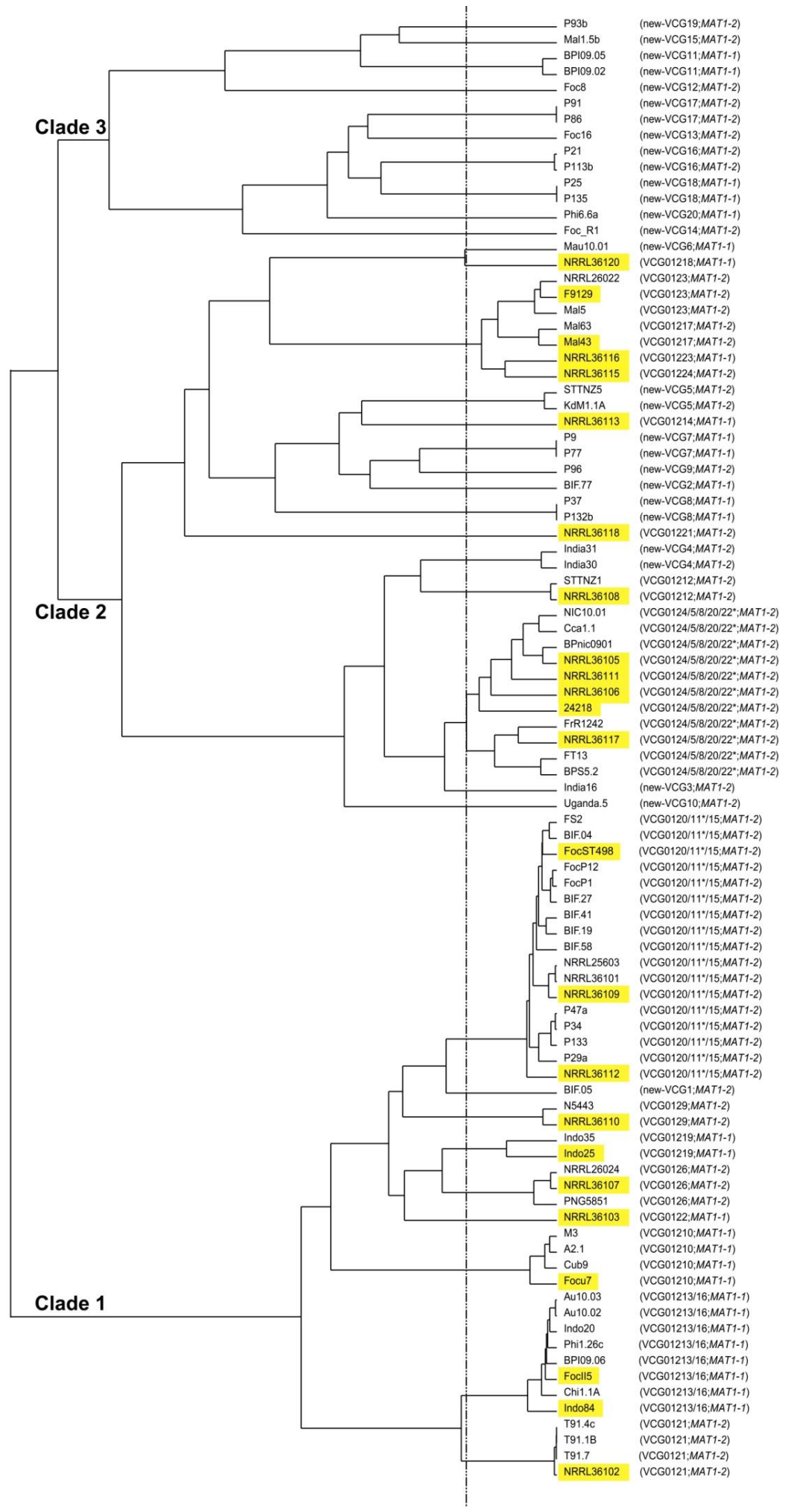


Figure 1. Hierarchical clustering of 92 selected Fusarium oxysporum f.sp. cubense (Foc) isolates from the total collection comprising 296 isolates, which represent all previously reported 24 vegetative compatibility groups (representative VCGs highlighted) and 20 new-VCGs based on 25,282 markers derived from the genotyping by sequencing DArTseq. An extra Foc isolate was added for every VCG that was represented by more than one isolate and for isolates that were VCG tested. The dotted line indicates the threshold of successful heterokaryon formation between isolates.

\section{DArTseq based VCG assignment as an alternative for VCG testing}

The low genetic variation among isolates within VCG complexes may explain their cross-compatibility. Therefore, we tested the capacity of DArTseq to assign VCGs to Foc isolates by combining the analysis of genetic distances with VCG tests. Remarkably, only genetically closely related isolates with Jaccard and Hamming distances $<0.45$ and $<39$, respectively, were cross-compatible. The combined data of genetic distances and VCG tests allowed us to establish a threshold to assign VCGs to each of the isolates in our collection (Fig. 1 and Supplementary Fig. 2, dotted line). For isolates below this threshold and that met the above genetic distance criteria, we always successfully corroborated and efficiently assigned VCGs. Foc isolates previously characterized into a defined VCG consistently clustered with isolates of the same VCG. Nevertheless, nine isolates did not group together with the VCG assigned by our sample providers. In these cases, we suspected missassignments of their VCGs and subsequently corrected them by performing VCG tests, ultimately designating the correct VCG (Supplementary Table 1 and 2). Following the same approach, we assigned VCGs to the uncharacterized Foc isolates that grouped closely to known VCGs below the established threshold, and performed VCG tests for a subset of 31 isolates (Supplementary Fig. 5). With no exception, the VCG tested isolates were compatible with the DArTseq assigned VCGs. Similarly, we identified uncharacterized Foc isolates along clades 1, 2 and 3 that were distinct from any of the 24 known VCGs and tentatively named them as new-VCG1 to new-VCG20 (Table 3). Eight of the novel VCGs contained more than one isolate and corresponded to isolates recovered from diverse banana cultivars and farms mostly from Peru. It should be noted that fungal isolates above the established threshold were consistently not cross-compatible, showing that genetically distant Foc isolates above this threshold are related to different VCGs. In summary, we showed that the use of DArTseq markers is a reliable method to efficiently assign VCGs to uncharacterized Foc isolates and to corroborate or correct VCG assignments to characterized Foc isolates. 
Table 2. Average Jaccard and Hamming genetic distances within cross-compatible and unique vegetative compatibility groups (VCG) and their corresponding mating types. Isolates belonging to VCG01211, 01216 and 01222 were added to their corresponding cross-compatible complexes "*". The VCGs 0122, 01214, 01218, 01221, 01223 and 01224 were not analysed ("n.a.") as each consisted of single isolates.

\begin{tabular}{lllll}
\hline VCG & No. isolates & Jaccard & Hamming & $\begin{array}{l}\text { Mating } \\
\text { type }\end{array}$ \\
\hline $0120 / 11^{*} / 15$ & 77 & 0.18 & 6.4 & MAT1-2 \\
0121 & 7 & 0.03 & 3.14 & MAT1-2 \\
0122 & 1 & n.a. & n.a. & MAT1-1 \\
0123 & 3 & 0.12 & 39.3 & MAT1-2 \\
$0124 / 5 / 8 / 20 / 22^{*}$ & 72 & 0.32 & 27.2 & MAT1-2 \\
0126 & 8 & 0.32 & 44.2 & MAT1-2 \\
0129 & 5 & 0.13 & 14.6 & MAT1-2 \\
01210 & 4 & 0.09 & 13.0 & MAT1-1 \\
01212 & 2 & 0.05 & 6.0 & $M A T 1-2$ \\
$01213 / 16^{*}$ & 38 & 0.08 & 13.9 & MAT1-1 \\
01214 & 1 & n.a. & n.a. & MAT1-1 \\
01217 & 2 & 0.13 & 37.5 & $M A T 1-2$ \\
01218 & 1 & n.a. & n.a & MAT1-1 \\
01219 & 3 & 0.19 & 9.7 & MAT1-1 \\
01221 & 1 & n.a. & n.a. & MAT1-2 \\
01223 & 1 & n.a. & n.a. & MAT1-1 \\
01224 & 1 & n.a. & n.a. & MAT1-2 \\
\hline
\end{tabular}

Table 3. Fusarium oxysporum f.sp. cubense (Foc) isolates as of yet unknown vegetative compatibility groups (VCG) identified in our collection, and their corresponding mating types.

\begin{tabular}{|c|c|c|c|c|c|c|}
\hline new-VCG & Clade & Isolate code & Country & No. isolates & VCG testing & Mating type \\
\hline VCG1 & 1 & BIF.05 & Costa Rica & 1 & $\begin{array}{l}\text { No heterokaryon formation with } \\
\text { VCG0120,0120/15 and } 0129 \mathrm{NitM}\end{array}$ & MAT1-2 \\
\hline VCG2 & 2 & BIF.77 & Costa Rica & 1 & $\begin{array}{l}\text { No heterokaryon formation with } \\
\text { VCG01214 and STTNZ5 NitM }\end{array}$ & MAT1-1 \\
\hline VCG3 & 2 & India16 & India & 1 & n.d. & $M A T 1-2$ \\
\hline VCG4 & 2 & India30, India31 & India & 2 & n.d. & $M A T 1-2$ \\
\hline VCG5 & 2 & $\begin{array}{l}\text { KdM1.1A, KdM1.2A, } \\
\text { KdM1.3A, STTNZ5 }\end{array}$ & $\begin{array}{l}\text { Kenya, } \\
\text { Tanzania }\end{array}$ & 4 & $\begin{array}{l}\text { No heterokaryon formation with } \\
\text { VCG01212 and } 01214 \text { NitM }^{2} \\
\text { Heterokaryon formation between } \\
\text { KdM1,1A and STTNZ5 }\end{array}$ & $M A T 1-2$ \\
\hline VCG6 & 2 & Mau10.01 & Mauritius & 1 & $\begin{array}{l}\text { No heterokaryon formation with } \\
\text { VCG01218 NitM }\end{array}$ & MAT1-1 \\
\hline VCG7 & 2 & $\begin{array}{l}\text { P9, P14, P17, P18, P22, } \\
\text { P24a }{ }^{1}, \text { P49, P50, P61, } \\
\text { P77, P80b2, P84, P99 }\end{array}$ & Peru & 13 & n.d. & MAT1-1 \\
\hline VCG8 & 2 & $\begin{array}{l}\text { P20d, P37, P41 }{ }^{1}, \text { P } 54, \\
\text { P104, P113c, P132b }\end{array}$ & Peru & 7 & n.d. & MATI-1 \\
\hline VCG9 & 2 & P96 & Peru & 1 & n.d. & $M A T 1-2$ \\
\hline VCG10 & 2 & Uganda.5 & Uganda & 1 & n.d. & $M A T 1-2$ \\
\hline VCG11 & 3 & $\begin{array}{l}\text { BPI09.02, BPI09.04, } \\
\text { BPI09.05 }\end{array}$ & Indonesia & 3 & n.d. & MAT1-1 \\
\hline VCG12 & 3 & Foc $8^{1}$ & Nicaragua & 1 & n.d. & $M A T 1-2$ \\
\hline VCG13 & 3 & Foc $16^{1}$ & Nicaragua & 1 & n.d. & $M A T 1-2$ \\
\hline VCG14 & 3 & Foc_R $1^{1}$ & Brazil & 1 & $\begin{array}{l}\text { No heterokaryon formation with all } 24 \\
\text { VCGs NitM }\end{array}$ & $M A T 1-2$ \\
\hline
\end{tabular}




\begin{tabular}{|c|c|c|c|c|c|c|}
\hline new-VCG & Clade & Isolate code & Country & No. isolates & VCG testing & Mating type \\
\hline VCG15 & 3 & Mall. $^{1} \mathrm{~b}^{1}$ & Malawi & 1 & n.d. & $M A T 1-2$ \\
\hline VCG16 & 3 & $\begin{array}{l}\mathrm{P} 2 \mathrm{~d}, \mathrm{P} 20 \mathrm{a}^{1}, \mathrm{P} 21, \mathrm{P} 29 \mathrm{~b} \\
\mathrm{P} 113 \mathrm{~b}\end{array}$ & Peru & 5 & $\begin{array}{l}\text { No heterokaryon formation with all } 24 \\
\text { VCGs NitM }^{2}\end{array}$ & $M A T 1-2$ \\
\hline VCG17 & 3 & $\begin{array}{l}\text { P6, P15, P26 } 6^{1}, \mathrm{P} 55, \mathrm{P} 86, \\
\mathrm{P} 91, \mathrm{P} 132 \mathrm{~d}\end{array}$ & Peru & 7 & $\begin{array}{l}\text { No heterokaryon formation with all } 24 \\
\text { VCGs NitM }^{2}\end{array}$ & $M A T 1-2$ \\
\hline VCG18 & 3 & $\mathrm{P} 25, \mathrm{P} 65^{1}, \mathrm{P} 135$ & Peru & 3 & n.d. & MAT1-1 \\
\hline VCG19 & 3 & $\mathrm{P} 3^{1}$ & Peru & 1 & n.d. & $M A T 1-2$ \\
\hline VCG20 & 3 & Phi6.6a ${ }^{1}$ & Philippines & 1 & n.d. & MATI-1 \\
\hline
\end{tabular}

${ }^{1}$ These isolates were tested for production of sporodochia and chlamydospores. All isolates produced these morphological structures in cultural conditions, except for isolate Phi6.6a that did not produce chlamydospores. ${ }^{2}$ VCG testing performed only for KdM1.1A, STTNZ5, P20a and P26 against mentioned NitM testers. n.d. stands for "not determined".

\section{Phylogeography of Fusarium oxysporum f.sp. cubense vegetative compatibility groups}

Given that movement of bananas following human historical migration is believed to be the main driver that influenced the actual geographic distribution of Foc isolates (Ghag et al., 2015; Ploetz, 2015), we summarized circumstantial evidence of the dispersal of bananas to discuss the Foc VCG distribution in our global collection (Fig. 2A). The center of origin of modern edible bananas that were derived from two wild seedy species Musa acuminata and M. balbisiana extended from India to Papua New Guinea, including Indonesia and southern China (Marin et al., 1998; Perrier et al., 2011; Robinson \& Sauco, 2010; Simmonds \& Shepherd, 1955). The banana center of origin contained the highest number of VCGs compared to other banana-growing regions in our study (Fig. 2B and Supplementary Table 7), in concordance with previous reports (Bentley et al., 1998; Blomme et al., 2013; Boehm et al., 1994; Bogale et al., 2006; Fourie et al., 2009; Groenewald et al., 2006; Karangwa et al., 2018; Koenig et al., 1997; Ploetz, 2015). In our study, the VCG diversity associated with the banana center of origin corresponded to all reported VCGs from clade 1 and 2 except for VCGs 0129, 01210, 01211, 01212 and 01214. For this region, four novel VCGs from clade 2 (new-VCG3 and new-VCG4) and 3 (new-VCG11 and new-VCG20) were also recorded. It is estimated that bananas farms in Oceania were commonplace as early as 2,500 years BCE, following human migration from Southeast Asia (Nayar, 2010). Oceania, the nearest region to the banana center of origin, registered the second largest number of reported VCGs, including five VCGs from clade 1 and one VCG complex from clade 2. Although novel VCGs or Foc isolates from clade 3 were not found in Oceania, VCG0129 and 01211 from clade 1 were recorded only in Australia. As bananas were later moved to Africa and America probably between 200 years BCE and 500 years CE or in the case of America in the 1500s through the Caribbean islands as well (Marin et al., 1998; Nayar, 2010; Perrier et al., 2011; Robinson \& Sauco, 2010; Simmonds \& Shepherd, 1955), diversity of Foc VCGs in both continental regions was limited to VCG0120/15 and 0124/5/8 complexes in our study, these VCGs were ubiquitous to banana-growing regions worldwide. Nearly $50 \%$ of our uncharacterized Foc isolates from Latin America corresponded to the VCG0120/15 complex, including the first report of these isolates in Peru. VCG01212 and 01214 in Africa and VCG01210 in America were endemic to these regions. Additionally, we reported three novel VCGs from clade 2 (new-VCG5 and new-VCG6) and clade 3 (new-VCG15) in Africa and 12 new-VCGs from 
clade 1 (new-VCG1), clade 2 (new-VCG2 and new-VCG7-9) and largely from clade 3 (newVCG12-14 and new-VCG16-19) in America. Following the movement of bananas around the globe, isolates from the VCG0124/5/8 complex that is widely spread across all banana-growing areas trail their host dispersal (Fig. 2C). In our collection, isolation of Foc isolates from this VCG complex dated from the early 1990s in Asia and Oceania to the 2010s in Latin America. Other VCGs showed a more restricted dispersal from the banana center of origin such as for VCG01213, also referred as TR4 (Fig. 2C). In this study and recent reports (Chittarath et al., 2017; García-Bastidas et al., 2014; Hung et al., 2017; Mostert et al., 2017; Ordóñez et al., 2016; Ordóñez et al., 2015; Vézina, 2018; Zheng et al., 2018), VCG01213 is present in Asia (Southeast Asia and Middle East), Oceania (Australia) and Africa (Mozambique). In our collection, VCG01213 isolates that are reported outside South Asia were isolated from 2014 onwards, following the first report of this strain in Jordan (GarcíaBastidas et al., 2014). We evaluated the genetic distances of VCGs at country and continental levels and considered also the time of sampling to evaluate genetic variation of Foc in a context of varying spatial and temporal scales. This may show evidence of Foc VCG dispersal that follows the movement of bananas at a global scale. However, Foc isolates grouped together within VCGs regardless of their geographic origin and time of sampling (Supplementary Fig. 2). For instance, the 22615 (country: Australia; host: Cavendish) and CR1.1A (country: Costa Rica; host: 'Gros Michel') isolates in the VCG0120/15 complex collected at distant geographic regions, were sampled 22 years apart and isolated from different banana cultivars but showed low Jaccard/Hamming distances (0.35/12). Only VCG0126 isolates from clade 1 showed a geographical distinction at the continental scale since they clustered into three separate subgroups: America, Asia and Oceania. The average Jaccard/Hamming distances among VCG0126 isolates within their continental subgroups $(0.04 / 4.2)$ were lower than their overall distances (0.32/44.0). Moreover, average Jaccard/Hamming distances between VCG0126 isolates of Australian and American populations were lower $(0.26 / 23.3)$ compared to distances between both populations to the Asian population (0.54/83.5). In general, we did not find evidence of a distinctive genetic clustering of the Foc isolates in our global collection within the context of geographic origin and time of sampling. Lastly, the geographic distribution of mating types revealed that these were scattered along the three clades and present in all surveyed continents. The presence of both mating types was confirmed in $36 \%$ of surveyed countries, mainly in Asia and America; while only MAT1-2 and MAT1-1 isolates were reported from 50\% and 14\%, respectively, of the evaluated banana producing countries (Supplementary Table 7). In summary, Foc isolates from all three clades were present in all banana-growing areas in the globe, except for clade 3 in Oceania, with Southeast Asia containing the largest number of reported Foc VCGs. 


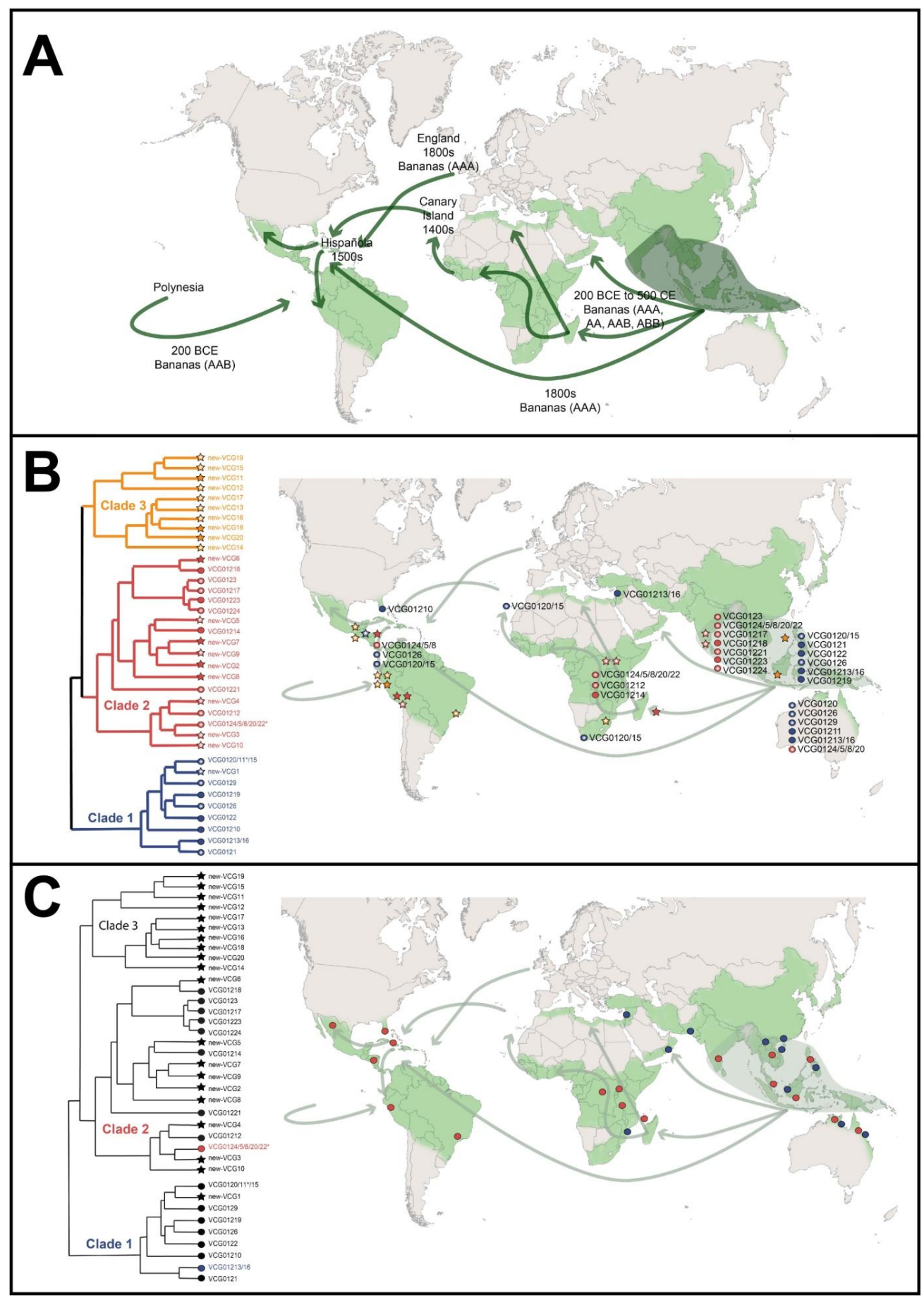


Figure 2. Phylogeography of the banana wilt pathogen Fusarium oxysporum f.sp. cubense (Foc). (A) Dissemination of bananas from their center of origin at the Indo-Malayan archipelago to the rest of the world (Marin et al., 1998; Nayar, 2010; Perrier et al., 2011; Robinson \& Sauco, 2010; Simmonds \& Shepherd, 1955). The large green area at the banana center of origin covers ancient distribution of the wild banana species Musa acuminata and M. balbisiana from which modern banana cultivars originated (Perrier et al., 2011). (B) Geographical distribution of all 24 reported vegetative compatibility groups (VCGs) and novel VCGs from all three clades in the FOSC. Reported Foc VCGs and new-VCGs are indicated with circles and stars symbols, respectively. Filled and un-filled symbols indicate the presence of MAT1-1 and MAT1-2 idiomorphs, respectively. (C) Detailed geographical distribution at the country level of isolates from the VCG0124/5/8 complex and VCG01213 based on our Foc collection and recent reports (Chittarath et al., 2017; García-Bastidas et al., 2014; Hung et al., 2017; Mostert et al., 2017; Ordóñez et al., 2016; Ordóñez et al., 2015; Vézina, 2018; Zheng et al., 2018).

\section{DISCUSSION}

Although phylogenetic studies in fungi can contribute to disease control, quarantine, free-trade and conservation (Kohn, 2005), fungi represent only $1.8 \%$ of all conducted studies in this field (Beheregaray, 2008). In the Fusarium genus, phylogeographic studies in the Gibberella fujikuroi species complex concluded that their three reported clades originated from three distinct continental regions generally associated with the center of origin of their hosts (O'Donnell et al., 1998b). The soil-borne fungus Foc that belongs to the FOSC and causes Fusarium wilt on bananas, contains a suite of genetically diverse strains with few cosmopolitan genotypes widely distributed across banana plantations as well as some endemic genotypes. Here, we investigated genetic variation among Foc isolates using thousands of insilico DArTseq markers, allowing meticulous genetic distance analyses of geographically diverse strains from a global collection. DArTseq technology generates thousands of markers that are distributed along the genome (Alves et al., 2014; Cruz et al., 2013; Jaccoud et al., 2001; Maryani et al., 2018a) and a former approach of DArTseq (DArT array) was applied to assess genetic diversity of $F$. oxysporum strains (f.sp. ciceris) pathogenic to chickpea (Sharma et al., 2014). In concordance with Foc genetic studies using other molecular markers e.g. microsatellites and AFLP (Baayen et al., 2000; Bentley et al., 1998; Bogale et al., 2006; Fourie et al., 2009; Groenewald et al., 2006; Koenig et al., 1997; O'Donnell et al., 1998a), DArTseq accurately resolved the topology of previously resolved clades of the FOSC, distinctively grouped the 24 known VCGs to either clade 1 or 2, determined lower genetic distances within cross-compatible and unique VCGs compared to differences among VCGs and grouped some Foc strains closer to $F$. oxysporum strains with different host specificity. However, DArTseq resolved a higher-resolution of genetic variation among Foc isolates within cross-compatible and unique VCGs compared to other molecular markers in previous studies (Bentley et al., 1998; Bogale et al., 2006; Fourie et al., 2009; Groenewald et al., 2006; Koenig et al., 1997). For instance, Jaccard similarities within cross-compatible and unique VCGs ranged from 0.68 to 0.97 using DArTseq markers (1-Jaccard distance) in this study and from 0.96 to 1.0 using DNA amplification fingerprinting (Bentley et al., 1998). Similarly, a higher-resolution of genetic variation using DArT array compared to microsatellite markers was estimated among other F. oxysporum strains (Sharma et al., 2014). Higher-resolution of genetic diversity contributes to earlier detection of genetic changes in pathogen populations and elaborates on their evolutionary potential (Agrios, 2005; Boddy, 2016; Boyd et al., 2013; 
Gurr et al., 2011; McDonald \& Linde, 2002; Scholthof, 2007). In addition, also efficiently corroborated and assigned VCGs to Foc isolates in our study. Since mutations at the vic locus governing vegetative compatibility could lead to isolates within the same VCG to become incompatible (Bentley et al., 1998), molecular-based methods are preferred to determine VCGs in Foc populations. In our study, classical VCG analyses consistently aligned with DArTseq-based VCG assignments, demonstrating that the latter can replace laborious and time consuming VCG tests. In brief, DArTseq proved to accurately group Foc VCGs within clades of the FOSC, elaborates at a high resolution on their genetic variation and efficiently assigns VCGs. We, therefore, propose to implement this technology for high-throughput and accurate characterization of (new) Foc populations that can be applied to other $F$. oxysporum strains.

In the FOSC, Foc comprises the largest number of VCGs among more than 70 formae speciales. (Bentley et al., 1998; Katan, 1999; Katan \& Di Primo, 1999; Moore et al., 1993; Ordóñez et al., 2015; Ploetz, 2015). Based on DArTseq analyses, we identified 20 as of yet unknown VCGs that are genetically distant and incompatible with the reported 24 Foc VCGs. All our Foc isolates grouped along the three defined clades in the FOSC, with nearly all our novel VCGs placed in clade 2 or 3. One of the most prominent Foc isolates in clade 3 is the Foc_R1 isolate (new-VCG14), pathogenic on 'Gros Michel' bananas, that originates from Brazil and which is routinely used for phenotyping germplasm in the Embrapa breeding program as well as in WUR greenhouse trials (García-Bastidas et al., 2018; Maryani et al., 2018b). The pathogenicity of the remaining novel VCGs requires further characterization, initially under greenhouse conditions. From recent surveys on symptomatic banana plants, novel Foc genotypes were also identified within and beyond clades 1 and 2 (Araújo et al., 2017; Bentley et al., 1998; Karangwa et al., 2018; Mostert et al., 2017). These novel Foc genotypes and our new VCGs provide evidence for a substantially larger genetic diversity in Foc than was hitherto considered.

The polyphyletic nature of Foc in the FOSC suggests that their capacity to cause disease in bananas evolved multiple times (O'Donnell et al., 1998a). In fact, polyphyly is a common trait for many other formae speciales in the FOSC, showing that strains pathogenic to a single host or related-hosts are actually genetically distant (Baayen et al., 2000). Since plant pathogens commonly co-evolved with their host (Möller \& Stukenbrock, 2017; Stukenbrock \& McDonald, 2008), Foc strains are assumed to co-evolve with bananas in their center of origin in Southeast Asia (Bentley et al., 1998; Fourie et al., 2009; O'Donnell et al., 1998a). Many of the wild ancestors of bananas are immune for Fusarium wilt, supporting this hypothesis (Buddenhagen, 2009; Li et al., 2014; García-Bastidas et al., 2018; Maryani et al., 2018a). Similarly, the constant largest Foc VCG diversity reported for Southeast Asia and Australia in this study and previous reports (Bentley et al., 1998; Blomme et al., 2013; Boehm et al., 1994; Bogale et al., 2006; Fourie et al., 2009; Groenewald et al., 2006; Karangwa et al., 2018; Koenig et al., 1997; Ploetz, 2015), together with evidence that clade 1 strains are predominant in surveys conducted from non-commercial banana plants in Indonesia (Maryani et al., 2018a) and from non-cultivated soils in Australia (Laurence et al., 2012) are indications of a Southeast Asian-Australian origin of Foc strains. For some clade 2 lineages including VCGs 0123, 01217, 01218 and the 0124/5/8/20 complex, their association with the banana center of origin is related to their capacity to cause disease in banana 
germplasm derived from the wild banana M. balbisina (Fourie et al., 2009) whose original geographical distribution extends from India to South China (Perrier et al., 2011). This can explain the presence of a large diversity of reported Foc VCGs from clade 2 in Southeast Asia but a limited diversity in Oceania in our collection. Although some Foc lineages within clade 2 may originate from Southeast Asia, VCG01212, 01214 and seven novel VCGs in clade 2 were only recorded for areas outside the host center of origin in our study. This observation and the here reported large number of clade 3 new-VCGs in Latin America supports a second hypothesis of Foc evolution in which local $F$. oxysporum populations evolved and became pathogenic on introduced bananas (Bentley et al., 1998; Boehm et al., 1994; Fourie et al., 2009; Groenewald et al., 2006; Koenig et al., 1997). More than $90 \%$ of $F$. oxysporum isolates obtained from agricultural soils in Ethiopia (Bogale et al., 2006) and Costa Rica (Alkemade, 2017) belonged only to clade 2 or 3. In a Foc Indonesian population, isolates were not reported in clade 3 , while approximately $60 \%$ of the recovered isolates grouped in clade 1 , $30 \%$ in clade 2 and $4 \%$ in a novel clade (Maryani et al., 2018a). Thus based on our reported VCG distribution and studies discussed above, we hypothesize that clade 1 and some lineages in clade 2 support the hypothesis of a banana-Foc co-evolution in the host center of origin. Likewise, some clade 2 and particularly clade 3 lineages are evidence for the emergence of Foc strains in local F. oxysporum populations outside Southeast Asia. For the FOSC, two phylogenetic species (PS) that included 17 independent evolutionary lineages were proposed; PS1 associated with clade 1 strains and PS2 with the remaining taxa (clade 2, 3 and 4) (Laurence et al., 2014). Clade 1 is believed to be the most ancestral based on its basal split from the remaining taxa, indicating that this clade may be descended from one of the earliest divergences within the FOSC (Laurence et al., 2012; O'Donnell et al., 1998a). Phylogeny of clades 2, 3 and 4 suggested an early divergence (Laurence et al., 2014; O'Donnell et al., 1998a; O'Donnell et al., 2004) that occasionally resulted in topological inconsistencies and poor bootstrap support (Laurence et al., 2012; Lievens et al., 2009; O'Donnell et al., 2009) and the proposal of novel in-between clades (Baayen et al., 2000; Laurence et al., 2012; Maryani et al., 2018a). In order to properly unveil the evolutionary history and origin of Foc strains, clonal lineage boundaries of clades need to be better resolved and phylogenetic studies must include $F$. oxysporum populations from uncultivated soils (Laurence et al., 2012; Summerell et al., 2010).

Beside co-evolution with its host, sexual reproduction might have also influenced Foc evolution. The presence of functional mating types among $F$. oxysporum strains is a premise of the assumption that sexual reproduction was possible during its evolution (Waalwijk et al., 2006; Yun et al., 2000). Our results confirmed the reported mating types for several Foc VCGs (Fourie et al., 2009) and additionally determined the mating types for VCGs 01221 to 01224 as well as for the novel VCGs. In our study, each Foc isolate contained either a MAT11 or MAT1-2 idiomorph but never both and all isolates in unique/cross-compatible VCGs contained a single mating type, in line with reports of a single mating type per VCG for other pathogenic $F$. oxysporum formae speciales (f.sp. dianthi, f.sp. lycopersici, f.sp. radicislycopersici and f.sp. vasinfectum) (Abo et al., 2005; Gómez-Lama, 2012; Kawabe et al., 2005; Lievens et al., 2009). Besides the presence of mating types scattered over the three reported clades, both mating idiomorphs occurred in all continents where bananas are grown, with 10 out of 33 surveyed countries containing both MAT1-1 and MAT1-2 Foc isolates in our 
collection. The presence of both mating types in the same geographical area is one of the key prerequisites for sexual reproduction to occur (Dyer \& Paoletti, 2005). Although crossing experiments between $F$. oxysporum isolates with opposite mating types were never successful (Fourie et al., 2009; Kawabe et al., 2005), it is still a good hypothesis that the sexual cycle for $F$. oxysporum strains is yet to be discovered as it occurred for the once-presumed-asexual fungi Aspergillus fumigates and A. lentulus (Dyer \& Paoletti, 2005; O'Gorman et al., 2008; Swilaiman et al., 2013).

Sampling and sequencing of F.oxyposrum strains are fundamental to determine their dissemination tracks, emergence and incursions. In our study, the spread of Foc strains was not resolved with the use of DArTseq. Instead in general, Foc isolates clustered in and among VCGs regardless of their spatial or temporal scales, similar to previous genetic studies (Bentley et al., 1998; Bogale et al., 2006; Fourie et al., 2009; Groenewald et al., 2006; Koenig et al., 1997). The dispersal of Foc strains from the banana center of origin is usually assumed to be a consequence of the dissemination of bananas (Bentley et al., 1998; Fourie et al., 2009; O'Donnell et al., 1998a). Dating the events when bananas were moved across the globe is challenging, particularly since their dispersal to regions outside Southeast Asia might have occurred multiple times (Marin et al., 1998; Nayar, 2010; Perrier et al., 2011; Robinson \& Sauco, 2010; Simmonds \& Shepherd, 1955). Not only Foc strains might have been transported through banana germplasm but also via soil or in the roots of non-host plant species, making the tracking of Foc dispersal difficult (Hennessy et al., 2005; Salacinas et al., 2018). In our study, the only spatial distinction identified using DArTseq concerned VCG0126 isolates from clade 1, which appear to be disseminated globally. We speculated that this spatial subgrouping is explained by microevolution as a consequence of a founder effect that took place after VCG0126 isolates, that belong to the presumed-ancestral clade 1, escaped from the banana center of origin, first to Australia and then to America, since the Australian VCG0126 isolates are genetically closer to the Asian population than to the American isolates. Thus, the genetic diversity of VCG0126 isolates provides circumstantial evidence of the movement of bananas from Southeast Asia, to Oceania and later to America. Recently, the incursion of VCG01213, popularly known as TR4, to Laos, Vietnam and Myanmar was estimated to originate from China; while the transcontinental incursion of TR4 in Pakistan was related to The Philippines based on SNPs among these isolates (Zheng et al., 2018). No evidence of the dispersal of these TR4 isolates was related to a specific movement of banana germplasm, soil or other sources. Thus, although molecular data can provide insights in the spatial distribution of Foc, resolving their spreading modes and dating of dispersal events still remain challenging.

In conclusion, the new insight of Foc genetic diversity and its geographical distribution is required to understand the genetic relationship between these genotypes in the FOSC and their distribution across banana-growing areas. This would help to develop strategies for Fusarium wilt management by resolving uncertainties about their origin, spreading routes and genotype diversity. Since DArTseq provides a high-resolution genetic diversity of isolates in VCGs, this technology could efficiently and rapidly monitor genetic changes in Foc populations following disease management strategies, e.g. introduction of resistant banana germplasm and fungicides. Although DArTseq efficiently discriminates VCGs and resolves the topology of the main clades for the FOSC, a thorough phylogeography 
requires the resequencing of many isolates, which we consider likely to happen in the forthcoming future to finally resolve the origin and dissemination of Foc genetic diversity.

\section{ACKNOWLEDGMENTS}

This research was funded by the Interdisciplinary Research and Education Fund (INREF) of Wageningen University \& Research, The Netherlands and various private and public partners (see www.fusariumwilt.org). Banana research at WUR is supported by the Dutch Dioraphte Foundation endowed chair in Tropical Phytopathology of GHJK at the WUR-Laboratory of Phytopathology. Research in the laboratory of M.F. Seidl is supported by the Research Council Earth and Life Science (ALW) of The Netherlands Organization of Scientific Research (NWO). Diverse providers around the world contributed isolates to be included in the current study. We thank M.V. Sloten and B. Alexander for their assistance with PCRs to identify mating types in studied isolates. We thank T. Saxby (banana), T. Saxby \& J.C. Fisher (root) and J. Woerner (weed) from Integration and Application Network, University of Maryland Center for Environmental Science (ian.umces.edu/imagelibrary/) for providing free vector images to create the Supplementary Fig. 1. 


\section{REFERENCES}

Abo, K., Klein, K.K., Edel-Hermann, V., Gautheron, N., Traore, D., \& Steinberg, C. (2005). High genetic diversity among strains of Fusarium oxysporum f.sp. vasinfectum from cotton in Ivory Coast. Phytopathology, 95(12), 1391-1396.

Agrios, G.N. (2005). Chapter 4 Genetics of plant disease. In t. Edition (Ed.), Plant Pathol: Academic Press.

Alkemade, J. (2017). Mapping the Fusarium oxysporum f.sp. cubense population in Costa Rica. Retrieved from Wageningen, NL.

Alves, A., Pereira, V., Leão, A., Formigheri, E., de Capdeville, G., \& Souza Junior, M. (2014). Advancing palm genomics by developing a high-density battery of molecular markers for Elaeis oleifera for future downstream applications. BMC Proceedings, 8(Suppl 4), P96.

Araújo, N.A.F., Pasqual, M., Pio, L.A.S., Alves, E., de Matos Moura, N., \& Costa, S.S. (2017). Identification and aggressiveness of four isolates of Fusarium oxysporum f.sp. cubense from Latundan banana in Brazil. J Phytopathol, 165, 254-264.

Avise, J.C., Arnold, J., Ball, R.M., Bermingham, E., Lamb, T., Neigel, J.E., . . . Saunders, N.C. (1987). Intraspecific phylogeography: the mitochondrial DNA bridge between population genetics and systematics. Annu Rev Ecol Syst, 18(1), 489-522.

Baayen, R.P., O'Donnell, K., Bonants, P.J.M., Cigelnik, E., Kroon, L.P.N.M., Roebroeck, E.J.A., \& Waalwijk, C. (2000). Gene genealogies and AFLP analyses in the Fusarium oxysporum complex identify monophyletic and nonmonophyletic formae speciales causing wilt and rot disease. Phytopathology, 90, 891-900.

Beheregaray, L.B. (2008). Twenty years of phylogeography: the state of the field and the challenges for the Southern Hemisphere. Mol Ecol, 17(17), 3754-3774.

Bentley, S., Pegg, K.G., Moore, N.Y., Davis, R.D., \& Buddenhagen, I. (1998). Genetic variation among vegetative compatibility groups of Fusarium oxysporum f.sp. cubense analyzed by DNA fingerprinting. Phytopathology, 88(12), 1283-1293.

Bentley, S., Pegg, K.G., \& Dale, J.L. (1995). Genetic variation among a world-wide collection of isolates of Fusarium oxysporum f.sp. cubense analysed by RAPD-PCR fingerprinting. Mycol Res, 99(11), 13781384.

Blomme, G., Ploetz, R., Jones, D., De Langhe, E., Price, N., Gold, C., . . . Buddenhagen, I. (2013). A historical overview of the appearance and spread of Musa pests and pathogens on the African continent: highlighting the importance of clean Musa planting materials and quarantine measures. Ann Appl Biol, 162(1), 4-26.

Boddy, L. (2016). Chapter 4 Genetics - Variation, Sexuality, and Evolution The Fungi (pp. 99-139). Boston: Academic Press.

Boehm, E.W.A., Ploetz, R., \& Kistler, H.C. (1994). Statistical analysis of electrophoretic karyotype variation among vegetative compatibility groups of Fusarium oxysporum f.sp. cubense. MPMI, 7(2), 196-207.

Bogale, M., Wingfield, B.D., Wingfield, M.J., \& Steenkamp, E.T. (2006). Characterization of Fusarium oxysporum isolates from Ethiopia using AFLP, SSR and DNA sequence analyses. Fungal Divers, 23, 51-66.

Boyd, L.A., Ridout, C., O'Sullivan, D.M., Leach, J.E., \& Leung, H. (2013). Plant-pathogen interactions: disease resistance in modern agriculture. Trends Genet, 29(4), 233-240.

Buddenhagen, I. (2009). Understanding strain diversity in Fusarium oxysporum f.sp. cubense and history of introduction of Tropical Race 4 to better manage banana production. Acta Hort, 828(Proc. IS on Banana Crop Prot., Sust. Prod. \& Impr. Livelihoods), 193-204.

Chao, A., Chazdon, R.L., Colwell, R.K., \& Shen, T.J. (2005). A new statistical approach for assessing similarity of species composition with incidence and abundance data. Ecol Lett, 8(2), 148-159.

Chittarath, K., Mostert, D., Crew, K.S., Viljoen, A., Kong, G., Molina, G., \& Thomas, J.E. (2017). First report of Fusarium oxysporum f.sp. cubense tropical race 4 (VCG 01213/16) associated with Cavendish bananas in Laos. Plant Dis, 449.

Correll, J.C. (1991). The relationships between formae speciales, races and vegetative compatibility groups in Fusarium oxysporum. Phytopathology, 81, 1061-1064. 
Cruz, V.M., Kilian, A., \& Dierig, D.A. (2013). Development of DArT marker platforms and genetic diversity assessment of the U.S. collection of the new oilseed crop lesquerella and related species. PLoS One, $8(5), 1-13$.

D'Hont, A., Denoeud, F., Aury, J.M., Baurens, F.C., Carreel, F., Garsmeur, O., . . . Wincker, P. (2012). The banana (Musa acuminata) genome and the evolution of monocotyledonous plants. Nature, 488(7410), 213-217.

Dalirsefat, S.B., da Silva Meyer, A., \& Mirhoseini, S.Z. (2009). Comparison of similarity coefficients used for cluster analysis with amplified fragment length polymorphism markers in the Silkworm, Bombyx mori. J Insect Sci, 9, 71.

Dean, R., Van Kan, J.A.L., Pretorius, Z.A., Hammond-Kosack, K.E., Di Pietro, A., Spanu, P.D., . . Foster, G.D. (2012). The Top 10 fungal pathogens in molecular plant pathology. Mol Plant Pathol, 13(4), 414-430.

Di Pietro, A., García-Maceira, F.I., Méglecz, E., \& Roncero, M.I.G. (2001). A MAP kinase of the vascular wilt fungus Fusarium oxysporum is essential for root penetration and pathogenesis. Mol Microbiol, 39(5), 1140-1152.

Dita, M.A., Waalwijk, C., Buddenhagen, I.W., Souza Jr, M.T., \& Kema, G.H.J. (2010). A molecular diagnostic for tropical race 4 of the banana Fusarium wilt pathogen. Plant Pathol, 59(2), 348-357.

Dyer, P.S., \& Paoletti, M. (2005). Reproduction in Aspergillus fumigatus: sexuality in a supposedly asexual species? Med Mycol, 43(Supplement_1), S7-S14.

Edel, V., Steinberg, C., Gautheron, N., \& Alabouvette, C. (2000). Ribosomal DNA-targeted oligonucleotide probe and PCR assay for Fusarium oxysporum. Mycol Res, 104(5), 518-526.

Fourie, G., Steenkamp, E.T., Ploetz, R.C., Gordon, T.R., \& Viljoen, A. (2011). Current status of the taxonomic position of Fusarium oxysporum forma specialis cubense within the Fusarium oxysporum complex. Infect Genet Evol, 11(3), 533-542.

Fourie, G., Steenkamp, E.T., Gordon, T.R., \& Viljoen, A. (2009). Evolutionary relationships among the Fusarium oxysporum f.sp. cubense vegetative compatibility groups. Appl Environ Microbiol, 75(14), 4770-4781.

García-Bastidas, F.A., Bakry, F., Irish, B., \& Kema, G.H.J. (2018). Evidence for wide variation of resistance to Fusarium oxysporum f.sp. cubense tropical race 4 and race 1 generated by vegetative propagation in banana. (PhD Degree), Wageningen University \& Research, Wageningen, The Netherlands.

García-Bastidas, F., Ordóñez, N., Konkol, J., Al-Qasim, M., Naser, Z., Abdelwali, M., . . Kema, G.H.J. (2014). First report of Fusarium oxysporum f.sp. cubense tropical race 4 associated with Panama disease of banana outside Southeast Asia. Plant Dis, 98(5), 694.

Ghag, S.B., Shekhawat, U.K.S., \& Ganapathi, T.R. (2015). Fusarium wilt of banana: biology, epidemiology and management. Int J Pest Manage, 1-14.

Gómez-Lama, C. (2012). Diversidad en poblaciones de Fusarium oxysporum f.sp. dianthi del sur de España. (PhD Degree), Universidad de Córdoba, Córdoba, Spain.

Groenewald, S., Van Den Berg, N., Marasas, W.F., \& Viljoen, A. (2006). The application of high-throughput AFLP's in assessing genetic diversity in Fusarium oxysporum f.sp. cubense. Mycol Res, 110(Pt 3), 297305.

Guo, L., Yang, L., Liang, C., Wang, G., Dai, Q., \& Huang, J. (2015). Differential colonization patterns of bananas (Musa spp.) by physiological race 1 and race 4 isolates of Fusarium oxysporum f.sp. cubense. $J$ Phytopathol, 1-11.

Gurr, S., Samalova, M., \& Fisher, M. (2011). The rise and rise of emerging infectious fungi challenges food security and ecosystem health. Fungal Biol Rev, 25(4), 181-188.

Hennessy, C., Walduck, G., Daly, A., \& Padovan, A. (2005). Weed hosts of Fusarium oxysporum f.sp. cubense tropical race 4 in northern Australia. Australas Plant Pathol, 34(1), 115-117.

Hung, T.N., Hung, N.Q., Mostert, D., Viljoen, A., Chao, C. P., \& Molina, G. (2017). First report of Fusarium wilt on Cavendish bananas, caused by Fusarium oxysporum f.sp. cubense tropical race 4 (VCG 01213/16), in Vietnam. Plant Dis, 448.

Jaccoud, D., Peng, K., Feinstein, D., \& Kilian, A. (2001). Diversity Arrays: a solid state technology for sequence information independent genotyping. Nucleic Acids Res, 29(4), 1-7. 


\section{Chapter 4}

Karangwa, P., Mostert, D., Ndayihanzamaso, P., Dubois, T., Niere, B., zum Felde, A., . . Viljoen, A. (2018). Genetic diversity of Fusarium oxysporum f.sp. cubense in East and Central Africa. Plant Dis, 102(3), $552-560$.

Katan, T. (1999). Current status of vegetative compatibility groups in Fusarium oxysporum. Phytoparasitica, 27(1), 51-64.

Katan, T., \& Di Primo, P. (1999). Current status of vegetative compatibility groups in Fusarium oxysporum: Supplement (1999). Phytoparasitica, 27(4), 273-277.

Kawabe, M., Kobayashi, Y., Okada, G., Yamaguchi, I., Teraoka, T., \& Arie, T. (2005). Three evolutionary lineages of tomato wilt pathogen, Fusarium oxysporum f.sp. lycopersici, based on sequences of IGS, $M A T 1$, and pg1, are each composed of isolates of a single mating type and a single or closely related vegetative compatibility group. J Gen Plant Pathol, 71(4), 263-272.

Kilian, A. (2003). The fast and the cheap: SNP and DArT-based whole genome profiling for crop improvement P. R. L. Tuberosa R., Gale M. (eds.) (Ed.) Proceedings of the International Congress "In the Wake of the Double Helix: From the Green Revolution to the Gene Revolution" (pp. 1-19).

Koenig, R.L., Ploetz, R., \& Kistler, H.C. (1997). Fusarium oxysporum f.sp. cubense consists of a small number of divergent and globally distributed clonal lineages. Phytopathology, 87(9), 915-923.

Kohn, L.M. (2005). Mechanisms of fungal speciation. Annu Rev Phytopathol, 43, 279-308.

Laurence, M.H., Summerell, B.A., Burgess, L.W., \& Liew, E.C. (2014). Genealogical concordance phylogenetic species recognition in the Fusarium oxysporum species complex. Fungal Biol, 118(4), 374-384.

Laurence, M.H., Burgess, L.W., Summerell, B.A., \& Liew, E.C. (2012). High levels of diversity in Fusarium oxysporum from non-cultivated ecosystems in Australia. Fungal Biol, 116(2), 289-297.

Leslie, J.F., Anderson, L.L., Bowden, R.L., \& Lee, Y.W. (2007). Inter- and intra-specific genetic variation in Fusarium. Int J Food Microbiol, 119(1-2), 25-32.

Leslie, J.F., \& Summerell, B. (2006). The Fusarium Laboratory Manual: Blackwell Publishing.

Leslie, J.F. (1990). Genetic exchange within sexual and asexual populations of the genus Fusarium. In R. Ploetz (Ed.), Fusarium wilt of banana (pp. 37-48).

Li, C., Chen, S., Zuo, C., Sun, Q., Ye, Q., Yi, G., \& Huang, B. (2011). The use of GFP-transformed isolates to study infection of banana with Fusarium oxysporum f.sp. cubense race 4. Eur J Plant Pathol, 131(2), 327-340.

Li, W.M., Dita, M., Wu, W., Hu, G.B., Xie, J.H., \& Ge, X.J. (2014). Resistance sources to Fusarium oxysporum f.sp. cubense tropical race 4 in banana wild relatives. Plant Pathol, 1-7.

Lievens, B., van Baarlen, P., Verreth, C., van Kerckhove, S., Rep, M., \& Thomma, B.P. (2009). Evolutionary relationships between Fusarium oxysporum f.sp. lycopersici and F. oxysporum f.sp. radicis-lycopersici isolates inferred from mating type, elongation factor-1alpha and exopolygalacturonase sequences. Mycol Res, 113(Pt 10), 1181-1191.

Marin, D.H., Sutton, T.B., \& Barker, K.R. (1998). Dissemination of bananas in Latin America and the Caribbean and its relationship to the occurrence of Radopholus similis. . Plant Dis, 82(9), 964-974.

Maryani, N., Lombard, L., Poerba, Y.S., Subandiyah, S., Crous, P.W., \& Kema, G.H.J. (2018a). Phylogeny and genetic diversity of the banana Fusarium wilt pathogen Fusarium oxysporum f.sp. cubense in the Indonesian centre of origin. (PhD Degree), Wageningen University \& Research, Wageningen, The Netherlands.

Maryani, N., Ahmad, F., Kleizer, P., Poerba, Y. S., Crous, P. W., \& Kema, G. H. J. (2018b). Pathogenic diversity of Fusarium wilt on banana pathogen in the Indonesian wild and cultivated bananas. $(\mathrm{PhD}$ Degree), Wageningen University \& Research, Wageningen, The Netherlands.

McDonald, B.A., \& Linde, C. (2002). Pathogen population genetics, evolutionary potential, and durable resistance. Annu Rev Phytopathol, 40, 349-379.

Meirmans, P.G. (2015). Seven common mistakes in population genetics and how to avoid them. Mol Ecol, 24, 3223-3231.

Meyer, D., \& Buchta, C. (2017). proxy: Distance and similarity measures. R package version 0.4-17. https://CRAN.R-project.org/package=proxy.

Michielse, C.B., \& Rep, M. (2009). Pathogen profile update: Fusarium oxysporum. Mol Plant Pathol, 10(3), 311-324. 
Möller, M., \& Stukenbrock, E.H. (2017). Evolution and genome architecture in fungal plant pathogens. Nat Rev Microbiol, 15, 756.

Moore, N.Y., Pegg, K.G., Allen, R.N., \& Irwin, J.A.G. (1993). Vegetative compatibility and distribution of Fusarium oxysporum f.sp. cubense in Australia. Aust J Exp Agri, 33, 797-802.

Mostert, D., Molina, A.B., Daniells, J., Fourie, G., Hermanto, C., Chao, C.P., . . . Viljoen, A. (2017). The distribution and host range of the banana Fusarium wilt fungus, Fusarium oxysporum f.sp. cubense, in Asia. PLoS One, 12(7), 1-24.

Nayar, N. (2010). The Bananas: botany, origin, dispersal (J. Janick Ed.): Wiley-Blackwell.

O'Donnell, K., Gueidan, C., Sink, S., Johnston, P.R., Crous, P.W., Glenn, A., . . Sarver, B.A. (2009). A twolocus DNA sequence database for typing plant and human pathogens within the Fusarium oxysporum species complex. Fungal Genet Biol, 46(12), 936-948.

O'Donnell, K., Sutton, D.A., Rinaldi, M.G., Magnon, K.C., Cox, P.A., Revankar, S.G., . . . Robinson, J.S. (2004). Genetic diversity of human pathogenic members of the Fusarium oxysporum complex inferred from multilocus DNA sequence data and amplified fragment length polymorphism analyses: evidence for the recent dispersion of a geographically widespread clonal lineage and nosocomial origin. $J$ Clin Microbiol, 42(11), 5109-5120.

O'Donnell, K., Cigelnik, E., \& Nirenberg, H.I. (1998a). Molecular systematics and phylogeography of the Gibberella fujikuroi species complex. Mycologia, 90(3), 465-493.

O'Donnell, K., Kistler, H.C., Cigelnik, E., \& Ploetz, R. (1998b). Multiple evolutionary origins of the fungus causing Panama disease of banana: Concordant evidence from nuclear and mitochondrial gene genealogies. Proc Natl Acad Sci USA, 95, 2044-2049.

O'Gorman, C.M., Fuller, H.T., \& Dyer, P.S. (2008). Discovery of a sexual cycle in the opportunistic fungal pathogen Aspergillus fumigatus. Nature, 457, 471.

Oksanen, J., Guillaume, F.B., Friendly, M., Kindt, R., Legendre, P., McGlinn, D., . . Wagner, H. (2017). vegan: Community Ecology Package. R package. version 2.4-3. https://CRAN.R-project.org/package=vegan.

Ordóñez, N., García-Bastidas, F., Laghari, H.B., Akkary, M.Y., Harfouche, E.N., al Awar, B.N., \& Kema, G.H.J. (2016). First report of Fusarium oxysporum f.sp. cubense tropical race 4 causing Panama disease in Cavendish bananas in Pakistan and Lebanon. Plant Dis, 100(1), 209.

Ordóñez, N., Seidl, M.F., Waalwijk, C., Drenth, A., Kilian, A., Thomma, B.P., . . Kema, G.H. (2015). Worse comes to worst: Bananas and Panama disease-when plant and pathogen clones meet. PLoS Pathog, 11(11), 1-7.

Perrier, X., De Langhe, E., Donohue, M., Lentfer, C., Vrydaghs, L., Bakry, F., . . . Denham, T. (2011). Multidisciplinary perspectives on banana (Musa spp.) domestication. Proc Natl Acad Sci USA, 108(28), 11311-11318.

Ploetz, R.C. (2006). Panama disease: An old nemesis rears its ugly head. Part2. The Cavendish era and beyond. Plant Health Progress.

Ploetz, R.C. (2015). Fusarium Wilt of Banana. Phytopathology, 105(12), 1512-1521.

Ploetz, R.C., Kema, G.H., \& Ma, L.J. (2015). Impact of diseases on export and smallholder production of banana. Annu Rev Phytopathol, 53, 269-288.

Ploetz, R.C., \& Pegg, K.G. (2000). Fusarium wilt. In: Diseases of Banana, Abaca and Enset. Wallingford, UK: CABI Publishing.

Puhalla, J.E. (1985). Classification of strains of Fusarium oxysporum on the basis of vegetative compatibility. Can J Bot, 63, 179-183.

Robinson, J.C., \& Sauco, G.V. (2010). Bananas and plantains. Wellingford, Oxfordshire, UK: CABI.

Roman, C.H. (2012). Consideraciones epidemiológicas para el manejo de la Marchitez por Fusarium (Fusarium oxysporum f.sp. cubense) del banano en la región central del Perú. (Magister Scientiae en Agricultura Ecológica), Centro Agronómico Tropical de Investigación y Enseñanza, Turrialba, Costa Rica.

Salacinas, M.A., Stoorvogel, J., Mendes, O., Schoen, C., Landeweert, R., Rebuta, A.M., . . . Kema, G.H.J. (2018). Tracing contamination of Fusarium oxysporum f.sp. cubense tropical race 4 in soil, water, weeds and field sanitation by burning in The Philippines. (PhD Degree), Wageningen University \& Research, Wageningen, The Netherlands.

Sambrook, J., Fritsch, E.F., \& Maniatis, T. (1989). Molecular cloning: A laboratory manual. (2nd. ed. ed.). New York: Cold Spring Harbour Press. 


\section{Chapter 4}

Scholthof, K.G. (2007). The disease triangle: pathogens, the environment and society. Nat Rev Microbiol, 5(2), 152-156.

Sharma, M., Nagavardhini, A., Thudi, M., Ghosh, R., Pande, S., \& Varshney, R.K. (2014). Development of DArT markers and assessment of diversity in Fusarium oxysporum f.sp. ciceris, wilt pathogen of chickpea (Cicer arietinum L.). BMC Genomics, 15, 454.

Simmonds, N.W., \& Shepherd, K. (1955). Taxonomy and origins of cultivated bananas. J Linn Soc Bot, 55, 302312.

Smith, E.F. (1910). A Cuban banana disease. Science, 31, 754-755.

Stukenbrock, E.H., \& McDonald, B.A. (2008). The origins of plant pathogens in agro-ecosystems. Аnnu Rev Phytopathol, 46, 75-100.

Summerell, B.A., Laurence, M.H., Liew, E.C.Y., \& Leslie, J.F. (2010). Biogeography and phylogeography of Fusarium: a review. Fungal Divers, 44(1), 3-13.

Swilaiman, S.S., O'Gorman, C. M., Balajee, S.A., \& Dyer, P.S. (2013). Discovery of a sexual cycle in Aspergillus lentulus, a close relative of A. fumigatus. Eukaryot Cell, 12(7), 962-969.

van Brunschot, S. (2006). Fusarium wilt of banana. Laboratory diagnostic manual. Australia.

Vézina, A. (Producer). (2018, 05.05.2018). Tropical race 4. Retrieved from http://www.promusa.org/Tropical+race+4+-+TR4.

Waalwijk, C., Keszthelyi, A., van der Lee, T., Jeney, A., de Vries, I., Kerenyi, Z., . . Hornok, L. (2006). Mating type loci in Fusarium: structure and function. Mycotoxin Res, 22(1), 54-60.

Weik, M. (2001). Hamming distance Computer Science and Communications Dictionary (pp. 706-706). Boston, MA: Springer US.

Yun, S.H., Arie, T., Kaneko, I., Yoder, O.C., \& Turgeon, B.G. (2000). Molecular organization of mating type loci in heterothallic, homothallic, and asexual Gibberella/Fusarium species. Fungal Genet Biol, 31(1), 7-20.

Zeng, L.S., Zhao, Z.H., Lu, S., Xi, Z.J., Li, M.H., Xi, P.G., \& Jiang, Z.D. (2013). The Fusarium species isolated from banana and their phylogenetic relationships. Mycosystema, 32, 617-632.

Zheng, S., García-Bastidas, F.A., Li, X., Zheng, L., Bai, T.T., Xu, S., . . . Kema, G.H.J. (2018). New geographical insights of the latest expansion of Fusarium oxysporum f.sp. cubense tropical race 4 into the Greater Mekong subregion. Front Plant Sci, 9(457), 1-9. 
Supplementary Table 1. Fusarium oxysporum f.sp. cubense isolates including all 24 reported vegetative compatibility groups (VCGs) used in this study.

\begin{tabular}{|c|c|c|c|c|c|c|c|}
\hline $\begin{array}{l}\text { Isolate } \\
\text { code }\end{array}$ & $\begin{array}{l}\text { Macro } \\
\text { region }\end{array}$ & Country & Area & VCG & Host & $\begin{array}{l}\text { Year of } \\
\text { isolation }\end{array}$ & Provider \\
\hline 15638 & Asia & Malaysia & n.d. & VCG0120 & n.d. & n.d. & R.C. Ploetz, FL, USA \\
\hline 22615 & Oceania & Australia & $\begin{array}{l}\text { Ewingsdale, Byron } \\
\text { Bay }\end{array}$ & VCG0120 & Cavendish & 1992 & A. Drenth, Brisbane, Australia \\
\hline 23486 & Oceania & Australia & Wamuran & VCG0120 & Cavendish & 1993 & A. Drenth, Brisbane, Australia \\
\hline 34661 & America & Honduras & n.d. & VCG0120 & Highgate & n.d. & R.C. Ploetz, FL, USA \\
\hline BPI09.01 ${ }^{1,2}$ & Asia & Indonesia & Java & VCG0120 & Cavendish & n.d. & I.W. Buddenhagen, USA \\
\hline CR1.1A & America & Costa Rica & Border to Panama & VCG0120 & Gros Michel & 2015 & $\begin{array}{l}\text { R. Segura, Corbana, Costa } \\
\text { Rica, N. Ordóñez }{ }^{9} \text {, } \\
\text { Netherlands }\end{array}$ \\
\hline FCJ7 & America & Jamaica & n.d. & VCG0120 & Cavendish & n.d. & R.C. Ploetz, FL, USA \\
\hline Foc $19508^{1}$ & America & Costa Rica & Guapiles & VCG0120 & Gros Michel & 2008 & M. Guzmán, Costa Rica \\
\hline FocST $498^{1,3}$ & Africa & Spain & Canary Island & VCG0120* & Dwarf Cavendish & 1998 & J. Hernandez, Spain \\
\hline Focul & Oceania & Australia & Queensland & VCG0120 & Mons Mari & n.d. & $\begin{array}{l}\text { M.J. Daboussi, Université } \\
\text { Paris -Sud }\end{array}$ \\
\hline Focu2 & America & Costa Rica & n.d. & VCG0120 ${ }^{4}$ & Gros Michel & n.d. & $\begin{array}{l}\text { M.J. Daboussi, Université } \\
\text { Paris -Sud }\end{array}$ \\
\hline FOO27 & Africa & South Africa & n.d. & VCG0120 & Goldfinger & 1996 & A. Drenth, Brisbane, Australia \\
\hline GAL1 & Africa & Spain & $\begin{array}{l}\text { Las Galletas, Canary } \\
\text { Island }\end{array}$ & VCG0120 & Dwarf Cavendish & n.d. & R.C. Ploetz, FL, USA \\
\hline Guad5.1 & America & France & Guadeloupe & VCG0120 & Cavendish & n.d. & R.C. Ploetz, FL, USA \\
\hline NRRL36101 ${ }^{1,2}$ & Oceania & Australia & Queensland & VCG0120 5 & $\begin{array}{l}\text { Musa sapientum cv } \\
\text { Mons Mari }\end{array}$ & n.d. & $\begin{array}{l}\text { K. O'Donnell, Washington, } \\
\text { USA }\end{array}$ \\
\hline Pacovan & America & Brazil & Bahia & VCG0120 & Pacovan & n.d. & R.C. Ploetz, FL, USA \\
\hline SA2 & Africa & South Africa & Nelspruit & VCG0120 & Bluggoe & 1999 & A. Drenth, Brisbane, Australia \\
\hline SA4 & Africa & South Africa & Nelspruit & VCG0120 & Chinese Cavendish & 1999 & A. Drenth, Brisbane, Australia \\
\hline SA6 & Africa & South Africa & Nelspruit & VCG0120 & GCTCV-215 & 1999 & A. Drenth, Brisbane, Australia \\
\hline SA8 & Africa & South Africa & Natal, Pennington & VCG0120 & Dwarf Cavendish & n.d. & A. Drenth, Brisbane, Australia \\
\hline STGM1 & America & Costa Rica & n.d. & VCG0120 & Gros Michel & n.d. & R.C. Ploetz, FL, USA \\
\hline $\mathrm{TL}$ & Africa & South Africa & East Transvaal & VCG0120 & Williams & n.d. & R.C. Ploetz, FL, USA \\
\hline W91.307 & Oceania & Australia & Eungella & VCG0120 & Lady Finger & 1994 & A. Drenth, Brisbane, Australia \\
\hline W91.345 & Oceania & Australia & Mullumbimby & VCG0120 & Lady Finger & 1994 & A. Drenth, Brisbane, Australia \\
\hline BR13 & America & Brazil & n.d. & VCG0120/15 & n.d. & n.d. & R.C. Ploetz, FL, USA \\
\hline NRRL25603 & Oceania & Australia & n.d. & VCG0120/15 & Cavendish & n.d. & $\begin{array}{l}\text { K. O'Donnell, Washington, } \\
\text { USA }\end{array}$ \\
\hline K4 & Africa & South Africa & $\begin{array}{l}\text { Burgershall } \\
\text { Hazyview, Transvaal }\end{array}$ & VCG0120/15 & Cavendish & n.d. & R.C. Ploetz, FL, USA \\
\hline SAl & Africa & South Africa & Nelspruit & VCG0120/15 & FHIA-03 & 1999 & A. Drenth, Brisbane, Australia \\
\hline NRRL36102 $2^{1,2}$ & Asia & China & Taiwan & VCG0121* & $\begin{array}{l}\text { M. sapientum } \mathrm{cv} \\
\text { Cavendish }\end{array}$ & n.d. & $\begin{array}{l}\text { K. O'Donnell, Washington, } \\
\text { USA }\end{array}$ \\
\hline NRRL36103 & Asia & Philippines & n.d. & VCG0122* & $\begin{array}{l}\text { M. sapientum } \mathrm{cv} \\
\text { Cavendish }\end{array}$ & n.d. & $\begin{array}{l}\text { K. O'Donnell, Washington, } \\
\text { USA }\end{array}$ \\
\hline F9129 & Asia & China & Taiwan & VCG0123* & Latundan & n.d. & R.C. Ploetz, FL, USA \\
\hline NRRL26022 & Asia & Thailand & n.d. & VCG0123 & Pisang Awak & n.d. & $\begin{array}{l}\text { K. O'Donnell, Washington, } \\
\text { USA }\end{array}$ \\
\hline Mal5 & Asia & Malaysia & Perak & VCG0123 & Pisang Awak & n.d. & R.C. Ploetz, FL, USA \\
\hline 24409 & Oceania & Australia & Alstonville & VCG0124 & Bluggoe & 1996 & A. Drenth, Brisbane, Australia \\
\hline 24410 & Oceania & Australia & Alstonville & VCG0124 & Blue Java & 1996 & A. Drenth, Brisbane, Australia \\
\hline 24418 & Oceania & Australia & Alstonville & VCG0124 & Blue Java & 1996 & A. Drenth, Brisbane, Australia \\
\hline 24422 & Oceania & Australia & Alstonville & VCG0124 & Pisang Raja & 1996 & A. Drenth, Brisbane, Australia \\
\hline 24425 & Oceania & Australia & Alstonville & VCG0124 & Silver Bluggoe & 1996 & A. Drenth, Brisbane, Australia \\
\hline EA10 & Africa & Uganda & $\begin{array}{l}\text { Muhanga, Kabale } \\
\text { District }\end{array}$ & VCG0124 & Kibuzi & n.d. & R.C. Ploetz, FL, USA \\
\hline EA2 & Africa & Uganda & $\begin{array}{l}\text { Kawanda ARS, } \\
\text { Mpigi District }\end{array}$ & VCG0124 & Sukari ndizi & n.d. & R.C. Ploetz, FL, USA \\
\hline EA29 & Africa & Burundi & $\begin{array}{l}\text { Mugina, Cibitoke } \\
\text { Province }\end{array}$ & VCG0124 & Kayinja & n.d. & R.C. Ploetz, FL, USA \\
\hline EA32 & Africa & Burundi & $\begin{array}{l}\text { Cibitoke INIBAP } \\
\text { Trial Site }\end{array}$ & VCG0124 & Pelipita & n.d. & R.C. Ploetz, FL, USA \\
\hline
\end{tabular}




\begin{tabular}{|c|c|c|c|c|c|c|c|}
\hline $\begin{array}{l}\text { Isolate } \\
\text { code }\end{array}$ & $\begin{array}{l}\text { Macro } \\
\text { region }\end{array}$ & Country & Area & VCG & Host & $\begin{array}{l}\text { Year of } \\
\text { isolation }\end{array}$ & Provider \\
\hline EA37 & Africa & Rwanda & $\begin{array}{l}\text { Mukoyoyo, Kibungo } \\
\text { Prefecture }\end{array}$ & VCG0124 & Kayinja & n.d. & R.C. Ploetz, FL, USA \\
\hline FCJ2 & America & Jamaica & n.d. & VCG0124 & Bluggoe & n.d. & R.C. Ploetz, FL, USA \\
\hline Foc_R $2^{1,2}$ & America & Brazil & $\begin{array}{l}\text { Cruz das Almas, } \\
\text { Bahia }\end{array}$ & VCG0124 & Monthan & 2008 & M.A. Dita, EMBRAPA, Brazil \\
\hline Focu3 & America & Honduras & n.d. & VCG0124 & Bluggoe & n.d. & $\begin{array}{l}\text { M.J. Daboussi, Université } \\
\text { Paris -Sud, France }\end{array}$ \\
\hline Focu 4 & America & Jamaica & n.d. & VCG0124 & Bluggoe & n.d. & $\begin{array}{l}\text { M.J. Daboussi, Université } \\
\text { Paris -Sud, France }\end{array}$ \\
\hline GMB & America & Brazil & Bahia & VCG0124 & Gros Michel & n.d. & R.C. Ploetz, FL, USA \\
\hline IJ.1 & America & Cuba & n.d. & VCG0124 & $\begin{array}{l}\text { Bluggoe, Burro } \\
\text { CENSA }\end{array}$ & n.d. & L.V. Pérez, Habana, Cuba \\
\hline India17 & Asia & India & Kovvur & VCG0124 & n.d. & 1999 & A. Drenth, Brisbane, Australia \\
\hline JLTH2 & Asia & Thailand & $\begin{array}{l}\text { Smoeng hwy } 1269 \text {, } \\
\text { Chiang Mai }\end{array}$ & VCG0124 & $\begin{array}{l}\text { Kluai nam wa sai } \\
\text { daeng }\end{array}$ & n.d. & R.C. Ploetz, FL, USA \\
\hline NRRL25607 & America & USA & Florida & VCG0124 & Bluggoe & n.d. & $\begin{array}{l}\text { K. O'Donnell, Washington, } \\
\text { USA }\end{array}$ \\
\hline MW38 & Africa & Malawi & Chitipa, Karonga & VCG0124 & Harare & n.d. & R.C. Ploetz, FL, USA \\
\hline MW52 & Africa & Malawi & Karonga South & VCG0124 & Sukali & n.d. & R.C. Ploetz, FL, USA \\
\hline MW67 & Africa & Malawi & Thyolo, Blantyre & VCG0124 & Kholobowa & n.d. & R.C. Ploetz, FL, USA \\
\hline NRRL36105 $5^{1,3}$ & America & Honduras & n.d. & VCG0124* & $\begin{array}{l}\text { M. sapientum } \mathrm{cv} \\
\text { Bluggoe }\end{array}$ & n.d. & $\begin{array}{l}\text { K. O'Donnell, Washington, } \\
\text { USA }\end{array}$ \\
\hline O. 1224 & Oceania & Australia & Queensland & VCG0124 & Mons & n.d. & R.C. Ploetz, FL, USA \\
\hline STD1 & America & Honduras & n.d. & VCG0124 & Highgate & n.d. & R.C. Ploetz, FL, USA \\
\hline STN1 & America & Nicaragua & Corinto & VCG0124 & Bluggoe & n.d. & R.C. Ploetz, FL, USA \\
\hline W96.054 & Oceania & Australia & Duranbah & VCG0124 & Lady Finger & 1996 & A. Drenth, Brisbane, Australia \\
\hline W96.064 & Oceania & Australia & Woolgoolga & VCG0124 & Lady Finger & 1996 & A. Drenth, Brisbane, Australia \\
\hline Ccal.1 & America & Cuba & n.d. & VCG0124/5 & Silk, Manzano & n.d. & L.V. Pérez, Habana, Cuba \\
\hline C.Esm1.3 & America & Cuba & n.d. & VCG0124/5 & $\begin{array}{l}\text { Bluggoe, Burro } \\
\text { Criollo }\end{array}$ & n.d. & L.V. Pérez, Habana, Cuba \\
\hline CVA & America & USA & Florida & VCG0124/5 & Apple & n.d. & R.C. Ploetz, FL, USA \\
\hline JLTH16 & Asia & Thailand & Ban Nok & VCG0124/5 & Kluai nam wa & n.d. & R.C. Ploetz, FL, USA \\
\hline Mex12 & America & Mexico & Tepic, Nayarit & VCG0124/5 & Gros Michel & n.d. & R.C. Ploetz, FL, USA \\
\hline MW5 & Africa & Malawi & Kaporo & VCG0124/5 & Zambia & n.d. & R.C. Ploetz, FL, USA \\
\hline Viet14 & Asia & Vietnam & $\begin{array}{l}\text { Tien Giang } \\
\text { Provience }\end{array}$ & VCG0124/5 & Chuoi xiem & 1996 & A. Drenth, Brisbane, Australia \\
\hline Viet 17 & Asia & Vietnam & Can Tho Provience & VCG0124/5 & Chuoi xiem & 1996 & A. Drenth, Brisbane, Australia \\
\hline EA35 & Africa & Burundi & $\begin{array}{l}\text { Murama Hill, Rotuna } \\
\text { Province }\end{array}$ & VCG0124/5/8 & Pome & n.d. & R.C. Ploetz, FL, USA \\
\hline Mex14 & America & Mexico & Tepic, Nayarit & VCG0124/5/8 & Bluggoe & n.d. & R.C. Ploetz, FL, USA \\
\hline Nic11 & America & Nicaragua & Moroca, Chato & VCG0124/5/8 & Bluggoe & n.d. & R.C. Ploetz, FL, USA \\
\hline PLBL & America & USA & Homestead, Florida & VCG0124/5/8 & Bluggoe & n.d. & R.C. Ploetz, FL, USA \\
\hline R1 & America & Cuba & FHIA, Villa Clara & VCG0124/5/8 & n.d. & n.d. & R.C. Ploetz, FL, USA \\
\hline RPTH49 & Asia & Thailand & Tha Tum, Si Sa Ket & VCG0124/5/8 & Kluai nam wa & n.d. & R.C. Ploetz, FL, USA \\
\hline 8606 & Oceania & Australia & $\begin{array}{l}\text { Currumbin, } \\
\text { Queensland }\end{array}$ & VCG0125 & Lady finger & n.d. & R.C. Ploetz, FL, USA \\
\hline 23906 & Oceania & Australia & Pimpama & VCG0125 & Lady finger & 1993 & A. Drenth, Brisbane, Australia \\
\hline 1S? & America & Jamaica & Bodles & VCG0125 & Williams & n.d. & R.C. Ploetz, FL, USA \\
\hline India 1 & Asia & India & n.d. & VCG0125 & Mysore & 1993 & A. Drenth, Brisbane, Australia \\
\hline JLTH20 & Asia & Thailand & Ban Nok & VCG0125 & Kluai nam wa & n.d. & R.C. Ploetz, FL, USA \\
\hline NRRL36106 ${ }^{1,2}$ & Oceania & Australia & $\begin{array}{l}\text { Queensland, } \\
\text { Currumbin }\end{array}$ & VCG0125* & $\begin{array}{l}\text { M. sapientum cv } \\
\text { Lady finger }\end{array}$ & n.d. & $\begin{array}{l}\text { K. O'Donnell, Washington, } \\
\text { USA }\end{array}$ \\
\hline STUGA3 & Africa & Uganda & $\begin{array}{l}\text { Magamaga, } 13 \mathrm{mi} \mathrm{e} \\
\text { of Jinja }\end{array}$ & VCG0125 & Pisang Awak & n.d. & R.C. Ploetz, FL, USA \\
\hline Viet2 & Asia & Vietnam & Hai Hu'ng Provience & VCG0125 & Chuoi xiem & 1996 & A. Drenth, Brisbane, Australia \\
\hline II7 & Asia & Indonesia & $\begin{array}{l}\text { Spp-Palopo, Luwa } \\
\text { District, Sulawesi }\end{array}$ & VCG0126 & Pisang Manurung & n.d. & R.C. Ploetz, FL, USA \\
\hline Jak2 & Asia & Indonesia & South Sulawesi & VCG0126 & Williams & n.d. & R.C. Ploetz, FL, USA \\
\hline NRRL26024 & America & France & n.d. & VCG0126 & M. acuminata & n.d. & $\begin{array}{l}\text { K. O'Donnell, Washington, } \\
\text { USA }\end{array}$ \\
\hline NRRL36107 & America & Honduras & n.d. & VCG0126* & $\begin{array}{l}\text { M. sapientum } \mathrm{cv} \\
\text { Maqueno }\end{array}$ & n.d. & $\begin{array}{l}\text { K. O'Donnell, Washington, } \\
\text { USA }\end{array}$ \\
\hline
\end{tabular}


Global Foc phylogeography

\begin{tabular}{|c|c|c|c|c|c|c|c|}
\hline $\begin{array}{l}\text { Isolate } \\
\text { code }\end{array}$ & $\begin{array}{l}\text { Macro } \\
\text { region }\end{array}$ & Country & Area & VCG & Host & $\begin{array}{l}\text { Year of } \\
\text { isolation }\end{array}$ & Provider \\
\hline S1 & America & Honduras & n.d. & VCG0126 & Highgate & n.d. & R.C. Ploetz, FL, USA \\
\hline 23997 & Oceania & Australia & Kamerunga & VCG0128 & Sugar & 1994 & A. Drenth, Brisbane, Australia \\
\hline 24225 & Oceania & Australia & Carnarvon & VCG0128 & n.d. & 1993 & A. Drenth, Brisbane, Australia \\
\hline 24253 & Oceania & Australia & n.d. & VCG0128 & n.d. & 1994 & A. Drenth, Brisbane, Australia \\
\hline NRRL36111 $11^{1,3}$ & Oceania & Australia & $\begin{array}{l}\text { Queensland, South } \\
\text { Johnstone }\end{array}$ & VCG0128* & $\begin{array}{l}\text { M. sapientum } \mathrm{cv} \\
\text { Bluggoe }\end{array}$ & n.d. & $\begin{array}{l}\text { K. O'Donnell, Washington, } \\
\text { USA }\end{array}$ \\
\hline SC. 3 & America & Cuba & n.d. & VCG0128 & $\begin{array}{l}\text { Bluggoe, Burro } \\
\text { Criollo }\end{array}$ & n.d. & L.V. Pérez, Habana, Cuba \\
\hline 23509 & Oceania & Australia & Gunalda & VCG0129 & Lady finger & 1994 & A. Drenth, Brisbane, Australia \\
\hline 23518 & Oceania & Australia & Kin Kin & VCG0129 & Lady finger & n.d. & A. Drenth, Brisbane, Australia \\
\hline 24234 & Oceania & Australia & Mooloolah & VCG0129 & Cavendish & 1994 & A. Drenth, Brisbane, Australia \\
\hline N5443 & Oceania & Australia & Doonan, Queensland & VCG0129 & Cavendish & n.d. & R.C. Ploetz, FL, USA \\
\hline NRRL36110 1,3 & Oceania & Australia & Queensland & VCG0129* & $\begin{array}{l}\text { M. sapientum } \mathrm{cv} \\
\text { Mons }\end{array}$ & n.d. & $\begin{array}{l}\text { K. O'Donnell, Washington, } \\
\text { USA }\end{array}$ \\
\hline A 2.1 & America & USA & Florida & VCG01210 & Apple & n.d. & R.C. Ploetz, FL, USA \\
\hline CUB9 & America & Cuba & $\begin{array}{l}\text { Sro. Domingo, Villa } \\
\text { Clara }\end{array}$ & VCG01210 & Gros Michel & n.d. & R.C. Ploetz, FL, USA \\
\hline Focu $7^{1,3}$ & America & USA & Florida & VCG01210* & Apple & n.d. & $\begin{array}{l}\text { M.J. Daboussi, Université } \\
\text { Paris -Sud, France }\end{array}$ \\
\hline M3 & America & Cuba & FHIA Villa Clara & VCG01210 & n.d. & n.d. & R.C. Ploetz, FL, USA \\
\hline NRRL36109 $9^{1,2}$ & Oceania & Australia & Queensland & VCG01211* & $\begin{array}{l}\text { M. sapientum cv } \\
\text { SH3142 }\end{array}$ & n.d. & $\begin{array}{l}\text { K. O'Donnell, Washington, } \\
\text { USA }\end{array}$ \\
\hline NRRL36108 & Africa & Tanzania & Tenquero Staion & VCG01212* & $\begin{array}{l}\text { M. sapientum cv } \\
\text { Ney Poovan }\end{array}$ & n.d. & $\begin{array}{l}\text { K. O'Donnell, Washington, } \\
\text { USA }\end{array}$ \\
\hline STTNZ1 & Africa & Tanzania & Kilamanjaro & VCG01212 & Kisubi & n.d. & R.C. Ploetz, FL, USA \\
\hline BPS1.1 & Asia & Indonesia & Kuta-village Bali & VCG01213 & Cavendish & 2008 & I.W. Buddenhagen, USA \\
\hline BPS3.1 & Oceania & Australia & Darwin & VCG01213 & Cavendish & 2008 & I.W. Buddenhagen, USA \\
\hline Foc.T105 & Asia & China & Nantow, Taiwan & VCG01213 & Cavendish & n.d. & P.F.L. Chang, Taiwan \\
\hline Foc.T14 & Asia & China & Taitung, Taiwan & VCG01213 & Cavendish & n.d. & P.F.L. Chang, Taiwan \\
\hline Foc.T202 & Asia & China & Nantow, Taiwan & VCG01213 & Cavendish & n.d. & P.F.L. Chang, Taiwan \\
\hline III 15 & Asia & Indonesia & $\begin{array}{l}\text { Cibinong Collection, } \\
\text { Java }\end{array}$ & VCG01213 & Pisang Kosta & n.d. & R.C. Ploetz, FL, USA \\
\hline $\mathrm{II} 5^{1,2}$ & Asia & Indonesia & $\begin{array}{l}\text { Central Sulawesi, } \\
\text { Luwa District }\end{array}$ & VCG01213* & Pisang Manurung & n.d. & C. Kistler, USA \\
\hline Indo20 & Asia & Indonesia & Jatesari, East Java & VCG01213 ${ }^{8}$ & Musa sp. & n.d. & R.C. Ploetz, FL, USA \\
\hline Indo97 & Asia & Indonesia & Halmahera & VCG01213 & Cavendish & n.d. & W. O'Neil, Brisbane, Australia \\
\hline JV11 & Asia & Jordan & Jordan Valley & VCG01213 & Cavendish & 2006 & R.C. Ploetz, FL, USA \\
\hline Leb $1.2 \mathrm{C}$ & Asia & Lebanon & Berghliyeh & VCG01213 & Cavendish & 2013 & $\begin{array}{l}\text { M.Y. Akkary, Debbane Freres, } \\
\text { Lebanon, N. Ordóñez", } \\
\text { Netherlands }\end{array}$ \\
\hline Mal123 & Asia & Malaysia & Johor & VCG01213 & $\begin{array}{l}\text { Cavendish } \\
\text { (Williams) }\end{array}$ & n.d. & W. O'Neil, Brisbane, Australia \\
\hline NRRL36114 & Asia & Indonesia & $\begin{array}{l}\text { Sulavesi, Central } \\
\text { Sulawesi luwa } \\
\text { District }\end{array}$ & VCG01213 & $\begin{array}{l}\text { M. sapientum } \mathrm{cv} \\
\text { Pisang Manurung }\end{array}$ & n.d. & $\begin{array}{l}\text { K. O'Donnell, Washington, } \\
\text { USA }\end{array}$ \\
\hline Pak1.1A & Asia & Pakistan & Baoo Pooran & VCG01213 & Cavendish & 2012 & $\begin{array}{l}\text { H.B. Laghari, Pakistan, N. } \\
\text { Ordóñez }{ }^{9} \text {, Netherlands }\end{array}$ \\
\hline Phil.1A & Asia & Philippines & $\begin{array}{l}\text { Davao MADC Clone } \\
\text { Trial Area }\end{array}$ & VCG01213 & Williams & 2013 & $\begin{array}{l}\text { L.M. Bacus, Philippines, N. } \\
\text { Ordóñez }{ }^{9} \text {, Netherlands }\end{array}$ \\
\hline Phi2.5C & Asia & Philippines & $\begin{array}{l}\text { Davao MADC Clone } \\
\text { Trial Area }\end{array}$ & VCG01213 & GCTCV218 & 2013 & $\begin{array}{l}\text { L.M. Bacus, Philippines, N. } \\
\text { Ordóñez }{ }^{9} \text {, Netherlands }\end{array}$ \\
\hline Phi2.6C & Asia & Philippines & $\begin{array}{l}\text { Davao MADC Clone } \\
\text { Trial Area }\end{array}$ & VCG01213 & GCTCV218 & 2013 & $\begin{array}{l}\text { L.M. Bacus, Philippines, N. } \\
\text { Ordóñez }{ }^{9}, \text { Netherlands }\end{array}$ \\
\hline Phi3.4C & Asia & Philippines & $\begin{array}{l}\text { MADC Valencia } \\
\text { City }\end{array}$ & VCG01213 & Williams & 2013 & $\begin{array}{l}\text { A.F. Penalosa and L.M. Bacus, } \\
\text { Philippines, N. Ordóñez", } \\
\text { Netherlands }\end{array}$ \\
\hline Phi4.3A & Asia & Philippines & n.d. & VCG01213 & UNIC4 & 2013 & $\begin{array}{l}\text { A.F. Penalosa and L.M. Bacus, } \\
\text { Philippines, N. Ordóñez, } \\
\text { Netherlands }\end{array}$ \\
\hline Phi4.5A & Asia & Philippines & n.d. & VCG01213 & UNIC4 & 2013 & $\begin{array}{l}\text { A.F. Penalosa and L.M. Bacus, } \\
\text { Philippines, N. Ordóñez, } \\
\text { Netherlands }\end{array}$ \\
\hline Phi5.2A & Asia & Philippines & $\begin{array}{l}\text { SFARMBEMCO, } \\
\text { Barangay Maratos, } \\
\text { Davao }\end{array}$ & VCG01213 & Grand Naine & 2014 & N. Ordóñez, Netherlands \\
\hline $\mathrm{S} 1 \mathrm{~B} 12$ & Asia & Philippines & n.d. & VCG01213 & Tall Williams & n.d. & R.C. Ploetz, FL, USA \\
\hline STSUM2 & Asia & Indonesia & Sumatra & VCG01213 & Pisang Kepok & n.d. & R.C. Ploetz, FL, USA \\
\hline 24662 & Oceania & Australia & $\begin{array}{l}\text { Middle Point, } \\
\text { Darwin }\end{array}$ & VCG01213/16 & Cavendish & 1999 & A. Drenth, Brisbane, Australia \\
\hline
\end{tabular}




\begin{tabular}{|c|c|c|c|c|c|c|c|}
\hline $\begin{array}{l}\text { Isolate } \\
\text { code }\end{array}$ & $\begin{array}{l}\text { Macro } \\
\text { region }\end{array}$ & Country & Area & VCG & Host & $\begin{array}{l}\text { Year of } \\
\text { isolation }\end{array}$ & Provider \\
\hline 24663 & Oceania & Australia & $\begin{array}{l}\text { Middle Point, } \\
\text { Darwin }\end{array}$ & VCG01213/16 & Cavendish & 1999 & A. Drenth, Brisbane, Australia \\
\hline 24664 & Oceania & Australia & $\begin{array}{l}\text { Middle Point, } \\
\text { Darwin }\end{array}$ & VCG01213/16 & Cavendish & 1999 & A. Drenth, Brisbane, Australia \\
\hline Indo87 & Asia & Indonesia & Sulawesi & VCG01213/16 & Pisang Raja Serah & n.d. & W. O'Neil, Brisbane, Australia \\
\hline MLS5 & Asia & Malaysia & $\begin{array}{l}\text { United Plantations- } \\
\text { Future }\end{array}$ & VCG01213/16 & Rastali & n.d. & R.C. Ploetz, FL, USA \\
\hline RPML60 & Asia & Malaysia & $\begin{array}{l}\text { Johor Bahru, Hulu } \\
\text { Tiram-JTP }\end{array}$ & VCG01213/16 & Grand Naine & n.d. & R.C. Ploetz, FL, USA \\
\hline S1LAC & Asia & Philippines & n.d. & VCG01213/16 & Harare & n.d. & R.C. Ploetz, FL, USA \\
\hline Tw5 & Asia & China & Pingtun, Taiwan & VCG01213/16 & Gros Michel & n.d. & W. O'Neil, Brisbane, Australia \\
\hline NRRL36113 $3^{1,2}$ & Africa & Malawi & $\begin{array}{l}\text { Misuki Hills, } \\
\text { Karonga, }\end{array}$ & VCG01214* & $\begin{array}{l}\text { M. sapientum } \mathrm{cv} \\
\text { Harare }\end{array}$ & n.d. & $\begin{array}{l}\text { K. O'Donnell, Washington, } \\
\text { USA }\end{array}$ \\
\hline NRRL36112 1,2 & Africa & South Africa & $\begin{array}{l}\text { Burgershall. hazyvie } \\
\text { w }\end{array}$ & VCG01215* & $\begin{array}{l}\text { M. sapientum } \mathrm{cv} \\
\text { Cavendish }\end{array}$ & n.d. & $\begin{array}{l}\text { K. O'Donnell, Washington, } \\
\text { USA }\end{array}$ \\
\hline Indo84 & Asia & Indonesia & Java & VCG01216* & $\begin{array}{l}\text { Cavendish } \\
\text { (Williams) }\end{array}$ & n.d. & W. O'Neil, Brisbane, Australia \\
\hline Mal72 & Asia & Malaysia & Johor & VCG01216 & $\begin{array}{l}\text { Cavendish } \\
\text { (Williams) }\end{array}$ & n.d. & W. O'Neil, Brisbane, Australia \\
\hline Mal43 ${ }^{1}$ & Asia & Malaysia & n.d. & VCG01217* & Pisang Rastali & 1995 & A. Drenth, Brisbane, Australia \\
\hline Mal63 & Asia & Malaysia & Negeri Sembilan & VCG01217 & Pisang Rastali & 1995 & A. Drenth, Brisbane, Australia \\
\hline NRRL36120 & Asia & Thailand & $\begin{array}{l}\text { Yala Prov., hwys } 410 \\
\text { x } 4063\end{array}$ & VCG01218* & $\begin{array}{l}\text { M. sapientum cv } \\
\text { Kluai nam wa }\end{array}$ & n.d. & $\begin{array}{l}\text { K. O'Donnell, Washington, } \\
\text { USA }\end{array}$ \\
\hline II12 & Asia & Indonesia & $\begin{array}{l}\text { Cibinong Collection, } \\
\text { Java }\end{array}$ & VCG01219 & $\begin{array}{l}\text { Pisang ambon } \\
\text { putah }\end{array}$ & n.d. & R.C. Ploetz, FL, USA \\
\hline Indo $25^{1,2}$ & Asia & Indonesia & n.d. & VCG01219* & Pisang Ambon & 1993 & A. Drenth, Brisbane, Australia \\
\hline Indo35 & Asia & Indonesia & n.d. & VCG01219 & Pisang Raja Sereh & 1993 & A. Drenth, Brisbane, Australia \\
\hline 24200 & Oceania & Australia & Carnarvon & VCG01220 & n.d. & 1993 & A. Drenth, Brisbane, Australia \\
\hline 24218 & Oceania & Australia & Carnarvon & VCG01220* & Cavendish & 1993 & A. Drenth, Brisbane, Australia \\
\hline NRRL3611 $18^{1}$ & Asia & Thailand & $\begin{array}{l}\text { North of Chiang Rai, } \\
\text { hwy } 1\end{array}$ & VCG01221* & $\begin{array}{l}\text { M. sapientum cv } \\
\text { Kluai nam wa }\end{array}$ & n.d. & $\begin{array}{l}\text { K. O'Donnell, Washington, } \\
\text { USA }\end{array}$ \\
\hline NRRL36117 $7^{1,2}$ & Asia & Malaysia & $\begin{array}{l}\text { Penang Island Panta } \\
\text { Acheh }\end{array}$ & VCG01222* & $\begin{array}{l}\text { M. sapientum } \mathrm{cv} \\
\text { Pisang awak legor }\end{array}$ & n.d. & $\begin{array}{l}\text { K. O'Donnell, Washington, } \\
\text { USA }\end{array}$ \\
\hline NRRL36116 $6^{1,2}$ & Asia & Malaysia & Kuching, Sarawak & VCG01223* & $\begin{array}{l}\text { M. sapientum cv } \\
\text { Pisang keling }\end{array}$ & n.d. & $\begin{array}{l}\text { K. O'Donnell, Washington, } \\
\text { USA }\end{array}$ \\
\hline NRRL36115 1,2 & Asia & Malaysia & $\begin{array}{l}\text { Kuching, Seman } \\
\text { Matang, Sarawak }\end{array}$ & VCG01224* & $\begin{array}{l}\text { M. sapientum } \mathrm{cv} \\
\text { Pisang ambon }\end{array}$ & n.d. & $\begin{array}{l}\text { K. O'Donnell, Washington, } \\
\text { USA }\end{array}$ \\
\hline
\end{tabular}

These isolates were randomly selected to perform ${ }^{1}$ one technical, and ${ }^{2}$ one and ${ }^{3}$ two biological replicates for quality control on Diversity Array Technology sequencing (DArTseq). These isolates were originally stated as ${ }^{4} \mathrm{VCG} 0121,{ }^{5} 0123,{ }^{6} 0122,{ }^{7} 01210$ and ${ }^{8} 0120$ by sample providers, but they were assigned to the above-mentioned VCGs based on VCG testing and DArTseq analyses. Additionally, the Indo20 isolate was positively characterized as VCG01213 ${ }^{8}$ using TR4 primers (Dita et al., 2010). ${ }^{9}$ Providers sent tissue samples to our facilities and the isolation of the fungal isolate was performed at Wageningen University \& Research. *These isolates were selected as representatives for each of the 24 reported VCGs and used to calculate Jaccard and Hamming distances among them. n.d. stands for "not determined". 
Supplementary Table 2. Uncharacterized Fusarium oxysporum f.sp. cubense isolates recovered from Fusarium wilt symptomatic bananas, indicating their assigned vegetative compatibility group (VCG).

\begin{tabular}{|c|c|c|c|c|c|c|c|}
\hline $\begin{array}{l}\text { Isolate } \\
\text { code }\end{array}$ & $\begin{array}{l}\text { Macro } \\
\text { region }\end{array}$ & Country & Area & $\begin{array}{l}\text { Assigned } \\
\text { VCG }\end{array}$ & Host & $\begin{array}{l}\text { Year of } \\
\text { Isolation }\end{array}$ & Provider \\
\hline BIF.01 & America & Costa Rica & San Martín & VCG0120/15 & n.d. & 2011 & N. Chaves, Costa Rica \\
\hline BIF.04 & America & Costa Rica & Guayabo & VCG0120/15 $5^{3}$ & n.d. & 2011 & N. Chaves, Costa Rica \\
\hline BIF.11 & America & Costa Rica & San Martín & VCG0120/15 & n.d. & 2011 & N. Chaves, Costa Rica \\
\hline BIF.16 & America & Costa Rica & San Juan & VCG0120/15 & n.d. & 2011 & N. Chaves, Costa Rica \\
\hline BIF.19 & America & Costa Rica & San Martín & $\mathrm{VCG} 0120 / 15^{3}$ & n.d. & 2011 & N. Chaves, Costa Rica \\
\hline BIF.21 & America & Costa Rica & Guayabo & VCG0120/15 & n.d. & 2011 & N. Chaves, Costa Rica \\
\hline BIF.24 & America & Costa Rica & Guayabo & VCG0120/15 & n.d. & 2011 & N. Chaves, Costa Rica \\
\hline BIF.27 & America & Costa Rica & San Juan & $\mathrm{VCG} 0120 / 15^{3}$ & n.d. & 2011 & N. Chaves, Costa Rica \\
\hline BIF.28 & America & Costa Rica & San Juan & VCG0120/15 & n.d. & 2011 & N. Chaves, Costa Rica \\
\hline BIF.29 & America & Costa Rica & San Juan & VCG0120/15 & n.d. & 2011 & N. Chaves, Costa Rica \\
\hline BIF.30 & America & Costa Rica & Piedra Redonda & VCG0120/15 & n.d. & 2011 & N. Chaves, Costa Rica \\
\hline BIF.38 & America & Costa Rica & Piedra Redonda & VCG0120/15 & n.d. & 2011 & N. Chaves, Costa Rica \\
\hline BIF.41 & America & Costa Rica & Guayabo & $\mathrm{VCG} 0120 / 15^{3}$ & n.d. & 2011 & N. Chaves, Costa Rica \\
\hline BIF.43 & America & Costa Rica & Piedra Redonda & VCG0120/15 & n.d. & 2011 & N. Chaves, Costa Rica \\
\hline BIF.44 & America & Costa Rica & Guayabo & VCG0120/15 & n.d. & 2011 & N. Chaves, Costa Rica \\
\hline BIF.54 & America & Costa Rica & San Juan & VCG0120/15 & n.d. & 2011 & N. Chaves, Costa Rica \\
\hline BIF. 55 & America & Costa Rica & San Juan & VCG0120/15 & n.d. & 2011 & N. Chaves, Costa Rica \\
\hline BIF. 58 & America & Costa Rica & San Juan & $\mathrm{VCG} 0120 / 15^{3}$ & n.d. & 2011 & N. Chaves, Costa Rica \\
\hline BIF.60 & America & Costa Rica & Guayabo & VCG0120/15 & n.d. & 2011 & N. Chaves, Costa Rica \\
\hline BIF.78 & America & Costa Rica & San Juan & VCG0120/15 & n.d. & 2011 & N. Chaves, Costa Rica \\
\hline FocD $^{1}{ }^{1}$ & America & Costa Rica & n.d. & VCG0120/15 & n.d. & n.d. & N. Chaves, Costa Rica \\
\hline FD8 & America & Costa Rica & CATIE & VCG0120/15 & n.d. & n.d. & N. Chaves, Costa Rica \\
\hline FocP1 & America & Costa Rica & Turrialba & VCG0120/15 $5^{3}$ & n.d. & n.d. & N. Chaves, Costa Rica \\
\hline FocP11 & America & Costa Rica & Turrialba & VCG0120/15 & n.d. & n.d. & N. Chaves, Costa Rica \\
\hline FocP12 & America & Costa Rica & Turrialba & $\mathrm{VCG} 0120 / 15^{3}$ & n.d. & n.d. & N. Chaves, Costa Rica \\
\hline FocP13 & America & Costa Rica & Turrialba & VCG0120/15 & n.d. & n.d. & N. Chaves, Costa Rica \\
\hline FocP17 & America & Costa Rica & Turrialba & VCG0120/15 & n.d. & n.d. & N. Chaves, Costa Rica \\
\hline FocP7 & America & Costa Rica & Turrialba & VCG0120/15 & n.d. & n.d. & N. Chaves, Costa Rica \\
\hline FS2 & America & Costa Rica & n.d. & VCG0120/15 3 & n.d. & n.d. & N. Chaves, Costa Rica \\
\hline $\mathrm{P} 2 \mathrm{c}$ & America & Peru & Puente Capelo & VCG0120/15 & Isla & 2012 & $\begin{array}{l}\text { C. Roman, Costa Rica, N. } \\
\text { Ordóñez }{ }^{8} \text {, Netherlands }\end{array}$ \\
\hline P3 & America & Peru & Puente Capelo & VCG0120/15 & Isla & 2012 & $\begin{array}{l}\text { C. Roman, Costa Rica, N. } \\
\text { Ordóñez }{ }^{8} \text {, Netherlands }\end{array}$ \\
\hline $\mathrm{P} 24 \mathrm{c}$ & America & Peru & Zona18 & VCG0120/15 & Seda & 2012 & $\begin{array}{l}\text { C. Roman, Costa Rica, N. } \\
\text { Ordóñez }{ }^{8} \text {, Netherlands }\end{array}$ \\
\hline P29a & America & Peru & Pampa Rica & VCG0120/15 $5^{3}$ & Isla & 2012 & $\begin{array}{l}\text { C. Roman, Costa Rica, N. } \\
\text { Ordóñez }{ }^{8} \text {, Netherlands }\end{array}$ \\
\hline P30 & America & Peru & Pampa Rica & VCG0120/15 & Isla & 2012 & $\begin{array}{l}\text { C. Roman, Costa Rica, N. } \\
\text { Ordóñez } \\
\text {, Netherlands }\end{array}$ \\
\hline P34 & America & Peru & San Francisco & VCG0120/15 3 & Isla & 2012 & $\begin{array}{l}\text { C. Roman, Costa Rica, N. } \\
\text { Ordóñez }{ }^{8} \text {, Netherlands }\end{array}$ \\
\hline $\mathrm{P} 38^{2}$ & America & Peru & San Francisco & VCG0120/15 & Isla & 2012 & $\begin{array}{l}\text { C. Roman, Costa Rica, N. } \\
\text { Ordóñez }{ }^{8} \text {, Netherlands }\end{array}$ \\
\hline $\mathrm{P} 47 \mathrm{a}$ & America & Peru & $\begin{array}{l}\text { Santa Rosa de } \\
\text { Yapaz }\end{array}$ & VCG0120/15 & Isla & 2012 & $\begin{array}{l}\text { C. Roman, Costa Rica, N. } \\
\text { Ordóñez }{ }^{8} \text {, Netherlands }\end{array}$ \\
\hline $\mathrm{P} 57^{2}$ & America & Peru & Zonal7 & VCG0120/15 & Isla & 2012 & $\begin{array}{l}\text { C. Roman, Costa Rica, N. } \\
\text { Ordóñez }{ }^{8} \text {, Netherlands }\end{array}$ \\
\hline P59 & America & Peru & Zona17 & VCG0120/15 & Isla & 2012 & $\begin{array}{l}\text { C. Roman, Costa Rica, N. } \\
\text { Ordóñez } \\
\text {, Netherlands }\end{array}$ \\
\hline P80b1 & America & Peru & Zona17 & VCG0120/15 & Morado & 2012 & $\begin{array}{l}\text { C. Roman, Costa Rica, N. } \\
\text { Ordóñez } z^{8} \text {, Netherlands }\end{array}$ \\
\hline P87 & America & Peru & Cascada & VCG0120/15 & Seda & 2012 & $\begin{array}{l}\text { C. Roman, Costa Rica, N. } \\
\text { Ordóñez }{ }^{8} \text {, Netherlands }\end{array}$ \\
\hline P90 & America & Peru & Cascada & VCG0120/15 & Isla & 2012 & $\begin{array}{l}\text { C. Roman, Costa Rica, N. } \\
\text { Ordóñez }{ }^{8} \text {, Netherlands }\end{array}$ \\
\hline P107 & America & Peru & Yapaz Bajo & VCG0120/15 & Isla & 2012 & $\begin{array}{l}\text { C. Roman, Costa Rica, N. } \\
\text { Ordóñez } z^{8} \text {, Netherlands }\end{array}$ \\
\hline
\end{tabular}




\begin{tabular}{|c|c|c|c|c|c|c|c|}
\hline $\begin{array}{l}\text { Isolate } \\
\text { code }\end{array}$ & $\begin{array}{l}\text { Macro } \\
\text { region }\end{array}$ & Country & Area & $\begin{array}{l}\text { Assigned } \\
\text { VCG }\end{array}$ & Host & $\begin{array}{l}\text { Year of } \\
\text { Isolation }\end{array}$ & Provider \\
\hline P113d & America & Peru & Santa Cruz & VCG0120/15 & Manzano & 2012 & $\begin{array}{l}\text { C. Roman, Costa Rica, N. } \\
\text { Ordóñez }{ }^{8}, \text { Netherlands }\end{array}$ \\
\hline P114 & America & Peru & Santa Cruz & VCG0120/15 & Manzano & 2012 & $\begin{array}{l}\text { C. Roman, Costa Rica, N. } \\
\text { Ordóñez } z^{8}, \text { Netherlands }\end{array}$ \\
\hline P131 & America & Peru & Mariscal Castilla & VCG0120/15 & Morado & 2012 & $\begin{array}{l}\text { C. Roman, Costa Rica, N. } \\
\text { Ordóñez }{ }^{8}, \text { Netherlands }\end{array}$ \\
\hline P133 & America & Peru & Mariscal Castilla & VCG0120/15 3 & Morado & 2012 & $\begin{array}{l}\text { C. Roman, Costa Rica, N. } \\
\text { Ordóñez }{ }^{8} \text {, Netherlands }\end{array}$ \\
\hline T91.1B & Asia & China & Taiwan & VCG0121 $1^{3}$ & n.d. & n.d. & $\begin{array}{l}\text { M.J. Daboussi, Université Paris- } \\
\text { Sud, France }\end{array}$ \\
\hline T91.2 & Asia & China & Taiwan & VCG0121 & n.d. & n.d. & $\begin{array}{l}\text { M.J. Daboussi, Université Paris- } \\
\text { Sud, France }\end{array}$ \\
\hline T91.4C & Asia & China & Taiwan & VCG0121 & n.d. & n.d. & $\begin{array}{l}\text { M.J. Daboussi, Université Paris- } \\
\text { Sud, France }\end{array}$ \\
\hline T91.5A & Asia & China & Taiwan & VCG0121 & n.d. & n.d. & $\begin{array}{l}\text { M.J. Daboussi, Université Paris- } \\
\text { Sud, France }\end{array}$ \\
\hline T91.6C & Asia & China & Taiwan & VCG0121 & n.d. & n.d. & $\begin{array}{l}\text { M.J. Daboussi, Université Paris- } \\
\text { Sud, France }\end{array}$ \\
\hline T91.7 & Asia & China & Taiwan & VCG0121 3 & n.d. & n.d. & $\begin{array}{l}\text { M.J. Daboussi, Université Paris- } \\
\text { Sud, France }\end{array}$ \\
\hline BPNic0901 & America & Nicaragua & $\begin{array}{l}\text { Sabana Grande, } \\
\text { Potosi }\end{array}$ & VCG0124/5 3 & $\begin{array}{l}\text { Bluggoe } \\
\text { (Guineo } \\
\text { cuadrado) }\end{array}$ & n.d. & $\begin{array}{l}\text { J. Fernandez, APLARI- } \\
\text { COPLARI, Nicaragua }\end{array}$ \\
\hline BPNic0902 & America & Nicaragua & $\begin{array}{l}\text { Tolesmaida, } \\
\text { Buenos Aires }\end{array}$ & VCG0124/5 & $\begin{array}{l}\text { Bluggoe } \\
\text { (Gigante) }\end{array}$ & n.d. & $\begin{array}{l}\text { J. Fernandez, APLARI- } \\
\text { COPLARI, Nicaragua }\end{array}$ \\
\hline BPNic0903 & America & Nicaragua & $\begin{array}{l}\text { San Gregório, San } \\
\text { Jorge }\end{array}$ & VCG0124/5 & Bluggoe & n.d. & $\begin{array}{l}\text { J. Fernandez, APLARI- } \\
\text { COPLARI, Nicaragua }\end{array}$ \\
\hline BPS5.2 & Africa & Uganda & NE Kampala & VCG0124/5 3 & Sukara & n.d. & I.W. Buddenhagen, USA \\
\hline FrR 1242 & Africa & France & $\begin{array}{l}\text { St. Pierre de la } \\
\text { Reunion }\end{array}$ & VCG0124/5 3 & n.d. & n.d. & CIRAD, France \\
\hline FT1 & Africa & Uganda & n.d. & VCG0124/5 & Pisang Awak & n.d. & J. Lorenzen, IITA, Uganda \\
\hline FT13 & Africa & Uganda & n.d. & $\mathrm{VCG} 0124 / 5^{3}$ & Pelipita & n.d. & J. Lorenzen, IITA, Uganda \\
\hline FT23 & Africa & Uganda & n.d. & VCG0124/5 & Pisang Ceylan & n.d. & J. Lorenzen, IITA, Uganda \\
\hline MUCL38369 & America & USA & South Carolina & VCG0124/5 & Musa sp. & n.d. & $\begin{array}{l}\text { Université Cath. Louvain, } \\
\text { Belgium }\end{array}$ \\
\hline MUCL38370 & America & USA & South Carolina & VCG0124/5 & Musa sp. & n.d. & $\begin{array}{l}\text { Université Cath. Louvain, } \\
\text { Belgium }\end{array}$ \\
\hline Nic10.01 & America & Nicaragua & Apompoa, Potosi & VCG0124/5 $5^{3}$ & Bluggoe & 2010 & J. Hernandez, Nicaragua \\
\hline Nic 10.02 & America & Nicaragua & $\begin{array}{l}\text { Punta Caliente, } \\
\text { Rivas }\end{array}$ & VCG0124/5 & Bluggoee & 2010 & J. Hernandez, Nicaragua \\
\hline Nic10.04 & America & Nicaragua & Buenos Aires & VCG0124/5 & Bluggoe & 2010 & J. Hernandez, Nicaragua \\
\hline P47 & America & Peru & $\begin{array}{l}\text { Santa Rosa de } \\
\text { Yapaz }\end{array}$ & VCG0124/5 & Isla & 2012 & $\begin{array}{l}\text { C. Roman, Costa Rica, N. } \\
\text { Ordóñez } z^{8}, \text { Netherlands }\end{array}$ \\
\hline PNG5850ba & Oceania & $\begin{array}{l}\text { Papua new } \\
\text { Guinea }\end{array}$ & n.d. & VCG0126 & Babi & 2010 & $\begin{array}{l}\text { M. Dita and C. Waalwijk, } \\
\text { Netherlands }\end{array}$ \\
\hline PNG5851 & Oceania & $\begin{array}{l}\text { Papua new } \\
\text { Guinea }\end{array}$ & n.d. & VCG0126 3 & Babi & 2010 & $\begin{array}{l}\text { M. Dita and C. Waalwijk, } \\
\text { Netherlands }\end{array}$ \\
\hline PNG5852 & Oceania & $\begin{array}{l}\text { Papua new } \\
\text { Guinea }\end{array}$ & n.d. & VCG0126 & n.d. & 2010 & $\begin{array}{l}\text { M. Dita and C. Waalwijk, } \\
\text { Netherlands }\end{array}$ \\
\hline Aul0.02 & Oceania & Australia & n.d. & VCG01213 3,4 & Cavendish & 2010 & $\begin{array}{l}\text { M. Dita and C. Waalwijk, } \\
\text { Netherlands }\end{array}$ \\
\hline Au10.03 & Oceania & Australia & n.d. & VCG01213 & Cavendish & 2010 & $\begin{array}{l}\text { M. Dita and C. Waalwijk, } \\
\text { Netherlands }\end{array}$ \\
\hline BPI09.06 & Asia & Indonesia & Sumatra & VCG01213 3,4 & Berangan & 2009 & I.W. Buddenhagen, USA \\
\hline Chil.1A & Asia & China & n.d. & VCG01213 3,4 & n.d. & 2015 & $\begin{array}{l}\text { G.H.J. Kema, N. Ordóñez }{ }^{8} \text {, } \\
\text { Netherlands }\end{array}$ \\
\hline Phil.26c & Asia & Philippines & $\begin{array}{l}\text { Kapalong, Davao } \\
\text { del Norte }\end{array}$ & VCG01213 3,4 & Grand Naine & 2010 & $\begin{array}{l}\text { G.H.J. Kema, N. Ordóñez }{ }^{8} \text {, } \\
\text { Netherlands }\end{array}$ \\
\hline BIF.05 & America & Costa Rica & San Juan & new-VCG1 & n.d. & 2011 & N. Chaves, Costa Rica \\
\hline BIF.77 & America & Costa Rica & San Juan & new-VCG2 & n.d. & 2011 & N. Chaves, Costa Rica \\
\hline India16 & Asia & India & Kovvur & new-VCG3 ${ }^{5}$ & n.d. & 1999 & A. Drenth, Brisbane, Australia \\
\hline India30 & Asia & India & Kerala collection & new-VCG4 ${ }^{6}$ & Sugandhi & 1999 & A. Drenth, Brisbane, Australia \\
\hline India31 & Asia & India & Kerala collection & new-VCG $4^{6}$ & Nam Rai & 1999 & A. Drenth, Brisbane, Australia \\
\hline KdM1.1A & Africa & Kenya & $\begin{array}{l}\text { Numba Safari } \\
\text { Farm }\end{array}$ & new-VCG5 & Mshale & 2013 & $\begin{array}{l}\text { C.M. Muriuki, Del Monte, } \\
\text { Kenya, N. Ordóñez } \\
\text { Netherlands }\end{array}$ \\
\hline $\mathrm{KdM} 1.2 \mathrm{~A}$ & Africa & Kenya & $\begin{array}{l}\text { Mtwapa-Salhim } \\
\text { Farm }\end{array}$ & new-VCG5 & Bokoboko & 2013 & $\begin{array}{l}\text { C.M. Muriuki, Del Monte, } \\
\text { Kenya, N. Ordóñez } \\
\text { Netherlands }\end{array}$ \\
\hline $\mathrm{KdM} 1.3 \mathrm{~A}$ & Africa & Kenya & $\begin{array}{l}\text { Mtwada- } \\
\text { Matumbo } \\
\text { Mdonya }\end{array}$ & new-VCG5 & Bokoboko & 2013 & $\begin{array}{l}\text { C.M. Muriuki, Del Monte, } \\
\text { Kenya, N. Ordóñez } \\
\text { Netherlands }\end{array}$ \\
\hline STTNZ5 & Africa & Tanzania & $\begin{array}{l}\text { Kingori area, } \\
\text { Arusha dist }\end{array}$ & new-VCG5 ${ }^{6}$ & Bluggoe & n.d. & R.C. Ploetz, FL, USA \\
\hline Maul0.01 & Africa & Mauritius & n.d. & new-VCG6 & Gingeli Bes & 2010 & $\begin{array}{l}\text { M. Dita and C. Waalwijk, } \\
\text { Netherlands }\end{array}$ \\
\hline P9 & America & Peru & Puente Capelo & new-VCG7 & Isla & 2012 & $\begin{array}{l}\text { C. Roman, Costa Rica, N. } \\
\text { Ordóñez }{ }^{8} \text {, Netherlands }\end{array}$ \\
\hline
\end{tabular}




\begin{tabular}{|c|c|c|c|c|c|c|c|}
\hline $\begin{array}{l}\text { Isolate } \\
\text { code }\end{array}$ & $\begin{array}{l}\text { Macro } \\
\text { region }\end{array}$ & Country & Area & $\begin{array}{l}\text { Assigned } \\
\text { VCG }\end{array}$ & Host & $\begin{array}{l}\text { Year of } \\
\text { Isolation }\end{array}$ & Provider \\
\hline P14 & America & Peru & Sanchiro & new-VCG7 & Isla & 2012 & $\begin{array}{l}\text { C. Roman, Costa Rica, N. } \\
\text { Ordóñez }{ }^{8} \text {, Netherlands }\end{array}$ \\
\hline P17 & America & Peru & Sanchiro & new-VCG7 & Isla & 2012 & $\begin{array}{l}\text { C. Roman, Costa Rica, N. } \\
\text { Ordóñez } \\
\text {, Netherlands }\end{array}$ \\
\hline P18 & America & Peru & Pampa Rica & new-VCG7 & Manzano & 2012 & $\begin{array}{l}\text { C. Roman, Costa Rica, N. } \\
\text { Ordóñez } \\
\text {, Netherlands }\end{array}$ \\
\hline $\mathrm{P} 22$ & America & Peru & Pampa Rica & new-VCG7 & Manzano & 2012 & $\begin{array}{l}\text { C. Roman, Costa Rica, N. } \\
\text { Ordóñez }{ }^{8} \text {, Netherlands }\end{array}$ \\
\hline P24a & America & Peru & Zona 18 & new-VCG7 & Seda & 2012 & $\begin{array}{l}\text { C. Roman, Costa Rica, N. } \\
\text { Ordóñez }{ }^{8} \text {, Netherlands }\end{array}$ \\
\hline P49 & America & Peru & $\begin{array}{l}\text { Santa Rosa de } \\
\text { Yapaz }\end{array}$ & new-VCG7 & Isla & 2012 & $\begin{array}{l}\text { C. Roman, Costa Rica, N. } \\
\text { Ordóñez }{ }^{8} \text {, Netherlands }\end{array}$ \\
\hline P50 & America & Peru & $\begin{array}{l}\text { Santa Rosa de } \\
\text { Yapaz }\end{array}$ & new-VCG7 & Isla & 2012 & $\begin{array}{l}\text { C. Roman, Costa Rica, N. } \\
\text { Ordóñez } z^{8} \text {, Netherlands }\end{array}$ \\
\hline P61 & America & Peru & Zona17 & new-VCG7 & Isla & 2012 & $\begin{array}{l}\text { C. Roman, Costa Rica, N. } \\
\text { Ordóñez }{ }^{8} \text {, Netherlands }\end{array}$ \\
\hline P77 & America & Peru & Rio Seco & new-VCG7 & Isla & 2012 & $\begin{array}{l}\text { C. Roman, Costa Rica, N. } \\
\text { Ordóñez }{ }^{8} \text {, Netherlands }\end{array}$ \\
\hline P80b2 & America & Peru & Zona17 & new-VCG7 & Morado & 2012 & $\begin{array}{l}\text { C. Roman, Costa Rica, N. } \\
\text { Ordóñez }\end{array}$ \\
\hline P84 & America & Peru & Mariscal Castilla & new-VCG7 & Seda & 2012 & $\begin{array}{l}\text { C. Roman, Costa Rica, N. } \\
\text { Ordóñez } \\
\text {, Netherlands }\end{array}$ \\
\hline $\mathrm{P} 99^{2}$ & America & Peru & $\begin{array}{l}\text { Santa Rosa de } \\
\text { Yapaz }\end{array}$ & new-VCG7 & Isla & 2012 & $\begin{array}{l}\text { C. Roman, Costa Rica, N. } \\
\text { Ordóñez } \\
\text {, Netherlands }\end{array}$ \\
\hline P20d & America & Peru & Pampa Rica & new-VCG8 & Manzano & 2012 & $\begin{array}{l}\text { C. Roman, Costa Rica, N. } \\
\text { Ordóñez }{ }^{8} \text {, Netherlands }\end{array}$ \\
\hline P37 & America & Peru & San Francisco & new-VCG8 & Isla & 2012 & $\begin{array}{l}\text { C. Roman, Costa Rica, N. } \\
\text { Ordóñez } \\
\text {, Netherlands }\end{array}$ \\
\hline P41 & America & Peru & Nueva Industria & new-VCG8 & Seda & 2012 & $\begin{array}{l}\text { C. Roman, Costa Rica, N. } \\
\text { Ordóñez }{ }^{8} \text {, Netherlands }\end{array}$ \\
\hline P54 & America & Peru & Mariscal Castilla & new-VCG8 & Seda & 2012 & $\begin{array}{l}\text { C. Roman, Costa Rica, N. } \\
\text { Ordónez }{ }^{8} \text {, Netherlands }\end{array}$ \\
\hline P104 & America & Peru & Yapaz Bajo & new-VCG8 & Isla & 2012 & $\begin{array}{l}\text { C. Roman, Costa Rica, N. } \\
\text { Ordóñez }\end{array}$ \\
\hline $\mathrm{P} 113 \mathrm{c}$ & America & Peru & Santa Cruz & new-VCG8 & Manzano & 2012 & $\begin{array}{l}\text { C. Roman, Costa Rica, N. } \\
\text { Ordóñez } \\
\text {, Netherlands }\end{array}$ \\
\hline P132b & America & Peru & Marankiari & new-VCG8 & Manzano & 2012 & $\begin{array}{l}\text { C. Roman, Costa Rica, N. } \\
\text { Ordóñez }{ }^{8} \text {, Netherlands }\end{array}$ \\
\hline P96 & America & Peru & Cascada & new-VCG9 & Isla & 2012 & $\begin{array}{l}\text { C. Roman, Costa Rica, N. } \\
\text { Ordóñez }{ }^{8} \text {, Netherlands }\end{array}$ \\
\hline Uganda.5 & Africa & Uganda & n.d. & new-VCG $10^{7}$ & Kainja & 1999 & A. Drenth, Brisbane, Australia \\
\hline BPI09.02 & Asia & USA & $\begin{array}{l}\text { Marian Islands } \\
\text { (Saipan) }\end{array}$ & new-VCG11 & Silk & 2009 & I.W. Buddenhagen, USA \\
\hline BPI09.04 & Asia & USA & $\begin{array}{l}\text { Marian Islands } \\
\text { (Rota CNMI) }\end{array}$ & new-VCG11 & Silk & 2009 & I.W. Buddenhagen, USA \\
\hline BPI09.05 & Asia & USA & $\begin{array}{l}\text { Marian Islands } \\
\text { (Tinian Island) }\end{array}$ & new-VCG11 & Silk & 2009 & I.W. Buddenhagen, USA \\
\hline Foc 8 & America & Nicaragua & Jinotega & new-VCG12 & Gros Michel & n.d. & P. Lichtemberg, Nicaragua \\
\hline Foc16 & America & Nicaragua & Jinotega & new-VCG13 & Gros Michel & n.d. & P. Lichtemberg, Nicaragua \\
\hline Foc_R $1^{1,2}$ & America & Brazil & $\begin{array}{l}\text { Cruz das Almas, } \\
\text { Bahia }\end{array}$ & new-VCG14 & Silk & 2008 & $\begin{array}{l}\text { M. Dita and C. Waalwijk, } \\
\text { Netherlands }\end{array}$ \\
\hline Mall.5b & Africa & Malawi & n.d. & new-VCG15 & n.d. & 2013 & $\begin{array}{l}\text { G.H.J. Kema, N. Ordóñez }{ }^{8} \text {, } \\
\text { Netherlands }\end{array}$ \\
\hline P2d & America & Peru & Puente Capelo & new-VCG16 & Isla & 2012 & $\begin{array}{l}\text { C. Roman, Costa Rica, N. } \\
\text { Ordóñez }{ }^{8} \text {, Netherlands }\end{array}$ \\
\hline $\mathrm{P} 20 \mathrm{a}$ & America & Peru & Pampa Rica & new-VCG16 & Manzano & 2012 & $\begin{array}{l}\text { C. Roman, Costa Rica, N. } \\
\text { Ordóñez }{ }^{8} \text {, Netherlands }\end{array}$ \\
\hline P21 & America & Peru & Pampa Rica & new-VCG16 & Manzano & 2012 & $\begin{array}{l}\text { C. Roman, Costa Rica, N. } \\
\text { Ordóñez }{ }^{8} \text {, Netherlands }\end{array}$ \\
\hline P29b & America & Peru & Pampa Rica & new-VCG16 & Isla & 2012 & $\begin{array}{l}\text { C. Roman, Costa Rica, N. } \\
\text { Ordóñez }{ }^{8} \text {, Netherlands }\end{array}$ \\
\hline P113b & America & Peru & Santa Cruz & new-VCG16 & Manzano & 2012 & $\begin{array}{l}\text { C. Roman, Costa Rica, N. } \\
\text { Ordóñez }{ }^{8} \text {, Netherlands }\end{array}$ \\
\hline P6 & America & Peru & Puente Capelo & new-VCG17 & Isla & 2012 & $\begin{array}{l}\text { C. Roman, Costa Rica, N. } \\
\text { Ordóñez }{ }^{8} \text {, Netherlands }\end{array}$ \\
\hline $\mathrm{P} 15^{2}$ & America & Peru & Sanchiro & new-VCG17 & Isla & 2012 & $\begin{array}{l}\text { C. Roman, Costa Rica, N. } \\
\text { Ordóñez }{ }^{8} \text {, Netherlands }\end{array}$ \\
\hline P26 & America & Peru & Zona20 & new-VCG17 & Seda & 2012 & $\begin{array}{l}\text { C. Roman, Costa Rica, N. } \\
\text { Ordóñez }{ }^{8} \text {, Netherlands }\end{array}$ \\
\hline P55 & America & Peru & Mariscal Castilla & new-VCG17 & Seda & 2012 & $\begin{array}{l}\text { C. Roman, Costa Rica, N. } \\
\text { Ordóñez } \\
\text {, Netherlands }\end{array}$ \\
\hline P86 & America & Peru & Cascada & new-VCG17 & Isla & 2012 & $\begin{array}{l}\text { C. Roman, Costa Rica, N. } \\
\text { Ordóñez }{ }^{8} \text {, Netherlands }\end{array}$ \\
\hline P91 & America & Peru & Cascada & new-VCG17 & Isla & 2012 & $\begin{array}{l}\text { C. Roman, Costa Rica, N. } \\
\text { Ordóñez }{ }^{8} \text {, Netherlands }\end{array}$ \\
\hline P132d & America & Peru & Marankiari & new-VCG17 & Manzano & 2012 & $\begin{array}{l}\text { C. Roman, Costa Rica, N. } \\
\text { Ordóñez }{ }^{8} \text {, Netherlands }\end{array}$ \\
\hline P25 & America & Peru & Zona 19 & new-VCG18 & Seda & 2012 & $\begin{array}{l}\text { C. Roman, Costa Rica, N. } \\
\text { Ordóñez }{ }^{8} \text {, Netherlands }\end{array}$ \\
\hline P65 & America & Peru & Zona 17 & new-VCG18 & Isla & 2012 & $\begin{array}{l}\text { C. Roman, Costa Rica, N. } \\
\text { Ordóñez }{ }^{8} \text {, Netherlands }\end{array}$ \\
\hline P135 & America & Peru & Rio Seco & new-VCG18 & Palillo & 2012 & $\begin{array}{l}\text { C. Roman, Costa Rica, N. } \\
\text { Ordóñez }{ }^{8} \text {, Netherlands }\end{array}$ \\
\hline P93 & America & Peru & Cascada & new-VCG19 & Isla & 2012 & $\begin{array}{l}\text { C. Roman, Costa Rica, N. } \\
\text { Ordóñez }{ }^{8}, \text { Netherlands }\end{array}$ \\
\hline Phi6.6A & Asia & Philippines & $\begin{array}{l}\text { Nazaire, Maco, } \\
\text { Com Val }\end{array}$ & new-VCG20 & UNIC29 & 2014 & $\begin{array}{l}\text { L.M. Bacus, Philippines, N. } \\
\text { Ordóñez }{ }^{8} \text {, herlands }\end{array}$ \\
\hline
\end{tabular}




\section{Chapter 4}

These isolates were randomly selected to perform one ${ }^{1}$ technical and ${ }^{2}$ biological replicate for quality control on Diversity Array Technology sequencing (DArTseq). The assigned VCG for these isolates was based on DArTseq analyses and was further corroborated by ${ }^{3} \mathrm{VCG}$ testing and with ${ }^{4} \mathrm{TR} 4$ primers (Dita et. al., 2010). These fungal isolates were originally stated as ${ }^{5} \mathrm{VCG} 0124 / 5,{ }^{6} 01212$ and ${ }^{7} 01222$ by providers, but they were assigned to the above-mentioned VCGs based on VCG testing and DArTseq analyses. ${ }^{8}$ Providers sent tissue samples to our facilities and the isolation of the fungal isolate was performed at Wageningen University \& Research. n.d. stands for "not determined".

Supplementary Table 3. Fusarium oxysporum isolates pathogenic to other plant species and a non-pathogenic F. oxysporum isolate included in this study.

\begin{tabular}{|c|c|c|c|}
\hline Isolate code & formae speciales & Host & Provider \\
\hline 0.1879 & F. oxysporum f.sp. melongenae & Eggplant & C. Waalwijk, Netherlands \\
\hline $0.1954^{1}$ & F. oxysporum f.sp. canariensis & Palm & C. Waalwijk, Netherlands \\
\hline Fo $47^{2}$ & F. oxysporumnon-pathogenic & Non-pathogenic & C. Waalwijk, Netherlands \\
\hline Fol $4287^{2}$ & F. oxysporum f.sp. lycopersici & Tomatoe & S.M. Schmidt, Netherlands \\
\hline NRRL25433 & F. oxysporum f.sp. vasinfectum & Cotton & S.M. Schmidt, Netherlands \\
\hline CBS196.65 & F. oxysporum f.sp. narcissi & Narcissus & C. Waalwijk, Netherlands \\
\hline NRRL26381/CL57 $7^{2}$ & F. oxysporum f.sp. radicis-lycopersici & Tomato & S.M. Schmidt, Netherlands \\
\hline NRRL26406/Fom001 & F. oxysporum f.sp. melonis & Melon & S.M. Schmidt, Netherlands \\
\hline NRRL26761/IPO99.04 & F. oxysporum f.sp. phaseoli & Bean & C. Waalwijk, Netherlands \\
\hline NRRL28781/IPO99.02 & F. oxysporum f.sp. erythroxyli & Coca & C. Waalwijk, Netherlands \\
\hline NRRL37622/HDV247² & F. oxysporum f.sp. pisi & Pea & S.M. Schmidt, Netherlands \\
\hline NRRL54005/PHW815² & F. oxysporum f.sp. raphani & Radish & S.M. Schmidt, Netherlands \\
\hline NRRL54008/PHW808² & F. oxysporum f.sp. conglutinans & Cabbage & S.M. Schmidt, Netherlands \\
\hline
\end{tabular}

These isolates were randomly selected to perform one ${ }^{1}$ technical and ${ }^{2}$ biological replicate for quality control on Diversity Array Technology sequencing. 
Global Foc phylogeography

Supplementary Table 4. Average Jaccard and Hamming distances within replicates of 39 selected isolates.

\begin{tabular}{|c|c|c|c|}
\hline Isolate code & No. replicates & Jaccard & Hamming \\
\hline 0.1954 & 2 & 0 & 0 \\
\hline BPI09.01 & 3 & 0.02 & 0.7 \\
\hline Fo47 & 2 & 0 & 1.0 \\
\hline Foc19508 & 2 & 0 & 0 \\
\hline Foc_R1 & 3 & 0.01 & 5.3 \\
\hline Foc_R2 & 3 & 0.01 & 0.7 \\
\hline FocD3 & 2 & 0.06 & 2.0 \\
\hline Focu7 & 4 & 0.01 & 1.5 \\
\hline FocST498 & 4 & 0.01 & 0.5 \\
\hline Fol4287 & 2 & 0.01 & 6.0 \\
\hline II5 & 3 & 0.01 & 1.3 \\
\hline Indo25 & 3 & 0.06 & 2.7 \\
\hline Mal43 & 2 & 0.07 & 17 \\
\hline NRRL26381/CL57 & 2 & 0.01 & 5.0 \\
\hline NRRL36101 & 3 & 0.02 & 0.7 \\
\hline NRRL36102 & 3 & 0.02 & 2.0 \\
\hline NRRL36103 & 4 & 0.02 & 1.0 \\
\hline NRRL36105 & 4 & 0.05 & 2.8 \\
\hline NRRL36106 & 3 & 0.05 & 4.0 \\
\hline NRRL36107 & 3 & 0.04 & 2.7 \\
\hline NRRL36108 & 3 & 0.05 & 5.3 \\
\hline NRRL36109 & 3 & 0.04 & 1.3 \\
\hline NRRL36110 & 4 & 0.02 & 1.7 \\
\hline NRRL36111 & 4 & 0.05 & 2.7 \\
\hline NRRL36112 & 3 & 0 & 0 \\
\hline NRRL36113 & 3 & 0.01 & 4.7 \\
\hline NRRL36114 & 3 & 0.01 & 2.0 \\
\hline NRRL36115 & 3 & 0.02 & 6.0 \\
\hline NRRL36116 & 3 & 0.01 & 2.0 \\
\hline NRRL36117 & 3 & 0.03 & 2.0 \\
\hline NRRL36118 & 2 & 0.02 & 21.0 \\
\hline NRRL36120 & 2 & 0.02 & 12.0 \\
\hline NRRL37622/HDV247 & 2 & 0.01 & 1.0 \\
\hline NRRL54008/PHW808 & 2 & 0.01 & 8.0 \\
\hline NRRL54005/PHW815 & 2 & 0.01 & 7.0 \\
\hline P15a & 3 & 0 & 0 \\
\hline P38 & 2 & 0.03 & 1.0 \\
\hline P57 & 2 & 0.06 & 2.0 \\
\hline P99 & 2 & 0 & 0 \\
\hline
\end{tabular}




\section{Chapter 4}

Supplementary Table 5. Jaccard distances among all 24 reported Fusarium oxysporum f.sp. cubense vegetative compatibility groups (VCGs). The isolates representing each of the VCGs are highlighted in Table 1. Genetic distances for cross-compatible VCGs are highlighted in grey.

\begin{tabular}{|c|c|c|c|c|c|c|c|c|c|c|c|c|c|c|c|c|c|c|c|c|c|c|c|}
\hline \multirow[b]{2}{*}{ VCG012 } & \multicolumn{11}{|c|}{ Clade 1} & \multicolumn{12}{|c|}{ Clade 2} \\
\hline & 1 & 13 & 16 & 10 & 2 & 6 & 19 & 9 & 15 & 0 & 11 & 12 & 20 & 22 & 5 & 4 & 8 & 18 & 21 & 14 & 17 & 3 & 24 \\
\hline 13 & 0.53 & & & & & & & & & & & & & & & & & & & & & & \\
\hline 16 & 0.53 & 0.18 & & & & & & & & & & & & & & & & & & & & & \\
\hline 10 & 0.86 & 0.90 & 0.90 & & & & & & & & & & & & & & & & & & & & \\
\hline 2 & 0.75 & 0.84 & 0.86 & 0.81 & & & & & & & & & & & & & & & & & & & \\
\hline 6 & 0.80 & 0.86 & 0.86 & 0.87 & 0.71 & & & & & & & & & & & & & & & & & & \\
\hline 19 & 0.85 & 0.90 & 0.90 & 0.86 & 0.68 & 0.67 & & & & & & & & & & & & & & & & & \\
\hline 9 & 0.85 & 0.88 & 0.88 & 0.84 & 0.78 & 0.85 & 0.81 & & & & & & & & & & & & & & & & \\
\hline 15 & 0.82 & 0.87 & 0.89 & 0.85 & 0.62 & 0.69 & 0.62 & 0.81 & & & & & & & & & & & & & & & \\
\hline 0 & 0.82 & 0.87 & 0.89 & 0.85 & 0.61 & 0.70 & 0.56 & 0.78 & 0.20 & & & & & & & & & & & & & & \\
\hline 11 & 0.82 & 0.88 & 0.89 & 0.83 & 0.63 & 0.71 & 0.64 & 0.81 & 0.27 & 0.23 & & & & & & & & & & & & & \\
\hline 12 & 0.96 & 0.95 & 0.96 & 0.95 & 0.94 & 0.93 & 0.94 & 0.93 & 0.90 & 0.91 & 0.91 & & & & & & & & & & & & \\
\hline 20 & 0.93 & 0.95 & 0.95 & 0.93 & 0.90 & 0.90 & 0.91 & 0.90 & 0.84 & 0.85 & 0.85 & 0.70 & & & & & & & & & & & \\
\hline 22 & 0.93 & 0.94 & 0.94 & 0.92 & 0.91 & 0.90 & 0.90 & 0.90 & 0.84 & 0.85 & 0.85 & 0.73 & 0.21 & & & & & & & & & & \\
\hline 5 & 0.95 & 0.94 & 0.92 & 0.93 & 0.94 & 0.90 & 0.92 & 0.92 & 0.88 & 0.88 & 0.90 & 0.77 & 0.45 & 0.41 & & & & & & & & & \\
\hline 4 & 0.93 & 0.95 & 0.94 & 0.92 & 0.91 & 0.90 & 0.90 & 0.90 & 0.84 & 0.85 & 0.85 & 0.72 & 0.20 & 0.14 & 0.42 & & & & & & & & \\
\hline 8 & 0.93 & 0.95 & 0.93 & 0.92 & 0.91 & 0.90 & 0.90 & 0.90 & 0.83 & 0.84 & 0.84 & 0.72 & 0.16 & 0.10 & 0.40 & 0.12 & & & & & & & \\
\hline 18 & 0.98 & 0.98 & 0.98 & 0.98 & 0.99 & 0.98 & 0.99 & 0.98 & 0.98 & 0.98 & 0.99 & 0.96 & 0.96 & 0.96 & 0.95 & 0.96 & 0.96 & & & & & & \\
\hline 21 & 0.99 & 0.99 & 0.99 & 0.99 & 0.99 & 0.99 & 1.00 & 0.99 & 0.99 & 0.99 & 0.99 & 0.98 & 0.98 & 0.98 & 0.98 & 0.98 & 0.98 & 0.96 & & & & & \\
\hline 14 & 0.98 & 0.98 & 0.97 & 0.98 & 0.98 & 0.97 & 0.98 & 0.98 & 0.97 & 0.97 & 0.97 & 0.96 & 0.96 & 0.95 & 0.94 & 0.95 & 0.95 & 0.95 & 0.97 & & & & \\
\hline 17 & 0.97 & 0.96 & 0.97 & 0.97 & 0.96 & 0.96 & 0.98 & 0.97 & 0.96 & 0.96 & 0.97 & 0.93 & 0.92 & 0.92 & 0.91 & 0.92 & 0.92 & 0.93 & 0.95 & 0.94 & & & \\
\hline 3 & 0.97 & 0.96 & 0.97 & 0.97 & 0.97 & 0.96 & 0.98 & 0.98 & 0.97 & 0.97 & 0.97 & 0.94 & 0.93 & 0.92 & 0.91 & 0.92 & 0.93 & 0.93 & 0.94 & 0.95 & 0.38 & & \\
\hline 24 & 0.97 & 0.97 & 0.97 & 0.97 & 0.96 & 0.96 & 0.98 & 0.97 & 0.97 & 0.97 & 0.97 & 0.94 & 0.91 & 0.91 & 0.92 & 0.91 & 0.91 & 0.93 & 0.95 & 0.95 & 0.36 & 0.40 & \\
\hline 23 & 0.97 & 0.97 & 0.97 & 0.97 & 0.96 & 0.96 & 0.98 & 0.97 & 0.96 & 0.97 & 0.97 & 0.93 & 0.92 & 0.92 & 0.92 & 0.92 & 0.92 & 0.93 & 0.94 & 0.95 & 0.36 & 0.39 & 0.32 \\
\hline
\end{tabular}

Supplementary Table 6. Hamming distances among all 24 reported Fusarium oxysporum f.sp. cubense vegetative compatibility groups (VCGs). The isolates representing each of the VCGs are highlighted in Table 1. Genetic distances for cross-compatible VCGs are highlighted in grey.

\begin{tabular}{|c|c|c|c|c|c|c|c|c|c|c|c|c|c|c|c|c|c|c|c|c|c|c|c|}
\hline \multirow[b]{2}{*}{ VCG012 } & \multicolumn{11}{|c|}{ Clade 1 } & \multicolumn{12}{|c|}{ Clade 2} \\
\hline & 1 & 13 & 16 & 10 & 2 & 6 & 19 & 9 & 15 & 0 & 11 & 12 & 20 & 22 & 5 & 4 & 8 & 18 & 21 & 14 & 17 & 3 & 24 \\
\hline 13 & 83 & & & & & & & & & & & & & & & & & & & & & & \\
\hline 16 & 90 & 31 & & & & & & & & & & & & & & & & & & & & & \\
\hline 10 & 165 & 222 & 231 & & & & & & & & & & & & & & & & & & & & \\
\hline 2 & 88 & 147 & 158 & 119 & & & & & & & & & & & & & & & & & & & \\
\hline 6 & 112 & 167 & 172 & 151 & 68 & & & & & & & & & & & & & & & & & & \\
\hline 19 & 103 & 160 & 165 & 126 & 49 & 59 & & & & & & & & & & & & & & & & & \\
\hline 9 & 143 & 196 & 201 & 160 & 95 & 127 & 96 & & & & & & & & & & & & & & & & \\
\hline 15 & 86 & 139 & 150 & 113 & 36 & 54 & 33 & 87 & & & & & & & & & & & & & & & \\
\hline 0 & 89 & 142 & 153 & 116 & 37 & 57 & 30 & 84 & 7 & & & & & & & & & & & & & & \\
\hline 11 & 90 & 145 & 154 & 113 & 40 & 60 & 37 & 91 & 10 & 9 & & & & & & & & & & & & & \\
\hline 12 & 176 & 225 & 234 & 199 & 130 & 148 & 125 & 171 & 104 & 109 & 110 & & & & & & & & & & & & \\
\hline 20 & 128 & 181 & 188 & 151 & 84 & 102 & 79 & 123 & 58 & 63 & 64 & 80 & & & & & & & & & & & \\
\hline 22 & 133 & 186 & 189 & 154 & 91 & 107 & 84 & 128 & 63 & 68 & 69 & 89 & 13 & & & & & & & & & & \\
\hline 5 & 159 & 204 & 205 & 180 & 117 & 127 & 108 & 152 & 87 & 92 & 95 & 113 & 39 & 36 & & & & & & & & & \\
\hline 4 & 134 & 189 & 190 & 157 & 92 & 108 & 85 & 129 & 64 & 69 & 70 & 88 & 12 & 9 & 37 & & & & & & & & \\
\hline 8 & 129 & 184 & 185 & 152 & 87 & 103 & 80 & 124 & 59 & 64 & 65 & 85 & 9 & 6 & 34 & 7 & & & & & & & \\
\hline 18 & 713 & 756 & 769 & 742 & 673 & 685 & 672 & 716 & 651 & 656 & 659 & 689 & 643 & 646 & 658 & 649 & 644 & & & & & & \\
\hline 21 & 1040 & 1091 & 1098 & 1065 & 998 & 1014 & 1001 & 1045 & 980 & 985 & 986 & 1016 & 986 & 985 & 1009 & 990 & 985 & 1483 & & & & & \\
\hline 14 & 400 & 451 & 452 & 427 & 356 & 370 & 353 & 403 & 332 & 337 & 338 & 386 & 342 & 345 & 357 & 346 & 341 & 869 & 1206 & & & & \\
\hline 17 & 309 & 350 & 365 & 334 & 261 & 277 & 262 & 310 & 241 & 246 & 249 & 285 & 239 & 244 & 258 & 247 & 242 & 752 & 1085 & 487 & & & \\
\hline 3 & 388 & 431 & 446 & 415 & 342 & 358 & 345 & 393 & 322 & 327 & 330 & 360 & 314 & 319 & 329 & 320 & 317 & 825 & 1142 & 572 & 129 & & \\
\hline 24 & 313 & 364 & 375 & 342 & 267 & 289 & 270 & 318 & 249 & 254 & 255 & 295 & 243 & 248 & 270 & 247 & 244 & 766 & 1091 & 505 & 104 & 139 & \\
\hline 23 & 314 & 363 & 374 & 341 & 266 & 288 & 269 & 317 & 248 & 253 & 254 & 292 & 244 & 251 & 273 & 250 & 247 & 761 & 1062 & 506 & 103 & 132 & 89 \\
\hline
\end{tabular}


Supplementary Table 7. Geographical distribution of Fusarium oxysporum f.sp. cubense vegetative compatible groups (VCGs) in our global collection.

\begin{tabular}{|c|c|c|c|c|c|}
\hline Macro region & Country (region) & $\begin{array}{l}\text { No. } \\
\text { isolates }\end{array}$ & VCG & $\begin{array}{l}\text { No. } \\
\text { VCGs }\end{array}$ & Mating type \\
\hline \multirow[t]{2}{*}{ Africa } & Burundi & 3 & $0124 / 5 / 8$ & 3 & MAT1-2 \\
\hline & France (La Reunion) & 1 & $0124 / 5$ & 2 & MAT1-2 \\
\hline Total number of isolates & Kenya & 3 & new-VCG5 & 1 & MAT1-2 \\
\hline 37 & Malawi & 6 & 0124/5, 01214, new-VCG15 & 4 & $\begin{array}{l}\text { MAT1-1; } \\
\text { MAT1-2 }\end{array}$ \\
\hline Total number of VCGs & Mauritius & 1 & new-VCG6 & 1 & MAT1-1 \\
\hline \multirow[t]{5}{*}{$11:$ reported $=7$, new $=4$} & Rwanda & 1 & 0124 & 1 & MAT1-2 \\
\hline & South Africa & 9 & $0120 / 15$ & 2 & MAT1-2 \\
\hline & Spain (Canary Island) & 2 & 0120 & 1 & $M A T 1-2$ \\
\hline & Tanzania & 3 & 01212, new-VCG5 & 2 & $M A T 1-2$ \\
\hline & Uganda & 8 & $0124 / 5$, new-VCG10 & 3 & $M A T 1-2$ \\
\hline \multirow[t]{2}{*}{ America } & Brazil & 5 & $0120 / 15,0124$, new-VCG14 & 4 & MAT1-2 \\
\hline & Costa Rica & 35 & 0120/15, new VCG1, new-VCG2 & 4 & MAT1-1; \\
\hline \multirow{2}{*}{$\begin{array}{l}\text { Total number of isolates } \\
134\end{array}$} & & & & & $M A T 1-2$ \\
\hline & Cuba & 7 & $0124 / 5 / 8,01210$ & 4 & $\begin{array}{l}\text { MAT1-1; } \\
\text { MAT1-2 }\end{array}$ \\
\hline \multirow{7}{*}{$\begin{array}{l}\text { Total number of VCGs } \\
\text { 19: reported }=7, \text { new }=12\end{array}$} & France (Caribbean islands) & 2 & $0120 / 15,0126$ & 3 & MAT1-2 \\
\hline & Honduras & 6 & $0120,0124,0126$ & 3 & MAT1-2 \\
\hline & Jamaica & 4 & $0120,0124 / 5$ & 3 & MAT1-2 \\
\hline & Mexico & 2 & $0124 / 5 / 8$ & 3 & MAT1-2 \\
\hline & Nicaragua & 10 & 0124/5/8, new-VCG12, new-VCG13 & 5 & $M A T 1-2$ \\
\hline & Peru & 56 & $\begin{array}{l}\text { 0120/15, 0124/5, new-VCG7, new-VCG8, new- } \\
\text { VCG9, new-VCG16, new-VCG17, new- } \\
\text { VCG18, new-VCG19 }\end{array}$ & 11 & $\begin{array}{l}\text { MAT1-1; } \\
\text { MAT1-2 }\end{array}$ \\
\hline & USA (Florida) & 7 & $0124 / 5 / 8,01210$ & 4 & $\begin{array}{l}\text { MAT1-1; } \\
\text { MAT1-2 }\end{array}$ \\
\hline Asia & China & 13 & $0121,0123,01213 / 16$ & 4 & $\begin{array}{l}\text { MAT1-1; } \\
\text { MAT1-2 }\end{array}$ \\
\hline Total number of isolates & India & 5 & 0124/5, new-VCG3, new-VCG4 & 4 & $M A T 1-2$ \\
\hline 73 & Indonesia & 16 & $0120 / 15,0126,01213 / 16,01219$ & 6 & $\begin{array}{l}\text { MAT1-1; } \\
\text { MAT1-2 }\end{array}$ \\
\hline Total number of VCGs & Jordan & 1 & 01213 & 1 & MAT1-1 \\
\hline \multirow{7}{*}{$21:$ reported $=17$, new $=4$} & Lebanon & 1 & 01213 & 1 & MAT1-1 \\
\hline & Malaysia & 11 & $\begin{array}{l}0120,0123,01213 / 16,01217,01222,01223 \text {, } \\
01224\end{array}$ & 8 & $\begin{array}{l}\text { MAT1-1; } \\
\text { MAT1-2 }\end{array}$ \\
\hline & Pakistan & 1 & 01213 & 1 & MAT1-1 \\
\hline & Philippines & 12 & $0122,01213 / 16$, new-VCG20 & 4 & MAT1-1 \\
\hline & Thailand & 7 & $0123,0124 / 5 / 8,01218,01221$ & 6 & $\begin{array}{l}\text { MAT1-1; } \\
\text { MAT1-2 }\end{array}$ \\
\hline & USA (Marian Islands) & 3 & new-VCG11 & 1 & MAT1-1 \\
\hline & Vietnam & 3 & $0124 / 5$ & 2 & $M A T 1-2$ \\
\hline Oceania & Australia & 36 & $0120,0124 / 5 / 8 / 20,0129,01211,01213 / 16,01220$ & 10 & $\begin{array}{l}\text { MAT1-1; } \\
\text { MAT1-2 }\end{array}$ \\
\hline $\begin{array}{l}\text { Total number of isolates } \\
39\end{array}$ & Papua New Guinea & 3 & 0126 & 1 & $M A T 1-2$ \\
\hline $\begin{array}{l}\text { Total number of VCGs } \\
\text { 11: reported }=11\end{array}$ & & & & & \\
\hline
\end{tabular}


Chapter 4

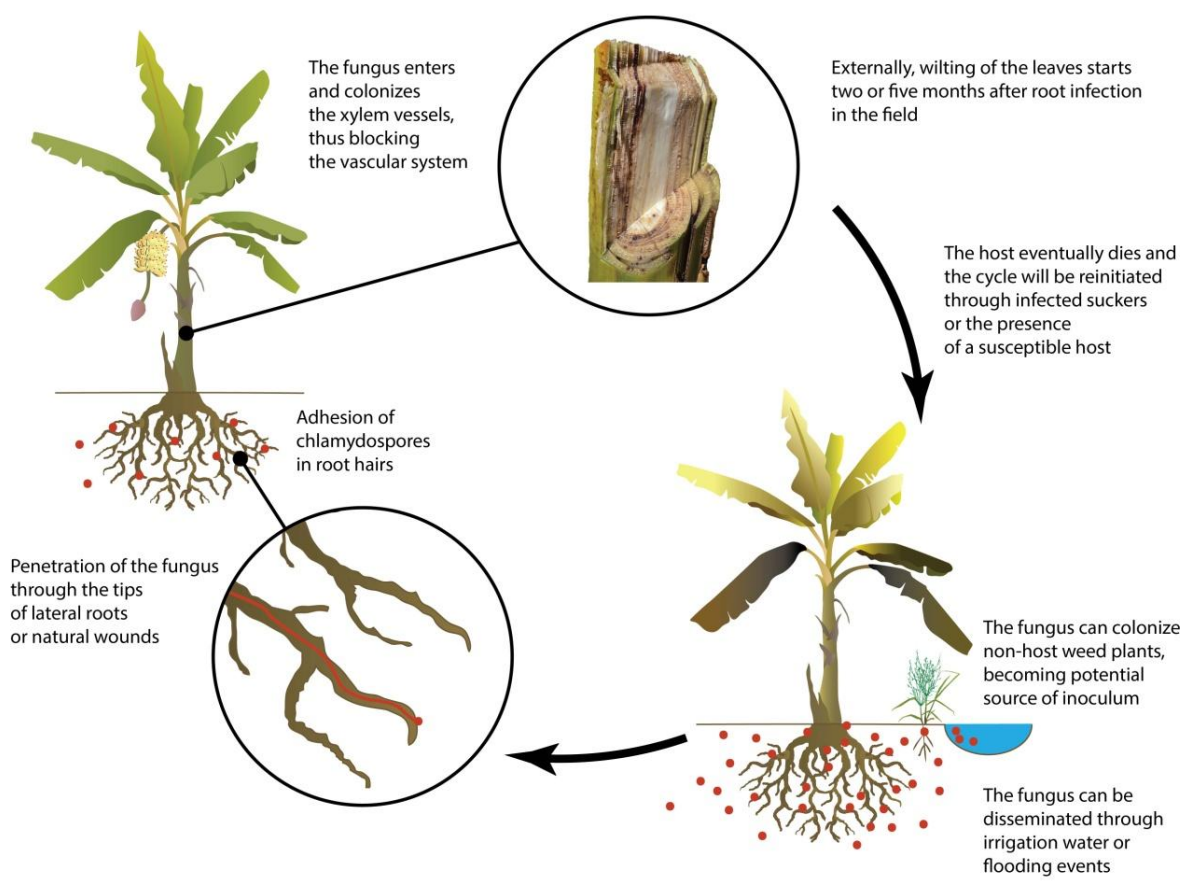

Supplementary Figure 1. Disease cycle of Fusarium oxysporum f.sp. cubense in bananas. 


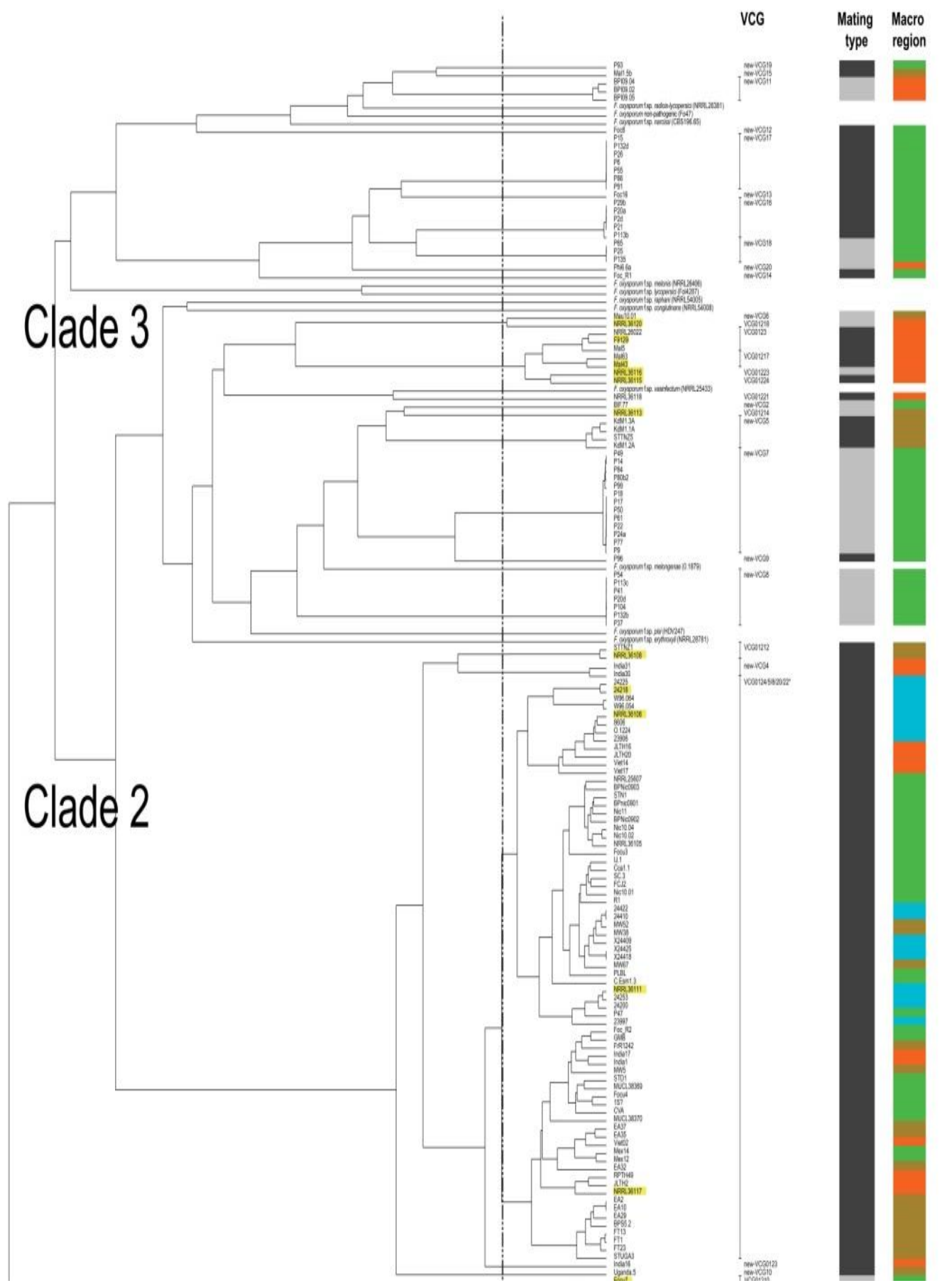


Chapter 4

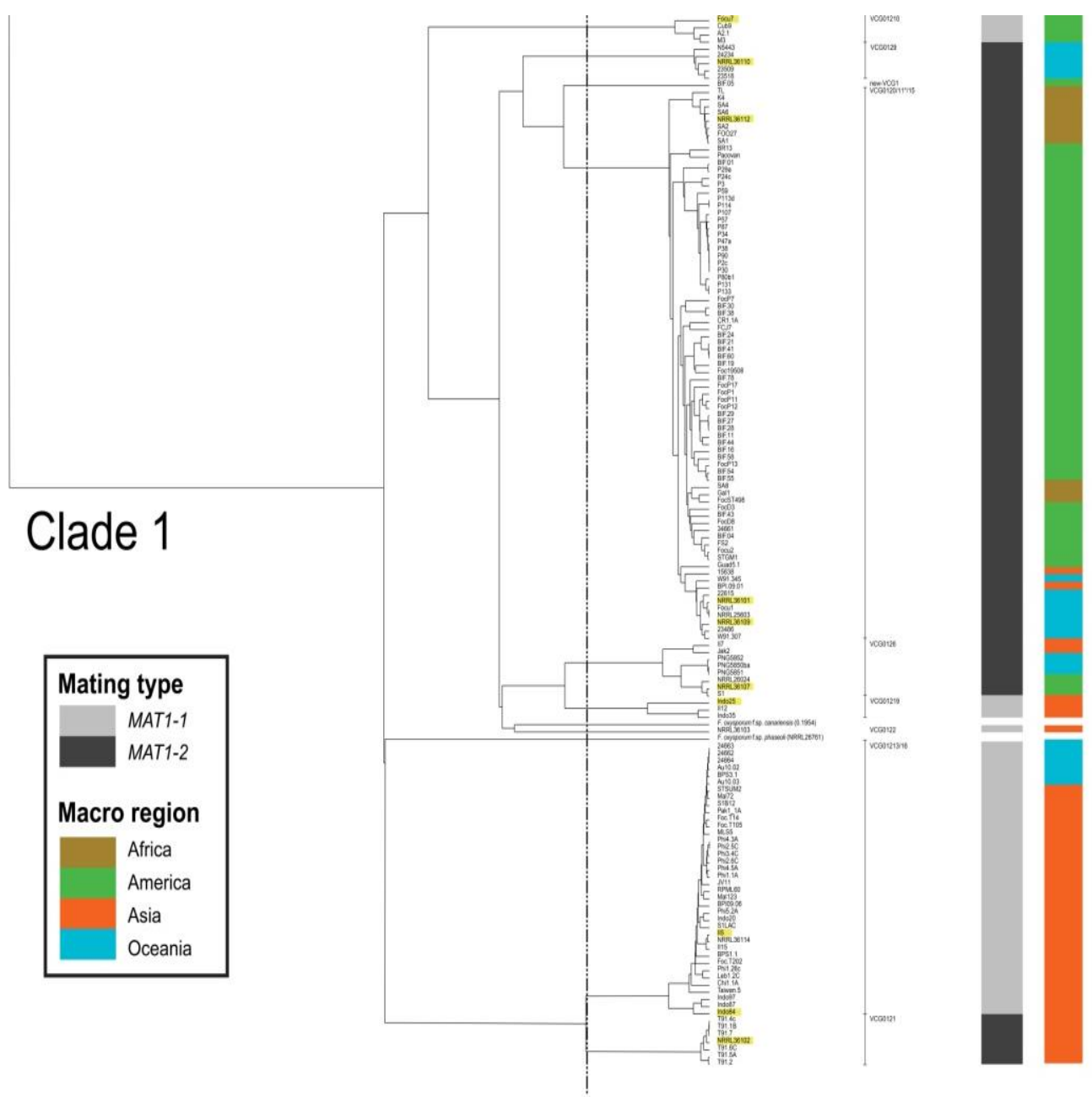

Supplementary Figure 2. Hierarchical clustering of all 296 Fusarium oxysporum f.sp. cubense isolates included in our global collection based on 25,282 DArTseq markers (representative 24 vegetative compatibility groups highlighted). The dotted line indicates the threshold of successful heterokaryon formation between isolates. The mating types and continental regions of isolates are indicated in colors. 


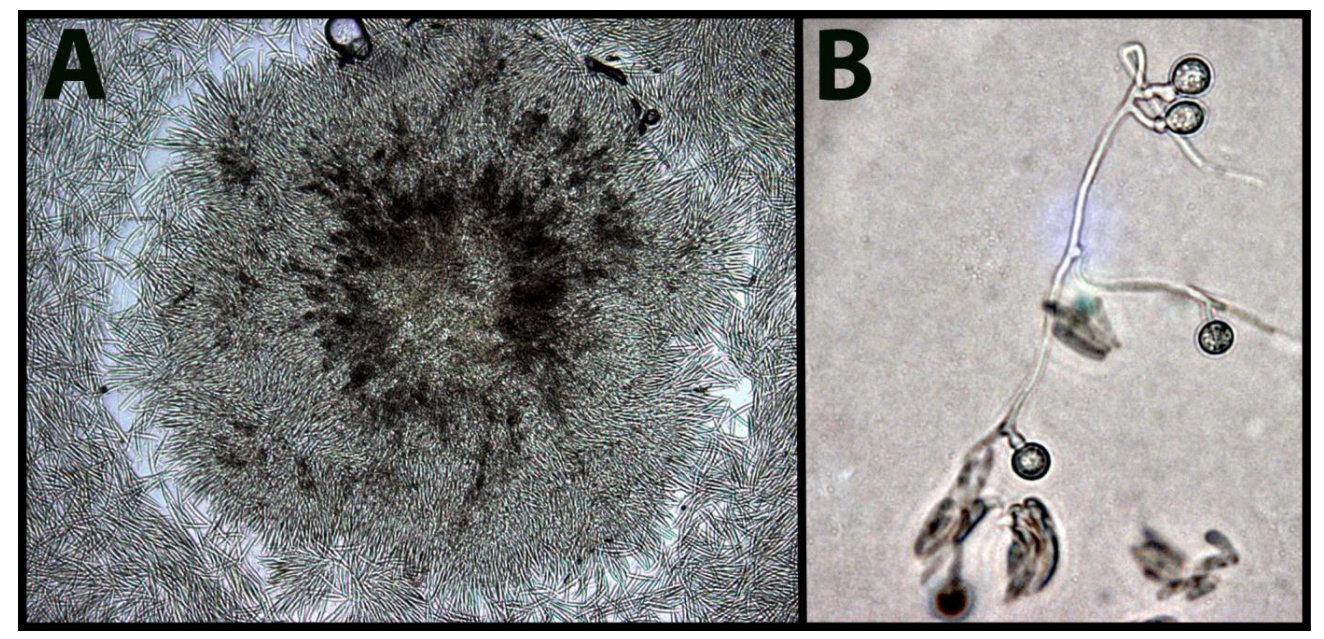

Supplementary Figure 3. Typical morphological features for F. oxysporum strains observed for Foc_R1 isolate: A) sporodochia and B) chlamydospores.

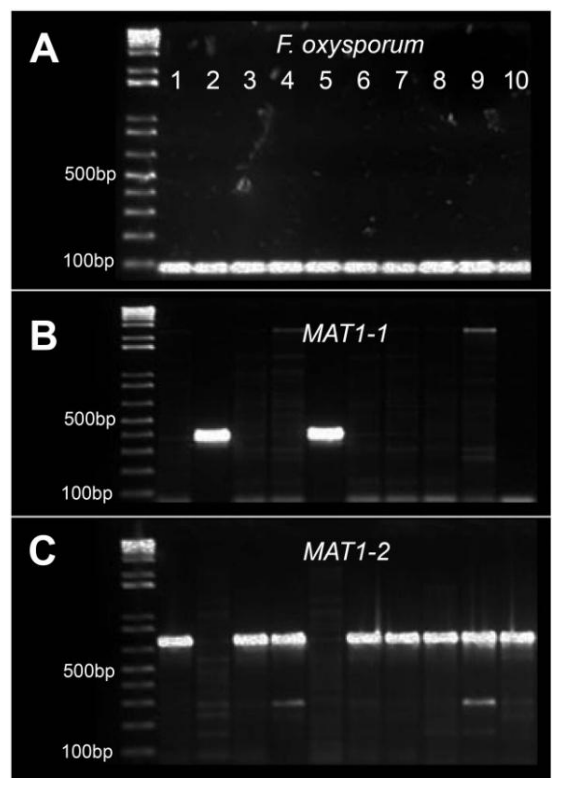

Supplementary Figure 4. PCR characterization of $F$. oxysporum strains using (A) F. oxysporum, (B) MAT1-1 and (C) MAT1-2 primers on (1-10) NRRL36101, BPI09.04, India31, 24200, Indo35, Indo30, 23906, 23509, Foc16 and FT23 isolates. 


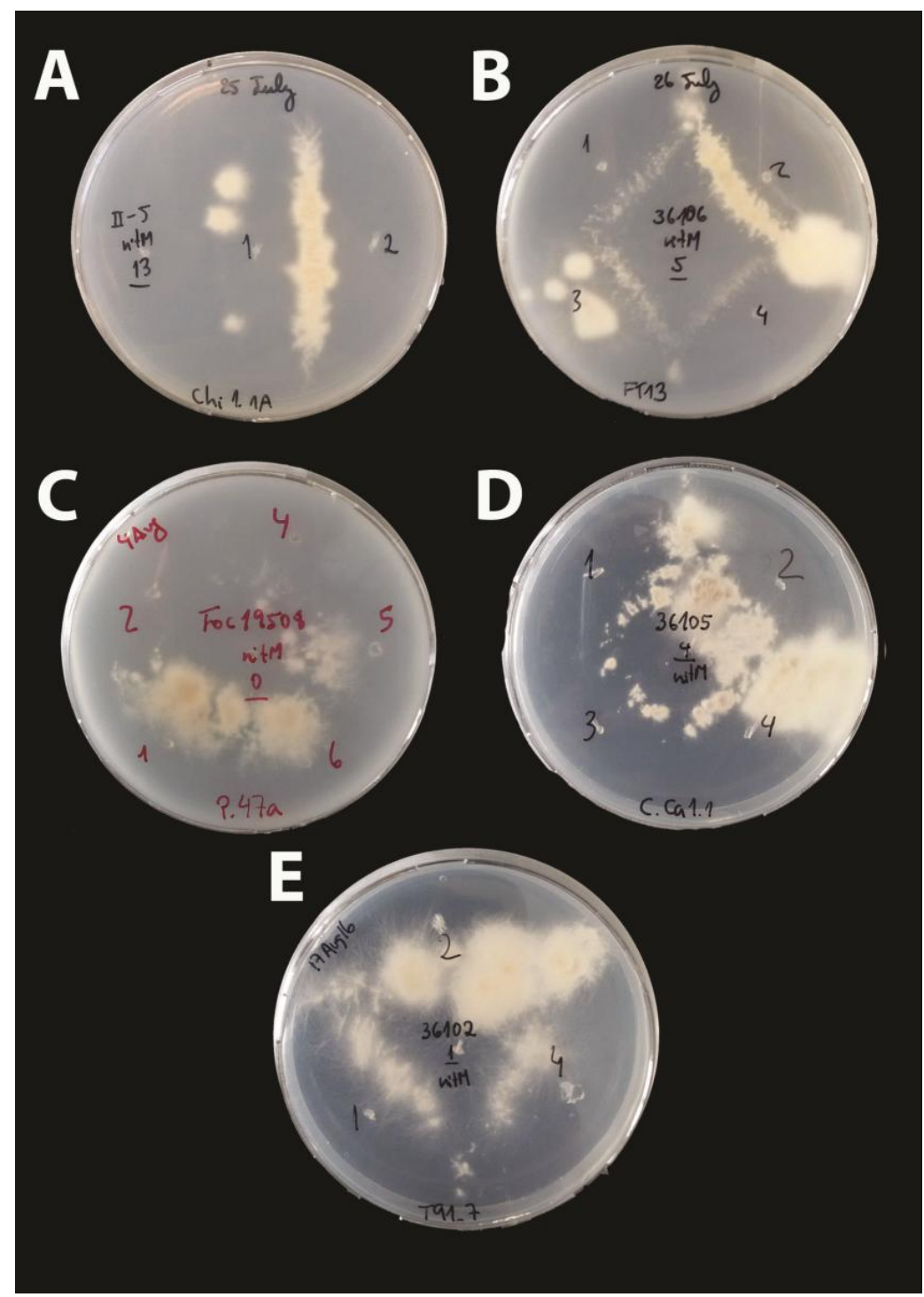

Supplementary Figure 5. Heterokaryon formation between compatible isolates during vegetative compatibility testing. (A) Chi1.1A isolate (1) assigned as VCG01213, tested against NitM VCG01213 (II5) and selfcompatible with its own NitM (2). (B) FT13 isolate assigned as VCG0124/5, tested against VCG0125 (NRRL36106) NitM with more than one nit1 and nit3 mutant (1-4). (C) P47a isolate assigned as VCG0120, tested against VCG0120 (Foc19508) NitM with more than one nit1 and nit3 mutant (1-6). (D) C.cal.1 isolate originally provided as VCG01210 but assigned in this study as 0124, tested against VCG0124 (NRRL36105) NitM with more than one nitl and nit3 mutant $(1,3,4)$ and self-compatible with its own NitM (2). (E) T91.7 isolate assigned as VCG0121, tested against VCG0121 (NRRL36102) NitM with more than one nit1 and nit3 mutant $(1,2,4)$. 



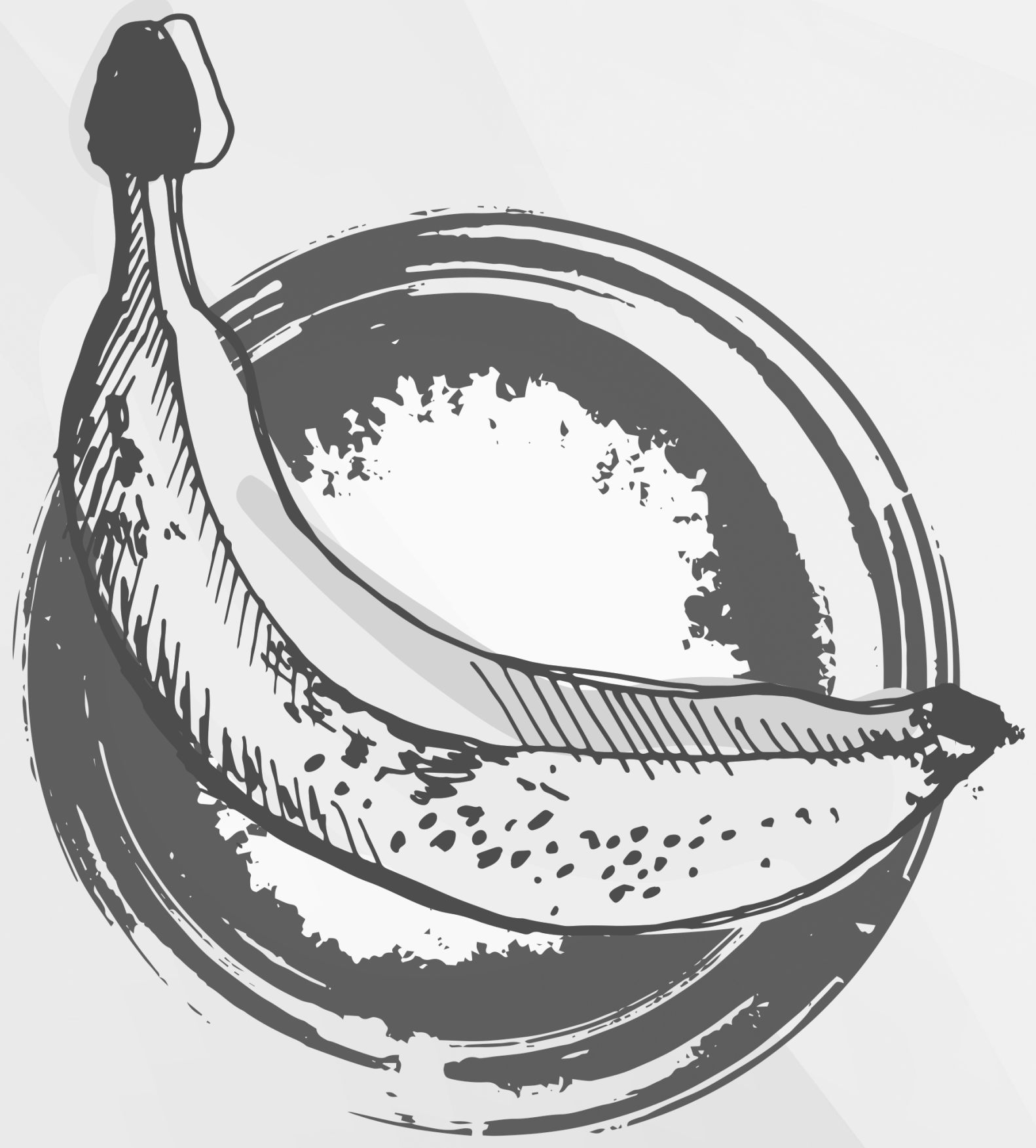




\section{CHAPTER 5}

Unveiling the pathogenicity of the widest array of genetically diverse Fusarium oxysporum f.sp. cubense isolates on 'Gros Michel' and 'Grand Naine' banana cultivars

Ordóñez, N*., García-Bastidas, F*., Nakasato, G., Papagiannaki, E., Kalle, V., Arango, R., Meijer, H.J.G., Seidl, M.F. \& Kema, G.H.J. (Manuscript to be submitted).

*These authors contributed equally to this work.
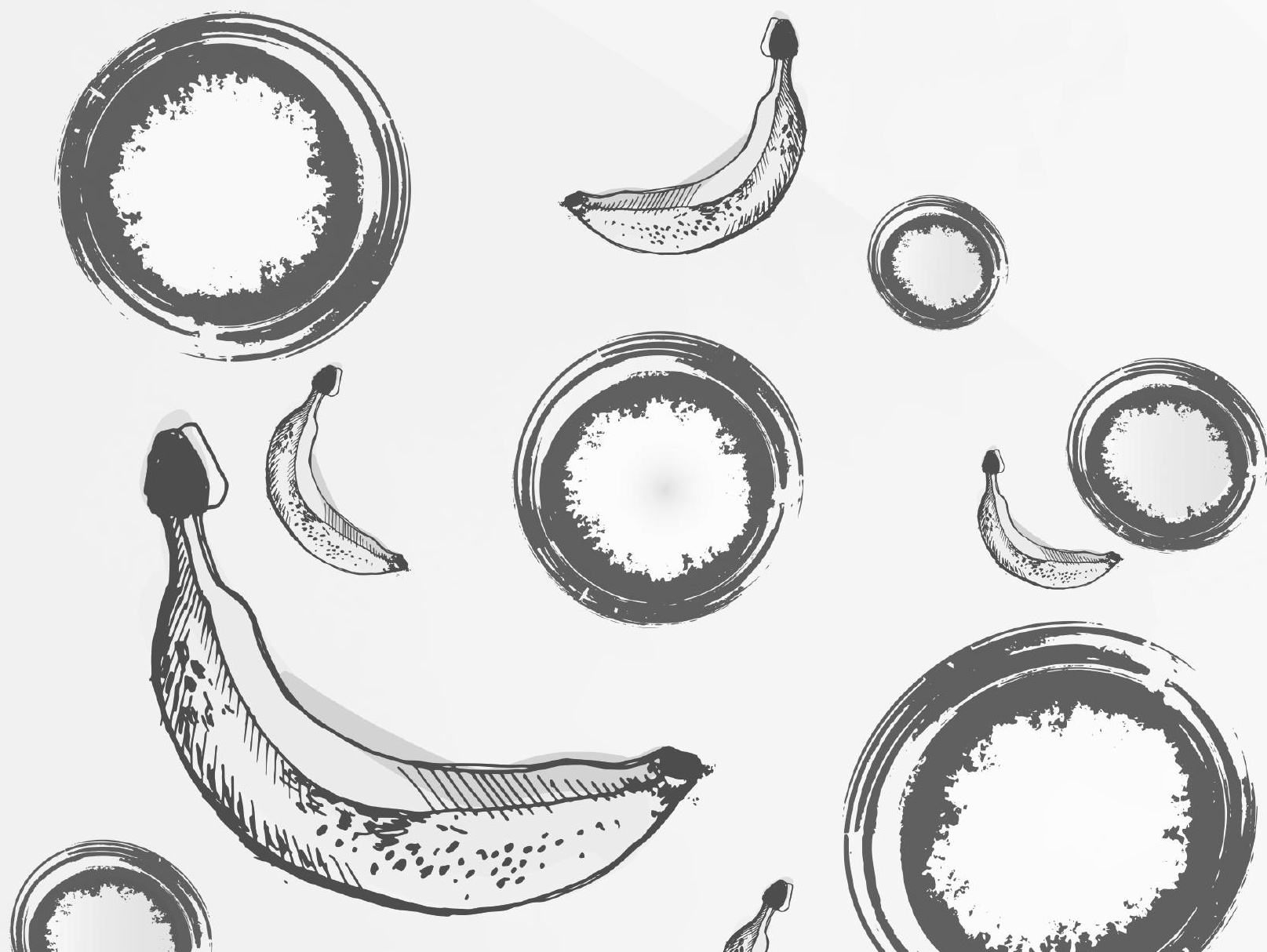


\section{ABSTRACT}

Fusarium wilt caused by Fusarium oxysporum f.sp. cubense (Foc) is one of the most devastating fungal diseases on bananas. Foc belongs to the $F$. oxysporum species complex (FOSC) and is composed of genetically diverse isolates, grouped into vegetative compatibility groups (VCGs). Based on pathogenicity towards a set of banana cultivars, Foc strains are classified into races. However, race designations are often solely based on the origin from which a particular Foc strain was sampled, without phenotyping for pathogenicity on other cultivars. In this study, the pathogenicity of 22 Foc VCGs was explored on 'Gros Michel' and 'Grand Naine', two iconic banana cultivars from the Musa AAA group, under greenhouse conditions. Additionally, the virulence of Foc isolates, popularly known as tropical race 4 (TR4, unified in VCG01213), was tested on 'Grand Naine' plants. Genetically diverse Foc genotypes caused distinct pathogenic responses on 'Gros Michel' and 'Grand Naine' cultivars. 'Gros Michel' was generally more susceptible to various VCGs than 'Grand Naine'. All VCG01213 isolates, regardless of the year of isolation and country of origin, were highly infectious on both 'Gros Michel' and 'Grand Naine', underpinning the risk for disease outbreaks in banana plantations that are planted to these cultivars. The plant responses of both cultivars were indistinctively associated with Foc VCGs from clade 1 and 2 of the FOSC and did not frequently correspond to their related Foc races. These findings show that the current race concept does not accurately reflect the virulence of the diverse Foc genotypes on bananas.

\section{INTRODUCTION}

Food security is challenged by emergent fungal diseases that decimate yields, causing widespread malnutrition and starvation (Gurr et al., 2011). Bananas (Musa spp.) are among the most important food and fruit crops, representing a major commodity for numerous agrobased economies worldwide and an important staple food in Asia and Africa (Aurore et al., 2009; FAOSTAT, 2013; Frison \& Sharrock, 1998). In 2014, world banana production reached 78.8 million tonnes, with India contributing 38\% of produced bananas (FruitTrop, 2017). Edible bananas result from interspecific and intra-specific hybridization of the two founding species: Musa acuminata (AA) and Musa balbisiana (BB) (Simmonds \& Shepherd, 1955). They have evolved through a selection of diploid and triploid seedless clones that were reproduced over centuries via asexual vegetative propagation. Therefore, edible bananas are often sterile or parthenocarpic (Perrier et al., 2011). Nevertheless, the genetic and phenotypic diversity is enormous, with hundreds of banana cultivars largely destined for domestic markets (FAOSTAT, 2013; FruitTrop, 2017). To classify this diversity, the international standard is to refer to the genus name Musa, followed by a code denoting the genome group and ploidy level, the subgroup name (if any) and lastly the popular name of the cultivar, for example Musa AAA (Cavendish subgroup) 'Grand Naine' (Robinson \& Sauco, 2010). Despite the immense genetic diversity of banana germplasm, the export trade relies on a few dessert or sweet cultivars from the Musa AAA group (Perrier et al., 2011; Robinson \& Sauco, 2010). Among them are 'Gros Michel' and 'Grand Naine' cultivars, two economically important dessert bananas in the Gros Michel and Cavendish subgroups, respectively (Robinson \& Sauco, 2010). The Cavendish subgroup accounts for more than $40 \%$ of total 
banana production around the globe (Ploetz, 2015b), with 'Grand Naine' as one of the major constituents across the world (Robinson \& Sauco, 2010). From the plant pathology perspective, such monoculture production systems are easily jeopardized by disease and pest threats (Ploetz, 2015a). For instance by the 1960s, the dominating export 'Gros Michel' cultivar was nearly wiped out during a Panama disease epidemic. This disease that is also known as Fusarium wilt, is caused by the pathogen Fusarium oxysporum f.sp. cubense (Foc), which comprises a set of genetically diverse clonally propagating strains (Bentley et al., 1998; Boehm et al., 1994; Bogale et al., 2006; Fourie et al., 2009; Groenewald et al., 2006; Koenig et al., 1997), is considered one of the most devastating fungal diseases of bananas (Ploetz, 2015a; Ploetz et al., 2015). The pathogen initially infects the root system and reaches the rhizome causing internal tissue discoloration. Later, the pseudostem xylem vessels get clogged due to deposition of callose, formation of tyloses and gels, accumulation of phenolics and intense mycelium and microconidia production. As a result, the transport of nutrients and water is impeded (Ghag et al., 2015; Ploetz, 2015a). Under natural conditions, external symptoms appear relatively late, often six months after the initial infection, showing chlorosis of older leaves that progress to the younger leaves until the whole plant wilts and dies.

In 1910, Foc was isolated for the first time from wilted banana plants in Cuba (Smith, 1910). Since then, Foc strains have been recovered from nearly all banana-growing regions in the world. These strains are commonly characterized by vegetative compatibility, also known as heterokaryon compatibility. It is a naturally occurring characteristic of many fungi, governed by a specific set of nuclear loci known as het or vic-loci (Correll, 1991; Puhalla, 1985). Compatible fungal isolates share an allele at the vic locus enabling them to form a stable hyphal fusion, resulting in heterokaryon formation, and such compatible isolates are then assigned to the same vegetative compatibility group (VCG) (Correll, 1991; Leslie, 1990; Leslie \& Summerell, 2006). Until now, 24 VCGs have been recognized for Foc, from VCG0120 through 0126 and 0128 through 01224 (Bentley et al., 1995; Katan, 1999; Katan \& Di Primo, 1999; Moore et al., 1993; Ordóñez et al., 2015; Ploetz, 2015a). Additionally, since some isolates from different VCGs frequently form stable heterokaryons, three VCG complexes have been proposed, namely 0120/15, 0124/5/8/20 and 01213/16 (Ploetz, 2006). The VCG01213/16 complex is considered as a single group (01213) composed of genetically similar isolates (Bentley et al., 1998; Ordóñez et al., 2015). More recently, VCG01211 and 01222 were included in the $0120 / 15$ and $0124 / 5 / 8 / 20$ complexes, respectively, based on VCG cross-compatibility (Mostert et al., 2017; see Chapter 4).

The Foc strains belong to the F. oxysporum species complex (FOSC) that is composed of four main clades (1, 2, 3 and 4) containing cosmopolitan non-pathogenic and several pathogenic strains that are morphologically indistinguishable (Baayen et al., 2000; G. Fourie et al., 2009; O'Donnell et al., 1998). With the advent of molecular anaylses, the reported Foc genotypes have been grouped into clade 1 and 2. In these clades, Foc isolates within the same VCG and VCG complexes showed a high level of genetic similarity (Bentley et al., 1998; Boehm et al., 1994; Bogale et al., 2006; Fourie et al., 2009; Groenewald et al., 2006; Koenig et al., 1997; see Chapter 4). Given that to date no sexual cycle was reported for Foc (Fourie et al., 2009), this genetic similarity suggests a clonal reproductive behavior (Bentley et al., 1998; Boddy, 2016; Fourie et al., 2009). Only for Foc isolates from the VCG0124/5/8/20 complex, 
some degree of recombination, related to parasexual events, has been reported (Taylor et al., 1999).

Despite, extensive progress in the molecular differentiation of Foc isolates, little advance has been made in analysing the pathogenicity towards banana. Traditionally, Foc strains have been classified into three races: 1, 2 and 4, depending on field responses of a set of banana cultivars (Armstrong \& Armstrong, 1981; Stover, 1962). Race 1 is virulent to 'Gros Michel' and also affects 'Maqueño', 'Pisang Awak', Pome and Silk. Race 2 affects Bluggoe and other cooking bananas. Lastly, race 4 is the most damaging since it affects race 1 and 2 susceptible cultivars as well as Cavendish bananas (Ploetz, 2015a). Race 4 is further subdivided into subtropical race 4 (ST4) and tropical race 4 (TR4). ST4 strains cause disease in Cavendish plantations in subtropical regions under abiotic stress such as low temperatures (Ploetz, 2006). TR4, however, is highly pathogenic and infects bananas irrespective of environmental conditions (Buddenhagen, 2009). Generally, race 1 and 2 (VCGs 0124, 0125, 0128,01217 and 1218) reside in clade 2 of the FOSC, and have been mostly recovered from bananas containing a B genome ( $M$. acuminata and $M$. balbisiana hybrids), while race 4 strains (VCGs 0120/15, 0121, 0122, 0126, 0129, 01211, 01213/16 and 01214) are mostly placed in clade 1 and were recovered from bananas containing A genomes (M. acuminata related) (Bentley et al., 1998; Boehm et al., 1994; Fourie et al., 2009; Groenewald et al., 2006; Koenig et al., 1997). Despite these general trends, exceptions with dissimilar pathogenic profiles occur. For instance, VCG0124, commonly related to racel and 2, caused a disease outbreak in a commercial Cavendish plantation in India (Thangavelu \& Mustaffa, 2010). Thus, presently a single VCG can be related to multiple races.

Since Foc race designation is commonly defined by the banana host cultivar, we decided to scrutinize the pathogenicity of 22 Foc VCGs towards 'Gros Michel' and 'Grand Naine', thereby estimating their potential risk for current banana production. The former cultivar dominated the export trade in the previous century but was wiped out by race 1 strains. The latter currently dominates the trade market and represents $40 \%$ of the global production, but is extremely susceptible to TR4. Therefore, this banana cultivar is a vehicle for the rapid expansion of Fusarium wilt in global Cavendish production (Ordóñez et al., 2015; Ploetz, 2015a, 2015b; Zheng et al., 2018). Additionally, geographically diverse VCG01213 isolates were tested on 'Grand Naine' plants to determine variation in TR4 aggressiveness. Our findings challenge the Foc race concept, by showing that the current definition inadequately reflects Foc virulence on banana cultivars.

\section{MATERIAL AND METHODS}

\section{Phenotyping test under greenhouse conditions}

\section{Plant material}

Tissue culture plantlets of 'Gros Michel' and 'Grand Naine' were transferred upon arrival to small pots containing standard soil (Swedish sphagnum peat 5\%, grinding clay granules $41 \%$, garden peat $5 \%$, beam structure $4 \%$, steamed 140 compost $33 \%$, PG-Mix- 15 $10-20-12 \%$ ) from the UNIFARM greenhouse facility of Wageningen University \& Research, 
Wageningen, The Netherlands and maintained for two weeks at $28 \pm 2^{\circ} \mathrm{C}$ and $\sim 100 \%$ relative humidity $(\mathrm{RH})$ to acclimatize. Thereafter, they were transplanted to $2 \mathrm{~L}$ pots with the same soil and maintained for approximately three months at the same temperature, $\mathrm{RH}(\sim 70 \%)$ and a 16/8 diurnal schedule until inoculation.

\section{Inoculum preparation}

Fusarium isolates were transferred to potato dextrose agar (PDA, Difco ${ }^{\mathrm{TM}}$, USA) and incubated at $25^{\circ} \mathrm{C}$. After five days, four circular plugs ( $\sim 5 \mathrm{~mm}$ diameter $)$ from the edge of the colony of each isolate were incubated together with sterile maize kernels on Petri dishes for five days at $25^{\circ} \mathrm{C}$ (Dita et al., 2011; Lichtenzveig et al., 2006). Likewise, five additional circular plugs were inoculated into a sterile mung bean media for inoculum production $\left(10^{6}\right.$ conidia/mL) following the protocol of García-Bastidas et al. (2018a).

\section{Plant inoculation and disease assessment}

Three-month-old 'Gros Michel' and 'Grand Naine' plants were tested under the aforementioned greenhouse conditions. Per Foc isolate representing each of the 22 VCGs (Table 1), six plants per banana cultivar were inoculated following the pouring method developed by García-Bastidas et al. (2018a) supplemented with placing five infested maize kernels in each pot and six control plants were treated only with water. To test potential differences in aggressiveness of the VCG01213 isolates (Table 1), we inoculated five 'Grand Naine' plants with each isolate and five control plants were inoculated with either race 1 or water. After inoculation, plants were maintained in the greenhouse at the aforementioned conditions, but at a slightly higher RH of $80 \%$ until scoring, and were monitored weekly for disease development and progress. Final scoring was conducted at nine weeks after inoculation (wai) according to the protocol of García-Bastidas et al. (2018a) with slight modifications depending on disease development. We also scored secondary symptoms such as pseudostem splitting at the base of the plants and the presence of stunted new leaves.

\section{Recovery and confirmation of inoculated genotypes}

During final scoring, we collected rhizome tissue for each Foc isolate to fulfill Koch's postulates (Koch, 1912). Samples were surface sterilized starting with an initial washing step using tap water followed by an immersion in 70\% alcohol for 5 minutes (min). Thereafter, they were rinsed with sterile water for $5 \mathrm{~min}$ and dried on filter paper. Subsequently, two pieces $\left(\sim 5 \times 2 \mathrm{~mm}^{2}\right)$ of rhizome tissue per plant were plated on $1 / 4$ enriched PDA amended with streptomycin $(1 \mathrm{~g} / \mathrm{L})$, and incubated for seven to 10 days at $25^{\circ} \mathrm{C}$ in darkness. Growing strains were identified by PCR and/or VCG testing. For PCR diagnostics, mycelium was transferred to $2 \mathrm{~mL}$ Eppendorf tube and freeze-dried (Epsilon 1-4 LSC, Christ GmbH, Germany) prior to DNA extraction. VCG testing was performed on for every strain recovered from the inoculated plants, except for VCG01213 (see below section). 
Table 1. Fusarium oxysporum f.sp. cubense isolates included in this study.

\begin{tabular}{|c|c|c|c|c|c|c|c|c|}
\hline VCG & Race $^{2}$ & Clade $^{3}$ & $\begin{array}{l}\text { Isolate } \\
\text { code }\end{array}$ & $\begin{array}{l}\text { Host } \\
\text { name }\end{array}$ & $\begin{array}{l}\text { Host } \\
\text { genotype }\end{array}$ & Country & $\begin{array}{l}\text { Year of } \\
\text { isolation }\end{array}$ & Provider \\
\hline 0120 & ST4, R1 & 1 & FocST498 & $\begin{array}{l}\text { Dwarf } \\
\text { Cavendish }\end{array}$ & AAA & $\begin{array}{l}\text { (Canary } \\
\text { Islands) }\end{array}$ & 1998 & Julio Hernandez, Spain \\
\hline 0121 & $\begin{array}{l}\text { ST4, } \\
\text { TR4 }\end{array}$ & 1 & NRRL36102 & Cavendish & AAA & $\begin{array}{l}\text { Spain } \\
\text { (Taiwan) } \\
\text { China }\end{array}$ & n.d. & K. O'Donnell, USA \\
\hline 0122 & $\mathrm{R} 2, \mathrm{TR} 4$ & 1 & NRRL36103 & Cavendish & AAA & Philippines & n.d. & K. O'Donnell, USA \\
\hline 0124 & $\mathrm{R} 1, \mathrm{R} 2$ & 2 & NRRL36105 & Bluggoe & $\mathrm{ABB}$ & Honduras & n.d. & K. O'Donnell, USA \\
\hline 0125 & $\mathrm{R} 1, \mathrm{R} 2$ & 2 & NRRL36106 & Lady finger & $\mathrm{AAB}$ & Australia & n.d. & K. O'Donnell, USA \\
\hline 0126 & $\mathrm{R} 1, \mathrm{ST} 4$ & 1 & NRRL36107 & Maqueno & $\mathrm{AAB}$ & Honduras & n.d. & K. O'Donnell, USA \\
\hline 0128 & $\mathrm{R} 1, \mathrm{R} 2$ & 2 & NRRL36111 & Bluggoe & $\mathrm{ABB}$ & Australia & n.d. & K. O'Donnell, USA \\
\hline 0129 & $\mathrm{R} 1, \mathrm{ST} 4$ & 1 & NRRL36110 & Mons & AAA & Australia & n.d. & K. O'Donnell, USA \\
\hline 01210 & $\mathrm{R} 1$ & 1 & Focu7 & Apple & $\mathrm{AAB}$ & $\begin{array}{l}\text { (Florida) } \\
\text { USA }\end{array}$ & n.d. & $\begin{array}{l}\text { M.J. Daboussi, Université Paris -Sud, } \\
\text { France }\end{array}$ \\
\hline 01211 & ST4 & 1 & NRRL36109 & SH 3142 & AA & Australia & n.d. & K. O'Donnell, USA \\
\hline 01212 & n.d. & 2 & NRRL36108 & Ney Poovan & $\mathrm{AB}$ & Tanzania & n.d. & K. O'Donnell, USA \\
\hline $01213 / 16$ & TR4 & 1 & 24662 & Cavendish & AAA & Australia & 1999 & A. Drenth, Australia \\
\hline $01213^{1}$ & TR4 & 1 & II5 & $\begin{array}{l}\text { Pisang } \\
\text { Manurung }\end{array}$ & $\mathrm{AAB}$ & Indonesia & n.d. & C. Kistler, USA \\
\hline 01213 & TR4 & 1 & Foc.T105 & Cavendish & AAA & $\begin{array}{l}\text { (Taiwan) } \\
\text { China }\end{array}$ & n.d. & P.F.L. Chang, Taiwan \\
\hline 01213 & TR4 & 1 & JV11 & Cavendish & AAA & Jordan & 2006 & R.C. Ploetz, USA \\
\hline 01213 & TR4 & 1 & Leb1.2C & Cavendish & AAA & Lebanon & 2013 & $\begin{array}{l}\text { M.Y. Akkary, Debbane Freres, } \\
\text { Lebanon, N. Ordóñez }{ }^{4} \text {, The Netherlands }\end{array}$ \\
\hline 01213 & TR4 & 1 & Mal123 & $\begin{array}{l}\text { Cavendish, } \\
\text { Williams }\end{array}$ & AAA & Malaysia & n.d. & W. O'Neil, Australia \\
\hline 01213 & TR4 & 1 & Pak1.1A & Cavendish & AAA & Pakistan & 2012 & $\begin{array}{l}\text { Hadi Bux Laghari, Pakistan, N. } \\
\text { Ordóñez } z^{4} \text {, The Netherlands }\end{array}$ \\
\hline 01213 & TR4 & 1 & Phi2.6C & GCTCV218 & AAA & Philippines & 2013 & \\
\hline 01214 & $\mathrm{R} 2$ & 2 & NRRL36113 & Harare & $\mathrm{ABB}$ & Malawi & n.d. & K. O'Donnell, USA \\
\hline $\begin{array}{l}01215 \\
01217\end{array}$ & $\begin{array}{l}\text { ST4, R1 } \\
\text { R1 }\end{array}$ & $\begin{array}{l}1 \\
2\end{array}$ & $\begin{array}{l}\text { NRRL36112 } \\
\text { Mal43 }\end{array}$ & $\begin{array}{l}\text { Cavendish } \\
\text { Pisang Rastali }\end{array}$ & $\begin{array}{l}\text { AAA } \\
\text { AAB }\end{array}$ & $\begin{array}{l}\text { South Africa } \\
\text { Malaysia }\end{array}$ & $\begin{array}{l}\text { n.d. } \\
1995\end{array}$ & $\begin{array}{l}\text { K. O'Donnell, USA } \\
\text { A. Drenth, Australia }\end{array}$ \\
\hline 01218 & $\mathrm{R} 1$ & 2 & NRRL36120 & Kluai Nam Wa & $\mathrm{ABB}$ & Thailand & n.d. & K. O'Donnell, USA \\
\hline 01219 & n.d. & 1 & Indo25 & Pisang Ambon & AAA & Indonesia & 1993 & A. Drenth, Australia \\
\hline 01220 & $\mathrm{R} 4$ & 2 & 24218 & Cavendish & AAA & Australia & 1993 & A. Drenth, Australia \\
\hline 01221 & n.d. & 2 & NRRL36118 & Kluai Nam Wa & $\mathrm{ABB}$ & Thailand & n.d. & K. O'Donnell, USA \\
\hline 01222 & n.d. & 2 & NRRL36117 & $\begin{array}{l}\text { Pisang Awak } \\
\text { Legor }\end{array}$ & $\mathrm{ABB}$ & Malaysia & n.d. & K. O'Donnell, USA \\
\hline 01223 & n.d. & 2 & NRRL36116 & Pisang Keling & $\mathrm{AAB}$ & Malaysia & n.d. & K. O'Donnell, USA \\
\hline 01224 & n.d. & 2 & NRRL36115 & Pisang Ambon & AAA & Malaysia & n.d. & K. O'Donnell, USA \\
\hline n.d. & $\mathrm{R} 1$ & 3 & Foc_R1 & Silk & $\mathrm{AAB}$ & Brazil & 2008 & $\begin{array}{l}\text { M. Dita and C. Waalwijk, The } \\
\text { Netherlands }\end{array}$ \\
\hline
\end{tabular}

${ }^{1}$ Only the II5 isolate (VCG01213) was used for the assay with multiple VCGs. ${ }^{2}$ Race related (race 1, R1; race 2, R2 and race 4, R4) to each VCG according to previous reports (Boehm et al., 1994; Koenig et al., 1997; Bentley et al., 1998; Groenewald et al., 2006; Fourie et al., 2009; Fraser-Smith et al., 2013). ${ }^{3}$ The selected isolates were previously analysed (Ordonez et al., 2015; see Chapter 4) and grouped into the three clades of the Fusarium oxysporum species complex described in O'Donnell et al. (1998). ${ }^{4}$ Providers sent tissue samples to our facilities and the strain isolation was performed at Wageningen University \& Research. n.d. stands for "not determined".

\section{DNA isolation and molecular identification}

The DNA isolation was carried out using a Kingfisher robot (Thermo Labsystems, Oy, Finland) using the AGOWA Sbeadex ${ }^{\circledR}$ Maxi plant DNA isolation kit from LGC Genomics (Germany) according to the manufacturer's instructions. Samples were mixed with $600 \mu 1$ of lysis buffer and homogenized for 40 seconds at $5800 \mathrm{rpm}$ in the homogenizer Precellys ${ }^{\circledR}$ (Bertin Technologies, France). Subsequently, they were incubated at $65^{\circ} \mathrm{C}$ for $15 \mathrm{~min}$. Supernatants $(200 \mu \mathrm{l})$ were recovered after centrifugation for $20 \mathrm{~min}$ at 13,000 rpm and transferred to a deep well plate containing $520 \mu \mathrm{l}$ of binding buffer. The process was finished 
according to the manufacturer's protocol using the KingFisher technology (ThermoFisher Scientific, USA). The total amount of genomic DNA was quantified using Quant-iT ${ }^{\mathrm{TM}}$ Picogreen ${ }^{\circledR}$ dsDNA Reagent and Kit (Life Technologies, USA), according to the manufacturer's instructions. The fluorometric measurements were performed using Tecan Infinite $^{\circledR}$ M200 PRO monochromator (Tecan, Männedorf, Switzerland) using Icontrol 107 software (US, Morrisville, NC). DNA samples were adjusted to $5 \mathrm{ng} / \mu \mathrm{L}$ and stored at $-20^{\circ} \mathrm{C}$ until use. All DNA samples were assessed using the $F$. oxysporum primers (Edel et al., 2000), using an annealing temperature of $62^{\circ} \mathrm{C}$ (van Brunschot, 2006). Subsequently, the TR4 diagnostic primers (Dita et al., 2010) were used to verify VCG01213 isolates. PCR products $(10 \mu \mathrm{L})$ were visualized on a $1.5 \%$ agarose gel to check for predicted size products.

\section{Vegetative compatibility confirmation}

Testing of vegetative compatibility was performed on all recovered $F$. oxysporum strains, except for VCG01213. Single-spore cultures were generated (van Brunschot, 2006) and then, nit $\left(\mathrm{NO}_{3}\right.$-non-utilizing) mutants were obtained by incubating them for 7-14 days at $25^{\circ} \mathrm{C}$ in darkness on minimal medium (MM) amended with $1.5-2 \% \mathrm{KClO}_{3}$. The nit mutants were characterized as nit1, nit3 or NitM following the Leslie \& Summerell (2006) protocol. Pairing tests were run on MM for 7-14 days to check compatibility with NitM testers of corresponding inoculated VCG's, using at least two independent nit1 and/or nit3 mutants. Compatible isolates were scored based on their ability to form heterokaryons.

\section{RESULTS}

\section{Distinct responses to genetically diverse VCGs}

The tested VCGs represent the widest genetically diverse Foc panel which is distributed over clades 1 and 2 of the FOSC (Bentley et al., 1998; Boehm et al., 1994; Bogale et al., 2006; Fourie et al., 2009; Groenewald et al., 2006; Koenig et al., 1997; see Chapter 4). All strains elicit distinct responses in both banana cultivars, with 'Gros Michel' being, in general, more susceptible to various VCGs (Fig. 2). The typical leaf chlorosis was observed for all inoculated plants including the controls (Table 2). Usually, high percentages of chlorosis were accompanied by pseudostem splitting and stunted new leaves, particularly in 'Gros Michel', inoculated with VCGs 0120, 01213, 01218 and 01219 compared to 'Grand Naine' plants and the controls (Fig. 1), but the overall correlation with internal symptoms was low $\left(\mathrm{R}^{2}=0.44\right)$. All VCG treatments produced internal symptoms except for VCG0125 on 'Grand Naine' (Table 2). The obtained rhizome discoloration scales were used to calculate the Disease Index (DI) for each interaction as this internal symptom is a more reliable disease indicator (García-Bastidas et al., 2018a; Li et al., 2014; Paul et al., 2011). The DIs were then divided into three severity groups: high $(>50 \%)$, moderate $(15-50 \%)$ and low $(<15 \%)$ (Fig. 2 B). Inoculations with the compatible VCG01213 strain (II5) were used as a reference for all other VCGs, both on 'Gros Michel' and 'Grand Naine'. In general, 'Gros Michel' plants showed moderate to high severity to all VCGs, except for VCG01210 (DI =13.3\%). The most severe internal symptoms were recorded for VCG0120, 01212, 01213, 01218 and 01223 treatments (Fig. 2B). On the other hand, 'Grand Naine' plants were generally less affected by 
the Foc VCG panel, except for VCG01213 that represents TR4 (DI =60\%). In summary, ten out of the 22 VCGs were incompatible and showed no or slight rhizome damage in 'Grand Naine’ (Fig. 2B). All controls remained healthy with no rhizome discoloration (DI $=0 \%$ ).

Table 2. Phenotyping Fusarium oxysporum f.sp. cubense (Foc) on the banana varieties 'Grand Naine' and 'Gros Michel'. Internal and external disease scores are shown for each Foc isolate and the disease index has been calculated for each interaction.

\begin{tabular}{|c|c|c|c|c|c|c|c|c|}
\hline \multirow{3}{*}{ Foc isolate } & \multicolumn{4}{|c|}{ 'Gros Michel' } & \multicolumn{4}{|c|}{ 'Grand Naine' } \\
\hline & \multicolumn{2}{|c|}{$\begin{array}{c}\text { External symptom } \\
\text { Leaf yellowing }\end{array}$} & \multicolumn{2}{|c|}{$\begin{array}{c}\text { Internal symptom } \\
\text { Rhizome discoloration }\end{array}$} & \multicolumn{2}{|c|}{$\begin{array}{c}\text { External symptom } \\
\text { Leaf yellowing }\end{array}$} & \multicolumn{2}{|c|}{$\begin{array}{c}\text { Internal symptom } \\
\text { Rhizome discoloration }\end{array}$} \\
\hline & $\begin{array}{c}\text { Average } \\
\text { discoloration } \\
(\%)\end{array}$ & $\begin{array}{l}\text { Class } \\
\text { rate } \\
\text { scale }\end{array}$ & $\begin{array}{c}\text { Average } \\
\text { scale }\end{array}$ & DI (\%) & $\begin{array}{c}\text { Average } \\
\text { discoloration } \\
(\%)\end{array}$ & $\begin{array}{l}\text { Class } \\
\text { rate } \\
\text { scale }\end{array}$ & $\begin{array}{l}\text { Average } \\
\text { scale }\end{array}$ & DI (\%) \\
\hline VCG0120 & 80.2 & IV & 3.7 & 53.3 & 43.5 & II & 3.2 & 43.3 \\
\hline VCG0121 & 61.9 & III & 3.0 & 40.0 & 29.7 & II & 2.5 & 30.0 \\
\hline VCG0122 & 61.1 & III & 2.8 & 36.7 & 39.7 & II & 2.7 & 33.3 \\
\hline VCG0124 & 60.5 & III & 2.5 & 30.0 & 27.9 & II & 3.2 & 43.3 \\
\hline VCG0125 & 67.0 & III & 3.3 & 46.7 & 24.1 & I & 1.0 & 0.0 \\
\hline VCG0126 & 66.6 & III & 1.8 & 16.7 & 31.7 & II & 1.3 & 6.7 \\
\hline VCG0128 & 59.8 & III & 2.2 & 23.3 & 28.8 & II & 2.0 & 20.0 \\
\hline VCG0129 & 50.9 & III & 1.8 & 16.7 & 29 & II & 1.2 & 3.3 \\
\hline VCG01210 & 52.1 & III & 1.7 & 13.3 & 22.1 & I & 1.2 & 3.3 \\
\hline VCG01211 & 68.6 & III & 3.0 & 40.0 & 34.1 & II & 3.2 & 43.3 \\
\hline VCG01212 & 66.9 & III & 4.0 & 60.0 & 33.1 & II & 1.3 & 6.7 \\
\hline VCG01213 & 77.3 & IV & 4.0 & 60.0 & 58.3 & III & 4.0 & 60.0 \\
\hline VCG01214 & 60.2 & III & 2.3 & 26.7 & 22.1 & I & 2.8 & 36.7 \\
\hline VCG01215 & 71.8 & III & 2.5 & 30.0 & 60.5 & III & 2.7 & 33.3 \\
\hline VCG01217 & 64.8 & III & 3.2 & 43.3 & 38.3 & II & 1.2 & 3.3 \\
\hline VCG01218 & 74.9 & IV & 4.7 & 73.3 & 25.4 & II & 1.7 & 13.3 \\
\hline VCG01219 & 75.9 & IV & 3.3 & 46.7 & 33.1 & II & 1.2 & 3.3 \\
\hline VCG01220 & 63.2 & III & 2.7 & 33.3 & 52.5 & III & 3.3 & 46.7 \\
\hline VCG01221 & 67.7 & III & 3.2 & 43.3 & 27.3 & II & 2.3 & 26.7 \\
\hline VCG01222 & 71.6 & III & 3.3 & 46.7 & 29.5 & II & 1.7 & 13.3 \\
\hline VCG01223 & 64.9 & III & 4.5 & 70.0 & 19.7 & I & 2.0 & 20 \\
\hline VCG01224 & 55.6 & III & 3.2 & 43.3 & 26.2 & II & 1.2 & 3.3 \\
\hline Control & 47.4 & II & 1.0 & 0.0 & 26.3 & II & 1.0 & 0.0 \\
\hline
\end{tabular}

In terms of clade classification of the tested Foc isolates, nine out of 10 isolates from clade 1 and all clade 2 isolates caused severe disease symptoms in 'Gros Michel', while for 'Grand Naine' cultivar, six isolates from each clade elicited moderate rhizome discoloration (Fig. 2A). The cross-compatible Foc isolates from the VCG0120/11/15 complex produced moderate disease levels in each cultivar, except for VCG0120 that was particularly severe on 'Gros Michel'. All isolates from the VCG0124/5/8/20/22 complex inflicted moderate severities in 'Gros Michel', but induced low to moderate severities in 'Grand Naine'. In terms 
of race classification commonly designated to the tested Foc VCGs (Table 1), race 1 strains were generally very pathogenic for 'Gros Michel' but avirulent on 'Grand Naine', whereas ST4 and TR4 strains were particularly pathogenic towards 'Grand Naine' (Fig. 2C). However, we also observed that some race 1 isolates caused only limited disease in 'Gros Michel' (VCG01210), but moderate severities on 'Grand Naine' (VCG0124 and 0128), whereas some race 4 isolates caused limited disease levels in 'Grand Naine' (VCG0126 and 0129). Unexpectedly, the race 2 isolate (VCG01214) cause moderate disease levels in both 'Gros Michel' and 'Grand Naine'. Lastly, the undefined VCGs 01212, 01219 and 01221-01224 were categorized as race $1(01212,01219,01222$ and 01224) and race 4 (01221 and 01223), based on the current Foc race concept.
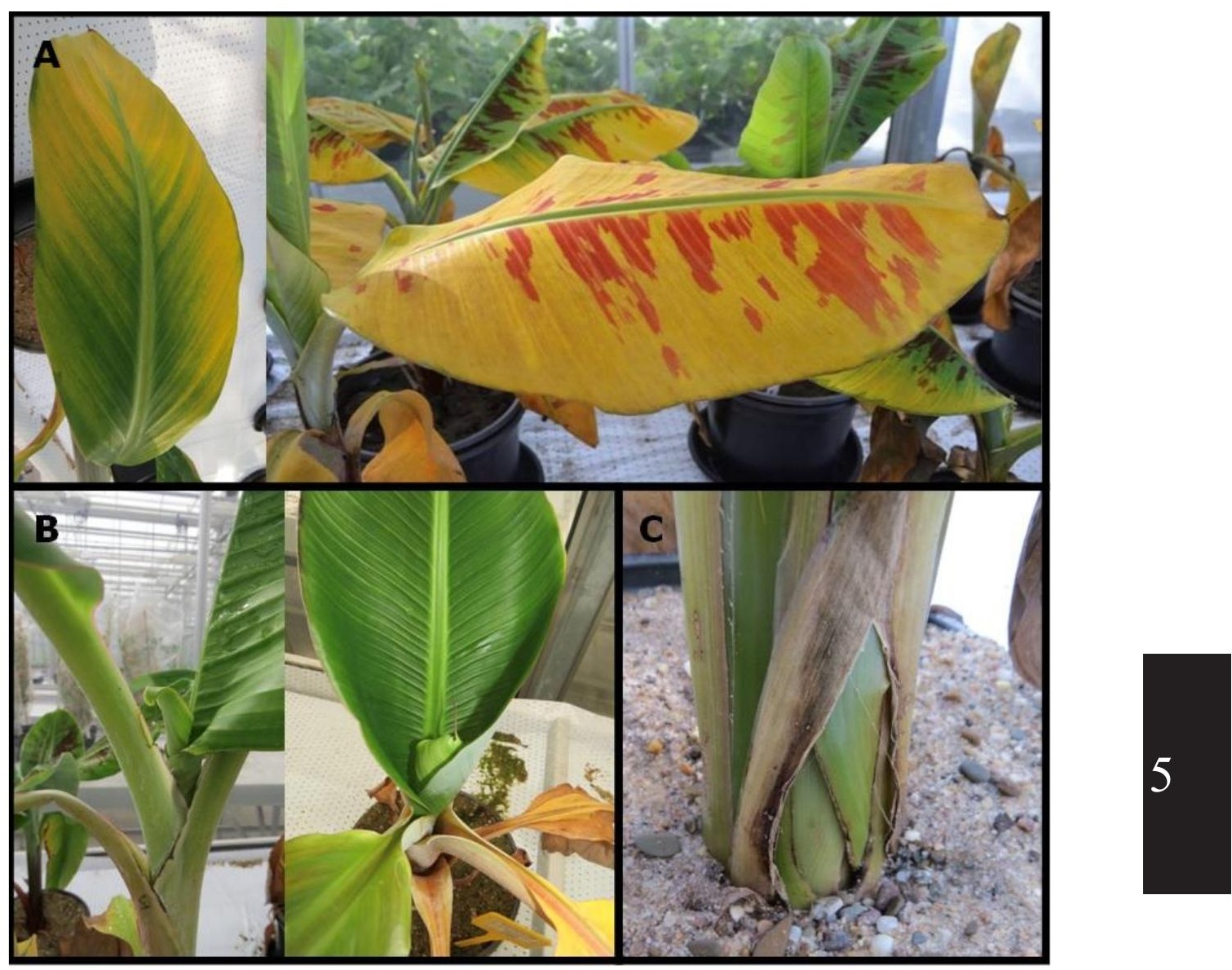

Figure 1. External symptoms of Fusarium wilt recorded under greenhouse conditions: (A) leaf chlorosis, (B) stunted new leaf and (C) splitting on the base of the pseudostem. 

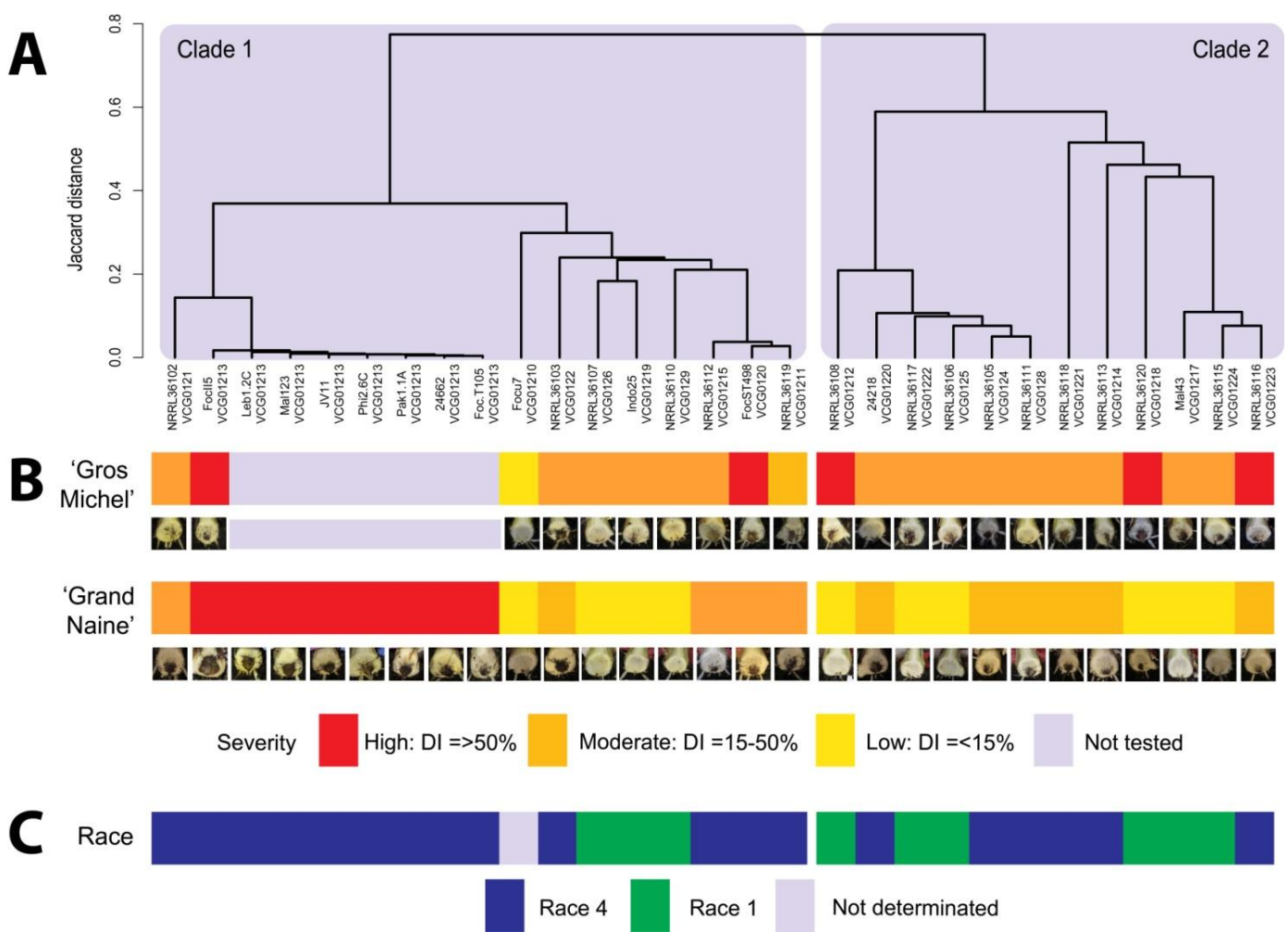

Figure 2. Disease severity caused by 22 vegetative compatibility groups (VCGs) of Fusarium oxysporum f.sp. cubense (Foc), including multiple isolates belonging to VCG01213, on 'Gros Michel' and 'Grand Naine' banana cultivars. (A) The dendrogram represents the genetic diversity of the tested Foc isolates based on DArTseq markers (adapted from Ordóñez et al., 2015). (B) Categorization of disease severities (high, moderate and low) on 'Gros Michel' and 'Grand Naine' as shown by the different levels of rhizome discoloration. (C) Race designation based on the current Foc race concept.

\section{Quantitative variation among tropical race 4 isolates on 'Grand Naine'}

The eight geographically diverse VCG01213 isolates representing TR4 caused severe symptoms in 'Grand Naine' (Fig 2 B). During the final scoring at nine wai, chlorosis of the foliage was $>40 \%$, while the controls showed $6.7-13 \%$ (Table 3). The isolates from Lebanon and Pakistan seemed more aggressive $(>80 \%)$ followed by isolates from Indonesia, Jordan and Malaysia (60-66.7\%). Such quantitative variation was also observed for the internal symptoms. DIs varied between 56 and $88 \%$ (Table 3), with highest DI values $(>80 \%)$ for isolates from Indonesia, Lebanon and Pakistan. All controls (water and 'Grand Naine' with R1) remained healthy with no internal symptoms. 
Table 3. Phenotyping aggressiveness levels of Fusarium oxysporum f.sp. cubense VCG01213 isolates on banana variety 'Grand Naine'. Internal and external disease scores are shown for each isolate and the disease index has been calculated for each interaction.

\begin{tabular}{|c|c|c|c|c|c|}
\hline \multirow{2}{*}{$\begin{array}{c}\text { Isolate } \\
\text { code }\end{array}$} & \multirow[b]{2}{*}{ VCG } & \multicolumn{2}{|c|}{$\begin{array}{c}\text { External symptoms } \\
\text { Leaf yellowing }\end{array}$} & \multicolumn{2}{|c|}{$\begin{array}{c}\text { Internal symptoms } \\
\text { Rhizome discoloration }\end{array}$} \\
\hline & & $\begin{array}{c}\text { Average } \\
\text { discoloration } \\
(\%)\end{array}$ & $\begin{array}{c}\text { Class rate } \\
\text { scale }\end{array}$ & $\begin{array}{c}\text { Average } \\
\text { scale }\end{array}$ & DI (\%) \\
\hline Leb1.2C & 01213 & 86.7 & IV & 5.4 & 88.0 \\
\hline Mal123 & 01213 & 66.7 & III & 4.6 & 72.0 \\
\hline Phi2.6C & 01213 & 43.0 & II & 4.4 & 68.0 \\
\hline JV11 & 01213 & 66.7 & III & 4.8 & 76.0 \\
\hline Pak1.1A & 01213 & 80.0 & IV & 5.0 & 80.0 \\
\hline II5 & 01213 & 60.0 & III & 5.2 & 84.0 \\
\hline Foc.T105 & 01213 & 40.0 & II & 3.8 & 56.0 \\
\hline 24662 & 01213 & 46.7 & II & 3.8 & 56.0 \\
\hline Foc_R1 & n.d & 6.7 & I & 1.0 & 0.0 \\
\hline Water & - & 13.0 & I & 1.0 & 0.0 \\
\hline
\end{tabular}

\section{Recovery of inoculated fungal genotypes associated with severity groups}

Rhizome samples from all interactions were collected and analysed. For samples from interactions with high DIs, mycelium rapidly developed on PDA and isolate identities were confirmed by VCG analysis or molecular diagnostics. Similarly, we retrieved Foc isolates from interactions with moderate DIs $(<37 \%)$, but none from 'Grand Naine' plants inoculated with strains representing VCG0122, 01214, 01221 and 01223 and neither from any interaction with low DIs. The few developing colonies from these isolations did not morphologically resemble $F$. oxysporum strains and also tested negative with $F$. oxysporum primers (Edel et al., 2000). Finally, all samples from the controls did not result in any fungal colonies on PDA (Fig. 3).

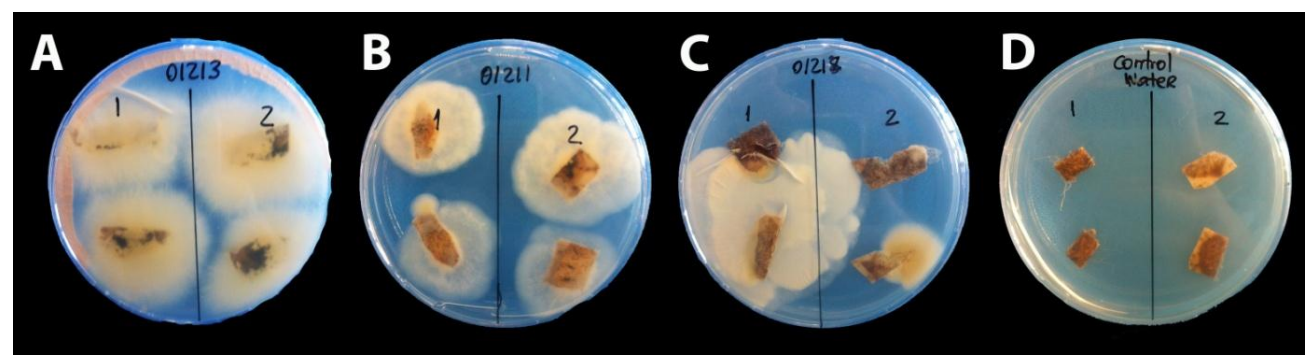

Figure 3. Typical fungal growth from rhizome tissue incubated for five days on PDA, originating from plants with (A) high, (B) moderate and (C) low disease severities. (D) No fungal growth was observed from rhizomes of the control plants. 


\section{DISCUSSION}

Plant diseases affect human wellbeing by provoking serious agricultural and economic losses, as those exemplified by for instance late blight disease on potatoes and Karnal bunt on wheat (Anderson et al., 2004). Nowadays, crop-destroying fungi account for perennial yield losses of $\sim 20 \%$ worldwide, with a further $10 \%$ loss postharvest (Fisher et al., 2018). In bananas, the race 1 outbreak of Fusarium wilt caused havoc in Latin America, wiping out 'Gros Michel' plantations that caused an estimated loss of \$400 million up to 1960s (Ploetz, 2005). Despite the importance of Panama disease, only a handful of studies addressed pathogenicity of Foc strains to banana germplasm (García-Bastidas et al., 2018b; Groenewald et al., 2006; Li et al., 2013; Li et al., 2014; Ploetz et al., 1999), and even fewer determined Foc races in inoculation trials (Araújo et al., 2017; Thangavelu et al., 2012). Instead, Foc races are traditionally designated by the banana variety from which they are isolated, mostly under field conditions. Therefore, pathogenic specialization of Foc VCGs is unclear, since pathogenicity is not systematically assessed by inoculating various banana cultivars with a suite of Foc isolates. Moreover, mechanisms of host resistant are not considered under the current Foc race concept. In other pathosystems such trials have been the basis for resistance discovery research. Cereal rusts have been threatening global wheat production for decades, and detailed phenotyping trials have eventually resulted in the identification of effectors (Chartrain et al., 2005; Kema et al., 2018; Saintenac et al., 2018), which are currently being used in advanced breeding programs and Phytophthora research has benefited enormously from phenotyping data in the discovery of RXLR effectors (Anderson et al., 2015). Therefore, we considered that such a plant-pathogen matrix would be foundational for understanding the banana-Fusarium pathosystem and decided to test all the known Foc VCGs on 'Gros Michel' and 'Grand Naine', two important banana varieties that dominated the banana trade for the last century and historically are considered race 1 and race 4 differential cultivars, respectively (Ploetz, 2005; Ploetz, 2015b). Contrary to field screening, our assays were conducted under controlled conditions, that provide comparable data and different responses are assumed to reflect genetic differences between the Foc isolates. In general, the infection with 22 genetically diverse Foc VCGs resulted in distinct responses, with 'Gros Michel' being more susceptible to the majority of VCGs. The Foc isolates related to clade 1 and 2 of the FOSC indistinctly inflicted a moderate or high rhizome discoloration to 'Gros Michel' and 'Grand Naine'. This finding is in accordance with phylogenetic studies suggesting that Foc pathogenicity towards a certain banana cultivar is a polyphyletic trait (Fourie et al., 2009; Fourie et al., 2011; Fraser-Smith et al., 2013), and challenges the observation that genotypes in clade 1 are usually associated with Fusarium wilt on Cavendish cultivars and clade 2 to 'Gros Michel' (Bentley et al., 1998; Boehm et al., 1994; Fourie et al., 2009; Groenewald et al., 2006; Koenig et al., 1997). Foc VCGs are phylogenetically distant genotypes with multiple evolutionary origins (O'Donnell et al., 1998), exempting isolates within VCG complexes such as VCG0120/11/15 and 0124/5/8/20/22 complexes that are genetically related (Bentley et al., 1998; Fourie et al., 2009; Maryani et al., 2018a; Ordóñez et al., 2015). In our study, isolates from the VCG0120/11/15 complex caused similar rhizome discoloration on both banana cultivars, but those from the VCG0124/5/8/20/22 complex differentially affected 'Grand Naine' plants. Despite their relative close genetic distance, isolates from this VCG complex are not regarded as clonal. Instead, parasexual recombination is suggested to occur 
among isolates of this VCG complex (Taylor et al., 1999). Such genetic differences might explain the diverse responses of 'Grand Naine' to these slightly diverse genotypes. Conversely, the genetically similar VCG01213 were equally highly pathogenic to both banana cultivars regardless of the year of isolation or geographical origin, despite quantitative variation in aggressiveness towards 'Grand Naine' (DI from 56\% to 88\%). This was recently also confirmed by Maryani et al. (2018b) who studied pathogenicity of a suite of Indonesia TR4 isolates. Our data show that despite the limited single nucleotide polymorphisms (SNPs) that geographically diversified these VCG01213 isolates (Zheng et al., 2018), the overall sequence identity ( $0.01 \%$ SNPs) (Ordóñez et al., 2015) was reflected in their high pathogenicity in the current trials. These results indicate that phenotyping trials in the bananaFusarium pathosystem should consider testing multiple strains from each VCG. However, the current methodologies, despite recent improvements (García-Bastidas et al., 2018a), constrains throughput. Therefore, future phenotyping should ideally be based on effector screens, which will revolutionize the understanding of pathosystem, as was also shown in many other pathosystems (Anderson et al., 2015; Chartrain et al., 2005; Kema et al., 2018; Mes et al., 1999; Saintenac et al., 2018).

The effect of varying environmental conditions on Foc race classification was primarily associated with unexpected disease development in Cavendish cultivars by other Foc lineages than VCG01213 (Bentley et al., 1998; Boehm et al., 1994; Fourie et al., 2009; Fraser-Smith et al., 2013; Groenewald et al., 2006; Koenig et al., 1997; Mostert et al., 2017). As a result, other VCGs such as 0121 (Aguayo et al., 2017; Fraser-Smith et al., 2013) and 0122 (Fraser-Smith et al., 2013) have also, but incorrectly, been regarded as TR4s. In our study, 11 Foc VCGs caused moderate rhizome damage in 'Grand Naine' plants. Such isolates might be potentially harmful, particularly once unfavourable soil and environmental conditions predispose 'Gros Michel' and 'Grand Naine' (Deltour et al., 2017; Pegg et al., 1995; Shivas et al., 1995; Wen et al., 2015), but should never be considered as TR4. Also, the concentration and distribution of Foc inoculum in the soil might determine disease severity. Banana cultivars that were symptomatic under greenhouse conditions remained unaffected in field conditions, due to a lower concentration of inoculum under natural conditions ( $\mathrm{Li}$ et al., 2014). Clearly, varying genetic background of banana germplasm also affects disease development. In our study, VCGs associated with race 1 caused moderate to high severities in 'Gros Michel', except for VCG01210 isolate Focu7. This isolate was originally recovered from the so-called Apple banana cultivar (Musa AAB group), and might not affect 'Gros Michel' (AAA), given their different host genotype. Similarly, VCGs associated with race 4 affected 'Grand Naine', except for isolates from VCG0126 and 0129 which were recovered from Cavendish plants (Fraser-Smith et al., 2013). However, this is no guarantee that such isolates also are pathogenic on 'Grand Naine', as shown in our experiments. The Cavendish subgroup belongs to the Musa AAA group with a large phenotypic diversity as a result of selection and random somatic variation that can influence diverse responses to the same pathogen (Hwang \& Ko, 2004; Robinson \& Sauco, 2010).

Taken together we conclude that the genetic diversity of the tested Foc panel underlies the diverse responses of 'Gros Michel' and 'Grand Naine'. Their responses were indistinctively associated with VCGs from clade 1 and 2 of the FOSC and did not frequently correspond with their assumed Foc races. Hence, the current race concept requires significant 
revision based on extended isolate-germplasm evaluations along with genetic and genomic analyses as in for instance the tomato- $F$. oxysporum f.sp. lycopersici pathosystem where a range of effector and resistance genes were identified and cloned (Catanzariti et al., 2015; Mes et al., 1999; van Dam et al., 2016). From that perspective, the understanding of the banana-Fusarium pathosystem is at its very early stage. However, the recent discovery and cloning of the first resistance gene (Dale et al., 2017a; Dale et al., 2017b) is an important step forward that should be extended to formal genetics for gene discovery in the host as well as further investigations to understand the complexity of Fusarium pathogens in bananas (Maryani et al., 2018b). Our studies contribute to that aim (Ordóñez et al., 2015; see Chapter 4) and should eventually result in enhanced disease control.

\section{ACKNOWLEDGMENTS}

This research was funded by the Interdisciplinary Research and Education Fund (INREF) of Wageningen University \& Research (WUR), The Netherlands, and various private and public partners (see www.fusariumwilt.org). Banana research at WUR is supported by the Dutch Dioraphte Foundation endowed chair in Tropical Phytopathology of GHJK at the WUR-Laboratory of Phytopathology. Research in the laboratory of M.F. Seidl is supported by the Research Council Earth and Life Science (ALW) of The Netherlands Organization of Scientific Research (NWO). Dr. Eli Khayat, Rahan Meristem, Israel and Rafael Segura MSc, CORBANA, Costa Rica, are gratefully acknowledged for providing 'Grand Naine' and 'Gros Michel' plants, respectively. UNIFARM, WUR, The Netherlands is greatly acknowledged for greenhouse maintenance and plant care. 


\section{REFERENCES}

Aguayo, J., Mostert, D., Fourrier-Jeandel, C., Cerf-Wendling, I., Hostachy, B., Viljoen, A., \& Ioos, R. (2017). Development of a hydrolysis probe-based real-time assay for the detection of tropical strains of Fusarium oxysporum f.sp. cubense race 4. PLoS One, 12(2), 1-20.

Anderson, R.G., Deb, D., Fedkenheuer, K., \& McDowell, J.M. (2015). Recent Progress in RXLR Effector Research. Mol Plant Microbe Interact, 28(10), 1063-1072.

Anderson, P.K., Cunningham, A.A., Patel, N.G., Morales, F.J., Epstein, P.R., \& Daszak, P. (2004). Emerging infectious diseases of plants: pathogen pollution, climate change and agrotechnology drivers. Trends Ecol Evol, 19(10), 535-544.

Araújo, N.A.F., Pasqual, M., Pio, L.A.S., Alves, E., de Matos Moura, N., \& Costa, S.S. (2017). Identification and aggressiveness of four isolates of Fusarium oxysporum f.sp. cubense from Latundan banana in Brazil. J Phytopathol, 165, 254-264.

Armstrong, G.M., \& Armstrong, J.K. (1981). Formae speciales and races of Fusarium oxysporum causing wilt diseases. In: Nelson, P.E., Toussoun, T.A. \& Cook, R.J. (Eds), Fusarium: Diseases, biology and taxonomy, Pennsylvania State University Press, University Park and London, 391-399.

Aurore, G., Parfait, B., \& Fahrasmane, L. (2009). Bananas, raw materials for making processed food products. Trends in Food Sci Tech, 20(2), 78-91.

Baayen, R.P., O'Donnell, K., Bonants, P.J.M., Cigelnik, E., Kroon, L.P.N.M., Roebroeck, E.J.A., \& Waalwijk, C. (2000). Gene genealogies and AFLP analyses in the Fusarium oxysporum complex identify monophyletic and nonmonophyletic formae speciales causing wilt and rot disease. Phytopathology, 90, 891-900.

Bentley, S., Pegg, K.G., Moore, N.Y., Davis, R.D., \& Buddenhagen, I. (1998). Genetic variation among vegetative compatibility groups of Fusarium oxysporum f.sp. cubense analyzed by DNA fingerprinting. Phytopathology, 88(12), 1283-1293.

Bentley, S., Pegg, K.G., \& Dale, J.L. (1995). Genetic variation among a world-wide collection of isolates of Fusarium oxysporum f.sp. cubense analysed by RAPD-PCR fingerprinting. Mycol Res, 99(11), 13781384.

Boddy, L. (2016). Chapter 4 Genetics - Variation, Sexuality, and Evolution The Fungi (pp. 99-139). Boston: Academic Press.

Boehm, E.W.A., Ploetz, R., \& Kistler, H.C. (1994). Statistical analysis of electrophoretic karyotype variation among vegetative compatibility groups of Fusarium oxysporum f.sp. cubense. MPMI, 7(2), 196-207.

Bogale, M., Wingfield, B.D., Wingfield, M.J., \& Steenkamp, E.T. (2006). Characterization of Fusarium oxysporum isolates from Ethiopia using AFLP, SSR and DNA sequence analyses. Fungal Divers, 23, 51-66.

Buddenhagen, I. (2009). Understanding strain diversity in Fusarium oxysporum f.sp. cubense and history of introduction of 'tropical race 4' to better manage banana production. Acta Horticulturae, 828, 193-204.

Catanzariti, A.M., Lim, G.T., \& Jones, D.A. (2015). The tomato I-3 gene: a novel gene for resistance to Fusarium wilt disease. New Phytol, 207(1), 106-118.

Chartrain, L., Brading, P.A., \& Brown, J.K.M. (2005). Presence of the Stb6 gene for resistance to septoria tritici blotch (Mycosphaerella graminicola) in cultivars used in wheat-breeding programmes worldwide. Plant Pathol, 54(2), 134-143.

Correll, J. (1991). The relationship between formae speciales, races, and vegetative compatibility groups in Fusarium oxysporum. Phytopathology, 81(9), 1061-1064.

Dale, J., Paul, J.Y., Dugdale, B., \& Harding, R. (2017a). Modifying Bananas: From Transgenics to Organics? Sustainability, 9(3), 333.

Dale, J., James, A., Paul, J.Y., Khanna, H., Smith, M., Peraza-Echeverria, S., . . . Harding, R. (2017b). Transgenic Cavendish bananas with resistance to Fusarium wilt tropical race 4. Nat Commun, 8(1), 1496.

Deltour, P., França, C.S., Liparini-Pereira, O., Cardoso, I., De Neve, S., Debode, J., \& Höfte, M. (2017)a. Disease suppressiveness to Fusarium wilt of banana in an agroforestry system: Influence of soil characteristics and plant community. Agr Ecosys Environ, 239, 173-181. 
Dita, M.A., Waalwijk, C., Paiva, L.V., Sauza Jr, M.T., \& Kema, G.H.J. (2011). A greenhouse bioassay for the Fusarium oxysporum f.sp. cubense x 'Grand Naine' (Musa, AAA, Cavendish Subgroup) interaction. Acta Hort, 897, 377-380.

Dita, M.A., Waalwijk, C., Buddenhagen, I.W., Souza Jr, M.T., \& Kema, G.H.J. (2010). A molecular diagnostic for tropical race 4 of the banana Fusarium wilt pathogen. Plant Pathol, 59(2), 348-357.

Edel, V., Steinberg, C., Gautheron, N., \& Alabouvette, C. (2000). Ribosomal DNA-targeted oligonucleotide probe and PCR assay for Fusarium oxysporum. Mycol Res, 104(5), 518-526.

FAOSTAT. (2013). FAO statistical database.

Fisher, M.C., Hawkins, N.J., Sanglard, D., \& Gurr, S.J. (2018). Worldwide emergence of resistance to antifungal drugs challenges human health and food security. Science, 360(6390), 739-742.

Fourie, G., Steenkamp, E.T., Ploetz, R.C., Gordon, T.R., \& Viljoen, A. (2011). Current status of the taxonomic position of Fusarium oxysporum forma specialis cubense within the Fusarium oxysporum complex. Infect Genet Evol, 11(3), 533-542.

Fourie, G., Steenkamp, E., Gordon, T., \& Viljoen, A. (2009). Evolutionary relationships among the Fusarium oxysporum f.sp. cubense vegetative compatibility groups. Applied and environmental microbiology, 75(14), 4770-4781.

Fraser-Smith, S., Czislowski, E., Meldrum, R.A., Zander, M., O'Neill, W., Balali, G.R., \& Aitken, E.A.B. (2013). Sequence variation in the putative effector gene SIX8 facilitates molecular differentiation of Fusarium oxysporum f.sp. cubense. Plant Pathol, 63(5), 1044-1052.

Frison, E., \& Sharrock, S. (1998). The economic, social and nutritional importance of banana in the world. Paper presented at the Bananas and food security, Douala, Cameroon.

FruitTrop. (2017). Banana-statistics. Fruit Trop, 248, 86-87.

García-Bastidas, F.A., van der Veen, A.J.T., Nakasato-Tagami, G., Meijer, H.J.G., Arango-Isaza, R.E., \& Kema, G.H.J. (2018a). An improved spore production protocol facilitates a high throughput phenotyping assay for the banana - Fusarium oxysporum f.sp. cubense pathosystem. ( $\mathrm{PhD}$ Degree), Wageningen University \& Research, Wageningen, The Netherlands.

García-Bastidas, F.A., Bakry, F., Irish, B., \& Kema, G.H.J. (2018b). Evidence for wide variation of resistance to Fusarium oxysporum f.sp. cubense tropical race 4 and race 1 generated by vegetative propagation in banana. (PhD Degree), Wageningen University \& Research, Wageningen, The Netherlands.

Ghag, S.B., Shekhawat, U.K.S., \& Ganapathi, T.R. (2015). Fusarium wilt of banana: biology, epidemiology and management. Int J Pest Manage, 1-14.

Groenewald, S., van den Bergh, N., Marasas, W.F.O., \& Viljoen, A. (2006). Biological, physiological and pathogenic variation in a genetically homogenous population of Fusarium oxysporum f.sp. cubense Australas Plant Path, 35, 401-409.

Gurr, S., Samalova, M., \& Fisher, M. (2011). The rise and rise of emerging infectious fungi challenges food security and ecosystem health. Fungal Biol Rev, 25(4), 181-188.

Hwang, S.C., \& Ko, W.H. (2004). Cavendish banana cultivars resistant to Fusarium wilt acquired through somaclonal variation in Taiwan somaclonal variation in Taiwan. Plant Dis, 88(6), 580-588.

Katan, T. (1999). Current status of vegetative compatibility groups in Fusarium oxysporum. Phytoparasitica, 27(1), 51-64.

Katan, T., \& Di Primo, P. (1999). Current status of vegetative compatibility groups in Fusarium oxysporum: Supplement (1999). Phytoparasitica, 27(4), 273-277.

Kema, G.H.J., Mirzadi-Gohari, A., Aouini, L., Gibriel, H.A.Y., Ware, S.B., van den Bosch, F., . . . Seidl, M.F. (2018). Stress and sexual reproduction affect the dynamics of the wheat pathogen effector AvrStb6 and strobilurin resistance. Nat Genet, 50(3), 375-380.

Koch, R. (1912). Complete Works. George Thieme, Leipzig, I, 650-660.

Koenig, R.L., Ploetz, R., \& Kistler, H.C. (1997). Fusarium oxysporum f.sp. cubense consists of a small number of divergent and globally distributed clonal lineages. Phytopathology, 87(9), 915-923.

Leslie, J. F., \& Summerell, B. (2006). The Fusarium Laboratory Manual: Blackwell Publishing.

Leslie, J.F. (1990). Genetic exchange within sexual and asexual populations of the genus Fusarium. In R. Ploetz (Ed.), Fusarium wilt of banana (pp. 37-48). 
Li, C.Y., Mostert, G., Zuo, C.W., Beukes, I., Yang, Q.S., Sheng, O., . . . Yi, G.J. (2013). Diversity and distribution of the banana wilt pathogen Fusarium oxysporum f.sp. cubense in China. Fungal Genom Biol, 3(2), 1-6.

Li, W.M., Dita, M., Wu, W., Hu, G.B., Xie, J.H., \& Ge, X.J. (2014). Resistance sources to Fusarium oxysporum f.sp. cubense tropical race 4 in banana wild relatives. Plant Pathol, 1-7.

Lichtenzveig, J., Bonfil, D.J., Zhang, H.B., Shtienberg, D., \& Abbo, S. (2006). Mapping quantitative trait loci in chickpea associated with time to flowering and resistance to Didymella rabiei the causal agent of Ascochyta blight. Theoretical and Applied Genetics, 113(7), 1357-1369.

Maryani, N., Lombard, L., Poerba, Y.S., Subandiyah, S., Crous, P.W., \& Kema, G.H.J. (2018a). Phylogeny and genetic diversity of the banana Fusarium wilt pathogen Fusarium oxysporum f.sp. cubense in the Indonesian centre of origin. ( $\mathrm{PhD}$ Degree), Wageningen University \& Research, Wageningen, The Netherlands.

Maryani, N., Ahmad, F., Kleizer, P., Poerba, Y.S., Crous, P.W., \& Kema, G.H.J. (2018b). Pathogenic diversity of Fusarium wilt on banana pathogen in the Indonesian wild and cultivated bananas. (PhD Degree), Wageningen University \& Research, Wageningen, The Netherlands.

Mes, J.J., Weststeijn, E.A., Herlaar, F., Lambalk, J.J.M., Wijbrandi, J., Haring, M.A., \& Cornelissen, B.J.C. (1999). Biological and molecular characterization of Fusarium oxysporum f.sp. lycopersici divides Race 1 isolates into separate virulence groups. Phytopathology, 89(2), 156-160.

Moore, N.Y., Pegg, K.G., Allen, R.N., \& Irwin, J.A.G. (1993). Vegetative compatibility and distribution of Fusarium oxysporum f.sp. cubense in Australia. Aust J Exp Agri, 33, 797-802.

Mostert, D., Molina, A.B., Daniells, J., Fourie, G., Hermanto, C., Chao, C.P., . . . Viljoen, A. (2017). The distribution and host range of the banana Fusarium wilt fungus, Fusarium oxysporum f.sp. cubense, in Asia. PLoS One, 12(7), 1-24.

O'Donnell, K., Kistler, H.C., Cigelnik, E., \& Ploetz, R. (1998). Multiple evolutionary origins of the fungus causing Panama disease of banana: Concordant evidence from nuclear and mitochondrial gene genealogies. Proc Natl Acad Sci USA, 95, 2044-2049.

Ordóñez, N., Seidl, M.F., Waalwijk, C., Drenth, A., Kilian, A., Thomma, B.P., . . Kema, G.H. (2015). Worse comes to worst: Bananas and Panama disease-when plant and pathogen clones meet. PLoS Pathog, 11(11), 1-7.

Paul, J.Y., Becker, D.K., Dickman, M.B., Harding, R.M., Khanna, H.K., \& Dale, J.L. (2011). Apoptosis-related genes confer resistance to Fusarium wilt in transgenic 'Lady Finger' bananas. Plant Biotechnol J, 9(9), 1141-1148.

Pegg, K.G., Shivas, R.G., Moore, N.Y., \& Bentley, S. (1995). Characterization of a unique population of Fusarium oxysporum f.sp. cubense causing Fusarium wilt in Cavendish bananas at Carnarvon, Western Australia. Aust J Agric Res, 46, 167-178.

Perrier, X., De Langhe, E., Donohue, M., Lentfer, C., Vrydaghs, L., Bakry, F., . . . Denham, T. (2011). Multidisciplinary perspectives on banana (Musa spp.) domestication. Proc Natl Acad Sci USA, 108(28), 11311-11318.

Ploetz, R.C. (2015a). Fusarium Wilt of Banana. Phytopathology, 105(12), 1512-1521.

Ploetz, R.C. (2015b). Management of Fusarium wilt of banana: A review with special reference to tropical race 4. Crop Protection, 73, 7-15.

Ploetz, R.C., Kema, G.H., \& Ma, L.J. (2015). Impact of diseases on export and smallholder production of banana. Annu Rev Phytopathol, 53, 269-288.

Ploetz, R.C. (2006). Panama disease: An old nemesis rears its ugly head. Part2. The Cavendish era and beyond. Plant Health Progress.

Ploetz, R.C. (2005). Panama Disease: An old nemesis rears its ugly head. Part1: The beginnings of the banana export trades. Plant Health Progress.

Ploetz, R.C., Haynes, J.L., \& Vázquez, A. (1999). Responses of new banana accessions in South Florida to Panama disease. Crop Prot, 18(7), 445-449.

Puhalla, J.E. (1985). Classification of strains of Fusarium oxysporum on the basis of vegetative compatibility. Can J Bot, 63, 179-183.

Robinson, J.C., \& Sauco, G.V. (2010). Bananas and plantains. Wellingford, Oxfordshire, UK: CABI. 


\section{Chapter 5}

Saintenac, C., Lee, W. S., Cambon, F., Rudd, J. J., King, R. C., Marande, W., . . Kanyuka, K. (2018). Wheat receptor-kinase-like protein Stb6 controls gene-for-gene resistance to fungal pathogen Zymoseptoria tritici. Nat Genet, 50(3), 368-374.

Shivas, R.G., Wood, P.M., Darcey, M.W., \& Pegg, K.G. (1995). First record of Fusarium oxysporum f.sp. cubense on Cavendish bananas in Western Australia. Australas Plant Path, 24, 38-43.

Simmonds, N.W., \& Shepherd, K. (1955). Taxonomy and origins of cultivated bananas. J Linn Soc Bot, 55, 302312 .

Smith, E.F. (1910). A Cuban banana disease. Science, 31, 754-755.

Stover, R.H. (1962). Fusarial wilt (Panama disease) of bananas and other Musa species. UK: Commonwealth Mycological Institute.

Taylor, J.W., Jacobson, D.J., \& Fisher, M.C. (1999). The evolution of asexual fungi: Reproduction, speciation and classification. Annu Rev Phytopathol, 37, 197-246.

Thangavelu, R., Kumar, K.M., Devi, P.G., \& Mustaffa, M.M. (2012). Genetic diversity of Fusarium oxysporum f.sp. cubense isolates (Foc) of India by inter simple sequence repeats (ISSR) analysis. Mol Biotechnol, 51(3), 203-211.

Thangavelu, R., \& Mustaffa, M.M. (2010). First report on the occurrence of a virulent strain of Fusarium wilt pathogen (Race-1) infecting Cavendish (AAA) group of bananas in India. Plant Dis, 94(11), 1379.

van Brunschot, S. (2006). Fusarium wilt of banana. Laboratory diagnostic manual. Australia.

van Dam, P., Fokkens, L., Schmidt, S.M., Linmans, J.H., Kistler, H.C., Ma, L.J., \& Rep, M. (2016). Effector profiles distinguish formae speciales of Fusarium oxysporum. Environmental Microbiology, 18(11), 4087-4102.

Wen, T., Huang, X., Zhang, J., Zhu, T., Meng, L., \& Cai, Z. (2015). Effects of water regime, crop residues, and application rates on control of Fusarium oxysporum f.sp. cubense. J Environ Sci, 31, 30-37.

Zheng, S., García-Bastidas, F.A., Li, X., Zheng, L., Bai, T.T., Xu, S., . . . Kema, G.H.J. (2018). New geographical insights of the latest expansion of Fusarium oxysporum f.sp. cubense tropical race 4 into the Greater Mekong subregion. Front Plant Sci, 9(457), 1-9. 



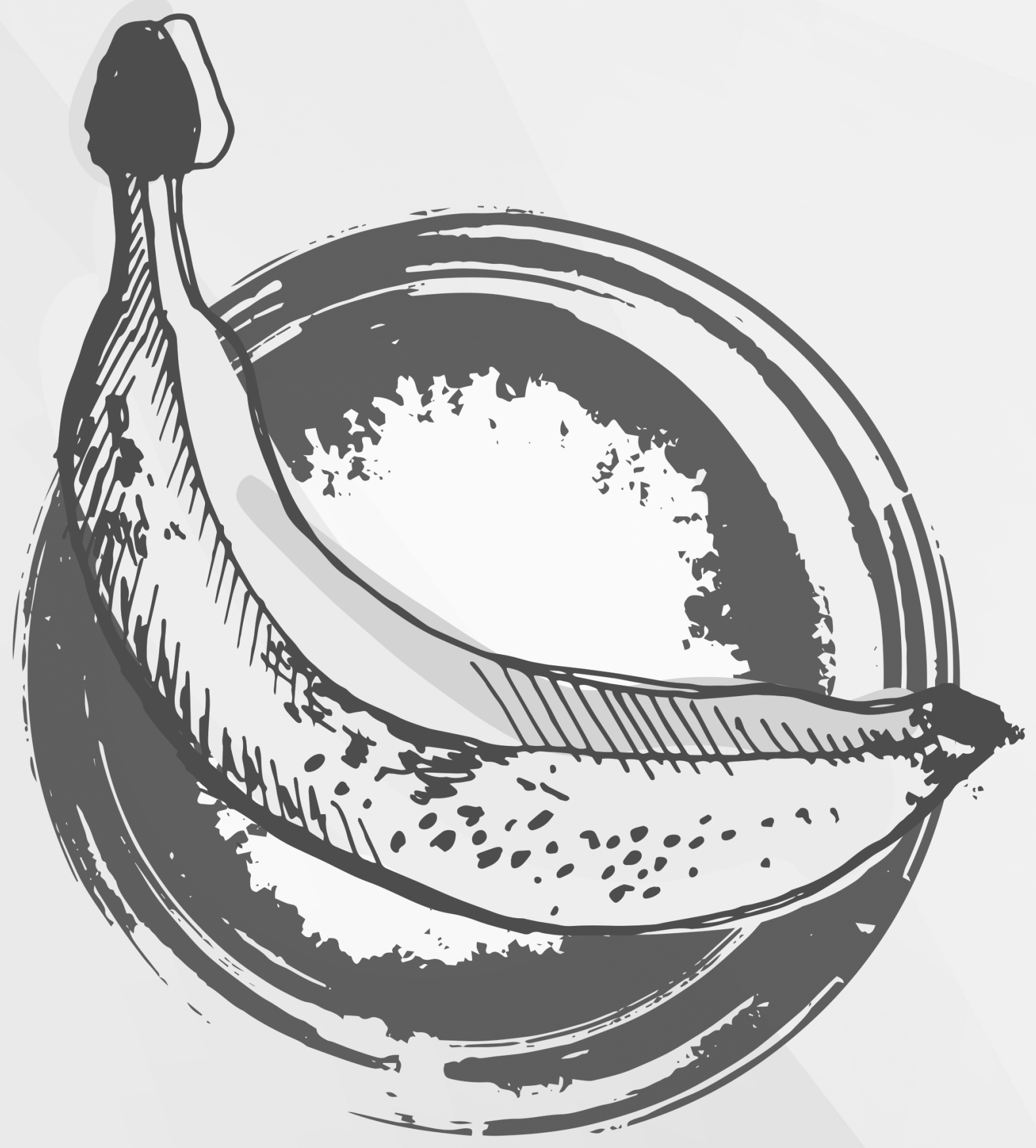




\section{CHAPTER 6}

\section{General discussion}

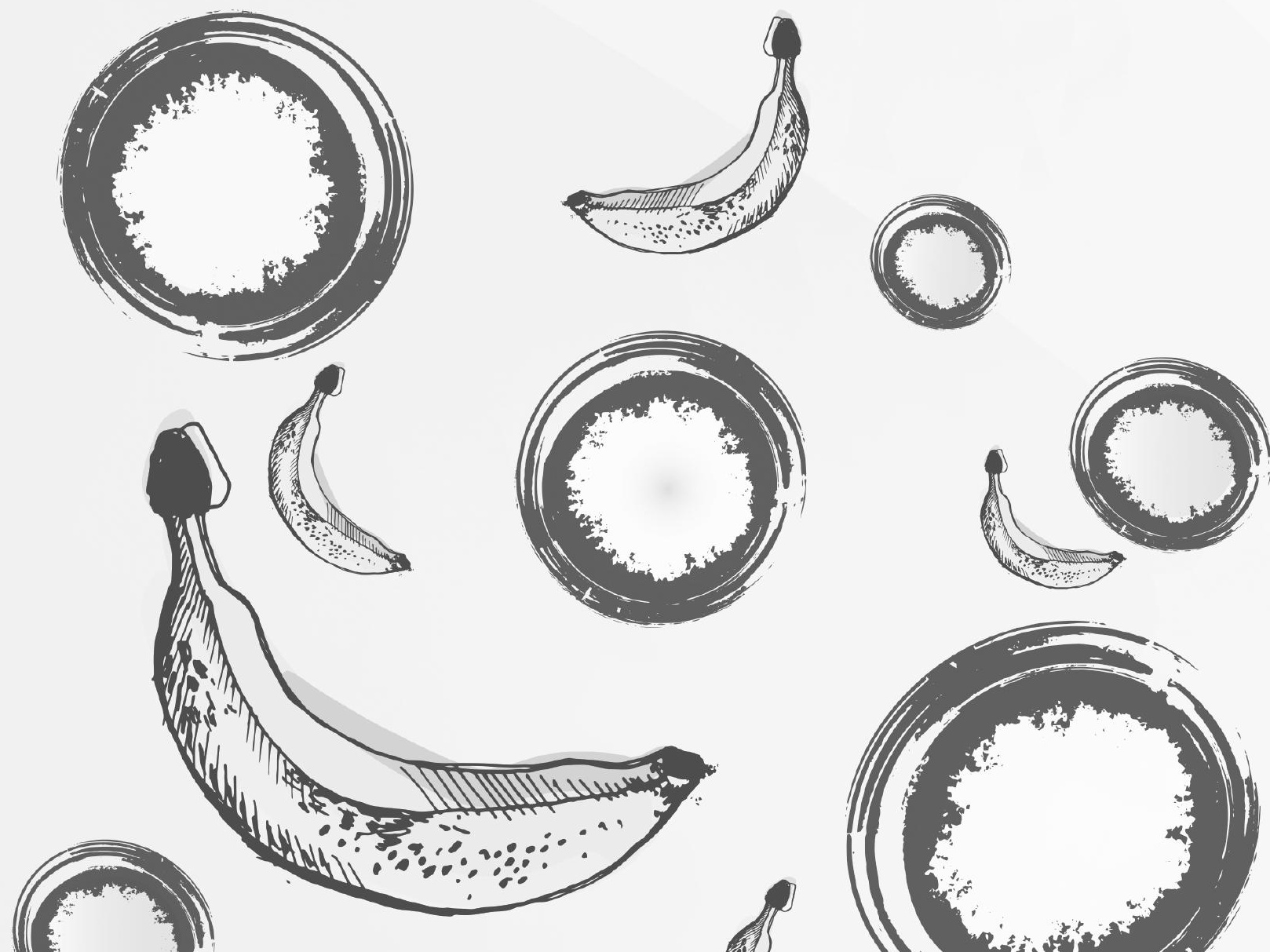




\section{INTRODUCTION}

In human history, plant disease epidemics caused by fungi challenged food security by dramatically reducing yields, leading to huge social-economic impacts (Anderson et al., 2004; Dean et al., 2012; Gurr et al., 2011). Besides epidemics that had significant demographic implications such as the potato leaf blight epidemic in Ireland (Yoshida et al., 2013), banana production is an insightful example of how plant diseases such as Fusarium wilt can dramatically reduce yields (Jones, 2009; Ploetz et al., 2015) and generate controversy on how its risk is to be managed at international and national scales (De la Cruz, 2017). Fusarium wilt, popularly known as Panama disease is one of the major threats affecting banana production (Ploetz et al., 2015). Nevertheless, research on its causal agent, the fungal pathogen Fusarium oxysporum f.sp. cubense (Foc), is limited and merely follows major outbreaks of the disease. Initially, Fusarium wilt in bananas gained research interest after a wilting outbreak that started in 1890 on banana farms relying on the 'Gros Michel' cultivar in Latin America (Ploetz, 1994; Stover, 1962). During this outbreak, Foc strains associated with race 1 were held responsible (Ploetz, 2015a; Stover, 1962), and over time, multiple Foc vegetative compatibility groups (VCGs) were associated with this epidemic that wiped out the 'Gros Michel' based banana production across Central America (see Chapter 2). However, identification of Foc genotype(s) that were explicitly involved in the epidemic is lacking, let alone the molecular underpinning of the plant-pathogen interaction that lead to the vulnerability of 'Gros Michel'. Once the replacement of 'Gros Michel' with resistant Cavendish banana cultivars "quenched" the epidemic and revived the industry (Ploetz, 2015a), the initial efforts on elucidating the underlying mechanisms for the epidemic shrank. Shortly after the Cavendish era begun in Latin America, Fusarium wilt heavily impacted pioneer Cavendish plantations in Southeast Asia in the late 1960s. Farms were abandoned, but no major efforts to scrutinize this emerging so-called tropical race 4 (TR4) strain were pursued (Buddenhagen, 2009). Only in 1994, VCG01213 was recognized as the genotype circumventing the resistance of Cavendish plants (Buddenhagen, 2009; Pegg et al., 1993; Ploetz, 1994). Around 20 years later, when the spreading potential of TR4 was apparent with new reports outside Southeast Asia (DAFF, 2015; García-Bastidas et al., 2014; IITA, 2013; Ordóñez et al., 2016) and claims that this emerging strain may potentially wipe-out today's bananas (Butler, 2013; Kema \& Weise, 2013; Kupferschmidt, 2012; Pearce, 2003), an increasing interest into Fusarium wilt once again arose. This was also driven by the engagement of the public and a strong social media interest. Fusarium wilt history is clearly lacking a deeper understanding of the mechanisms and the nature of the strains that cause the disease. The collaborative Interdisciplinary Research and Education Fund (INREF) program on Fusarium wilt of banana was a response to the developing TR4 threat and comprises seven $\mathrm{PhD}$ projects, including the currently study that focuses on elucidating the genetic diversity and virulence potential of global Foc strains, thereby significantly contributing to the genetic classification and the development of tools for disease management strategies. 
TOWARDS AN INFORMATIVE CLASSIFICATION OF FUSARIUM OXYSPORUM F.SP. CUBENSE

Generally, species are defined and recognized based on phenotype (the morphological species concept), reproductive isolation (the biological species concept) and genetic isolation (the phylogenetic species concept) (Boddy, 2016). In the genus Fusarium, the F. oxysporum species complex (FOSC) is composed of cosmopolitan non-pathogenic and pathogenic fungal species that are morphologically indistinguishable and lack a known sexual stage (Kerényi et al., 2004; Leslie \& Summerell, 2006; Michielse \& Rep, 2009; Taylor et al., 1999). Therefore they cannot be defined under the morphological and biological species concept. Instead, the most well established sub-specific nomenclature in literature for strains in this species complex is the use of forma specialis (f.sp.), a grouping system based on plant pathogenicity towards a host or a group of, usually related, hosts (Leslie \& Summerell, 2006; Lievens et al., 2008). This widely adopted classification usually does not reflect the phylogeny of strains. Nearly all formae speciales show a polyphyletic structure (Di Pietro et al., 2003; O'Donnell et al., 1998). Strains with pathogenicity to bananas are grouped under the f.sp. cubense. Further subdivisions of Foc strains include the use of races, VCGs and phylogenetic clades/lineages. The relationships among these classification systems are complex in Foc and consensus among researchers is still to be reached.

\section{Addressing challenges associated with race and vegetative compatibility group classification}

Historically, Foc strains were initially classified into three races (race 1, 2 and 4), based on virulence towards five to six banana cultivars (Stover, 1962). Although the Foc race concept is important to communicate disease outbreaks and describe banana cultivar responses (Buddenhagen, 2009; FAO, 2014), this does not accurately reflect the virulence of Foc strains. Race is commonly assigned to Foc isolates based on the banana cultivar from which the isolate is recovered. As a result, the assigned race does not fully disclose the pathogenic potential of Foc isolates. In Chapter 5, we demonstrated that some Foc isolates associated with race 1 and 2 also caused disease on 'Grand Naine' plants, and under the current race concept we would label them as race 4. Another drawback of the current Foc race concept is that environmental conditions can substantially influence the host responses (Brake et al., 1995; Deltour et al., 2017). For example, Cavendish bananas, the differential race 4 cultivars, have different responses to Fusarium wilt under diverse environmental conditions. Thus, race 4 is further subdivided in subtropical race 4 (ST4) and TR4, where ST4 affects Cavendish bananas growing under unfavorable environmental conditions; and TR4 causes disease even in the best environmental settings (Ploetz, 2015a). Also, soil conditions can influence disease development, Cavendish plants were symptomatic to a race 1 isolate by exposure to detrimental soil $\mathrm{pH}$ and nitrogen content under greenhouse conditions (Segura et al., 2016). Thus, if an environmental constraint is not properly discarded, Foc strains recovered from Cavendish plants in the tropics might be suspected as TR4, which can lead to serious quarantine restrictions for the affected farm and country. To overcome environmental influences, a race system that integrates molecular plant-pathogenic interactions of a select panel of plant cultivars is usually more reliable at assigning races. Unlike in Foc, races in $F$. oxysporum strains causing wilting on tomato (f.sp. lycopersici) are distinguished by their 
differential pathogenicity on five tomato cultivars containing race-specific, dominant resistance genes (Kawabe et al., 2005; Mes et al., 1999). This race system not only accurately assigns races to the isolates affecting the selected tomato cultivars but also helps to adopt management strategies directed to a well defined fungal genotype. The broad adoption of extensively validated greenhouse phenotyping protocols to avoid discordant results among research groups and the commercial availability of bananas plants are also essential to reach a well-established race system and extend on the virulence range of Foc strains to various banana cultivars (García-Bastidas et al., 2018a). In brief, I argue that the current Foc race concept is misleading since it does not usually follow pathogenicity testing using multiple banana cultivars, is largely influenced by environmental conditions and lacks the molecular genetic underpinning.

The subsequent classification of Foc strains into VCGs elaborated on their genetic diversity since vegetative compatibility has a multi-genic basis (Puhalla, 1985) and to date, 24 VCGs have been described for Foc (Bentley et al., 1995; Katan, 1999; Katan \& Di Primo, 1999; Moore et al., 1993; Ploetz, 2015a). Given the above-discussed disadvantages associated with the current race concept, the race-VCG relation in Foc is complex. Typically in Foc, more than one race is reported within a single VCG, and isolates related to the same race are located in different VCGs (Correll, 1991). VCG designation of Foc populations is broadly adopted among Foc research groups, allowing comparative studies on the presence/absence of reported VCGs among banana-growing areas (Table 1) (see Chapter 4). Also, vegetative compatibility was crucial to clearly distinguish the strain responsible for the recent outbreaks in Cavendish farms in Asia, Africa and Australia as VCG01213 (García-Bastidas et al., 2014; Molina et al., 2009; Ordóñez et al., 2016; Ordóñez et al., 2015; Zheng et al., 2018) from other genotypes such as VCGs 0121,0122 and 0124 that occasionally also caused disease in Cavendish in the tropics (Aguayo et al., 2017; Fraser-Smith et al., 2013; Thangavelu \& Mustaffa, 2010). In this way, global disease awareness efforts among banana-growing countries are directed to the diagnostic and spread prevention of VCG01213 (FAO, 2014). The downside of VCG testing is that it is labor intensive, time consuming and not always feasible due to intrinsic self-incompatibility of strains and quarantine restrictions on mutant testers (Leslie \& Summerell, 2006). As a consequence, molecular approaches to simplify VCG designation of a Foc population are proposed (Bentley et al., 1998; Fourie et al., 2009). In Chapter 4, we describe the use genotyping-by-sequencing data to develop a molecularbased approach to efficiently and rapidly assign VCGs to Foc isolates as of yet unknown VCGs that have the potential to eliminate or significantly reduce VCG testing efforts. In summary, initiatives to move away from VCG testing and promoting molecular-based characterization are highly desirable to rapidly assign genotypes and to study population structure and expansion. Studies that include VCG testing of thousands of isolates are unworkable because of the required time and labor to process isolates. Consequently, DNA based methods unequivocally allow comparative analyses of geographical diverse Foc populations and the reliable characterization of key genotypes such as for TR4 (VCG01213). 


\section{Addressing challenges associated with molecular classification}

Vegetative compatibility is a good indicator of genetic similarity but is not phylogenetically informative since it does not assess genetic relatedness of isolates within and among VCGs (Fourie et al., 2011; Ghag et al., 2015; Koenig et al., 1997; Leslie \& Summerell, 2006). Molecular classification studies using molecular markers e.g. microsatellites, AFLP and DArTseq markers allow for a higher level of organization of $F$. oxysporum strains into clades, phylogenetic species and lineages (Bentley et al., 1998; Bogale et al., 2006; Fourie et al., 2009; Groenewald et al., 2006; Koenig et al., 1997; O'Donnell et al., 1998; see Chapter 4). In the FOSC, two phylogenetic species were established, containing a total of 17 independent evolutionary lineages. Strains in clade 1 and in the remaining taxa (clade 2, 3 and 4) were named as phylogenetic species 1 and 2, respectively (Laurence et al., 2014). In terms of genetic lineages of Foc strains, seven to ten lineages within clade 1 and 2 containing a single or a group of VCGs are reported (Table 1) (Bentley et al., 1998; Fourie et al., 2009; Groenewald et al., 2006; Koenig et al., 1997; O'Donnell et al., 1998) and nine independent lineages were recently named as individual species (Maryani et al., 2018). In these studies, the polymorphic power of the selected molecular marker and the subsequent adopted criteria of genetic similarity as well as the number and geographic origin of the assessed Foc isolates defined the number of reported Foc lineages. Based on Table 1, it is evident that researchers differ in what they regard as a sufficient genetic resemblance among these strains. Consequently, a grey area exists for combining and separating lineages in Foc. Here, I define lineages based on the highest genetic similarity for confirmed cross-compatible Foc strains in Chapter 4 ( $>0.64$ Jaccard similarity for VCG0124/5/8/20/22 complex), resulting in 14 lineages among isolates in our Foc collection (Table 1, see Chapter 4). In Chapter 5, we report differences in severity towards two banana cultivars among VCGs that are normally assigned into single lineages, namely $0120 / 15,0126,0129,01219$ as well as for 0121 and 01213 . This observation highlights the importance to associate a genetic grouping system with other fungal attributes such as pathogenicity, reproductive behavior and evolutionary potential. Similarly, major pest cryptic species complexes were resolved following an integrative taxonomic approach that included the biology, cytogenetics, ecology, morphology, genetics and physiology of taxonomically challenging fruit fly groups of economic importance (Hendrichs et al., 2015). Notably, development of a grouping system that is highly biased towards pathogenic strains to one of few hosts and ignores the extensive and diverse nature of non-pathogenic strains from natural ecosystems fails to reveal mechanisms that may have played a role in its evolution and geographic distribution (Beheregaray, 2008; Summerell et al., 2010). In summary, I argue that a higher organizational level that elaborates not only on their genetic diversity but fungal attributes relevant for disease management is needed for Foc. As knowledge increases, consensus among researchers can be reached to organize $F$. oxysporum strains into a higher organizational level; in this regard, expanding the research community to include other Fusarium spp. and intensifying the scientific debate is necessary. 


\section{Chapter 6}

Table 1. Comparison of lineages of Fusarium oxysporum f.sp. cubense within clade 1 and 2 of the FOSC for reported vegetative compatibility groups. Roman numerals to indicate lineages are the same as described in the references. The criteria to define clades and lineages are stated in parenthesis.

\begin{tabular}{|c|c|c|c|c|c|c|c|c|c|c|c|c|}
\hline Genetic diversity & Clade & & & & & & Clade & & & & & \\
\hline $\begin{array}{l}\text { RFLP } \\
\text { Clonal lineage }=10 \text { (genetic } \\
\text { similarities }>0.94 \text { ) } \\
\text { VCG0123 (VII, X) and } \\
01214 \text { (V) were reported in } \\
\text { clade } 1 \text { (Koenig et al., 1997). }\end{array}$ & $\begin{array}{l}\text { II } \\
0120 \\
0126 \\
0129 \\
01215\end{array}$ & $\begin{array}{l}\text { IX } \\
01211\end{array}$ & $\begin{array}{l}\text { IV } \\
01210\end{array}$ & $\begin{array}{l}\text { VI } \\
0122\end{array}$ & $\begin{array}{l}\text { III } \\
0121 \\
01213\end{array}$ & & $\begin{array}{l}\text { I } \\
0124 \\
0125 \\
0128\end{array}$ & $\begin{array}{l}\text { VIII } \\
01212\end{array}$ & & & & \\
\hline $\begin{array}{l}\text { DNA amplification } \\
\text { fingerprinting } \\
\text { Clonal lineage }=9 \text { (genetic } \\
\text { similarities }>0.80 \text { ) } \\
\text { Other two clonal lineages } \\
\text { were reported on the basis of } \\
\text { new genotypes } \\
\text { (Bentley et al., 1998). }\end{array}$ & $\begin{array}{l}\text { I } \\
0120 \\
0129 \\
01211 \\
01215\end{array}$ & & $\begin{array}{l}\text { II } \\
0122 \\
0126 \\
01210 \\
01219\end{array}$ & & $\begin{array}{l}\text { III } \\
0121 \\
01213 \\
01216\end{array}$ & & $\begin{array}{l}\text { IV } \\
0124 \\
0125 \\
0128 \\
01212 \\
01220\end{array}$ & & $\begin{array}{l}\mathrm{V} \\
0123 \\
01217\end{array}$ & $\begin{array}{l}\text { VI } \\
01218\end{array}$ & $\begin{array}{l}\text { VII } \\
01214\end{array}$ & \\
\hline $\begin{array}{l}\text { DNA sequencing of } \\
\text { two loci } \\
\text { Clonal lineage }=5 \text { (bootstrap } \\
\text { support values }>63 \% \text { ) } \\
\text { (O'Donnell et al., 1998). }\end{array}$ & $\begin{array}{l}\text { II } \\
0120 \\
01215\end{array}$ & & $\begin{array}{l}\text { IV } \\
0126\end{array}$ & & & & $\begin{array}{l}\text { I } \\
0124 \\
0125 \\
0128 \\
01220\end{array}$ & & $\begin{array}{l}\text { III } \\
0123\end{array}$ & & $\begin{array}{l}\mathrm{V} \\
01214\end{array}$ & \\
\hline $\begin{array}{l}\text { AFLP } \\
\text { Clonal lineage }=7 \text { (bootstrap } \\
\text { support values }>67 \% \text { ) } \\
\text { (Groenewald et al., 2006). }\end{array}$ & $\begin{array}{l}\text { I } \\
0120 \\
01215\end{array}$ & & $\begin{array}{l}\text { II } \\
0122 \\
0126 \\
0129 \\
01219\end{array}$ & & $\begin{array}{l}\text { III } \\
01213 \\
01216\end{array}$ & $\begin{array}{l}\text { IV } \\
0121\end{array}$ & $\begin{array}{l}\text { VII } \\
0124 \\
0125\end{array}$ & & $\begin{array}{l}V \\
0123 \\
01217\end{array}$ & $\begin{array}{l}\text { VI } \\
01218\end{array}$ & & \\
\hline $\begin{array}{l}\text { DNA sequencing of } \\
\text { four loci } \\
\text { Clonal lineage }=8 \text { (bootstrap } \\
\text { support values }>70 \% \text { and } \\
\text { Bayesian posterior } \\
\text { probabilities }>0.7 \text { ) } \\
\text { (Fourie et al., 2009). }\end{array}$ & $\begin{array}{l}\text { IV } \\
0120 \\
0122 \\
01215\end{array}$ & $\begin{array}{l}\text { III } \\
0129 \\
01211\end{array}$ & $\begin{array}{l}\text { I } \\
01219\end{array}$ & $\begin{array}{l}\text { II } \\
0126 \\
01210\end{array}$ & $\begin{array}{l}\mathrm{V} \\
0121 \\
01213 \\
01216\end{array}$ & & $\begin{array}{l}\text { VII } \\
0124 \\
0125 \\
0128 \\
01212 \\
01220\end{array}$ & & $\begin{array}{l}\text { VI } \\
0123 \\
01217 \\
01218\end{array}$ & & $\begin{array}{l}\text { VIII } \\
01214\end{array}$ & \\
\hline $\begin{array}{l}\text { DNA sequencing of } \\
\text { three loci } \\
\text { Independent lineage }=9 ; \\
\text { (bootstrap support values } \\
>70 \% \text { and Bayesian } \\
\text { posterior probabilities } \\
>0.95 \text { ) } \\
\text { Lineage VIII was reported as } \\
\text { a novel genotype in clade } 2 \\
\text { (Maryani et al., 2018). }\end{array}$ & $\begin{array}{l}\text { III } \\
0120 \\
0122 \\
0129 \\
01211 \\
01215 \\
01219\end{array}$ & & & $\begin{array}{l}\text { II } \\
0126 \\
01210\end{array}$ & $\begin{array}{l}\text { I } \\
0121 \\
01213\end{array}$ & & $\begin{array}{l}\text { VI } \\
0124 \\
0125 \\
0128 \\
01212 \\
01220\end{array}$ & & $\begin{array}{l}\mathrm{V} \\
01217 \\
01223 \\
01224\end{array}$ & $\begin{array}{l}\text { IV } \\
01218\end{array}$ & $\begin{array}{l}\text { IX } \\
01214\end{array}$ & $\begin{array}{l}\text { VII } \\
01221\end{array}$ \\
\hline $\begin{array}{l}\text { DArTseq markers } \\
\text { Clonal lineage }=14 ; \text { (genetic } \\
\text { similarities }>0.64) \\
(\text { see Chapter } 4)\end{array}$ & $\begin{array}{l}\text { I } \\
0120 \\
01211 \\
01215\end{array}$ & $\begin{array}{l}\text { II to VI } \\
\text { each r } \\
\text { single } \\
0129 \text {, } \\
\text { respecti }\end{array}$ & $\begin{array}{l}\text { resented } \\
\text { CG } 0122, \\
1210 \text { and } \\
\text { ly }\end{array}$ & $\begin{array}{l}\text { with a } \\
0126 \\
01219\end{array}$ & $\begin{array}{l}\text { VII } \\
01213 \\
01216\end{array}$ & $\begin{array}{l}\text { VIII } \\
0121\end{array}$ & $\begin{array}{l}\text { IX } \\
0124 \\
0125 \\
0128 \\
01220 \\
01222\end{array}$ & $\begin{array}{l}X \\
01212\end{array}$ & $\begin{array}{l}\text { XI } \\
0123 \\
01217 \\
01223 \\
01224\end{array}$ & $\begin{array}{l}\text { XII } \\
01218\end{array}$ & $\begin{array}{l}\text { XIII } \\
01214\end{array}$ & $\begin{array}{l}\text { XIV } \\
01221\end{array}$ \\
\hline
\end{tabular}




\section{THE IMPLICATIONS OF PATHOGEN GENETIC DIVERSITY FOR FUSARIUM WILT MANAGEMENT}

In plant pathology, disease outcomes result from the interaction of three drivers: pathogen, host and environment, as exemplified on the disease triangle concept (Gurr et al., 2011; Scholthof, 2007). Biotic stresses caused by pathogens: fungi, bacteria, oomycetes and viruses are a major constraint to production of staple crops that are destined to feed an everincreasing world population (Boyd et al., 2013). As discussed above, genetic studies are one of the key factors to elaborate on species boundaries within species complexes. This, in turn, supports disease and pest management by facilitating the development of international market policies and the improvement of diverse applications (Hendrichs et al., 2015; Poulickova et al., 2017). For example, fine taxonomic resolution of species complexes in diatoms resulted in a better ecological assessment of water quality (Poulickova et al., 2017), while for fruit flies it facilitated international horticultural trade as well as simplified pest control techniques (Hendrichs et al., 2015). In-depth studies of Foc genetic diversity elaborates on the genetic structure, the evolutionary potential, the development of molecular-based diagnostics and the clarification of molecular plant-pathogen interactions for this pathogen, leading to improvement of Fusarium wilt management strategies.

\section{Pathogen genetic structure in effective cultivar deployment}

Understanding the genetic structure of pathogen populations, defined as the amount and distribution of genetic variation within and among populations, is essential to guide cultivar deployment from breeding-strategies (McDonald \& Linde, 2002a). Despite the global occurrence of Fusarium wilt (Ploetz, 2015a), Foc sampling campaigns are not commonplace. Actually, most of the Foc isolates used in global genetic diversity studies are shared among research groups (Bentley et al., 1998; Boehm et al., 1994; Fourie et al., 2009; Groenewald et al., 2006; Koenig et al., 1997; O'Donnell et al., 1998). In these Foc collections, Latin America and the Caribbean banana producing countries are usually underrepresented. Only recently, sampling efforts were carried out for Southeast Asia (Maryani et al., 2018; Mostert et al., 2017), East and Central Africa (Karangwa et al., 2018) and Latin America (Alkemade, 2017; Araújo et al., 2017; Costa et al., 2014; Cunha et al., 2015; Magdama \& Jimenez-Gasco, 2015; see Chapter 4). In Chapter 4, we report 20 new Foc genotypes, mostly from recently sampled areas in Latin America. Similarly in recent reports, there is increasing evidence of novel Foc strains that are genetically distant from the reported 24 VCGs (Araújo et al., 2017; Bentley et al., 1998; Karangwa et al., 2018; Maryani et al., 2018; Mostert et al., 2017). This highlights the importance of monitoring Foc populations as new distinct genotypes may remain to be discovered. These can potentially circumvent resistance of deployed cultivars, obstructing local management efforts that fail to account for an expanded diversity of local pathogenic strains. Novel genotypes might reflect unique pathogenic properties and genomic characteristics, as exemplified by the race 1 isolate (Foc_R1), pathogenic to Silk cultivars, used in screening for resistance by Embrapa, Brazil (Dita et al., 2010) that is now placed in clade 3 of FOSC (see Chapter 4). Importantly, the resulting Foc collections from ongoing sampling campaigns should be available to the banana research community for comparative studies in order to decipher the spreading and emergence of Foc strains. In some molecular 
studies (Costa et al., 2014; Ingle \& Ingle, 2013; Kumar et al., 2006), no reference isolates/VCGs were included hampering the comparison with previously reported clade/lineages of the FOSC and, as a result, disabling the tracking the spread of novel pathogenic lineages in and across these banana-growing areas. Altogether, for insights in genetic diversity and its geographic distribution, it is indispensable to cross reference to previously reported Foc genetic studies in order to monitor changes in Foc populations. Consequently, the proper characterization of Foc strains is fundamental to select for relevant local fungal genotypes for disease evaluation and the screening of resistant banana cultivars.

\section{Pathogen evolutionary potential in host resistance durability}

Genetic diversity studies of pathogen populations are imperative to elaborate on their evolutionary potential and history (Agrios, 2005; Boddy, 2016; Boyd et al., 2013; Gurr et al., 2011; McDonald \& Linde, 2002; Scholthof, 2007). In general, F. oxysporum strains pathogenic to many crops are at the lowest risk of evolutionary potential in a comparative evaluation of diverse plant pathogens due to strictly asexual reproduction, a limited number of clones existing within fields, and the low potential for natural genotype flow among field populations (McDonald \& Linde, 2002b). In contrast, Phytophthora infestans on potatoes, Zymoseptoria tritici and Parastagonospora nodorum on wheat posed the highest risk of breaking down crop resistance due to mixed reproduction/mating systems and significant gene flow among pathogen lineages (McDonald \& Linde, 2002b). Molecular studies support the concept that Foc strains are generally stable clonal lineages demonstrating that multiple VCGs have similar genetic profiles regardless of their geographic origin, year of isolation or host origin (Bentley et al., 1998; Bogale et al., 2006; Fourie et al., 2009; Groenewald et al., 2006; Koenig et al., 1997; see Chapter 4). In Fusarium wilt history, despite more than 50 years growing Cavendish bananas in race 1 infested soils around the world, race 1 strains have not circumvented this cornerstone of contemporary banana production. The current outbreak in Cavendish corresponds to a genetically distant strain (VCG01213) related to an independent lineage (Maryani et al., 2018; O'Donnell et al., 1998; Ordóñez et al., 2015). Molecular markers such as RFLP, AFLP and DArTseq markers show that Foc strains are genetically distant and usually relate to two distinct clades (1 and 2) within the FOSC (Bentley et al., 1998; Bogale et al., 2006; Fourie et al., 2009; Groenewald et al., 2006; Koenig et al., 1997; see Chapter 4), suggesting independent convergent evolution of host pathogenicity towards bananas (Baayen et al., 2000; O'Donnell et al., 1998; see Chapter 5). In the evolutionary history of Foc, strains are believed to co-evolve with their host (Musa spp.) in the IndoMalayan archipelago, which is supported by extensive Foc diversity in this region compared to other banana-growing areas (Boehm et al., 1994; Fourie et al., 2009; Maryani et al., 2018; Ploetz \& Pegg, 1997; see Chapter 4) and the exclusive presence of clade 1 strains from natural soil in Southeast Asia and Oceania (Laurence et al., 2012). The evolutionary potential of lineages in clade 1 and 2 might result in unique characteristics over time. A comparison of Secreted In Xylem (SIX) effectors between F. oxysporum strains pathogenic to cotton (f.sp. vasinfectum) in clade 1 and 2 revealed substantial sequence divergence and differences with reported SIX genes (Chakrabarti et al., 2011). The hypothesis for Foc genotypes that are not present in the host center of origin is that they originate from local $F$. oxysporum populations after the introduction of bananas (Bentley et al., 1998; Boehm et al., 1994; Fourie et al., 2009; 
Groenewald et al., 2006; Koenig et al., 1997). In Chapter 4, we report 18 VCGs beyond clade 1 that are only present in banana-growing areas outside Southeast Asia. Drivers shaping this genetic diversity in $F$. oxysporum strains in the absence of sexual recombination are parasexuality (Taylor et al., 1999) and horizontal gene transfer (HGT) (Ma et al., 2010; Mehrabi et al., 2017). Parasexual recombination might have occurred among isolates of the VCG0124/5/8/20 complex (Taylor et al., 1999). If so, new genotypes may arise and the generated genetic diversity might influence the responses of these Foc isolates to overcome disease management strategies compared to other lineages. Horizontal and vertical gene transfer also can potentially lead to the emergence of novel pathogenic $F$. oxysporum lineages (Czislowski et al., 2017; Laurence et al., 2015; Ma et al., 2010; van Dam et al., 2016; Vlaardingerbroek et al., 2016). Pathogenicity genes were confirmed in F. oxysporum isolates from natural soils, showing evidence for HGT between $F$. oxysporum strains from agroecosystems (Rocha et al., 2015). In Foc, recent evidence for HGT of SIX genes involved in host pathogenicity was reported (Czislowski et al., 2017). In addition to this, the genomic composition of $F$. oxysporum proved to be very versatile, where a single $F$. oxysporum strain demonstrated trans-kingdom host infections of tomato plants, mice and insects (NavarroVelasco et al., 2011; Ortoneda et al., 2004). In summary, research on the evolutionary potential of Foc strains is necessary to predict when targeted genotypes might overcome host resistance and to explain possible drivers of genetic diversity.

\section{Pathogen sequencing in disease surveillance}

Genome sequencing projects aid in the tracking of disease spreading and the development of molecular detection methods to support disease surveillance. This is particularly important in the case of the TR4 strain. At the beginning of this PhD project, TR4 was reported only in Southeast Asia (China, Indonesia, Malaysia and The Philippines) and Australia (Darwin) (Buddenhagen, 2009; Molina et al., 2009). We were the first to report TR4 outside South-East Asia (García-Bastidas et al., 2014) which then culminated in a range of reports describing trans-continental dissemination of this genotype to Mozambique (IITA, 2013), Middle East (Ordóñez et al., 2016), across the Greater Mekong area (Zheng et al., 2018) and a re-incurrence in Australia (Queensland) (DAFF, 2015). These recent reports were confirmed with the use of diagnostic TR4 primers (Dita et al., 2010). In some cases, TR4 went undiagnosed for years before it surfaced as a new incursion. For instance, Fusarium wilt symptoms on Cavendish plants were first observed in 2006 in Jordan, but TR4 was only identified eight years later (García-Bastidas et al., 2014). In Chapter 3, we develop a highly specific and rapid LAMP assay for TR4 diagnosis that targets a genomic region that remains unique to TR4, including the assessment of recently released genomic data on $97 \mathrm{~F}$. oxysporum strains (https://www.ncbi.nlm.nih.gov/genome/genomes/707) and DArTseq data on more than 300 isolates. This assay is directed for on-site diagnosis that even non-skilled personnel can perform in a basic laboratory set up, particularly useful for developing countries that largely depend on banana production but have limited access to technology. After implementation, the LAMP diagnostic has the potential to significantly reduce the time to diagnosis prompting to deliver immediate management responses. Cavendish banana growers in The Philippines adopted our LAMP assay technology and efficiently tracked TR4 spreading on their farms (see Chapter 3). Similar molecular-based diagnostics can be 
developed for the entire suite of Foc strains or specific genotypes. Molecular identification of formae speciales is highly desirable for effective disease management, although it is an intricate goal as pathogenic and non-pathogenic $F$. oxysporum strains largely share the same core of genes (Recorbet et al., 2003). Besides these difficulties, molecular-based diagnostics for other formae especiales of the FOSC were successfully developed (Lievens et al., 2008; van Dam et al., 2016). In Foc, molecular methods to diagnose Foc strains are not yet developed, thus demanding pathogenicity testing to determine the virulence of $F$. oxysporum strains towards bananas. Ideally, banana virulence genes common among Foc strains should be the target for the development of molecular diagnostic tools. The detection of virulence genes in host-microbe interactions is nowadays possible, especially given the advancement of whole genome sequencing technologies and increasing availability of genomic data (Gibriel et al., 2016). Research on the molecular aspects of the banana-Foc was recently initiated, leading to the detection of effectors secreted by Foc strains during the infection process (Czislowski et al., 2017; Meldrum et al., 2012; Sutherland et al., 2013) and more recently to the discovery of the first Fusarium wilt banana resistance gene to TR4 (Dale et al., 2017a; Dale et al., 2017b). Lastly, whole genome sequencing supports epidemiological studies and maps disease dynamics (Gilchrist et al., 2015; Grad \& Lipsitch, 2014) such as for the ongoing Ebola epidemic in West Africa (Gire et al., 2014). In Foc, in-depth sequencing projects performed on TR4 isolates revealed the potential sources of spread across the Greater Mekong area in Asia, despite their highly clonal genetic structure (Zheng et al., 2018). In summary, prevention is better than control, thus rapid and reliable detection and genotyping of Foc strains as well as the establishment of their dissemination are essential to make timely disease management decisions, impeding the massive dissemination of pathogenic strains across the globe.

\section{MULTIDISCIPLINARITY IN FUSARIUM WILT RESEARCH}

Traditionally, plant disease management centered on the use of fungicides (Dun-Chun et al., 2016; Pandey et al., 2016), with copper and sulfur first used to control crop disease more than 150 years ago (Fisher et al., 2018). In the late 1960s, a movement towards integrated plant disease management that promotes agricultural sustainability initiated, consolidating a holistic approach of cultural practices, genetic resistance, physical and mechanical measures, biological control, chemical, quarantine and regulatory measures (Pandey et al., 2016). This PhD thesis is part of an INREF program (http://www.fusariumwilt.org/index.php/en/projects/\#INREF) that includes biological, environmental and social research projects to support Fusarium wilt disease control. It addresses Fusarium wilt of bananas from a pathogen perspective, extensively unveiling pathogen diversity using a genotype-by-sequence technology with genome-wide leverage (see Chapter 2 and 4) and extending on its pathogenic attributes (see Chapter 5). Important biological initiatives on disease control extend to the understanding of host biology. In banana, disease resistance is the most effective strategy to manage Fusarium wilt, as exemplified during its first outbreak on 'Gros Michel', where the adoption of resistant cultivars saved the banana industry (Ploetz, 2006). Conventional banana breeding programs generated resistant banana varieties to race 1 and ST4 that were successfully tested under field 
conditions in Australia (Smith et al., 2014). Similarly, Cavendish-based somaclones, partially resistant to TR4, are currently implemented in The Philippines to manage TR4 after its incursion in 2006 (Hwang \& Ko, 2004; Molina et al., 2009; Ploetz, 2015b). In crops, traditional breeding for resistance is slow, with a 20 -year lag from finding a suitable diseaseresistance gene to releasing it in commercial lines, or approximately 10 years with markerassisted breeding (Fisher et al., 2018). In contrast, genome editing techniques, such as CRISPR, could revolutionize plant breeding by accelerating this lengthy process to meet increasing food demands (Gao, 2018). Screening for resistant banana germplasm started with an emphasis on TR4, the strain causing the current epidemic in Cavendish (García-Bastidas et al., 2018b; Hwang \& Ko, 2004; Li et al., 2014). Following the discovery of Fusarium wilt resistance genes (Beckman, 2000; Ghag et al., 2014; Koch et al., 2013; Pereza-Echeverria, 2007; Ramu et al., 2016), genetically modified bananas resistant to Fusarium wilt caused by TR4 (Dale et al., 2017a) and race 1 (Magambo, 2012; Paul et al., 2011) were generated. Genetically modified food is, however, a controversial issue that involves social elements such as risk and benefit perceptions, trust, knowledge and purchasing decisions (Costa-Font et al., 2008). In developing banana producing countries, hunger was identified as the economic compulsion that moves states into accepting biotechnological solutions, where a risk-tradeoff to solve pressing concerns of food insecurity prevailed against perceived risks associated with genetically modified products (De la Cruz, 2017). Alternatively, strategies to reduce disease incidence are also important, as abiotic and biotic factors can aggravate or minimize crop vulnerability (Dun-Chun et al., 2016). In this regard, nutritional, biological and physical properties of soils are essential components influencing the prevalence of diseases (Deltour et al., 2017). In bananas, nutrients, the microbial community and physical attributes of soil influenced Fusarium wilt disease incidence to various degrees in the field (Alabouvette et al., 2009; Cao et al., 2004; Forsyth et al., 2006; Huang et al., 2012; Mohandas et al., 2010; Segura et al., 2016; Shen et al., 2015; Wen et al., 2015; Xue et al., 2015; Yuan et al., 2012). Interestingly, a microbial community that enhances the presence of incompatible Foc strains prior to infection with a compatible strain, confers resistant to banana germplasm (Thakker et al., 2013; Wu et al., 2013). Similarly, soil disinfestation that has been successfully applied to control diverse soil-borne pathogens in other crops (Strauss \& Kluepfel, 2015) is another promising alternative to control Fusarium wilt (Huang et al., 2015). Ultimately, disease control requires coordinated private and public action at the national and international level that police risk perception and disease management by establishing responsibilities of the various involved actors (governmental bodies, growers, grower associations, trade companies, research institutes and civil society organizations; see De la Cruz, 2017). In summary, Fusarium wilt management prompts to a multidisciplinary research strategy that covers biological, environmental and social drivers from regional to global scales in order to provide an integrative solution to this detrimental disease of our beloved banana fruit. 


\section{FINAL REMARKS}

Genetic studies revealed the genomic diversity of Foc strains causing Fusarium wilt on bananas and that their pathogenic attributes are still to be defined and explored. Current classification of Foc strains into races generally does not reflect a stable designation as it is based on host responses of mature banana varieties largely influenced by environmental conditions and lacks host-pathogen molecular understanding. Vegetative compatibility linked with molecular analyses is the approach that gives the most explanatory understanding of the genetic diversity of Foc populations and elaborates on their grouping strategy into VCG, phylogenetic lineages and clades. A higher organizational level of Foc strains must be complemented by revealing relevant pathogenic and reproductive behaviors that are essential for disease management. From a taxonomic point of view, elucidation of genetic groups in Foc must include $F$. oxysporum strains from the entire FOSC, regardless of their pathogenicity. The findings discussed in this $\mathrm{PhD}$ project contribute to the understanding of the genetic and pathogenic diversity of Foc strains which in turn provides relevant information and tools for better management strategies. Future key biological research lines in Foc should elucidate the molecular banana-Fusarium interaction, understand and explore genetics of resistance, population dynamics, evolutionary potential, pathogenic range and the development of molecular-based diagnostics. 


\section{REFERENCES}

Agrios, G.N. (2005). Chapter 4 Genetics of plant disease. In t. Edition (Ed.), Plant Pathol: Academic Press.

Aguayo, J., Mostert, D., Fourrier-Jeandel, C., Cerf-Wendling, I., Hostachy, B., Viljoen, A., \& Ioos, R. (2017). Development of a hydrolysis probe-based real-time assay for the detection of tropical strains of Fusarium oxysporum f.sp. cubense race 4. PLoS One, 12(2), 1-20.

Alabouvette, C., Olivain, C., Migheli, Q., \& Steinberg, C. (2009). Microbiological control of soil-borne phytopathogenic fungi with special emphasis on wilt-inducing Fusarium oxysporum. New Phytol, 184(3), 529-544.

Alkemade, J. (2017). Mapping the Fusarium oxysporum f.sp. cubense population in Costa Rica. Retrieved from Wageningen, NL.

Anderson, P.K., Cunningham, A.A., Patel, N.G., Morales, F.J., Epstein, P.R., \& Daszak, P. (2004). Emerging infectious diseases of plants: pathogen pollution, climate change and agrotechnology drivers. Trends Ecol Evol, 19(10), 535-544.

Araújo, N.A.F., Pasqual, M., Pio, L.A.S., Alves, E., de Matos Moura, N., \& Costa, S.S. (2017). Identification and aggressiveness of four isolates of Fusarium oxysporum f.sp. cubense from Latundan banana in Brazil. J Phytopathol, 165, 254-264.

Baayen, R.P., O'Donnell, K., Bonants, P.J.M., Cigelnik, E., Kroon, L.P.N.M., Roebroeck, E.J.A., \& Waalwijk, C. (2000). Gene genealogies and AFLP analyses in the Fusarium oxysporum complex identify monophyletic and nonmonophyletic formae speciales causing wilt and rot disease. Phytopathology, 90, 891-900.

Beckman, C.H. (2000). Phenolic-storing cells: keys to programmed cell death and periderm formation in wilt disease resistance and in general defence responses in plants? Physiol Mol Plant P, 57(3), 101-110.

Beheregaray, L.B. (2008). Twenty years of phylogeography: the state of the field and the challenges for the Southern Hemisphere. Mol Ecol, 17(17), 3754-3774.

Bentley, S., Pegg, K.G., Moore, N.Y., Davis, R.D., \& Buddenhagen, I. (1998). Genetic variation among vegetative compatibility groups of Fusarium oxysporum f.sp. cubense analyzed by DNA fingerprinting. Phytopathology, 88(12), 1283-1293.

Bentley, S., Pegg, K.G., \& Dale, J.L. (1995). Genetic variation among a world-wide collection of isolates of Fusarium oxysporum f.sp. cubense analysed by RAPD-PCR fingerprinting. Mycol Res, 99(11), 13781384.

Boddy, L. (2016). Chapter 4 Genetics - Variation, Sexuality, and Evolution The Fungi (pp. 99-139). Boston: Academic Press.

Boehm, E.W.A., Ploetz, R., \& Kistler, H.C. (1994). Statistical analysis of electrophoretic karyotype variation among vegetative compatibility groups of Fusarium oxysporum f.sp. cubense. MPMI, 7(2), 196-207.

Bogale, M., Wingfield, B.D., Wingfield, M.J., \& Steenkamp, E.T. (2006). Characterization of Fusarium oxysporum isolates from Ethiopia using AFLP, SSR and DNA sequence analyses. Fungal Divers, 23, 51-66.

Boyd, L.A., Ridout, C., O'Sullivan, D.M., Leach, J.E., \& Leung, H. (2013). Plant-pathogen interactions: disease resistance in modern agriculture. Trends Genet, 29(4), 233-240.

Brake, V.M., Pegg, K.G., Irwin, J.A.G., \& Chaseling, J. (1995). The influence of temperature, inoculum level and race of Fusarium oxysporum f.sp. cubense on the disease reaction of banana cv. Cavendish. Aust J Agric Res.

Buddenhagen, I. (2009). Understanding strain diversity in Fusarium oxysporum f.sp. cubense and history of introduction of Tropical Race 4 to better manage banana production. Acta Hort, 828(Proc. IS on Banana Crop Prot., Sust. Prod. \& Impr. Livelihoods), 193-204.

Butler, D. (2013). Fungus threatens top banana. Nature, 504, 195-196.

Cao, L., Qiu, Z., Dai, X., Tan, H., Lin, Y., \& Zhou, S. (2004). Isolation of endophytic actinomycetes from roots and leaves of banana (Musa Acuminata) plants and their activities against Fusarium oxysporum f.sp. cubense. World J Microb Biot, 20(5), 501-504.

Chakrabarti, A., Rep, M., Wang, B., Ashton, A., Dodds, P., \& Ellis, J. (2011). Variation in potential effector genes distinguishing Australian and non-Australian isolates of the cotton wilt pathogen Fusarium oxysporum f.sp. vasinfectum. Plant Pathol, 60(2), 232-243. 
Correll, J.C. (1991). The relationships between formae speciales, races and vegetative compatibility groups in Fusarium oxysporum. Phytopathology, 81, 1061-1064.

Costa, S.N., Bragança, C.A.D., Ribeiro, L.R., Amorim, E.P., Oliveira, S.A.S., Dita, M.A., . . Haddad, F. (2014). Genetic structure of Fusarium oxysporum f.sp. cubense in different regions from Brazil. Plant Pathol, 1-10.

Costa-Font, M., Gil, J.M., \& Traill, W.B. (2008). Consumer acceptance, valuation of and attitudes towards genetically modified food: Review and implications for food policy. Food Policy, 33(2), 99-111.

Cunha, C.M.S., Hinz, R.H., Pereira, A., Tcacenco, F.A., \& Stadnik, M.J. (2015). Aggressiveness and genetic diversity of Fusarium oxysporum f.sp. cubense from Santa Catarina, southern Brazil. Trop Plant Pathol, 40(5), 326-334.

Czislowski, E., Fraser Smith, S., Zander, M., O’Neill, W.T., Meldrum, R.A., Tran-Nguyen, L.T.T., . . A Aitken, E.A. (2017). Investigating the diversity of effector genes in the banana pathogen, Fusarium oxysporum f.sp. cubense, reveals evidence of horizontal gene transfer. Mol Plant Pathol.

DAFF. (2015). Testing results confirm Panama disease on banana farm near Tully. Retrieved from https://www.daf.qld.gov.au/services/news-and-updates/plants/news/testing-results-confirm-panamadisease-on-banana-farm-near-tully.

Dale, J., James, A., Paul, J.Y., Khanna, H., Smith, M., Peraza-Echeverria, S., . . . Harding, R. (2017a). Transgenic Cavendish bananas with resistance to Fusarium wilt tropical race 4. Nat Commun, $8(1)$, 1496.

Dale, J., Paul, J. Y., Dugdale, B., \& Harding, R. (2017b). Modifying Bananas: From Transgenics to Organics? Sustainability, 9(3), 333.

De la Cruz, J. (2017). Panama disease in banana and neoliberal governance: towards a political ecology of risk. (PhD Degree), Wageningen University \& Research, Wageningen. Retrieved from http://edepot.wur.nl/423693.

Dean, R., Van Kan, J.A.L., Pretorius, Z.A., Hammond-Kosack, K.E., Di Pietro, A., Spanu, P.D., . . Foster, G.D. (2012). The Top 10 fungal pathogens in molecular plant pathology. Mol Plant Pathol, 13(4), 414-430.

Deltour, P., França, C.S., Liparini-Pereira, O., Cardoso, I., De Neve, S., Debode, J., \& Höfte, M. (2017). Disease suppressiveness to Fusarium wilt of banana in an agroforestry system: Influence of soil characteristics and plant community. Agr Ecosys Environ, 239, 173-181.

Di Pietro, A., Madrid, M.P., Caracuel, Z., Delgado-Jarana, J., \& Roncero, M.I. (2003). Fusarium oxysporum: exploring the molecular arsenal of a vascular wilt fungus. Mol Plant Pathol, 4(5), 315-325.

Dita, M.A., Waalwijk, C., Buddenhagen, I.W., Souza Jr, M.T., \& Kema, G.H.J. (2010). A molecular diagnostic for tropical race 4 of the banana Fusarium wilt pathogen. Plant Pathol, 59(2), 348-357.

Dun-Chun, H., Zhan, J., \& Lian-Hui, X. (2016). Problems, challenges and future of plant disease management: From an ecological point of view (Vol. 2016).

FAO. (2014). Technical manual prevention and diagnostic of Fusarium Wilt (Panama disease) of banana caused by Fusarium oxysporum f.sp. cubense Tropical Race 4 (TR4).

Fisher, M.C., Hawkins, N.J., Sanglard, D., \& Gurr, S.J. (2018). Worldwide emergence of resistance to antifungal drugs challenges human health and food security. Science, 360(6390), 739-742.

Forsyth, L.M., Smith, L.J., \& Aitken, E.A. (2006). Identification and characterization of non-pathogenic Fusarium oxysporum capable of increasing and decreasing Fusarium wilt severity. Mycol Res, $110(\mathrm{Pt}$ 8), 929-935.

Fourie, G., Steenkamp, E.T., Ploetz, R.C., Gordon, T.R., \& Viljoen, A. (2011). Current status of the taxonomic position of Fusarium oxysporum forma specialis cubense within the Fusarium oxysporum complex. Infect Genet Evol, 11(3), 533-542.

Fourie, G., Steenkamp, E.., Gordon, T.R., \& Viljoen, A. (2009). Evolutionary relationships among the Fusarium oxysporum f.sp. cubense vegetative compatibility groups. Appl Environ Microbiol, 75(14), 4770-4781.

Fraser-Smith, S., Czislowski, E., Meldrum, R.A., Zander, M., O'Neill, W., Balali, G.R., \& Aitken, E.A.B. (2013). Sequence variation in the putative effector gene SIX8 facilitates molecular differentiation of Fusarium oxysporum f.sp. cubense. Plant Pathol, 63(5), 1044-1052.

Gao, C. (2018). The future of CRISPR technologies in agriculture. Nat Rev Mol Cell Bio, 19, 275.

García-Bastidas, F.A., van der Veen, A.J.T., Nakasato-Tagami, G., Meijer, H.J.G., Arango-Isaza, R.E., \& Kema, G.H.J. (2018a). An improved spore production protocol facilitates a high throughput phenotyping assay 
for the banana - Fusarium oxysporum f.sp. cubense pathosystem. ( $\mathrm{PhD}$ Degree), Wageningen University \& Research, Wageningen, The Netherlands.

García-Bastidas, F.A., Bakry, F., Irish, B., \& Kema, G.H.J. (2018b). Evidence for wide variation of resistance to Fusarium oxysporum f.sp. cubense tropical race 4 and race 1 generated by vegetative propagation in banana. (PhD Degree), Wageningen University \& Research, Wageningen, The Netherlands.

García-Bastidas, F., Ordóñez, N., Konkol, J., Al-Qasim, M., Naser, Z., Abdelwali, M., . . Kema, G.H.J. (2014). First report of Fusarium oxysporum f.sp. cubense tropical race 4 associated with Panama disease of banana outside Southeast Asia. Plant Dis, 98(5), 694.

Ghag, S.B., Shekhawat, U.K.S., \& Ganapathi, T.R. (2015). Fusarium wilt of banana: biology, epidemiology and management. Int J Pest Manage, 1-14.

Ghag, S.B., Shekhawat, U.K., \& Ganapathi, T.R. (2014). Native cell-death genes as candidates for developing wilt resistance in transgenic banana plants. AoB Plants, 6, 1-12.

Gibriel, H.A., Thomma, B.P., \& Seidl, M.F. (2016). The age of effectors: Genome-based discovery and applications. Phytopathology, 106(10), 1206-1212.

Gilchrist, C.A., Turner, S.D., Riley, M.F., Petri, W.A., \& Hewlett, E.L. (2015). Whole-genome sequencing in outbreak analysis. Clin Microbiol Rev, 28(3), 541-563.

Gire, S.K., Goba, A., Andersen, K.G., Sealfon, R.S.G., Park, D.J., Kanneh, L., . . Sabeti, P.C. (2014). Genomic surveillance elucidates Ebola virus origin and transmission during the 2014 outbreak. Science, 345(6202), 1369-1372.

Grad, Y.H., \& Lipsitch, M. (2014). Epidemiologic data and pathogen genome sequences: a powerful synergy for public health. Genome Biol, 15(11), 538.

Groenewald, S., Van Den Berg, N., Marasas, W.F., \& Viljoen, A. (2006). The application of high-throughput AFLP's in assessing genetic diversity in Fusarium oxysporum f.sp. cubense. Mycol Res, 110(Pt 3), 297305.

Gurr, S., Samalova, M., \& Fisher, M. (2011). The rise and rise of emerging infectious fungi challenges food security and ecosystem health. Fungal Biol Rev, 25(4), 181-188.

Hendrichs, J., Vera, T., de Meyer, M., \& Clarke, A. (2015). Resolving cryptic species complexes of major tephritid pests. ZooKeys, 540.

Huang, X.Q., Wen, T., Zhang, J.B., Meng, L., Zhu, T.B., Liu, L.L., \& Cai, Z.C. (2015). Control of soil-borne pathogen Fusarium oxysporum by biological soil disinfestation with incorporation of various organic matters. Eur J Plant Pathol, 143(2), 223-235.

Huang, Y.H., Wang, R.C., Li, C.H., Zuo, C.W., Wei, Y.R., Zhang, L., \& Yi, G.J. (2012). Control of Fusarium wilt in banana with Chinese leek. Eur J Plant Pathol, 134(1), 87-95.

Hwang, S.C., \& Ko, W.H. (2004). Cavendish banana cultivars resistant to Fusarium wilt acquired through somaclonal variation in Taiwan somaclonal variation in Taiwan. Plant Dis, 88(6), 580-588.

IITA. (2013). New banana disease to Africa found in Mozambique. Joint statement issued by the Mozambique Department of Agriculture, Matanuska, IITA, Stellenbosch University and Bioversity International. Press release.

Ingle, A., \& Ingle, R. (2013). Isolation and identification of Fusarium oxysporum infecting Musa plants in Maharashtra region and their molecular characterization. Asiatic J Biotechnology Resources, 4(1), 2834.

Jansen, K. (2009). Implicit Sociology, Interdisciplinarity and Systems Theories in Agricultural Science. Sociol Ruralis, 49(2), 172-188.

Jones, D.R. (2009). Disease and pest constraints to banana production. Acta Hort, 828(Proc. IS on Banana Crop Prot., Sust. Prod. \& Impr. Livelihoods), 21-36.

Kawabe, M., Kobayashi, Y., Okada, G., Yamaguchi, I., Teraoka, T., \& Arie, T. (2005). Three evolutionary lineages of tomato wilt pathogen, Fusarium oxysporum f.sp. lycopersici, based on sequences of IGS, $M A T 1$, and pg1, are each composed of isolates of a single mating type and a single or closely related vegetative compatibility group. J Gen Plant Pathol, 71(4), 263-272.

Karangwa, P., Mostert, D., Ndayihanzamaso, P., Dubois, T., Niere, B., zum Felde, A., . . . Viljoen, A. (2018). Genetic diversity of Fusarium oxysporum f.sp. cubense in East and Central Africa. Plant Dis, 102(3), 552-560. 


\section{Chapter 6}

Katan, T. (1999). Current status of vegetative compatibility groups in Fusarium oxysporum. Phytoparasitica, 27(1), 51-64.

Katan, T., \& Di Primo, P. (1999). Current status of vegetative compatibility groups in Fusarium oxysporum: Supplement (1999). Phytoparasitica, 27(4), 273-277.

Kema, G.H.J., \& Weise, S. (2013). Pathogens: Appeal for funds to fight banana blight. Nature, 504(7479), 218.

Kerényi, Z., Moretti, A., Waalwijk, C., Oláh, B., \& Hornok, L. (2004). Mating type sequences in asexually reproducing Fusarium species. Appl Environ Microbiol, 70(8), 4419-4423.

Koch, A., Kumar, N., Weber, L., Keller, H., Imani, J., \& Kogel, K. H. (2013). Host-induced gene silencing of cytochrome P450 lanosterol C14alpha-demethylase-encoding genes confers strong resistance to Fusarium species. Proc Natl Acad Sci US A, 110(48), 19324-19329.

Koenig, R.L., Ploetz, R., \& Kistler, H.C. (1997). Fusarium oxysporum f.sp. cubense consists of a small number of divergent and globally distributed clonal lineages. Phytopathology, 87(9), 915-923.

Kumar, B.H., Shankar, U.A.C., Kini, R.K., Prakash, H.S., \& Shetty, S.H. (2006). Genetic variation in Fusarium oxysporum f.sp. cubense isolates based on random amplified polymorphic DNA and intergenic spacer. Arch Phytopathol PFL, 39(2), 151-160.

Kupferschmidt, K. (2012). Attack of the clones. Science, 337, 636-638.

Laurence, M. H., Summerell, B. A., \& Liew, E. C. Y. (2015). Fusarium oxysporum f.sp.canariensis: evidence for horizontal gene transfer of putative pathogenicity genes. Plant Pathol, 64(5), 1068-1075.

Laurence, M.H., Summerell, B.A., Burgess, L.W., \& Liew, E.C. (2014). Genealogical concordance phylogenetic species recognition in the Fusarium oxysporum species complex. Fungal Biol, 118(4), 374-384.

Laurence, M.H., Burgess, L.W., Summerell, B.A., \& Liew, E.C. (2012). High levels of diversity in Fusarium oxysporum from non-cultivated ecosystems in Australia. Fungal Biol, 116(2), 289-297.

Leslie, J.F., \& Summerell, B. (2006). The Fusarium Laboratory Manual: Blackwell Publishing.

Li, W.M., Dita, M., Wu, W., Hu, G.B., Xie, J.H., \& Ge, X.J. (2014). Resistance sources to Fusarium oxysporum f.sp. cubense tropical race 4 in banana wild relatives. Plant Pathol, 1-7.

Lievens, B., Rep, M., \& Thomma, B.P. (2008). Recent developments in the molecular discrimination of formae speciales of Fusarium oxysporum. Pest Manag Sci, 64(8), 781-788.

Ma, L.J., van der Does, H.C., Borkovich, K.A., Coleman, J.J., Daboussi, M.J., Di Pietro, A., . . Rep, M. (2010). Comparative genomics reveals mobile pathogenicity chromosomes in Fusarium. Nature, 464(7287), 367-373.

Magambo, B. (2012). Generating transgenic banana (cv. Sukali Ndizi) resistant to Fusarium wilt. (Master of Applied Science in the Science), Queensland University of Technology, Australia.

Magdama, F., \& Jimenez-Gasco, M.M. (2015). Populations of Fusarium oxysporum f.sp. cubense causing Panama disease of banana in Ecuador: Learning from the past for future perspectives. Phytopathology, 105, S4.162.

Maryani, N., Lombard, L., Poerba, Y.S., Subandiyah, S., Crous, P.W., \& Kema, G.H.J. (2018). Phylogeny and genetic diversity of the banana Fusarium wilt pathogen Fusarium oxysporum f.sp. cubense in the Indonesian centre of origin. (PhD Degree), Wageningen University \& Research, Wageningen, The Netherlands.

McDonald, B.A., \& Linde, C. (2002). Pathogen population genetics, evolutionary potential, and durable resistance. Annu Rev Phytopathol, 40, 349-379.

McDonald, B.A., \& Linde, C. (2002b). The population genetics of plant pathogens and breeding strategies for durable resistance. Euphytica, 124(2), 163-180.

Meldrum, R.A., Fraser-Smith, S., Tran-Nguyen, L.T.T., Daly, A.M., \& Aitken, E.A.B. (2012). Presence of putative pathogenicity genes in isolates of Fusarium oxysporum f.sp. cubense from Australia. Australas Plant Pathol, 41(5), 551-557.

Mehrabi, R., Mirzadi, A. G., \& Kema, G. H. J. (2017). Karyotype variability in plant-pathogenic fungi. Ann Rev Phytopathol, 55(1), 483-503.

Mes, J.J., Weststeijn, E.A., Herlaar, F., Lambalk, J.J.M., Wijbrandi, J., Haring, M.A., \& Cornelissen, B.J.C. (1999). Biological and molecular characterization of Fusarium oxysporum f.sp. lycopersici divides Race 1 isolates into separate virulence groups. Phytopathology, 89(2), 156-160.

Michielse, C.B., \& Rep, M. (2009). Pathogen profile update: Fusarium oxysporum. Mol Plant Pathol, 10(3), 311-324. 
Mohandas, S., Manjula, R., Rawal, R.D., Lakshmikantha, H.C., Chakraborty, S., \& Ramachandra, Y.L. (2010). Evaluation of arbuscular mycorrhiza and other biocontrol agents in managing Fusarium oxysporum f.sp. cubense infection in banana cv. Neypoovan. Biocontrol Sci Techn, 20(2), 165-181.

Molina, A.B., Fabregar, E., Sinohin, V.G., Yi, G., \& Viljoen, A. (2009). Recent occurrence of Fusarium oxysporum f.sp. cubense tropical race 4 in Asia. Acta Hort, 828(Proc. IS on Banana Crop Prot., Sust. Prod. \& Impr. Livelihoods), 109-115.

Moore, N.Y., Pegg, K.G., Allen, R.N., \& Irwin, J.A.G. (1993). Vegetative compatibility and distribution of Fusarium oxysporum f.sp. cubense in Australia. Aust J Exp Agri, 33, 797-802.

Mostert, D., Molina, A.B., Daniells, J., Fourie, G., Hermanto, C., Chao, C.P., . . . Viljoen, A. (2017). The distribution and host range of the banana Fusarium wilt fungus, Fusarium oxysporum f.sp. cubense, in Asia. PLoS One, 12(7), 1-24.

Navarro-Velasco, G.Y., Prados-Rosales, R.C., Ortiz-Urquiza, A., Quesada-Moraga, E., \& Di Pietro, A. (2011). Galleria mellonella as model host for the trans-kingdom pathogen Fusarium oxysporum. Fungal Genet Biol, 48(12), 1124-1129.

O'Donnell, K., Kistler, H.C., Cigelnik, E., \& Ploetz, R. (1998). Multiple evolutionary origins of the fungus causing Panama disease of banana: Concordant evidence from nuclear and mitochondrial gene genealogies. Proc Natl Acad Sci USA, 95, 2044-2049.

Ordóñez, N., García-Bastidas, F., Laghari, H.B., Akkary, M.Y., Harfouche, E.N., al Awar, B.N., \& Kema, G.H.J. (2016). First report of Fusarium oxysporum f.sp. cubense tropical race 4 causing Panama disease in Cavendish bananas in Pakistan and Lebanon. Plant Dis, 100(1), 209.

Ordóñez, N., Seidl, M.F., Waalwijk, C., Drenth, A., Kilian, A., Thomma, B.P., . . Kema, G.H. (2015). Worse comes to worst: Bananas and Panama disease-when plant and pathogen clones meet. PLoS Pathog, 11(11), 1-7.

Ortoneda, M., Guarro, J., Madrid, M.P., Caracuel, Z., Roncero, M.I.G., Mayayo, E., \& Di Pietro, A. (2004). Fusarium oxysporum as a multihost model for the genetic dissection of fungal virulence in plants and mammals. Infect Immun, 72(3), 1760-1766.

Pandey, A., Sain, S.K., \& Singh, P. (2016). A Perspective on integrated disease management in agriculture. Bio Bulletin, 2(2), 13-29.

Paul, J.Y., Becker, D.K., Dickman, M.B., Harding, R.M., Khanna, H.K., \& Dale, J.L. (2011). Apoptosis-related genes confer resistance to Fusarium wilt in transgenic 'Lady Finger' bananas. Plant Biotechnol J, 9(9), 1141-1148.

Pearce, F. (2003). Going bananas. New Sci, 177, 27.

Pegg, K.G., Moore, N.Y., \& Sorensen, S. (1993, 14-18 December, 1992). Fusarium wilt in the Asian Pacific region. Paper presented at the Procceedings of an International Symposium on Recent Developments in Banana Cultivation Technology, Pingtun, Taiwan (Los Banos, Laguna, Philippines: TBRI, ASPNET, INIBAP).

Pereza-Echeverria, S. (2007). Molecular cloning and characterisation of potential Fusarium resistance genes in banana (Musa acuminata ssp. malaccensis). (PhD Degree), Queensland University of Technology.

Ploetz, R.C. (2015a). Fusarium Wilt of Banana. Phytopathology, 105(12), 1512-1521.

Ploetz, R.C. (2015b). Management of Fusarium wilt of banana: a review with special reference to tropical race 4. Crop Prot, 73, 7-15.

Ploetz, R.C., Kema, G.H., \& Ma, L.J. (2015). Impact of diseases on export and smallholder production of banana. Annu Rev Phytopathol, 53, 269-288.

Ploetz, R.C. (2006). Panama disease: An old nemesis rears its ugly head. Part2. The Cavendish era and beyond. Plant Health Progress.

Ploetz, R.C., \& Pegg, K. (1997). Fusarium wilt of banana and Wallace's line: Was the disease originally restricted to his Indo-Malayan region? Australas Plant Pathol, 26, 239-249Ploetz, R.C. (1994). Panama disease: Return of the first banana menace. Int J Pest Manage, 40(4), 326-336.

Poulickova, A., Letakova, M., Hasler, P., Cox, E., \& Duchoslav, M. (2017). Species complexes within epiphytic diatoms and their relevance for the bioindication of trophic status. Sci Total Environ, 599-600, 820-833.

Puhalla, J.E. (1985). Classification of strains of Fusarium oxysporum on the basis of vegetative compatibility. Can J Bot, 63, 179-183. 


\section{Chapter 6}

Ramu, V., Venkatarangaiah, K., Krishnappa, P., Shimoga Rajanna, S.K., Deeplanaik, N., Chandra Pal, A., \& Kini, K.R. (2016). Identification of biomarkers for resistance to Fusarium oxysporum f.sp. cubense infection and in silico studies in Musa paradisiaca cultivar puttabale through proteomic approach. Proteomes, 4(1), E9.

Recorbet, G., Steinberg, C., Olivain, C., Edel, V., Trouvelot, S., Dumas-Gaudot, E., . . Alabouvette, C. (2003). Wanted: Pathogenesis-Related Marker Molecules for Fusarium oxysporum. New Phytol, 159(1), 73-92.

Rocha, L.O., Laurence, M.H., Ludowici, V.A.B., Puno, V.I., Lim, C.C., Tesoriero, L., . . . Liew, E.C.Y. (2015). Putative effector genes detected in Fusarium oxysporum from natural ecosystems of Australia. Plant Pathol, 1-16.

Scholthof, K.G. (2007). The disease triangle: pathogens, the environment and society. Nat Rev Microbiol, 5(2), 152-156.

Segura, R., Samuels, J., Stoorvogel, J., Guzman, M., \& Sandoval, J.A. (2016, April 19-22). The effect of soil management on nutrient accumulation in banana plants (Musa AAA, cv. Gros Michel) infected with panama disease (Fusarium oxysporum f.sp. cubense race 1). Paper presented at the VI International Banana Congress CORBANA and XXI International Meeting ACORBAT, Miami, USA.

Shen, Z., Ruan, Y., Wang, B., Zhong, S., Su, L., Li, R., \& Shen, Q. (2015). Effect of biofertilizer for suppressing Fusarium wilt disease of banana as well as enhancing microbial and chemical properties of soil under greenhouse trial. Appl Soil Ecol, 93, 111-119.

Smith, M.K., Langdon, P.W., Pegg, K.G., \& Daniells, J.W. (2014). Growth, yield and Fusarium wilt resistance of six FHIA tetraploid bananas (Musa spp.) grown in the Australian subtropics. Sci Hortic, 170, 176181.

Stover, R.H. (1962). Fusarial wilt (Panama disease) of bananas and other Musa species. UK: Commonwealth Mycological Institute.

Strauss, S.L., \& Kluepfel, D.A. (2015). Anaerobic soil disinfestation: A chemical-independent approach to preplant control of plant pathogens. J Integr Agr, 14(11), 2309-2318.

Summerell, B.A., Laurence, M.H., Liew, E.C. Y., \& Leslie, J.F. (2010). Biogeography and phylogeography of Fusarium: a review. Fungal Divers, 44(1), 3-13.

Sutherland, R., Viljoen, A., Myburg, A.A., \& Van den Bergh, E.B. (2013). Pathogenicity associated genes in Fusarium oxysporum f.sp. cubense race 4. S Afr J Sci, 109(5/6), 1-10.

Taylor, J.W., Jacobson, D.J., \& Fisher, M.C. (1999). The evolution of asexual fungi: Reproduction, speciation and classification. Annu Rev Phytopathol, 37, 197-246.

Thakker, J.N., Patel, S., \& Dhandhukia, P.C. (2013). Induction of defense-related enzymes in bananapPlants: effect of live and dead pathogenic strain of Fusarium oxysporum f.sp. cubense. ISRN Biotechnol, 2013, 601303.

Thangavelu, R., \& Mustaffa, M.M. (2010). First report on the occurrence of a virulent strain of Fusarium wilt pathogen (Race-1) infecting Cavendish (AAA) group of bananas in India. Plant Dis, 94(11), 1379.

van Dam, P., Fokkens, L., Schmidt, S.M., Linmans, J.H., Kistler, H.C., Ma, L.J., \& Rep, M. (2016). Effector profiles distinguish formae speciales of Fusarium oxysporum. Environmental Microbiology, 18(11), 4087-4102.

Vlaardingerbroek, I., Beerens, B., Schmidt, S. M., Cornelissen, B. J. C., \& Rep, M. (2016). Dispensable chromosomes in Fusarium oxysporum f.sp. lycopersici. Mol Plant Pathol, 17(9), 1455-1466.

Wen, T., Huang, X., Zhang, J., Zhu, T., Meng, L., \& Cai, Z. (2015). Effects of water regime, crop residues, and application rates on control of Fusarium oxysporum f.sp. cubense. J Environ Sci, 31, 30-37.

Wu, Y., Yi, G., Peng, X., Huang, B., Liu, E., \& Zhang, J. (2013). Systemic acquired resistance in Cavendish banana induced by infection with an incompatible strain of Fusarium oxysporum f.sp. cubense. J Plant Physiol, 170(11), 1039-1046.

Xue, C., Penton, C.R., Shen, Z., Zhang, R., Huang, Q., Li, R., . . . Shen, Q. (2015). Manipulating the banana rhizosphere microbiome for biological control of Panama disease. Sci Rep, 5, 11124.

Yoshida, K., Schuenemann, V. J., Cano, L. M., Pais, M., Mishra, B., Sharma, R., . . Burbano, H. A. (2013). The rise and fall of the Phytophthora infestans lineage that triggered the Irish potato famine. eLife, 2, e00731. 
Yuan, J., Raza, W., Shen, Q., \& Huang, Q. (2012). Antifungal activity of Bacillus amyloliquefaciens NJN-6 volatile compounds against Fusarium oxysporum f.sp. cubense. Appl Environ Microbiol, 78(16), 59425944.

Zheng, S., García-Bastidas, F.A., Li, X., Zheng, L., Bai, T. T., Xu, S., . . . Kema, G.H.J. (2018). New geographical insights of the latest expansion of Fusarium oxysporum f.sp. cubense tropical race 4 into the Greater Mekong subregion. Front Plant Sci, 9(457), 1-9. 


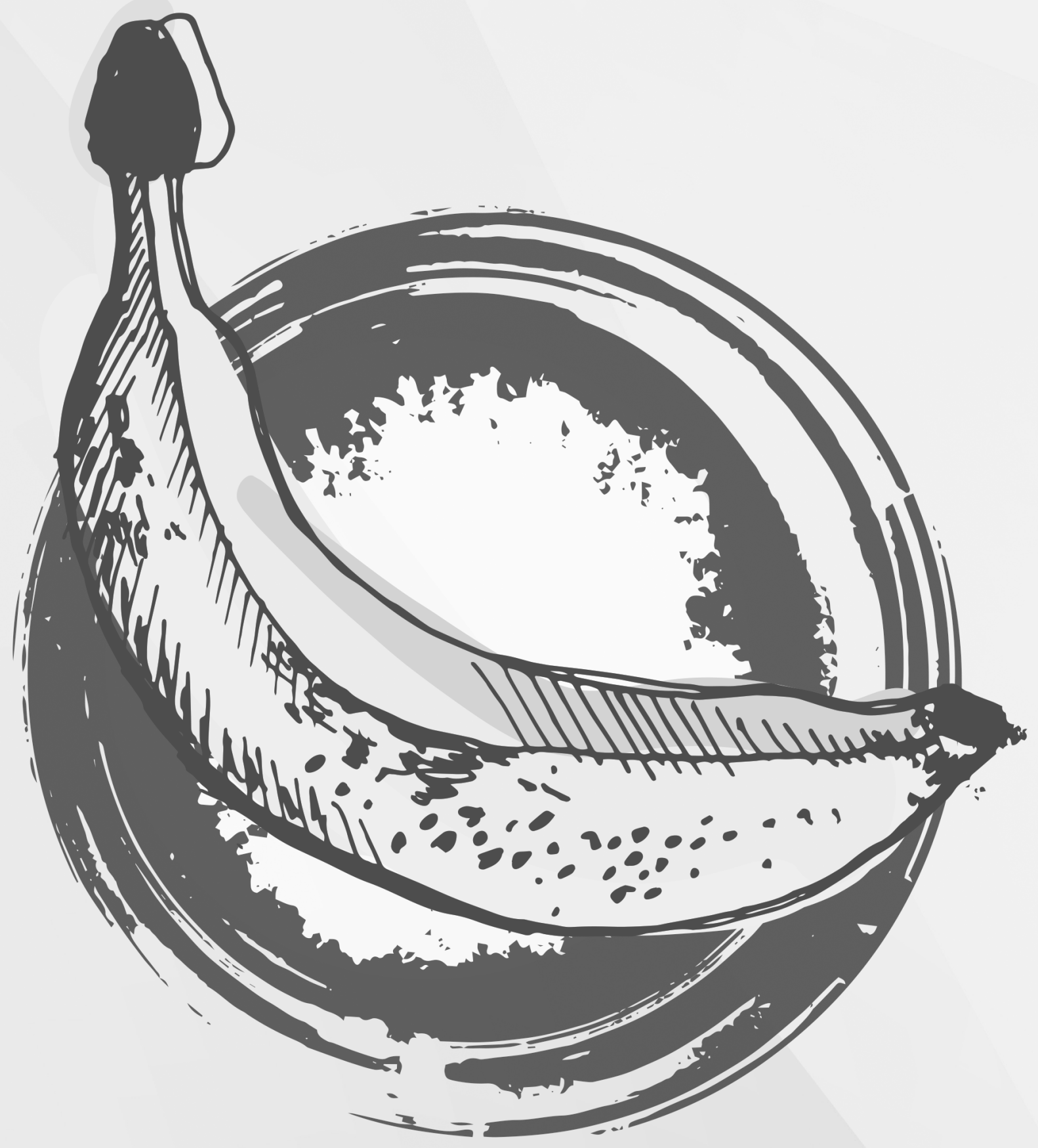




\section{SUMMARY}

Fusarium wilt of bananas, popularly known as Panama disease, is one of the most threatening fungal diseases of banana production. Bananas are an essential staple food and a significant income for agricultural-based economies in developing countries. Fusarium oxysporum f.sp. cubense (Foc) is the causal fungal agent of this disease. The first outbreak of the disease caused by Foc race 1 strains transformed the banana industry in Latin America in the early 1960s. Farmers rejected their preferred banana cultivar 'Gros Michel' as race 1 strains caused havoc in plantations that relied on this cultivar. To save the banana industry, farmers adopted the race 1-resistant Cavendish banana cultivars. Unfortunately shortly after, pioneer banana plantations using Cavendish clones in Taiwan succumbed to Fusarium wilt. This emerging strain is known as tropical race 4 (TR4), and has nowadays spread to multiple countries in Southeast Asia, Australia, the Middle East, the Indian subcontinent and Africa. Currently, there is no effective management strategy available to control this disease. This $\mathrm{PhD}$ thesis describes genetic diversity of Foc and its global dispersion as well as tools for rapid diagnosis of TR4 and vegetative compatible group (VCG) characterization of large Foc populations. This contributes to developing effective management strategies.

Chapter 1 is an introduction outlining the background of this thesis research: the importance of bananas, the Fusarium wilt disease cycle and the genetic diversity, classification, evolution and distribution of Foc strains. This chapter summarizes scientific publications available prior to the start of this project and our research objectives, including unraveling the genetic diversity of this pathogen, its current dissemination, available molecular diagnostic tools and pathogenicity.

Chapter 2 elaborates on the genetic diversity of Foc as captured by a suite of major genetic lineages and/or VCGs, with a focus on TR4. The data enabled comparison of resequenced and Diversity Array Technology sequencing (DArTseq) data of geographically diverse TR4 isolates, which suggests that a single clone is temporally and spatially dispersed. This finding underscores the need for global awareness and quarantine campaigns to protect banana producers from another pandemic that particularly hits vulnerable small-holder farmers and agricultural based countries.

Chapter 3 describes the development of a molecular detection tool to monitor the spread of TR4. In this study, we generated and used a genotyping by sequencing database to discover unique genomic regions for primer design. DNA was extracted from Foc strains representing the global genetic diversity of Foc. Alignments of the sequences with the reference genome of Foc TR4 II-5 enabled the design of Loop-Mediated Isothermal Amplification primers for TR4. We successfully used the developed assay to detect TR4 in artificially inoculated and naturally infected Cavendish banana rhizomes and pseudostems. This assay enables rapid, routine and unambiguous detection of TR4 in the field and is therefore of immense value for charting the progression of its spread.

Chapter 4 reveals the genetic diversity of a global Foc collection that includes Foc isolates from all banana-growing areas. In this study, we explore the genetic variation of Foc isolates by genotyping-by-sequencing using DArTseq. The generated 25,282 DArTseq insilico markers grouped all isolates into three clades within the Fusarium oxysporum species complex (FOSC), showing a robust genetic resolution of genetic variation among Foc isolates 
within VCGs. The 24 known VCGs were associated with either clade 1 or 2 , but we also report a new third clade for Foc isolates. The analyses show that DArTseq is an excellent approach to efficiently assign VCGs to Foc isolates without the need for laborious microbiological experimentation. For instance, we show for the first time that VCG0120/15 and 0126 are present in Peru and Papua New Guinea, respectively. More importantly, we detected 20 new VCGs, particularly linked with Latin America, which may point to a secondary center of diversity. Our results provide a high resolution picture of the genetic proximity of Foc strains and its global dispersal as well as highlight the immense versatility of Foc.

Chapter 5 describes the pathogenicity of the widest panel of Foc VCGs towards the iconic banana varieties 'Gros Michel' and 'Grand Naine' that dominated the international trade for over 100 years. In this study, we explore the pathogenicity of 22 Foc VCGs in addition to multiple TR4 isolates under greenhouse conditions. The results show that 'Gros Michel' was generally susceptible to more strains than 'Grand Naine'. All TR4 isolates, regardless of the year of isolation and country of origin, were highly infectious on both varieties, underpinning the risk for banana plantations that only rely on 'Gros Michel' and 'Grand Naine' cultivars. The responses of 'Gros Michel' and 'Grand Naine' were indistinctively associated with Foc VCGs from clade 1 and 2 of the FOSC and did not frequently correspond with the traditionally associated Foc races. These findings show that the current race concept does not accurately reflect the pathogenic diversity of Foc.

Chapter 6 is a summarizing discussion of the $\mathrm{PhD}$ thesis. The generated data are examined and contextualized with overall scientific information on the genetic diversity and virulence of Foc. The setbacks of the current classification system are debated and suggestions for improvement and future directions on diversity analyses are discussed. The genetic diversity of Foc will severely impact the management of Fusarium wilt. Therefore, it is urgently required to elucidate the banana-Foc interaction and to develop molecular tools for disease monitoring and containment. 


\section{SAMENVATTING}

Fusarium verwelkingsziekte van banaan, beter bekend als Panamaziekte, is een van de grootste bedreigingen van de bananenteelt. Bananen zijn een essentieel basisvoedsel en vormen tevens een belangrijke inkomstenbron voor de op landbouw gebaseerde economieën van ontwikkelingslanden. Fusarium oxysporum f.sp. cubense (Foc) is de veroorzaker van de ziekte. De eerste uitbraak van Panamaziekte werd veroorzaakt door fysio 1 van Foc en transformeerde de bananenindustrie in Latijns-Amerika in de vroege zestiger jaren van de vorige eeuw. Boeren verwierpen de populaire en geprefereerde 'Gros Michel' banaan omdat fysio 1 het verwoestte, met name in de grote plantages waar dit ras in monocultuur werd verbouwd. Om de industrie te redden adopteerden boeren Cavendish bananen die resistent zijn tegen fysio 1 stammen van Foc. Jammer genoeg bleek als snel dat Panamaziekte ook toesloeg in de eerste Cavendish plantages op Taiwan. De verantwoordelijke Foc stam wordt nu tropisch fysio 4 (TR4) genoemd en is inmiddels verspreid naar meerdere landen in Zuidoost-Azië, Australië, het Midden-Oosten, India, Pakistan en Afrika. Er is momenteel geen effectieve managementstrategie om de door TR4 veroorzaakte Panamaziekte te beheersen. In dit proefschrift worden de genetisch diversiteit van Foc - onder andere door middel van genoomanalysen en vegetatieve compatibiliteitsmetingen (zgn. VCGs) - en de wereldwijde verspreiding ervan beschreven. Daarnaast wordt ingegaan op het ontwikkelen van snelle moleculaire diagnostica voor TR4. Tezamen draagt deze informatie bij aan het ontwikkelen van effectieve managementstrategieën voor Panamaziekte in de teelt van Cavendish bananen.

Hoofdstuk 1 is een introductie die de achtergrond van het onderzoek schetst, met aandacht voor het belang van bananen, de levenscyclus en de genetische diversiteit van Foc die tot nu toe bekend is en hoe die geografisch is verspreid, alsmede de taxonomische classificering en evolutie van de schimmel. Dit hoofdstuk is daarmee een samenvatting van de literatuur bij de aanvang van het onderzoek. Hieruit zijn de doelstellingen gedestilleerd waaronder het nauwkeurig ontrafelen van de genetische diversiteit, de verspreiding ervan, het ontwikkelen van betere moleculaire diagnostica voor TR4 en het verkrijgen van meer inzicht in de pathogeniteit van Foc.

Hoofdstuk 2 geeft een nauwkeurige en gedetailleerde beschrijving van de genetische diversiteit van de bekende genotypen van Foc, met een focus op TR4. Dit werd gedaan met VCGs en sequentiemerkers die werden gegenereerd met Diversity Array Technology sequencing (DArTseq) in een reeks TR4 stammen van verschillende geografische oorsprong. Dit suggereerde dat de diverse TR4 stammen een enkele Foc kloon vertegenwoordigen die door tijd en ruimte is verspreid. Deze vondst onderstreept de noodzaak van wereldwijde bewustwordings-campagnes met grote nadruk op quarantaine procedures om bananentelers te beschermen tegen een nieuwe pandemie die vooral kleine boeren in landen met een op de landbouw gebaseerde economie ruïneert.

Hoofdstuk 3 beschrijft de ontwikkeling van moleculair diagnostisch gereedschap om de verspreiding van TR4 te volgen. Hiervoor is gebruik gemaakt van een database met sequentiegegevens om unieke genomische regio's te identificeren waarop diagnostische primers kunnen worden ontworpen. Hiertoe werd het DNA uit Foc stammen geïsoleerd die de 
DNA sequentie van het referentie TR4 isolaat II-5. Dit leidde tot de ontwikkeling van zgn. Loop-Mediated Isothermal Amplification (LAMP) primers voor TR4 detectie. Deze methode is succesvol getest in kunstmatig geïnfecteerde bananenplanten, alsmede in natuurlijk besmette Cavendish planten. De test is snel, kan routinematig worden uitgevoerd, levert ondubbelzinnige resultaten op, en is daardoor van grote waarde voor het volgen en inperken van de verspreiding van TR4.

Hoofdstuk 4 geeft een overzicht van de genetische diversiteit in een wereldwijde Foc collectie uit alle regio's waar bananen worden geteeld. In deze studie is gebruik gemaakt van DArTSeq en zijn 25,282 in-silico merkers gegenereerd die alle isolaten in drie groepen van het Fusarium oxysporum soorten complex (FOSC) verdeelden. Dit leverde een robuuste analyse van genetische diversiteit op, ook tussen Foc isolaten binnen VCGs. Alle bekende 24 VCGs werden in groep 1 of groep 2 geplaatst, maar de derde groep is nieuw en herbergt andere Foc isolaten. De analyse laat zien dat DArTSeq een uitstekende en snelle manier is om genetische diversiteit in kaart te brengen en om VCGs toe te kennen aan onbekende isolaten zonder uitgebreide en langdurige laboratoriumexperimenten. Wij hebben bijvoorbeeld voor de eerste keer aangetoond dat VCG0120/15 en 0126 voorkomen in resp. Peru en Papoea NieuwGuinea. Bovendien hebben wij laten zien dat 20 nieuwe VCGs met name voorkomen in Latijns-Amerika. Dit lijkt te wijzen op een secundair diversiteitscentrum voor deze schimmel. Onze resultaten geven een beeld met een hoge resolutie van de genetische verwantschap tussen Foc isolaten en de globale verdeling van deze diversiteit. Hiermee wordt de immense veelzijdigheid van de schimmel onderstreept.

Hoofdstuk 5 beschrijft de pathogeniteit van het breedst mogelijke palet van Foc VCGs op de iconische bananenrassen 'Gros Michel' en 'Grand Naine' die de mondiale bananenteelt gedurende de laatste 100 jaar hebben gedomineerd. In deze studie onderzoeken wij de pathogeniteit van 22 Foc VCGs naast meerdere TR4 stammen in kasexperimenten. De resultaten laten zien dat 'Gros Michel' in het algemeen voor meer stammen vatbaar is dan 'Grand Naine'. Alle TR4 stammen, onafhankelijk van het jaar van isolatie of geografische herkomst, waren zeer infectieus op beide rassen, waarmee het risico van monoculturen met deze rassen nog eens is aangegeven. De reacties van 'Gros Michel' en 'Grand Naine' waren zonder uitzondering geassocieerd met stammen uit groep 1 of groep 2 van het FOSC en correspondeerden meestal niet met de traditioneel bekende Foc fysio's. Deze resultaten demonstreren dat het huidige concept van fysiologische specialisatie in Foc de pathogeniteit niet accuraat weergeeft.

Hoofdstuk 6 is een samenvattende discussie van het proefschrift. De verzamelde data worden nader beschouwd en in een bredere context geplaatst van algemeen beschikbare wetenschappelijke informatie met betrekking tot genetische diversiteit en virulentie van Foc. De nadelen van het huidige taxonomische classificeringsysteem worden besproken en er worden suggesties gedaan voor verbetering en toekomstige onderzoeksrichtingen van diversiteitsonderzoek. De aangetoonde genetische diversiteit van Foc zal de beheersing van Panamaziekte in de toekomst sterk beïnvloeden. Het is daarom van zeer groot belang om de interactie tussen banaan en Foc op te helderen en moleculair gereedschap te ontwikkelen om Panamaziekte te volgen en in te perken. 


\section{RESUMEN}

La marchitez por Fusarium del banano, popularmente conocida como "mal de Panamá”, es una de las enfermedades fúngicas más amenazadoras de la producción bananera. El banano es un alimento básico y esencial, que además representa un ingreso significativo para los países en desarrollo cuya economía depende de su producción agrícola. El agente causal de esta enfermedad es el hongo Fusarium oxysporum f.sp. cubense (Foc). El primer brote de esta enfermedad, causado por las cepas raza 1 de Foc, transformó la industria bananera de América Latina a principios de los años sesenta. Los agricultores dejaron de plantar su cultivar de banano preferido, 'Gros Michel', ya que las cepas raza 1 destruyeron dichas plantaciones. Para salvar a la industria bananera, los agricultores adoptaron los cultivares de banano Cavendish, resistentes a raza 1. Lamentablemente, poco después, las plantaciones bananeras pioneras que usaron clones de Cavendish en Taiwán sucumbieron a la marchitez por Fusarium. Esta cepa emergente se conoce como raza tropical 4 (RT4) y actualmente se ha extendido a varios países en el sudeste asiático, Australia, Medio Oriente, el subcontinente Indio y África. Actualmente, no hay una estrategia de manejo efectiva disponible para controlar esta enfermedad. Esta tesis doctoral describe la diversidad genética de Foc y su dispersión global, así como las herramientas para el rápido diagnóstico de RT4 y la caracterización de grupos de compatibilidad vegetativa (GCV) de grandes poblaciones de Foc, contribuyendo así al desarrollo de estrategias de manejo efectivas.

El capítulo 1 es una introducción que describe la base teórica de esta tesis: la importancia del banano, el ciclo de la enfermedad de la marchitez por Fusarium y la diversidad genética, clasificación, evolución y distribución de las cepas de Foc. Este capítulo resume las publicaciones científicas disponibles al inicio de esta tesis doctoral y los objetivos de investigación, que incluyen el análisis de la diversidad genética y patogenicidad de las diversas cepas de Foc, su diseminación actual y herramientas de diagnóstico molecular disponibles.

El capítulo 2 describe en detalle la diversidad genética de RT4 y de otros relevantes linajes genéticos y/o GCV de Foc. La comparación de datos moleculares generados mediante técnicas de re-secuenciación y de Diversity Array Technology (DarTseq), usando aislados de RT4 provenientes de varias regiones afectadas por esta raza, demostraron que es un solo clon el que se dispersa temporal y espacialmente. Este hallazgo enfatiza la necesidad de concientización global y de campañas de cuarentena para proteger a los productores de banano de otra pandemia que golpearía particularmente a pequeños agricultores y a países cuya economía depende de su producción agrícola.

El capítulo 3 describe el desarrollo de una herramienta de detección molecular para monitorear la propagación de RT4. En este estudio, generamos y usamos una base de datos de genotipado por secuenciación para descubrir regiones genómicas únicas esenciales para el diseño de cebadores. El ADN se extrajo de cepas de Foc que representan la diversidad genética global del patógeno. Las alineaciones de las secuencias con el genoma de referencia de Foc RT4 II-5 permitieron el diseño de cebadores de amplificación isotérmica mediada por bucle (Loop-Mediated Isothermal Amplification or LAMP en inglés) para RT4. Utilizamos con éxito el test desarrollado en este capítulo para detectar RT4 en rizomas y pseudotallos de banano tipo Cavendish inoculados artificial y naturalmente. Este test permite la detección 
rápida, rutinaria y sin ambigüedades de RT4 en el campo y, por lo tanto, es de gran valor para trazar la progresión de su propagación.

El capítulo 4 revela la diversidad genética de una colección global de Foc que incluye aislados de Foc de todas las áreas donde se cultiva banano en el mundo. En este estudio, exploramos la variación genética de aislados de Foc por genotipado por secuenciación usando DArTseq. Los 25,282 marcadores in-silico DArTseq agruparon todos los aislados en tres clados dentro del complejo de especies de Fusarium oxysporum (FOSC), mostrando una resolución genética robusta de la variación genética entre aislados de Foc y sus GCVs. Los 24 conocidos GCVs se asociaron al clado 1 o 2, y a su vez los resultados revelaron un tercer clado para Foc. Los análisis muestran que DArTseq es una excelenta técnica para asignar de manera eficiente GCVs en aislados de Foc, evitando realizar laboriosos ensayos microbiológicos. En este capítulo, mostramos por primera vez que el GCV 0120/15 y 0126 están presentes en Perú y Papua Nueva Guinea, respectivamente. Más importante aún, detectamos 20 nuevos GCVs, particularmente vinculados con América Latina, que pueden apuntar a un centro secundario de diversidad. Nuestros resultados proporcionan una imagen de alta resolución de la proximidad genética de las diversas cepas de Foc y su dispersión global, así como resaltan la inmensa versatilidad del patógeno.

El capítulo 5 describe la patogenicidad de un amplio panel de GCV de Foc hacia las icónicas variedades de banano 'Gros Michel' y 'Grand Naine', importantes ejemplares que durante más de 100 años son parte de la industria bananera. En este estudio, exploramos la patogenicidad en condiciones de invernadero de 22 GCVs de Foc además de múltiples aislados de RT4. Los resultados muestran que 'Gros Michel' es generalmente susceptible a más cepas que 'Grand Naine'. Todos los aislados de RT4, independientemente del año de aislamiento y el país de origen, fueron altamente infecciosos en ambas variedades. Estos resultados ilustran el riesgo de plantaciones de banano que se basan en los cultivares 'Gros Michel' y 'Grand Naine' a dichas cepas. Las respuestas de 'Gros Michel' y 'Grand Naine' se asociaron indistintamente con los GCV de Foc del clado 1 y 2 en el FOSC, y con frecuencia no correspondieron a las razas tradicionalmente asociadas a dichos aislados. Estos hallazgos muestran que el concepto actual de razas en Foc no refleja con exactitud su diversidad patogénica.

El capítulo 6 es una discusión resumida de la tesis doctoral. Los datos generados se examinan y contextualizan con información científica general sobre la diversidad genética y la virulencia de Foc. Se debaten las ineficiencias del sistema actual de clasificación y se discuten sugerencias de mejora así como las perspectivas futuras en los análisis de su diversidad genética. En el manejo de la marchitez por Fusarium, dilucidar la diversidad genética de Foc es esencial. Por lo tanto, se requiere urgentemente investigar en detalle la interacción banana-Foc y a su vez desarrollar herramientas moleculares innovativas para el control y la contención de esta enfermedad. 


\section{ACKNOWLEDGMENTS}

The completion of this $\mathrm{PhD}$ thesis is a rewarding learning experience at the professional and personal level. Firstly, I would like to thank my thesis promotor Prof. Gert Kema for accepting me in his team at Wageningen University \& Research (WUR), The Netherlands. After spending four years in your group, I got to admire your networking and negotiation skills. I have not personally met somebody else that excels at these two skills as you do. Because of you, I was introduced to nearly all banana researchers in the world in just four years time. You helped me to develop connections of my own that were essential to complete this PhD. During our progress meetings, I would not only benefit from your extensive scientific knowledge but also I was encouraged to develop negotiation skills to set common goals. I am grateful for your life teaching experiences. My gratitude extends to the INREF-WUR program that funded my PhD scholarship. I would also like to thank my copromotors Dr. Harold Meijer and Dr. Michael Seidl for allocating time to review this book. You both fiercely challenged me with your comments and contributed to making of this book a great piece of scientific literature in bananas. Harold, it was a pleasure to share an office with you. You are full of entertaining stories to learn from and good music to enjoy. Michael, I enjoyed debating with you about my thesis since the very first day. It is a big pleasure to get to know you and work with you. You were a key collaborator for my thesis by providing your bioinformatic expertise and outstanding feedback for the entire thesis. I also would like to thank Prof. Bart Thomma for providing input for my thesis during my first $\mathrm{PhD}$ years.

During this $\mathrm{PhD}$ journey, I met wonderful people from the banana research community that I would like to acknowledge here. First of all to the other members of the INREF management team Dr. Jetse Stoorvogel, Dr. Sietze Vellema and Dr. Kees Jansen as well as to my INREF PhD colleagues Maricar, Malu, Jaye, Rafael, Rocky and Fernando with whom I was pleased to brainstorm about Fusarium wilt in areas outside my expertise. You all made of this $\mathrm{PhD}$ journey a fantastic team experience, engaging in several annual meetings, visiting banana farms impacted with Fusarium wilt in The Philippines, participating in a leading banana conference in Miami, USA. We played hard and had fun too. I thank Maricar and Fernando, my INREF office colleagues with whom I had the pleasure to closely collaborate on shared thesis chapters and scientific publications. This banana journey was nicely complemented by collaborating with my KNAW- SPIN Indonesian PhD colleagues Nani, Fajar, Nurmi, Heni and Iman. Thanks for showing me the beauty of Indonesia through your stories, photos, food and souvenirs. Now I am so curious to visit Indonesia and see the diverse range of bananas there. I am thankful to my PhD office colleagues Cauca and Pablo that supported banana research by shedding light on the black Sigatoka disease. You shared our passion for bananas and increased my knowledge on banana diseases. Beyond office work, I also praise all our dinners and outings. Cauca, thanks for joining me on the dancing floor to share our love for latin music. Pablo, I was delighted to be your paranymph to support you on your big day. Extend my gratitude to your lovely wife Adriana and your little daughter Aby, many more blessings with your second child. I feel reassured that outcomes from the several individual banana theses of our group contribute with innovative insights to secure bananas. Thanks to Prof. Andre Drenth and his supportive team for welcoming me at their research center in Brisbane, Australia and providing full access to their fungal collection. It 
was so exciting to join your banana field trials, tasting more than 14 different types of bananas and getting to talk to Aussi banana farmers. Thanks to Dr. Miguel Dita and Prof. Randy Ploetz whom greatly contributed not only with fungal isolates for this thesis but also connected me with researchers around the world to expand my fungal collection and contributed to my publications and chapters. Andre, Miguel and Randy, it was an honor to spend time together in Australia, The Philippines, The Netherlands and USA, having the chance to learn from your large expertise in the banana world. The strong enthusiasm and genuine interest to save bananas from all researchers that I met helped me to focus and try harder when faced with challenges during my $\mathrm{PhD}$. I am thankful to you all and I wish to stay in touch.

Outside the banana research, I also had the pleasure to learn about wheat research from my $\mathrm{PhD}$ office colleagues and great friends Lamia and Amir. Lamia, I felt very blessed for sharing an office with you and I treasure every moment that we spent together outside office walls. You are my dearest friend, the politest woman that I ever met. During these four years, you showered me with Tunisian souvenirs. Now my flat is full of Tunisian decorations, I guess it is time to actually visit your lovely country and try more of your tasty couscous. Amir, I felt privileged that you chose me to be your paranymph for your defense and wish you much success as a professor at Tehran University in Iran. At our office, we also welcomed several students that diligently supported us to accomplish our goals and enlightened the office environment. Many thanks to Elina, Valery, Saiful, Ruud, Hayet, Giuli, Niko, Thijs, Denja, Blanca, Lex, Ricky, Kevin and Isabel. Beyond my office team, I had the pleasure to share lunch, drinks, cakes, lab activities and corridor chats with the amazing team at Wageningen Plant Research. You are awesome people and very welcome to the international staff. I would love to write a short story from each of you, but sincerely I would have enough material to write a short memoir. I feel particularly in debt to Cor and Odette who were crucial collaborators on the LAMP TR4 chapter, in the development of primers and conducting lab work. I enjoyed so much the cross-functional team that we were, with each of us contributing with our area of expertise. We were the vivid example for 'If you want to go fast, go alone. If you want to go far, go together'. For the Dutch staff, feel reassured that I take with me a wonderful impression of your culture. Your country is particularly beautiful during the tulip season. I will miss the herring, your passion for bikes and your openness to speak English. Many hugs to Marion, Marga, Trudy, Theo, Els V, Els N, Pieter, Cees, Patricia, Bram, Henk, Helen, Yvonne, Stefan, Marc, Ilse, Dirk-Jan, Carin, Willem, WillemJan, Carolien, Pieter, Peter, José, Mirjam, Marjon, Annette, Marieke, Gerrie and Henry. For the international staff from all over the world, your presence in the lab made work enjoyable and lighter during difficult times. I treasure all memories from our dinners, drinks, parties and outings. Many hugs to Flor, Alex, Tjasa, Flavi, Adriaan, Irene, Sebastiano, Leoni, Giovanny, Roberto, Kamil, Iara, Flavio, Tanvi, Juan and Dong. Double thanks to Odette and Flor for accepting being my paranymphs and standing by my side during my $\mathrm{PhD}$ defense. Being part of Wageningen Plant Research was a wonderful experience that showed me how important is to connect with other research groups to learn from their projects and life experiences.

Outside the scientific work, I also met incredible souls from everywhere. The entire world lives in Wageningen! During my first $\mathrm{PhD}$ year, I met my Dutch roommates at the Haarweg student dorms. I was the only international student in my corridor but I felt very 
welcome by them, dank u wel to you all, especially to Nora, Malou and my German roommate Jan. I spent my very first summer in town with you and we shared many laughs. Then I moved to the town-famous K24 house that was an incredibly supportive family. You made me feel happy to come home. It was always cozy, with entertaining drama from time to time and fully enriched with diverse languages. Thank you so much Sol, Isra, Delphi, Nikolay, Fred, Jime, Katyuce, Pau, Vicky, Lisa, Gaetan and Ambar, you are not only exroommates but became longtime friends. Also thank you to my landlord Jack, you are a kind soul and set an example of all desirable qualities for a fair landlord. Also, to my surprise, a large and very supportive Ecuadorian community existed in Wageningen. I met more than 50 Ecuadorian students that would "come and go" in town, I sincerely enjoyed meeting you all and becoming a friend of yours. I would particularly like to thank Luchito, Pablo, Flakita, Iri, and Carlos with whom I enjoyed friendship along my four years in Wageningen. My Ecuadorian friend Cris who organized a surprise Bachelor party for me. After that party, I do not see cucumbers the same way as I did before. How to forget my beloved friends in town Qiushi, her husband Paul, Kyra, Juli and his son Ale, Laurinha, Massimo, Nicole and Suraj who I met through diverse circumstances. My friends outside the Dutch borders, Sol, Uzma, Johana, Andrea, Diana, Lida and my circle of friends back in Ecuador who supported me beside the distance. Thank you all for dancing with me, sharing a beer, laughing about life, celebrating birthdays, going out for dinners, traveling in Europe, sharing Pilates sessions, watching boring TV together and engaging on Skype sessions, in a nutshell for offering me your sincere friendship. You show me that 'Phd circles around your life, instead of $\mathrm{PhD}$ being the center of your life'.

Above all, I am in debt with my family that bears my absence in their lives to support my dreams. My mother, Ivonne, is very brave to let her only daughter fly away from the nest. I admire her for her endless support to her kids' goals. I treasure my childhood memories with my father Vicente, caring for me very dearly. To my brothers, Vicente and Javier, if it was not for them, I would not be the person that I am today. I never felt lonely growing up with my brothers and found so much pleasure playing with them soccer, video games and climbing trees. Many hugs to your life partners Marcela and Tilsa for cheering me up too. To my cousin-brother Daniel and his partner Daisy, for unfailing support during my stay in Europe and their love for my brothers and mum. To my beloved abuelito, Pacífico, that passed away during my $\mathrm{PhD}$, for constantly looking after the family, his heart was always in the right place. During my PhD, my family extended when I got married to the kindest man that I ever met in my entire life. Mike, mein Engel, mein Mann, words are not enough to describe how much I am indebted to you. I am especially thankful for funding my last stretch of my $\mathrm{PhD}$. You are always there for me to lift me up when I am at my lowest, to restore my faith when I feel lost and to encourage me when I feel that I can't do it. I love you so much that without you in my life I do not think any of this would be worthy or enjoyable. I used to be an independent happy woman, but now I feel as if I need to hold your hand for every step I take, I love you so much and hate you for that too. Vielen Dank to my German family in-law, especially to Cordi and Harald that always spoil my husband and I with the best Bavarian treats when they welcome us at their home. I am excited to turn the page to a next chapter in my life, this time building a family life project while pursuing the same professional ambitions and dreams. 
This is the end of my $\mathrm{PhD}$ journey, and I certainly found more pleasure in the journey itself than in the culmination of it. It was along my $\mathrm{PhD}$ years that I gained crucial input to become a better scientist and enriched myself with so many wonderful personal experiences making friends and tying the knot with my life partner. I hope life gives back to you the double or more of what you all gave to me. 


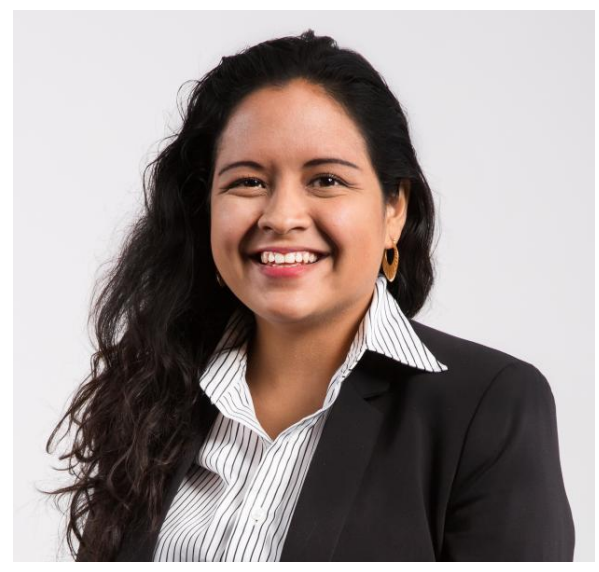

Nadia Ordóñez R. was born on June 25th, 1986 in Machala, El Oro Ecuador. In 2004, she started her bachelor studies at Escuela Superior Politécnica del Litoral (ESPOL) in Guayaquil, Ecuador, where she obtained a bachelor degree in Biology with a mention in Marine Biology. She executed her bachelor thesis "Isolation and identification of terrestrial microfungi from Punta Fort William, Antarctica" at the Biomedical Lab at ESPOL under the supervision of Prof. Washington Cárdenas, and external supervision of Prof. Siti Aisyah from University of Malaya. Her passion for Antarctic microbes granted her the opportunity to collaborate as a field assistant at three expeditions to Antarctica supported by the Antarctic Institute of Ecuador and to join a summer program at the University Centre in Svalbard, Norway. After completing her bachelor diploma in 2009, she worked for the Biotechnology Center of Ecuador- ESPOL at the Microbiology Department as a Research Scientist. Here, she was involved in a collaborative project with the Crop field Department on the microbial analyses of teas (biols), bacteria and fungi, to enhance crop health and yield. Then in 2010, she was awarded a scholarship to pursue her Master degree in Applied Ecology, as part of the Erasmus Mundus European program. Here, she executed as part of her Master thesis an experimental cost-effective tool-box for assessment and monitoring of water quality in an agricultural impacted water body in Portugal. The tool-box included various ecological receptors from bacteria to small vertebrates in order to monitor the impact of crop pesticides in the food chain. Right after finishing her master, she combined her interest for microbes and agriculture by joining the group of Prof. Gert Kema at Wageningen University and Research, The Netherlands in 2013 to deal with a current threat to bananas caused by the fungus Fusarium oxysporum f.sp. cubense. This dissertation summarizes the latest insights on genetic diversity and pathogenicity of this banana pathogen and provides tools for its rapid characterization. After completing her $\mathrm{PhD}$ thesis, she will move to Germany to advance her career. 


\section{LIST OF PUBLICATIONS}

Ordóñez, N.*, Salacinas, M*., Mendes, O., Seidl, M.F., Meijer, H.J.G., M., Schoen, C., \& Kema., G.H.J. (2018). A Loop-Mediated Isothermal Amplification assay based on unique markers derived from genotyping by sequencing data for rapid in-plant diagnosis of Fusarium oxysporum f.sp. cubense tropical race 4 in banana (Accepted manuscript).

Ordóñez, N., Seidl, M.F., Dita, M., Chaves, N., Roman C., Drenth, A., Ploetz, R.C., Waalwijk, C., Papagiannaki, E., Islam, S., Pérez, L.V., Meijer, H.J.G., Kema, G.H.J. (2018). The phylogeography of the banana wilt pathogen Fusarium oxysporum f.sp. cubense (Manuscript to be submitted).

Ordóñez, N.*, García-Bastidas, F.*, Nakasato, G., Papagiannaki, E., Kalle, V., Seidl, M.F. Meijer, H.J.G., Arango, R. \& Kema, G.H.J. (2018) Plant responses of the iconic Gros Michel and Grand Naine banana varieties to a Fusarium oxysporum f.sp. cubense diversity panel. (Manuscript to be submitted)

Ordóñez, N.*, García-Bastidas, F.*, Laghari, H.B., Akkary, M.Y., Harfouche, E.N., al Awar, B.N., \& Kema, G.H.J. (2016). First report of Fusarium oxysporum f.sp. cubense tropical race 4 causing Panama disease in Cavendish bananas in Pakistan and Lebanon. Plant Dis, 100(1), 209.

Ordóñez, N., García-Bastidas, F., Papagiannaki, E., Seidl, M. F., Waalwijk, C., Drenth, A., Thomma, B.P., Ploetz, R.C., Meijer, H. \& Kema, G.H.J. (2016). Unveiling the genetic and pathogenic diversity of the banana pathogen Fusarium oxysporum f.sp. cubense. In the Proceedings of CBS symposium Fungi and global challenges. Amsterdam, Netherlands, April 14-15, 27.

Salacinas, M., Ordóñez, N., Schoen, C., Lancieweer, R., Mendes, O., Meijer, H. \& Kema., G.H.J. (2016). Rapid diagnostic: track and trace of Fusarium oxysporum f.sp. cubense tropical race 4. In the Proceedings of VI International Banana congress CORBANA and XXI International Meeting ACORBAT. Miami, Florida, USA. April 19-22. 45-46.

Ordóñez, N.*, Seidl, M. F.*, Waalwijk, C., Drenth, A., Kilian, A., Thomma, B.P., Ploetz, R.C., \& Kema, G.H.J. (2015). Worse comes to worst: Bananas and Panama diseasewhen plant and pathogen clones meet. PLoS Pathog, 11(11), 1-7.

Ordóñez, N., Salacinas, M., Schoen, C., Mendes, O., Kilian, A. \& Kema., G.H.J (2015). Developing a molecular diagnostic for Fusarium oxysporum f.sp. cubense tropical race 4 through Diversity Array Technology genotyping. In the Proceedings of the APS Annual meeting, Pasadena California, USA. August1-5. 125-O. 
Kema, G.H.J., Ordóñez, N., Salacinas, M., Schoen, C., Mendes, O., Waalwijk, C., Seidl M.F. \& Drenth, A., (2015). Developing a molecular diagnostic for Fusarium oxysporum f.sp. cubense tropical race 4 through Diversity Array Technology genotyping. In the Proceedings of the APS Annual meeting, Pasadena California, USA. August1-5. 105S.

Ordóñez, N.*, García-Bastidas, F.*, Konkol, J., Al-Qasim, M., Naser, Z., Abdelwali, M., Salem, N., Waalwijk, C., Ploetz, R.C. \& Kema, G.H.J. (2014). First report of Fusarium oxysporum f.sp. cubense tropical race 4 associated with Panama disease of banana outside Southeast Asia. Plant Dis, 98(5), 694.

*Equal contribution 


$\begin{array}{ll}\text { Issued to: } & \text { Nadia Ivonne Ordónez Román } \\ \text { Date: } & 16 \text { October 2018 } \\ \text { Group: } & \text { Biointeractions \& Plant Health, and Laboratory of Phytopathology } \\ \text { University: } & \text { Wageningen University \& Research }\end{array}$

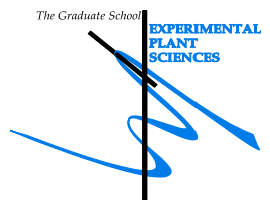

\section{1) Start-up phase}

- First presentation of your project

Understanding the causal agent of Panama disease: Genetic and pathogenic diversity of Fusarium oxysporum f. sp. Cubense

Writing or rewriting a project proposal

Understanding the causal agent of Panama disease: Genetic and pathogenic diversity of Fusarium oxysporum f. sp. cubense

Writing a review or book chapter

Worse comes to worst: Bananas and Panama disease - when plant and pathogen clones meet, PLOS Pathogens 11 (Nov 2015). DOI:10.1371/journal.ppat.1005197

- MSC courses

\begin{tabular}{|c|c|}
\hline$\underline{\text { date }}$ & $\underline{c p}$ \\
27 Jun 2014 & 1,5 \\
Feb 2013-Mar 2014 & 6,0 \\
Feb-Sep 2015 & 6,0 \\
\hline
\end{tabular}

Subtotal Start-up Phase

\section{2) Scientific Exposure}

EPS PhD student day

EPS PhD student day, Get2gether, Soest, The Netherlands

EPS PhD student day, Get2gether, Soest, The Netherlands

- EPS theme symposia

EPS Theme 2 Symposium 'Interactions between Plants and Biotic Agents, together with Willie Commelin Scholten Day, Amsterdam, The Netherlands

EPS Theme 4 Symposium 'Genome Biology', Wageningen, The Netherlands

EPS Theme 1 Symposium 'Developmental Biology of Plants', Wageningen, The Netherlands

EPS Theme 2 Symposium 'Interactions between Plants and Biotic Agents, together with Willie Commelin Scholten Day, Leiden, The Netherlands

- National meetings (e.g. Lunteren days) and other National Platforms

Annual Meeting 'Experimental Plant Sciences, Lunteren, The Netherlands

29th meeting KNPV Fusarium, Utrecht, The Netherlands

30th meeting KNPV Fusarium, Utrecht, The Netherlands

Annual meeting 'Experimental Plant Sciences, Lunteren, The Netherlands

- Seminars (series), workshops and symposia

Seminar: 'An inordinate Fondness for Fusarium', Kerry O'Donnell

Seminar: 'Fusarium and Bananas', Miguel Dita

Seminar: 'Molecular Insights into Spore Biology and Metabolism of Phytophora infestants, the Potato Blight Pathogen', Howard S. Judelson

Effector-Targeted Breeding for Durable Disease Control of Xanthomonas diseases in Tomato and Cassava, Brian Staskawicz.

Banana INREF workshop, Ede, The Netherlands

Seminar: 'The use of Next generation sequencing in diagnostic and detection of plant pathogens', Theo van der Lee \& Miriam Kooman

Banana Wageningen Day and Master Class, The Netherlands

Seminar: 'The evolutionary significance of gene and genome duplications', Yves van de Peer

Seminar: 'Long-distance endosome trafficking drives fungal effector production during plant infection', Gero

Steinberg

Banana INREF workshop in Wageningen, The Netherlands

Seminar: 'Molecular Oomycete-Host Interactions: The Good, the Bad and the Ugly', Laura Grenville-Briggs CBS-KNAW Spring Symposium: Fungi and Global Challenges, Amsterdam, The Netherlands Wageningen Plant Microbiome kick-off meeting, The Netherlands

Plant-soil-microbe interactions for crop and pest management, Wageningen, The Netherlands

- Seminar plus

- International symposia and congresses

Banana INREF workshop, Davao City, The Philippines

American Phytopathology Society (APS) Pasadena, California, USA

Fusarium Workshop, Paris, France

13th Eureopean Conference on Fungal Genetics (ECFG13), Paris, France

Banana INREF workshop, Miami, USA

6th International Banana Congress CORBANA and the XXI International meeting ACORBAT, Miami USA

\begin{tabular}{|c|c|}
\hline$\underline{\text { date }}$ & $\underline{c p}$ \\
\hline 28-29 Jan 2016 & 0,6 \\
\hline 09-10 Feb 2017 & 0,6 \\
\hline 25 Feb 2014 & 0,3 \\
\hline 03 Dec 2014 & 0,3 \\
\hline 21 Jan 2016 & 0,3 \\
\hline $22 \operatorname{Jan} 2016$ & 0,3 \\
\hline 14-15 Apr 2014 & 0,6 \\
\hline 29 Oct 2014 & 0,3 \\
\hline 26 Oct 2015 & 0,3 \\
\hline 11 Apr 2016 & 0,6 \\
\hline 15 Apr 2013 & 0,1 \\
\hline 16 Apr 2013 & 0,1 \\
\hline 07 May 2013 & 0,1 \\
\hline 21 May 2013 & 0,1 \\
\hline 23-24 Sep 2013 & 0,6 \\
\hline 11 Feb 2014 & 0,1 \\
\hline 18-20 Nov 2014 & 0,9 \\
\hline 03 Feb 2015 & 0,1 \\
\hline 05 Jun 2015 & 0,1 \\
\hline 06-07 Jul 2015 & 0,6 \\
\hline $19 \mathrm{Feb} 2016$ & 0,1 \\
\hline 14-15 Apr 2016 & 0,6 \\
\hline 29 Jun 2016 & 0,3 \\
\hline 30 Jun 2016 & 0,3 \\
\hline 03-07 Feb 2014 & 1,5 \\
\hline 01-05 Aug 2015 & 1,5 \\
\hline 03 Apr 2016 & 0,3 \\
\hline 04-06 Apr 2016 & 0,9 \\
\hline 18 Apr 2016 & 0,3 \\
\hline 19-22 Apr 2016 & 1,2 \\
\hline
\end{tabular}




\section{Presentations}

Banana INREF workshop in Ede, The Netherlands (talk)

Banana INREF workshop in Davao City, The Philippines (talk)

Banana Wageningen Day and Masterclass, The Netherlands (poster and talk)

Banana INREF workshop in Wageningen, The Netherlands (talk)

APS Pasadena, California, USA (talk)

30th meeting KNPV Fusarium, Utrecht, The Netherlands (talk)

Fusarium Workshop, Paris, France (talk)

ECFG13, Paris, France (poster)

ALW-NWO meeting 'Experimental Plant Sciences', Lunteren (poster)

CBS-KNAW Spring Symposium: Fungi and Global Challenges (poster)

Banana INREF workshop in Miami, USA (talk)

CORBANA and ACORBAT Banana meeting, Miami, USA (poster)

IAB interview

- Excursions

Meeting and visit to CIRAD and Bioversity in Montpellier, France

\begin{tabular}{|c|c|c|}
\hline \multirow{13}{*}{ and talk) } & 23-24 Sep 2013 & 1,0 \\
\hline & 03-07 Feb 2014 & 1,0 \\
\hline & 18-20 Nov 2014 & 2,0 \\
\hline & 06-07 Jul 2015 & 1,0 \\
\hline & 01-05 Aug 2015 & 1,0 \\
\hline & 26 Oct 2015 & 1,0 \\
\hline & 03 Apr 2016 & 1,0 \\
\hline & 04-06 Apr 2016 & 1,0 \\
\hline & 11-12 Apr 2016 & 0,0 \\
\hline & 14-15 Apr 2016 & 0,0 \\
\hline & 18 Apr 2016 & 1,0 \\
\hline & 19-22 Apr 2016 & 1,0 \\
\hline & 18-19 Jun 2013 & 0,6 \\
\hline
\end{tabular}

\section{3) In-Depth Studies}

- EPS courses or other PhD courses

Advanced course 'Bioinformatics - A User's Approach', Wageningen, The Netherlands

Advanced course 'Genome Assembly', Wageningen, The Netherlands

Advanced course 'CLC genome data analysis', Wageningen, The Netherlands

- Journal club

Internal Journal club, a literature discussion group

- Individual research training

At Ecoscience Prescint-Queensland University. Dr André Drenth (7 weeks training), Brisbane, Australia Subtotal In-Depth Studies

\begin{tabular}{|c|c|}
$\underline{\text { date }}$ & $\underline{c p}$ \\
26-30 Aug 2013 & 1,5 \\
28-29 Apr 2015 & 0,6 \\
20,27 Oct, 03, 10,17 Nov & 1,5 \\
& \\
Feb 2013 - Feb 2016 & 2,5 \\
& \\
Oct-Nov, 2013 & 3,0 \\
\hline
\end{tabular}

4) Personal development

- Skill training courses

Voice Matters - Voice and Presentation Skills, Wageningen, The Netherlands

Project and Time Management, Wageningen, The Netherlands

Information Literacy including EndNote Introduction, Wageningen, The Netherlands

WGS PhD Workshop Carousel, Wageningen, The Netherlands

Scientific Writing, Wageningen, The Netherlands

Career Orientation, Wageningen, The Netherlands

Scientific Artwork with Photoshop and Illustrator, Wageningen, The Netherlands

Adobe InDesign Essential Training, Wageningen, The Netherlands

Organisation of PhD students day, course or conference

$\checkmark$ Membership of Board, Committee or PhD council

\begin{tabular}{c|c:c|}
\hline date & $\underline{c p}$ \\
04, 17 Jun 2014 & 0,4 \\
12, 27 May, 24 Jun 2014 & 1,5 \\
26-27 Aug 2014 & 0,6 \\
17 Apr 2015 & 0,3 \\
& 23 Apr-25 Jun 2015 & 1,8 \\
& 02, 09, 16, 30 Oct, 06 Nov & 1,5 \\
& 19-20 Sep 2016 & 0,6 \\
& 07-08 Nov 2016 & 0,6 \\
& & \\
\hline
\end{tabular}

Subtotal Personal Development

Herewith the Graduate School declares that the PhD candidate has complied with the educational requirements set by the Educational Committee of EPS which comprises of a minimum total of 30 ECTS credits. 
The research described in this thesis was financially supported by the Interdisciplinary Research and Education Fund (INREF) program of Wageningen University \& Research.

Financial support from Wageningen University for printing this thesis is gratefully acknowledged.

Cover design and layout by Loes Kema.

Printed by GVO drukkers \& vormgevers, Ede, the Netherlands. 